
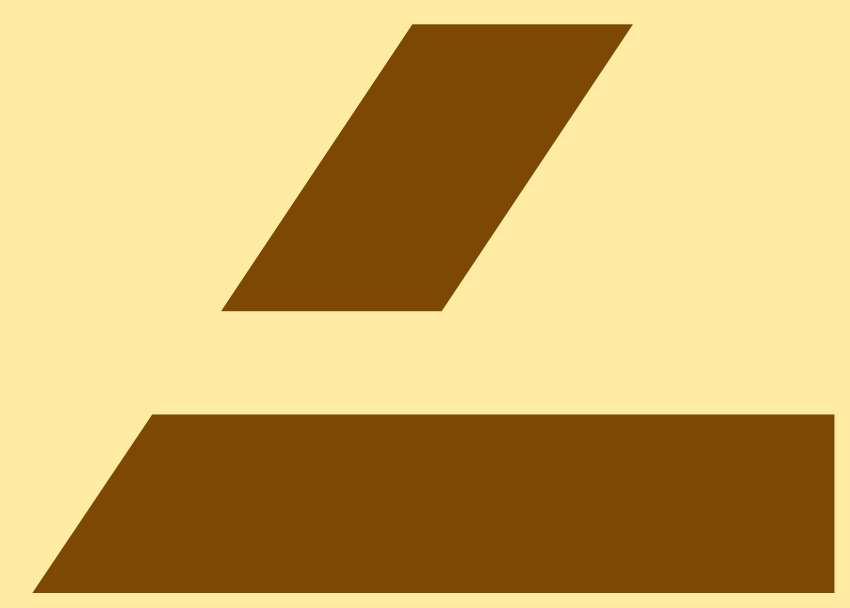

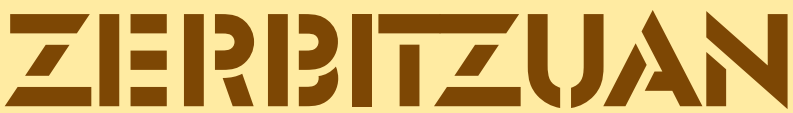

9 PRESTACIONES ECONÓMICAS VERSUS PRESTACIONES EN ESPECIE: EL RESURGIR DE UN VIEJO DEBATE 29 EL PAPEL DE LAS ORGANIZACIONES EMPRESARIALES Y SINDICALES EN LA POLÍTICA SOCIAL DE ATENCIÓN A LA DEPENDENCIA 41 CÓDIGOS DEONTOLÓGICOS E IDEOLOGÍA EN TRABAJO SOCIAL 47 DINÁMICAS RELACIONALES ENTRE SERVICIOS SOCIALES COMUNITARIOS Y ENTIDADES SOCIALES. UN ESTUDIO DE CASO 57 EL PAPEL DE LOS OBSERVATORIOS EN EL CONOCIMIENTO DE LOS PROCESOS DE EXCLUSIÓN SOCIAL 71 INFANCIA Y EXCLUSIÓN SOCIAL EN ESPAÑA: REALIDADES Y RETOS A PARTIR DE LA CRISIS 85 ANÁLISIS DE LA CALIDAD PERCIBIDA EN USUARIOS/AS DE SERVICIOS SOCIALES COMUNITARIOS 101 ACTITUDES Y OPINIONES SOBRE EL USO DE PRESTACIONES ECONÓMICAS POR PARTE DEL COLECTIVO INMIGRANTE EN EL PAÍS VASCO 111 EL PAPEL DEL ASOCIACIONISMO EN LA INTEGRACIÓN SOCIOPOLÍTICA DE LAS PERSONAS MIGRANTES DE ORIGEN SUBSAHARIANO. EL CASO DEL PAÍS VASCO 121 EL MAPEO DE LAS NECESIDADES COMO MEDIO DE MEDIACIÓN SOCIAL 129 LA GRAN RECESIÓN Y EL MUNDO DESPUÉS DE LA CRISIS 143 EUSKADIN ETXEZ ETXEKO LAGUNTZAREN ESLEIPENARI ETA INTENTSITATEARI BURUZ ORIENTABIDEA ESKAINTZEKO TRESNAREN GARAPENA 159 EXPERIENCIAS DE VOLUNTARIADO EN LA CAPV 


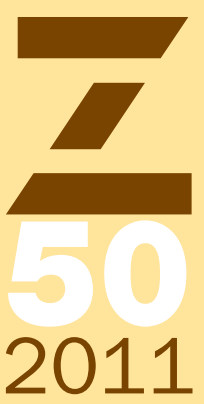

Zerbitzuan es una revista científica dedicada a las políticas de bienestar social. Se dirige a todos los agentes involucrados en este ámbito -profesionales, responsables institucionales, investigadores/as, voluntariado y usuarios/as $-y$ tiene como objetivo contribuir al debate sobre la mejora de las políticas y los servicios sociales. Su periodicidad es semestral y se edita tanto en papel como en formato electrónico.

Las colaboraciones publicadas en esta revista con la firma de sus autores expresan la opinión de éstos y no necesariamente la de Zerbitzuan o la del SIIS.

\section{PRODUCE}

SIIS Centro de Documentación y Estudios

SIIS Dokumentazio eta Ikerketa Zentroa

Fundación Eguía Careaga Fundazioa

General Etxague 10 bajo

20003 Donostia

Tel. 943423656

Fax 943293007

www.siis.net

publicaciones@siis.net

CONSEJO DE REDACCIÓN

Edorta Azpiazu

Maite Etxabe

Iñaki Heras

Elena Martín Zurimendi

Jesus Otaño

Arantxa Rodríguez Berrio

Luis Sanzo

Ramón Saizarbitoria

Helena Sotelo

Joseba Zalakain

EDITA

Eusko Jaurlaritzaren Argitalpen

Zerbitzu Nagusia

Servicio Central de Publicaciones del

Gobierno Vasco

Donostia-San Sebastián, 1

01010 Vitoria-Gasteiz

(c) Administración de la Comunidad Autónoma del País Vasco

Departamento de Empleo

y Asuntos Sociales

DISEÑO

Estudio Lanzagorta

MAQUETACIÓN

Concetta Probanza

Depósito Legal: SS-101/86

ISSN: $1134-7147$

doi:10.5569/1134-7147.50

( ) SIIS Centro de Documentación

y Estudios de la Fundación

Eguía-Careaga

Está permitida la reproducción total o parcial por cualquier medio de los artículos contenidos en esta revista, siempre que se cite la fuente y el autor o autores de los mismos.

Aldizkaria honako datu-baseetan

zerrendatuta dago:

Esta revista está incluida en las

siguientes bases de datos:

- Dialnet, DOAJ, IN-RECS, ISOC, Latindex,

MIAR, Inguma. 


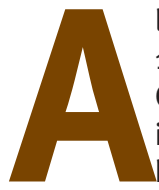

Idizkari hau hastapenetan zegoenean, 1986. urtean, jada krisiak jota zegoen Ongizate Estatua. Izan ere, gure gertuko ingurunean behintzat, aldagabea izan da krisialdi-egoera hori Ongizate Estatuan, kontuan hartzen bada behintzat eraikitzen hasitako garai berean bere bideragarritasuna zalantzan jartzen hasiak zirela inguruko beste herrialdetan. Orain gutxi arte, ordea, ez du etenik izan Ongizate Estatuaren hazkuntzak, gureari dagokionean behintzat; gizartezerbitzuen alorrera mugatuz gero, etengabe handitzen joan da artatutako pertsona-kopurua, landunen kopurua edota arlo horretara bideratutako gastua. Esaterako, 2009. urtean -datuak eskuragarri dauden azkeneko urtean- BPGari loturiko $(\% 3,3)$ historian inoiz egindako gasturik handiena bideratu eta inoiz baino handiagoa izan da biztanle bakoitzeko gastuaren zenbatekoa, ia mila euro, nahiz eta euro konstantean hartu gastuaren neurri hori.

Horiek horrela izanda ere, badirudi benetan larria dela krisialdia oraingoan. Ez da, inolaz ere, gizartezerbitzuen berariazko krisia, ez eta Ongizate Estatuari esklusiboki loturiko gaia, nahiz eta osagai batzuek -zahartze demografikoa, gizarte-arrisku berrien sortzea, eskubide berrien aitortzea...- eragin zuzena duten gizarte-zerbitzuen ekonomi iraunkortasunean. Egiatan, krisialdi orokor bati aurre egin behar diogu -Europako herrialdeetan bereziki-, eta krisi hori zalantzan jartzen ari da, bestelako osagairen batzuen artean, esku-hartze publikoaren rola bere osotasunean. Kontua ez da gizarte-zerbitzuen iraunkortasuna; aitzitik, zalantzan jartzen da hiritar ororen aukera-berdintasuna, birbanaketa eta bizikalitatea lortzea ahalbidetzeko asmoaren bideragarritasuna, horretarako bideratu izandako esku-hartze publikoa, eta, azken batean, gastu publikoaren bideragarritasuna.

Ez du zentzu handirik etorkizuneko aurreikustea egiteak orain, baina erraz ulertzekoa ematen du azken urte hauetako esku-hartze eta gasturako gaitasun berbera ez dutela izango administrazio publikoek etorkizunean. Egoera horren aurrean, nahiz eta aipatu bezala ez izan gizarte-zerbitzuen berariazko krisia, eszenatoki berrira egokitzeko estrategiamoduez gogoeta egitera behartuta dago alor honetako langintzan ari den pertsona oro.

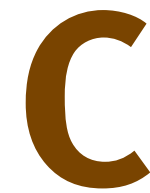
uando esta revista nació, en 1986, el Estado del bienestar ya estaba en crisis. De hecho, al menos en nuestro entorno más cercano, el Estado del bienestar nunca ha dejado de estar en crisis, si se tiene en cuenta al menos que su construcción se inició cuando en otros países su viabilidad se había empezado a cuestionar seriamente. Y sin embargo, al menos hasta hace muy poco, el Estado del bienestar no ha dejado de crecer entre nosotros: si nos limitamos al ámbito de los servicios sociales, ni el número de personas atendidas, ni el número de personas ocupadas, ni el gasto destinado a este ámbito del bienestar ha dejado de aumentar. En 2009, último año para el que se dispone de datos, se registra el mayor porcentaje de la historia de gasto en servicios sociales en relación al PIB (3,3\%) y el mayor gasto en servicios sociales por habitante, casi mil euros, aun cuando este gasto se mida en términos de euros constantes.

Y, pese a todo, parece que esta vez la crisis va en serio. No se trata, en cualquier caso, de una crisis específica del ámbito de los servicios sociales, o incluso exclusivamente relacionada con el Estado del bienestar, por mucho que determinados elementos -envejecimiento demográfico, aparición de nuevos riesgos sociales, reconocimiento de nuevos derechos...- afecten a la sostenibilidad económica de los servicios sociales. Nos encontramos, en realidad, ante una crisis más general, que afecta especialmente a los países de Europa, y que cuestiona, entre otros elementos, el papel de la intervención pública en toda su integridad. No es la sostenibilidad de los servicios sociales lo que ahora se discute, sino la viabilidad de un modelo en el que los objetivos de igualdad de oportunidades, redistribución y calidad de vida para toda la ciudadanía se han pretendido alcanzar, fundamentalmente, recurriendo a la intervención pública y, por tanto, al gasto público.

En estos momentos tiene poco sentido hacer previsiones, pero cabe pensar que difícilmente las administraciones públicas volverán en el futuro a disponer de la capacidad de intervención y de gasto que han tenido durante los últimos años. Ante esa situación, y aunque, como se ha dicho, no estemos hablando propiamente de una crisis de los servicios sociales, las personas que trabajan en este ámbito 
Asko dira erantzun beharreko galderak. Gastuari dagokionaren ikuspegitik, jada zehaztu ditugu -indarrean dagoen Gizarte Zerbitzuei buruzko Legearen bidez- zein eskubide aitortu ahal izango diren; egiatako atzera egitea izango bailitzake, oraindik ere asko gauzatzeke daudelarik, eskubide horien babesari uko egitea. Bada, ordea, eskubide horien prestazioak bermatzerakoan kalitate-estandarrei buruzko gogoeta egiterik -langile-ratioak, ekipamenduak eta abar-, batik bat, kalitate-estandar horiek gastuarengan duten ondorioen garrantziaren arabera mailakatuz.

Gainera, ezinbestekoa da gizarte-zerbitzuetako gastuaren efizientziaren inguruko hausnarketa egitea, kontuan harturik erabiltzaile bakoitzeko jakineko gastu maila batzuek ez dutela nahitanahiez egiatako kalitate-hazkuntza ekartzen zerbitzu-mailan edota erabiltzailearen egoera hobetzeari dagokionean; baina bestetik, zerbitzu berbera jasotzeko eragozle gertatzen dira, plaza berrien sortzea zailtzen duten heinean. Ikuspuntu horretatik, gizartezerbitzuen iraunkortasunak eskatzen du -eta zerbitzu publikoak, oro har- zerbitzuen kostuen birbalioztatzea egitea, bereziki, maila jasoagoan goratzeko joera izaten duten kudeaketa publikoaren arloan. Zentzu honetan, oroitarazi beharra dago hiru modutako eragile-talderen arteko gaiak adostu behar dituztela zerbitzu publikoen prestazioek -kalitatezko zerbitzuen beharra duten erabiltzaileak, batetik; zerbitzuak eman ahal izateko lan-baldintza egokiak behar dituzten profesionalak, bestetik; eta gastua finantzatzen duten heinean, efizientziarik gehiena eskatzen duten zerga-ordaintzaileak, azkenik-, eta ezin dira hobetsi talde berezitu batzuen interes edo beharrak besteenen goitik. Halaber, aztertu beharra dago partaide diren hainbat eragileren produktibitate-maila, betiere ahalezko emaitza-maila jasoenak lortu behar baitira zerga-ordaintzaileen bidez lortutako baliabide publikoak erabiltzerakoan.

Bestetik, derrigorrekoa da, egungo egoeran, sistemaren unibertsaltasun eta selektibitateaz atxiki beharreko orekaz gogoeta burutzea, eta, baita ere, beharren arabera prestazioa onartua izateko neurriaren gogoeta egitea. Arlo zehatz batzuetan izaera unibertsalaren egokieraz zalantzarik ez izan arren, beste batzuetan -batik bat, diru laguntzen arloanefizienteagoa izango litzateke gastua, betiere prestazioa bideratzen bada baliabide-maila baxuena duen biztanleriari.

Horretaz guztiaz gain, eta betiere gastuaren ikuspegia kontuan hartuz gero, hausnartu beharko da gizartean bere kabuz elkar laguntzeko osatutako sareen bidez, arlo publikoaren derrigorreko laguntza formala edota esku-hartzeaz gain, pertsonen beharrei erantzuteko boluntariotza, gizarte-ardura korporatiboa, zaintza komunitarioa eta antolatutako autolaguntzak hartu beharreko rolen inguruko askotariko eginbeharrez. Gai hortaz beste, ezinbestekoa da prebentzio politikak kontuan hartzea egoera berriak ekiditen eta azaleratzen laguntzeko -mendetasuna, gizarte-bazterketa edo babes-eza-, gehienbat, kasu están obligadas a reflexionar sobre cuáles deben ser las estrategias de adaptación a ese nuevo escenario.

Las preguntas a las que es necesario dar respuesta son muchas. Desde el punto de vista del gasto, ya hemos definido en Euskadi -mediante la vigente Ley de Servicios Sociales- qué derechos se han de reconocer a la ciudadanía; renunciar a la protección de esos derechos, cuando en muchos casos aun no se ha empezado a materializar, constituiría un verdadero retroceso. Sí cabe, sin embargo, valorar qué estándares de calidad -ratios de personal, equipamientos, etc.- deben garantizarse a la hora de la prestación de esos derechos, sobre todo en la medida en que esos estándares de calidad tengan importantes consecuencias en términos de gasto.

Además, resulta necesario reflexionar sobre la eficiencia del gasto que se realiza en servicios sociales, teniendo en cuenta que determinados niveles de gasto por cada persona usuaria pueden no suponer un incremento real en la calidad del servicio, o en la mejora de la situación de la persona atendida, pero impiden el acceso de nuevas personas usuarias a los mismos servicios, en la medida en que dificultan la creación de nuevas plazas. Desde ese punto de vista, la sostenibilidad de los servicios sociales $-y$ del conjunto de los servicios públicos- requiere una reevaluación de los costes que provocan los diferentes servicios, especialmente cuando se trata de servicios de gestión pública, cuyos costes, por lo general, tienden a ser más elevados. Debe recordarse, en ese sentido, que la prestación de servicios públicos debe conciliar los intereses de tres grupos de agentes -las personas usuarias, por una parte, que requieren un servicio de calidad; los profesionales, por otra, que requieren unas condiciones laborales adecuadas para la prestación de ese servicio; $y$, finalmente, los contribuyentes, como financiadores que demandan la mayor eficiencia posible en el gasto-, sin anteponer los intereses o necesidades de un grupo específico frente a los demás. También debe analizarse la productividad de los diferentes agentes implicados, desde la base de que, cuando se utilizan recursos públicos obtenidos de los contribuyentes, debería alcanzarse el mejor nivel de resultados posible.

Por otro lado, es necesario reflexionar sobre el equilibrio que ha de mantenerse, en las actuales circunstancias, entre la universalidad y la selectividad del sistema, y en el grado de necesidad que debe tenerse en cuenta a la hora de reconocerse el derecho a una prestación. Si bien es cierto que, en determinados ámbitos, la adecuación de la universalidad está fuera de toda duda, hay otros -especialmente en lo que se refiere a las ayudas económicas- en los que el gasto podría ser más eficiente si se destinara únicamente a las personas con un menor nivel de recursos.

Además de todo ello, y siempre desde el punto de vista del gasto, será necesario reflexionar sobre el papel que deben jugar las fórmulas de voluntariado, la responsabilidad social corporativa, la atención comunitaria y la autoayuda organizada, mediante las 
larrienetan edota gastu gehien bideratu behar den kasu horietarako guztietarako. Gizarte-zerbitzuen berariazko arloan, bestetik, aintzat hartu beharrekoa da, gizartearen behar berrietara egokitzeko ikuspegitik, ekonomi prestazio eta zuzeneko zaintzazerbitzuen inguruko orekaz eztabaida indartzea; izan ere, ekonomia-mailako prestazioak bideratu dituzte herrialde batzuetan, sistemaren efizientzia hobetzeko formula gisara ulertzeaz gain, zerbitzuen erabiltzaileei autonomia eta aukera-gaitasun zabalagoa ematearren.

Gizarte-zerbitzuen arloaz haratago, gogoeta indartu behar da gizarteak hobetsi nahi dituen zerbitzu publikoen inguruan, hau da, indartu beharrekoen eta eskaintzeari utzi beharreko prestazioen inguruko hausnarketa eginez. Izan ere, egungo gastu publikoak bere gain hartzen ditu, administrazioen eskutik, hainbat ardura, eta egungo egoeran berriz ere eztabaidan hartu daitezke, nahiz eta iraganaldian berauen izaera beharrekotzat eduki. Betebeharreko berriak onartzen diren heinean, espero izatekoa beharko luke, lehentasunekoak salbu, administrazioek bidean uzten joatea beste zerbitzu batzuek. Horri dagokionean, gero eta gehiago dira, adibidez, Palier edo Esping Andersen, gastu publikoaren ideia inbertsio publikoaren ideiaz ordezkatzearen aldeko egileak, eta, horrekin batera, itzultze jasoagoak lortzen dituzten jarduerak lehenestea, hau da, izaera efizienteagoa eta bai prebentzio bai birbanatze-maila jasoagoa duten horiek nagusiaraztea.

Baina beharrekoak izango dira ere zerbitzuen inguruko finantzatzeaz neurriak berritzea. Ez da soilik gutxiago gastatzea, batik bat, hobeto bideratu beharko da egindako gastu hori; eta, gaur egungo gastu publikoa jaitsiz gero, nekez defendatu daiteke Ongizate Estatu sendo bat. Aitzitik, bistan dago gizarte-zerbitzuetako gastu publikoak hazten joan beharko duela, eta, horrekin bat, finkatu beharko dira gastuaren hazkuntza hori egoki finantzatzea bermatuko duten politikak. Europan egun nagusitu diren iritzien aurrean, aldarrikatu behar da zerbitzu publikoen rola, eta, horien artetik, ongizatezerbitzuak galdatu behar dira, enplegu eta hazkuntzarako ardatz izateko.

Ikuspegi honi jarraikiz, oso egokia da -nahiz eta tamalez berandu heldu- Euskadin eta Estatu espainiarrean zerga-sistemaren bilketaren hazkuntzaz abian diren gogoetak. Edonola ere, presio-fiskala aipamen hartzean, kontuan hartu behar da ez dela krisiaren eszenatoki berriari aurre egiteko baliabide publikoez jardun behar, soilik; aspalditik desegokia izan da zerga-ordainen bidez lortutako baliabide publikoen eta gizarte-beharrei aurre egiteko nahien arteko oreka hori, eta ezin da helburutzat hartu, zerga-erreformaren bidez, soilik krisialdiaren aurreko presio-fiskalaren maila berbera berreskuratzea. Eztabaidaz kanpo uzten da, noski, fiskalitate-sistema horren izaera progresiboa edota errentaren araberako taldeen zerga-kargaren banaketa. Eztabaida horren hastapenerako ekarpen gisara egokia izan daiteke euskal administrazioek ofizialki argitaratzea cuales la propia sociedad se organiza en redes de apoyo mutuo para dar respuesta a las necesidades de las personas, sin recurrir necesariamente a la prestación de servicios formales o a la intervención pública. Junto a esta cuestión, también es necesario reflexionar sobre las políticas preventivas que deben ponerse en marcha al objeto de que evitar la aparición de las situaciones - de dependencia, exclusión o de desprotección- más severas y que requieren un mayor gasto. Otro de los debates que es necesario abordar, en el ámbito específico de los servicios sociales y desde el punto de vista de su adecuación a las nuevas necesidades sociales, es el del equilibrio entre prestaciones económicas y servicios de atención directa, en la medida en que las primeras se han querido impulsar, en algunos países, como fórmula para mejorar la eficiencia del sistema, así como para dotar de mayor autonomía y capacidad de opción a las personas usuarias.

Más allá del ámbito de los servicios sociales, la sociedad también debe llevar a cabo una reflexión sobre los servicios públicos a los que quiere darse prioridad, aquellos que deben reforzarse y aquellos que deben dejar de ser prestados. Sin duda, el gasto público actual es producto de la asunción, por parte de las administraciones, de responsabilidades en materias cuya necesidad es, en la actualidad, discutible, por mucho que se consideraran necesarias en el pasado. De la misma manera que se asumen nuevas obligaciones públicas, debería ser natural que las administraciones abandonaran otras, ya no prioritarias. En ese sentido, son cada vez más los autores, como Palier o Esping Andersen, que insisten en la necesidad de sustituir la idea de gasto público por la de inversión pública, y de primar el gasto en actividades y servicios con retornos elevados, más eficientes y con mayor efecto preventivo y redistributivo.

Pero también será necesario tomar medidas relativas a la financiación de los servicios. No se trata sólo de gastar menos, sino sobre todo de gastar mejor, y difícilmente puede defenderse un Estado del bienestar sólido con un menor nivel de gasto público que en la actualidad. Al contrario, es obvio que el gasto público en servicios sociales debe seguir creciendo, y que deben establecerse políticas que permitan financiar adecuadamente ese incremento del gasto. Frente a las corrientes de opinión que imperan hoy en Europa, es preciso reivindicar el papel de los servicios públicos, y dentro de ellos, de los servicios de bienestar, como motor de empleo y de crecimiento.

Desde ese punto de vista, es muy oportuna -aunque llega lamentablemente tarde-, la reflexión que se está realizando en Euskadi y en el conjunto del Estado sobre el necesario incremento de la recaudación tributaria. En cualquier caso, al hablar de presión fiscal no ha de olvidarse que el problema en Euskadi o en España no se limita a la insuficiencia de los recursos públicos en el nuevo escenario de crisis; la inadecuación entre los recursos públicos obtenidos vía impuestos y las necesidades sociales que con ellos se quería cubrir viene de lejos, y el objetivo de 
konparazioak ahalbidetzeko datuak, eta, horien bidez, bestelako Europako herrialdeekin alderatzea Euskadiko zerga-karga eta errentaren arabera sailkatutako taldeen ordainen ekarpenak. Horrela, jakiterik izango genuke, egungo esanek dioten bezala, ea nahikoa ote den Europako batezbesteko herrialdeen mailarekiko defizita murrizteko gehien mesedetutako gizarte-mailako pertsonei zergak haztarazteko neurria.

Presio-fiskal horretaz gain, beharrekoa da Euskadiko sistemaren izaera zuzena, homogeneoa eta eraginkorra lortzeko aurrerabidea egitea, ezarri ahal izateko erabiltzaileen ekonomi partaidetza zerbitzuen finantzan. Baina, betiere kontuan hartu behar da mendeko eta gizarte-beharrak dituztenek ez luketela ordaindu beharrik izango -nahiz eta horretarako baliabideak eduki- gizarte-zerbitzu edo laguntzazerbitzuak jasotzeagatik; bai, aldiz, bestelako osagai izaerako prestazioak jasotzean, adibidez, mantenu edota ostatu hartzean, bestelako hiritarrek berauen baliabideez ordaintzen duten gisara.

Azkenik, gizarte-zerbitzuek egoera berrira moldarazteko gogoeta burutzeaz gain, beharrekoa da krisiari aurre egiteko gizarte-zerbitzuen erantzunaren nolakotasunaz jakitea, eta gainditzerako bidean nolako ekarpenak egin daitezkeenaren inguruko hausnarketa bultzatzea. Ikuspuntu horretatik, ez dago aipatzeke lagatzerik gizarte-zerbitzuek eta, oro har, Ongizate Estatuak sortzen dituzten lanpostuek langabezia beheratzen laguntzen dutela, eta, bestetik, diru-sartze publikoak eta gizarte-kotizazioak hazteko lagungarri direla. Bestetik, bistan dago gizartezerbitzuek artatu eta beharreko laguntzak ematen dizkietela sarri krisiak sortutako gizarte-arazo gehien duten edadetuei. Hala ere, balioztatu behar da ea gizarte-zerbitzuek emandako laguntzak behar gehien duten adinduei bideratzen ari ote diren, eta zein neurriko eraginkortasun eta efizientzian hobetu den pertsona horien egoera. las reformas fiscales no puede limitarse a recuperar los niveles de presión fiscal previos a la crisis. Al margen queda, obviamente, la discusión sobre la progresividad de ese sistema fiscal y el reparto de las cargas fiscales entre los diversos grupos de renta. Una primera aportación a ese debate sería la publicación por parte de las administraciones vascas de datos comparativos, de carácter oficial, que permitan valorar la presión fiscal vasca en relación a la de otros países de Europa, y la distribución de las cargas fiscales que otros países realizan entre los diversos grupos de renta con la que se realiza en Euskadi. Así veríamos si, como ahora se dice, es suficiente con aumentar los impuestos a las clases más favorecidas para equilibrar el déficit que tenemos con la media europea en términos de recaudación fiscal.

Y, junto a la presión fiscal, es necesario avanzar en la definición en Euskadi de un sistema justo, homogéneo y eficaz para determinar la participación económica de las personas usuarias en la financiación de los servicios, sobre la base de que las personas dependientes o con necesidades sociales -aun cuando dispongan de recursos para ellono deberían pagar por la percepción de servicios sociales o asistenciales, pero sí por la percepción de prestaciones complementarias, como la manutención o el alojamiento, que el resto de la población abona por sus propios medios.

Finalmente, además de reflexionar sobre cómo debe el edificio de los servicios sociales adaptarse a esta nueva situación, también es necesario reflexionar sobre qué tipo de respuesta deben dar los servicios sociales a la crisis y qué aportación pueden realizar para superarla. Desde ese punto de vista, no debe olvidarse que los servicios sociales y los del conjunto del Estado del bienestar generan, por una parte, puestos de trabajo que reducen el desempleo y suponen un incremento en la recaudación tributaria y en las cotizaciones sociales. Por otra, resulta evidente que son los servicios sociales los que ofrecen a las personas con mayores necesidades sociales, en muchos casos provocadas por la crisis, los apoyos que precisan. Debe valorarse, sin embargo, si el apoyo de los servicios sociales se está dirigiendo a las personas con mayores necesidades, y en qué medida está resultando eficaz y eficiente para mejorar la situación de esas personas. 


\section{Aurkibidea Índice}

9

Prestaciones económicas versus prestaciones en especie: el resurgir de un viejo debate

SIIS Centro de Documentación y Estudios

29

El papel de las organizaciones empresariales y sindicales en la política social de atención a la dependencia Vicente Marbán Gallego

\section{1}

Códigos deontológicos e ideología en trabajo social

Rogelio Gómez García

\section{7}

Dinámicas relacionales entre servicios sociales comunitarios y entidades sociales. Un estudio de caso Germán Jaraíz Arroyo Auxiliadora González Portillo Guadalupe Cordero Martín

57

El papel de los observatorios en el conocimiento de los procesos de exclusión social Isabel Serrano Rodríguez Juan Benito Martínez Manuel Hernández Pedreño

71

Infancia y exclusión social en España: realidades y retos a partir de la crisis Mònica Clua-Losada

Albert Sesé i Ballart

Marta Tur i Tur

\section{5}

Análisis de la calidad percibida en usuarios/as de servicios sociales comunitarios

Manuel E. Medina Tornero

Elvira Medina Ruiz
101

Actitudes y opiniones sobre el uso de prestaciones económicas por parte del colectivo inmigrante en el País Vasco Gorka Moreno Márquez

Arkaitz Fullaondo Elordui-Zapaterietxe

\section{1}

El papel del asociacionismo en la integración sociopolítica de las personas migrantes de origen subsahariano. El caso del País Vasco

Maria Giulia Di Carlo

\section{1}

El mapeo de las necesidades como medio de mediación social

Ada Manfreda

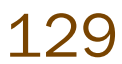

La Gran Recesión y el mundo después de la crisis

Ramón Barinaga Osinalde

143

Euskadin etxez etxeko laguntzaren esleipenari eta intentsitateari buruz orientabidea eskaintzeko tresnaren garapena

SIIS Dokumentazio eta Ikerketa Zentroa

159

Experiencias de voluntariado en la CAPV Dirección de Política Familiar y Comunitaria, Dpto. de Empleo y Asuntos Sociales, Eusko Jaurlaritza-Gobierno Vasco 



\section{Prestaciones económicas versus prestaciones en especie: el resurgir de un viejo debate.}

\section{SIIS Centro de Documentación y Estudios}

Fundación Eguía-Careaga

<estudios@siis.net>

Egungo Europako gizarte-zerbitzu sistema gehienetan daude zaintzaren inguruko prestazio ekonomikoak eskuratzeko bideak. Etenik gabeko finkatze honek kezka sortzen du bere hedatzeak, epe luzean, Ongizate Estatuan izan ditzakeen eraginengatik; eta kezkagarria da, partikularki, erantzukizun publikoak progresiboki atzera egitearen iragarpen gisara ulertu daitekeen heinean. Artikulu honetan deskribatzen dira eredu desberdinetan hartutako askotariko formulak, eta erakusgai jartzen da eraginaren hedadura mugatzen duela bere sartzeak finkatu izandako helburuen arabera, emandako garrantzia eta diseinuaren ezaugarriengatik. Osagai horiek guztiak oso aldakorrak dira Estatu bakoitzaren gizarte-babesaren tradizioaren arabera, gizarte-zerbitzuetako izaera berezitu edota unibertsalaren arabera, eta ezarri edo mantentzen direneko egoera soziopolitikoak ere baldintzatzen ditu.

\section{HITZ-GAKOAK:}

Ongizate Estatua, ereduak, gizarte-zerbitzuak, prestazio ekonomikoak, nazioarteko ikuspegia.
Las prestaciones económicas destinadas a la adquisición de atención están hoy presentes en la mayoría de los sistemas de servicios sociales vigentes en Europa. Este progresivo afianzamiento causa inquietud en relación con el impacto que su extensión pudiera tener, a largo plazo, en la estructura del Estado del bienestar; en particular, preocupa cuanto pudiera conllevar de augurio de un progresivo retranqueamiento de la responsabilidad pública. Este artículo describe la diversidad de fórmulas adoptadas por los diferentes modelos y muestra que la mayor o menor amplitud de su impacto viene determinada por el objetivo perseguido con su introducción, por el peso que se les otorga y por las características de su diseño, elementos, a su vez, fuertemente modulados por la tradición de protección social propia de cada Estado, la naturaleza universal o selectiva de su sistema de servicios sociales, y la coyuntura sociopolítica en la que se implantan y mantienen.

\section{Palabras Clave:}

Estado del bienestar, modelos, servicios sociales, prestaciones económicas, panorama internacional.

${ }^{1}$ Este artículo se basa en un informe realizado por el SIIS Centro de Documentación y Estudios, a solicitud de la Diputación Foral de Gipuzkoa y terminado a comienzos de 2011. 


\section{Presentación}

A lo largo de la última década, el ámbito de la política social y de los servicios sociales ha presenciado, tanto en Europa como en Norteamérica, el progresivo afianzamiento de las prestaciones económicas como vía de acceso a la adquisición de servicios de atención personal formal, o como vía de compensación económica de los cuidados informales. Si bien tuvo su origen entre las décadas de 1980 y 1990 , en esa época inicial este fenómeno no había dado muestras de la dinámica extensiva que, sin duda, tiene en la actualidad.

Con carácter general, pueden diferenciarse dos grandes categorías de medidas económicas:

- Un primer grupo está compuesto por las prestaciones económicas atribuidas directamente a los cuidadores informales desde la Administración, bien en forma de compensación económica por la reducción de ingresos derivada de la dedicación a la atención de familiares (prácticamente como un complemento de ingresos mínimos), bien en forma de salario. Aunque anteriores a las medidas comprendidas en el segundo grupo, estas fórmulas están mucho menos difundidas.

- El segundo grupo de medidas está integrado por fórmulas que vienen a ser equivalentes, en mayor o menor grado, a las prestaciones económicas de atención a la dependencia, vigentes en nuestro sistema. Todas ellas tienen en común que: a) sus beneficiarios directos son las personas usuarias, es decir, las personas que necesitan apoyos para las actividades de la vida diaria; $y$ b) se otorgan para que la persona usuaria se encargue de adquirir o compensar con ellas la atención que requiere, prestada, según los casos, por entidades de servicios, cuidadores profesionales autónomos y/o cuidadores informales.

Se articulan como alternativas a la prestación de servicios en especie, es decir, ofrecen la posibilidad de sustituir la atención diseñada, organizada y prestada -directa o indirectamente- desde los servicios sociales públicos por la atención diseñada, organizada y contratada por la propia persona usuaria, dotándola para ello de medios económicos que puede utilizar para contratar los apoyos requeridos, prestados por las entidades o los cuidadores de su elección. Para hacerlo, los sistemas vigentes optan unas veces por prestaciones económicas en sentido estricto, es decir, cuantías concedidas en metálico a la persona beneficiaria, y otras veces por una asignación económica individual en un presupuesto o fondo personal o individual, expresado en horas de apoyo y/o en cuantía económica.

En el ámbito internacional, este conjunto de medidas obedecen a la filosofía de la 'atención dirigida por la persona usuaria', integrada en los sistemas de servicios sociales bajo diferentes denominaciones: unas referidas a los instrumentos que articulan sus varian- tes -individual funding, personal budget, direct payment-; otras, con mayor fuerza expresiva, referidas al protagonismo de la persona usuaria -consumer-directed care, self-directed support, selfmanaged care-. Muchos sistemas las han introducido, aunque en grado muy variable y, como se verá, respondiendo a muy diversos objetivos. Con el fin de abarcar esa variedad, se incluye en el análisis una selección de países que obedece a dos criterios:

- Por un lado, la necesidad de observar nuestra realidad más cercana -la europea-, tratando de recoger ejemplos suficientemente representativos y documentados de la gran diversidad existente en el diseño y la articulación de las fórmulas de asignación económica individual: Suecia, como ejemplo del modelo nórdico; Alemania, Austria, Francia y Holanda, como ejemplos del modelo continental; Reino Unido (y más específicamente, Inglaterra), como ejemplo del modelo anglosajón.

- Por otro lado, el interés de contrastar esta realidad con la existente en Estados Unidos, habida cuenta del carácter a veces muy novedoso de las diferentes iniciativas estatales y federales en esta materia, y de una labor evaluadora de su aplicación y de su impacto, considerablemente más desarrollada que en cualquier país europeo.

En el Cuadro 1, se señalan las fórmulas económicas vigentes en cada uno de los países seleccionados.

Cuadro 1. Prestaciones económicas y fondos individuales asignados a la persona usuaria para la adquisición de atención

\begin{tabular}{|c|c|}
\hline País & Denominación \\
\hline Austria & $\begin{array}{l}\text { Prestación económica de cuidados de larga } \\
\text { duración (Pflegegeld) }\end{array}$ \\
\hline \multirow[t]{2}{*}{ Alemania } & $\begin{array}{l}\text { Prestación económica de cuidados de larga } \\
\text { duración (Pflegegeld) }\end{array}$ \\
\hline & Fondos personales (Persönliches Budget) \\
\hline \multirow[b]{2}{*}{ Francia } & $\begin{array}{l}\text { Prestación personalizada de autonomía } \\
\text { (Allocation personalisée d'autonomie, APA) }\end{array}$ \\
\hline & $\begin{array}{l}\text { Prestación compensatoria de la } \\
\text { discapacidad (Prestation de compensation } \\
\text { du handicap) }\end{array}$ \\
\hline Holanda & $\begin{array}{l}\text { Prestación económica del fondo } \\
\text { personal de cuidados de larga duración } \\
\text { (Persoonsgebonden budget) }\end{array}$ \\
\hline \multirow[t]{2}{*}{ Reino Unido } & $\begin{array}{l}\text { Prestación económica de atención } \\
\text { comunitaria (Direct Payment) }\end{array}$ \\
\hline & Fondo personal (Personal Budget) \\
\hline \multirow{2}{*}{ Suecia } & $\begin{array}{l}\text { Prestación económica de asistencia } \\
\text { personal para personas con discapacidad } \\
\text { (Assistansersättning) }\end{array}$ \\
\hline & $\begin{array}{l}\text { Prestación económica de apoyo en } \\
\text { el domicilio para personas mayores } \\
\text { (Anhörigbidrag) }\end{array}$ \\
\hline Estados Unidos & $\begin{array}{l}\text { Programas de atención dirigida por la } \\
\text { persona (Consumer-directed care programs) }\end{array}$ \\
\hline
\end{tabular}

Fuente: Elaboración propia a partir de SIIS Centro de Documentación y Estudios, 2011, pág. 14. 
Este artículo se centra en las medidas de este segundo grupo, no sólo porque son las que se encuentran en plena expansión, sino, sobre todo, porque son las que más abiertamente plantean los términos de un debate que contrapone prestaciones económicas a prestaciones de servicios, actualizando así un viejo duelo entre el modelo liberal y el modelo socialdemócrata de protección social.

Dados estos antecedentes, la introducción de fórmulas de asignación económica individual tiene, al margen del peso que realmente adquieran en cada Estado, un fuerte contenido simbólico. De ahí que el renovado interés por su aparición observado a lo largo de las dos últimas décadas haya despertado, tanto en Europa como en Norteamérica, tensas controversias - de corte teórico, ideológico y de práctica administrativa- con respecto al impacto que, a medio y largo plazo, pudiera tener en la estructura del Estado del bienestar y en los equilibrios entre sus principales agentes: el Estado, como representación de lo público; el individuo y la familia, como representación de la esfera privada; las organizaciones sin ánimo de lucro, como representación de la sociedad civil solidaria; y las organizaciones con ánimo de lucro, como representación del mercado.

En el marco de ese debate, las argumentaciones analizan estas tendencias en términos de modelo y de sistema y, desde esta óptica, adoptan un enfoque global: proyectan el impacto de las nuevas fórmulas si su aplicación se generalizara; su coherencia con los diferentes modelos de bienestar; su impacto a largo plazo en relación con la supervivencia del propio sistema; su impacto en el reconocimiento social de la función cuidadora y de las y los profesionales de asistencia y atención personal; y su impacto en el futuro de las y los cuidadores informales, en la medida en que se teme el progresivo engrosamiento de un colectivo que, a medio o largo plazo, dadas las bajas remuneraciones, pasará a engrosar las filas de la población en situación de precariedad económica.

Es cierto que, visto el peso todavía muy relativo de las prestaciones económicas en los sistemas de servicios sociales, el hipotético panorama de su generalización puede parecer lejano o incluso poco probable ${ }^{2} y$, por lo tanto, los términos del debate, innecesariamente alarmistas; pero pueden explicarse, además de por la rápida extensión y el acusado crecimiento de estas prestaciones, por su tremendo potencial de cambio, que si bien en algunos genera esperanzas, en otros muchos genera, sin duda, temores. Es un hecho innegable que esta nueva vía lleva aparejada la carga propia de los cambios que abren la puerta a un giro en la filosofía de la atención y, como tal, despierta la necesidad de mantenerse alerta, de prevenir y

${ }^{2}$ En contraposición con esa percepción general, en algunos países, se empieza a vislumbrar como posible. Así, en el Reino Unido, los fondos individuales se encuentran ahora disponibles para todos los colectivos y las administraciones tienen, desde 2001, la obligación de proponer esta alternativa a todas las personas con necesidades de cuidados de larga duración que cumplan los requisitos de acceso al sistema público. velar por sus posibles consecuencias³, abogando así, lógicamente, en contra de una adopción mimética e irreflexiva de estas medidas.

Por otra parte, para situarse en el debate, interesa no perder de vista que la introducción de las prestaciones económicas es el resultado de un complejo proceso en el que se dio la convergencia de una serie de factores reflejados en valores y en estrategias organizativas de la atención, y que, como se verá en el siguiente apartado, esta convergencia se dio, casi simultáneamente, en países de muy distinto corte ideológico y de muy distinta tradición de protección social: el contexto nacional en el que se inscriben es el que determina su verdadera naturaleza, su potencial y sus riesgos. La finalidad última de las fórmulas de asignación económica individual, su peso en el sistema y, en definitiva, su impacto en el modelo de bienestar vienen moduladas por la tradición de protección social propia de cada Estado, la naturaleza universal o selectiva de su sistema de servicios sociales, el marco político-administrativo que las establece o promueve, y las corrientes y movimientos sociales que las generan y dinamizan. De tal suerte que hay países que instrumentan estas alternativas con unos objetivos claramente centrados en la reducción de costes y orientados al progresivo retranqueamiento de lo público, y países que realmente las introducen con el fin principal y último de favorecer el ejercicio del derecho de elección de las personas usuarias y de contribuir a la modernización del Estado de bienestar, sin pretender ningún debilitamiento del modelo de responsabilidad pública.

Tampoco debe olvidarse que, en su configuración actual, los sistemas prestacionales son muy jóvenes y se ven sujetos a continuos cambios. De hecho, en su mayoría son el resultado de diferentes intentos y sucesivas reformas -algunas de ellas en curso actualmente- orientadas bien a mejorar el grado de consecución de los objetivos marcados, bien a corregir determinadas tendencias evolutivas, bien a abrir nuevas alternativas para descubrir o estimular el potencial de estos instrumentos o, al revés, para frenar un atractivo que, en función del grado de implantación, de la mayor o menor generalización de su aplicación, puede tener, a medio o largo plazo, consecuencias no deseadas para el conjunto del sistema.

\section{El contexto para el surgimiento de las fórmulas de asignación económica individual}

Como ya se ha apuntado, aunque con antecedentes en décadas previas, fueron los años noventa los que marcaron, si no la aparición, sí el progresivo

${ }^{3}$ De hecho, algunos teóricos, de ambas tendencias, han llegado a señalar que es un concepto que, en sí mismo, podría suponer, para los sistemas de servicios sociales, un giro de magnitud similar a la que, en su momento, representó el paso de un modelo institucional a un modelo comunitario. 
afianzamiento, en las políticas sociales de atención a la dependencia, de una vía hasta entonces poco transitada: la articulación de fórmulas de asignación económica individual para la adquisición de cuidados como alternativa a la prestación de servicios en especie. La cuestión es de dónde surgió la necesidad de introducirlas y en qué marco se produjo su introducción; a este respecto, interesa primero situar el contexto general en el que se inscribe, para después ver cómo, partiendo de realidades no excesivamente distantes, los modelos afectados adoptaron vías muy diferenciadas en función de sus finalidades prioritarias y de los fundamentos básicos de su modelo de protección social.

\subsection{El contexto general}

Sin perjuicio de la diversidad de los contextos nacionales, en el panorama internacional de finales de la década de 1980 y durante los años noventa se observa una serie de circunstancias comunes que, si bien no siempre están presentes con la misma intensidad, actuaron como vectores de convergencia que explicitaban una crisis del modelo de bienestar concebido y construido desde mediados del siglo XX, y forzaban a la búsqueda de soluciones que permitieran reajustarlo y modernizarlo:

- La crisis del modelo se identificó, en el discurso crítico del momento, con el fracaso del sector público para garantizar un sistema de atención social capaz de:

- Asumir realmente la extensión de su intervención al conjunto del espectro social y rebasar el núcleo de colectivos desfavorecidos que, tradicionalmente, habían constituido el sujeto de atención de los servicios sociales.

- Adecuarse a una situación de intensificación y renovación de las necesidades sociales y, especialmente, hacer frente a la proliferación de situaciones que no podían resolverse sólo con el arsenal clásico de medidas de protección social, constituido fundamentalmente por prestaciones económicas asistenciales y por un rígido y no muy desarrollado sistema de atención directa de corte institucional. En efecto, las previsiones de una evolución poblacional marcada por el envejecimiento demográfico, unidas a las previsiones de menor disponibilidad de una red natural de atención afectada por el impacto de las nuevas estructuras familiares, la creciente inclusión de la mujer en el mercado laboral y la movilidad geográfica asociada a un mercado laboral inestable, cada vez más orientado a la flexibilidad, determinaban que los nuevos riesgos sociales requirieran el desarrollo de un sector de atención hasta entonces residual, el de la prestación de servicios sociales personales $^{4}$ no institucionales, a partir de entonces

4 En el ámbito europeo el término 'sistema de servicios sociales' destinado a constituir un área esencial de las políticas de protección.

Ésta era una crisis tanto organizativa -que las voces más críticas atribuían a la rigidez y a los imperativos administrativos asociados a la prestación pública de servicios-, como financiera -centrada en la dificultad de sostener económicamente la prestación pública de servicios sociales ante la creciente demanda de servicios-. Esta necesidad entraba en contradicción con los límites presupuestarios y fiscales, pero también con lo que se percibía como una excesiva burocratización de los modelos vigentes, de modo que se consideró necesario buscar nuevas vías organizativas que hicieran viable la expansión del sistema y que permitieran:

- reducir los gastos de funcionamiento, mediante una utilización más eficiente, eficaz y racional de los recursos disponibles;

- incrementar los recursos económicos destinados a la prestación de servicios sociales personales, para garantizar su capacidad de respuesta a las previsiones poblacionales;

- regular el acceso al sistema público de servicios sociales para dar contenido al derecho de las personas en situación de necesidad y evitar la discrecionalidad hasta entonces vigente;

- diversificar la gama de servicios disponibles, para favorecer el paso de un modelo marcadamente institucional a un modelo comunitario y para reforzar la existencia de soluciones de carácter preventivo que retrasasen o evitasen el recurso a soluciones más costosas.

Simultáneamente a la crisis administrativa y financiera del modelo, se estaba produciendo un movimiento de fondo en la población atendida, a resultas del cual se fue imponiendo una corriente que, desde un enfoque de justicia social y de reconocimiento de derechos, defendía el establecimiento de un sistema de atención centrado en la persona usuaria y en la promoción de su autonomía, su libre elección y de su autodeterminación.

Un actor esencial en este proceso fue el movimiento de vida independiente que, desde los años setenta, había surgido con fuerza, primero en Estados Unidos, y más tarde en Europa, en particular en los países nórdicos y en el Reino Unido. Este movimiento, muy anclado en la defensa de un modelo social de discapacidad (por contraposición al hasta entonces imperante modelo médico), promovido por las organizaciones de defensa de los derechos de las personas con discapacidad-especialmente por adultos jóvenes con discapacidad física-, ejerció fuertes presiones y lideró una reivindicación básica

se utiliza para referirse a muy diversas realidades, por ejemplo, como sinónimo de política social, protección social, o asistencia social. Para evitar confusiones, la expresión más consensuada a escala europea para aludir a lo que en nuestro ámbito conocemos como servicios sociales es la de 'servicios sociales personales'. 
para ese colectivo: el derecho a vivir de forma independiente, fuera del marco institucional, adoptando sus propias decisiones en relación con su forma de vida, y también en relación con las alternativas de atención y apoyo que pudieran necesitar para llevar una vida autónoma. Progresivamente, se unieron a esta corriente las voces de otros colectivos, como manifestación generalizada de un cierto descontento con el funcionamiento de un sistema que estimaban excesivamente rígido.

En respuesta a esa insatisfacción, y de acuerdo también con planteamientos innovadores de intervención defendidos por algunos teóricos y promovidos por nuevas visiones y prácticas profesionales, se adoptaron medidas tendentes a reforzar -en particular a través de la gestión de caso- un mejor ajuste de la atención a las particularidades de cada situación, y un mayor protagonismo de la persona usuaria en la definición de sus necesidades y preferencias, y en el diseño de los apoyos más ajustados a éstas. Se implantaba así la idea de empoderamiento de la persona usuaria, como manifestación de la voluntad de requilibrar un modelo que, en su afán de protección, actuaba con fuertes rasgos paternalistas, determinantes de que tanto la construcción del sistema como la del modelo de atención estuvieran dominados por el imperativo público y por el criterio profesional, sin que la persona usuaria tuviera realmente voz en los procesos de intervención. Esta nueva visión suponía un cambio radical con respecto a la tradición anterior.

En cierto modo, puede decirse que las demandas y los deseos manifestados por las personas usuarias de contar con servicios menos estandarizados, más ajustados a las necesidades individuales, y más variados, que les permitieran elegir las opciones más adecuadas y participar activamente en el diseño de su paquete de apoyos, estaba en sintonía con las necesidades constatadas desde la propia Administración en términos de ampliación y diversificación de la red, y en términos de eficiencia y agilidad en la organización y el funcionamiento del sistema. Así es como los valores de personalización de la atención, empoderamiento, autodeterminación y de derecho de elección se integraron en el discurso público de los diferentes modelos de servicios sociales, y como se impuso, en todos ellos, la necesidad de ajustar mejor la oferta de servicios y el modelo de atención a las necesidades individuales $y$, en lo posible, a las preferencias de la persona usuaria. Se pasaba así del paradigma de la atención ofrecida en función de la red de servicios, al paradigma de la atención ofrecida en función de las necesidades individuales. Esto ocurrió, con mayor o menor énfasis, en todos los sistemas:

- Para los sistemas de corte liberal, este reforzamiento de la dimensión individual encajaba muy bien con los planteamientos de mercado, en los que éste se caracteriza por ofrecer alternativas diversas y es el consumidor quien elige la fórmula que más le conviene, que mejor responde a sus necesidades y preferencias.
- Para los sistemas de corte socialdemócrata, esta nueva concepción era una vía de modernización de los sistemas, una oportunidad de mejorar la connivencia entre la Administración y la colectividad y, en última instancia, de garantizar la pervivencia de un sistema de acción colectiva. En su marco, la modernización se presenta como una respuesta necesaria a un público cada vez más demandante y cada vez más competente en su demanda.

En ese contexto, muchas administraciones consideraron que había que responder a este conjunto de necesidades y demandas con una reorganización de los sistemas de servicios sociales. Pero las medidas adoptadas con ese objetivo no obedecieron a un plan coherente y estructurado de reforma, sino más bien a un proceso de progresiva adaptación a los problemas y a las necesidades. Lo primero que se hizo, en grados muy variables según los contextos nacionales, fue abrir el ámbito de los servicios sociales personales, hasta entonces dominado por el sector público y, en algunos países, por el sector privado no lucrativo, a las entidades mercantiles, es decir, al ánimo de lucro, lo cual era un cambio drástico en este sector de la acción pública. Esta estrategia perseguía diversos fines:

- ampliar la oferta de servicios, es decir, la capacidad de la red de atención;

- aumentar la diversidad en la gama de servicios, requerida para posibilitar la personalización de la atención y el ejercicio efectivo del derecho de elección;

- aumentar la competitividad entre unos y otros agentes, con el fin de disminuir los costes.

Se modificaron así los equilibrios existentes hasta entonces entre los diferentes sectores, con un progresivo incremento en la prestación de servicios desde el sector privado, tanto desde las entidades mercantiles como desde las organizaciones no lucrativas. Esto ocurrió en la mayoría de los países europeos, si bien con marcadas diferencias de intensidad y orientación (incluso en los países nórdicos empezó a desarrollarse un tercer sector de acción social hasta entonces prácticamente inexistente).

En coherencia con esa expansión, se intensificó la intervención de la Administración en funciones a las que, hasta entonces, no se había dedicado o sólo escasamente:

- Funciones de regulación de los estándares de atención. En efecto, la necesidad de extender la cobertura de la red de atención para dar respuesta a las crecientes necesidades requería la introducción de mecanismos destinados a garantizar la disponibilidad de servicios sociales y la equidad en el acceso a éstos, y ello llevó a la definición de niveles mínimos obligatorios de prestación y, en contrapartida, al establecimiento 
de una serie de requisitos de acceso a los diferentes servicios, lo cual fue el primer paso hacia un progresivo reconocimiento formal de derechos, en particular en el ámbito de los cuidados de larga duración.

- Funciones de autorización, concertación, homologación e inspección de servicios.

Se constituía así un nuevo ámbito de relaciones entre lo público, el tercer sector y el sector mercantil, habitualmente referido en términos de economía mixta del bienestar, que conllevaba la creación de un ámbito de prestación de servicios cercano al mercado (quasi-market), que se tradujo en nuevos modos de funcionamiento y relación, reflejo de un progresivo acercamiento a lo privado:

- Así, en algunos países, se implantaron en los servicios, incluso en los de gestión pública, las directrices del new managerialism, que trajo consigo la utilización de nuevos procedimientos de evaluación de costes y resultados, importados de modelos propios del sector empresarial y centrados en la gestión por objetivos, lo que traslucía una clara modificación de los principios de actuación y regulación de los servicios públicos.

- En las relaciones entre la Administración y el tercer sector de acción social, se pasó progresivamente de un sistema basado en la concesión de subvenciones globales, que dejaba mayor libertad a las organizaciones sin ánimo de lucro para idear y organizar servicios innovadores de carácter experimental, a un sistema de corte casi contractual entre el sector público y los agentes del tercer sector, que suponía una mayor regulación o formalización de las relaciones entre ambos.

- Simultáneamente, también se fue extendiendo la contratación de la prestación de servicios de responsabilidad pública con entidades privadas, por la vía del concurso, al que podían presentarse tanto las entidades mercantiles como las organizaciones sin ánimo de lucro, en condiciones idénticas, es decir, quedando sujetas a las reglas de la competencia.

- En algunos países, empezaron a aparecer nuevos sistemas de financiación que contribuyeron decisivamente a la creación de un mercado privado de servicios sociales, mediante la introducción de medidas destinadas a implicar e incentivar a operadores especializados del mercado (por ejemplo, compañías de seguro), produciéndose así un giro hacia lo que se conoce en la literatura especializada como la 'privatización de la financiación'.

Este conjunto de medidas fue una forma de dar respuesta a algunas de las necesidades y de las demandas antes mencionadas; en particular, favoreció la ampliación de la red de servicios y una mayor variedad en la gama de alternativas de apoyo disponibles, pero dejaba sin resolver algunos frentes clave:
- La demanda de autodeterminación de algunos colectivos que, desde la defensa del derecho a la igualdad de oportunidades, exigían, más allá de una participación activa en el diseño de su plan de atención, una total asunción, por sí mismos, sin intermediarios, de las funciones de diseño, contratación y organización de los apoyos personales que mejor pudieran responder a sus necesidades y preferencias, abogando, con ese objetivo, por la puesta en marcha de un sistema que les dotara de medios económicos suficientes destinados a la adquisición de esos apoyos.

- La existencia de una red informal de atención, poco reconocida y escasamente apoyada, con la salvedad de algunos servicios de formación y respiro que, si bien eran indispensables, no eran suficientes y no constituían una solución al riesgo real de debilitamiento de la red natural.

- El progresivo desarrollo de una economía sumergida en los domicilios, que dejaba al margen de cualquier control público tanto la situación de las personas atendidas como la de los cuidadores profesionales a domicilio.

- Las previsiones de crecimiento del gasto público asociadas al mantenimiento y la ampliación de la red formal de servicios.

Pues bien, la introducción de las prestaciones económicas para la adquisición de servicios de atención personal fue la vía de respuesta a estas cuestiones pendientes:

- Posibilitaban la intervención de la persona usuaria en el diseño de la asistencia personal requerida, en su organización y en la contratación de la o las personas o servicios que pudieran tomar parte en la prestación de esos apoyos.

- Permitían la retribución o la compensación económica a los cuidadores informales, lo que podía contribuir a la retención de la red informal, a su sostenimiento y a su futura renovación.

- Permitía aflorar situaciones laborales irregulares si se condicionaba la posibilidad de utilizar la prestación económica o el fondo personal para retribuir a un cuidador profesional a su contratación laboral.

- Auguraba, según todas las previsiones, una vía de contención del gasto.

Se daba así, con la introducción de las fórmulas de asignación económica individual, un paso más claro todavía que los anteriores hacia un mayor protagonismo de lo privado $y$, previsiblemente, hacia un debilitamiento de lo público.

\subsection{Los contextos nacionales}

El contexto general de introducción de las prestaciones económicas es el que se acaba de describir, pero el peso de los diversos factores que marcaron ese 
contexto y la combinación de objetivos perseguidos difiere tanto entre unos y otros países que determinaron orientaciones muy diversas en los modelos, aunque finalmente se instrumentaran a través de un mismo tipo de medida.

En los países que fueron pioneros en la aplicación de estas fórmulas, el telón de fondo estaba dominado por la presión que ejercían los colectivos de defensa y promoción de los derechos de las personas con discapacidad. Ése fue el caso, primero, en Estados Unidos, donde, en la década de 1970, surgió el movimiento de vida independiente. Como ya se ha dicho, este movimiento lideró una reivindicación básica: la de dotar a las personas con discapacidad de medios económicos suficientes para la adquisición de apoyos personales necesarios para llevar una vida independiente. Esto se tradujo en la aparición de toda una serie de iniciativas caracterizadas por el protagonismo otorgado a la persona usuaria en la selección y contratación de su o sus asistentes personales, en la definición de las tareas de apoyo y en la organización de sus horarios.

En Europa, los dos primeros países en los que se observó, con fuerza, la influencia del movimiento de vida independiente fueron, prácticamente en la misma época, Suecia y el Reino Unido. En Suecia, las primeras voces del movimientos de vida independiente se oyeron a comienzos de los ochenta, cuando un pequeño grupo de personas con discapacidad, inspiradas por el éxito y la fuerza de las iniciativas norteamericanas, lanzó el debate, oponiéndose a la tutela de los servicios de carácter colectivo y reivindicando el derecho a disponer de medios económicos suficientes para organizar por sí mismas servicios mejor adaptados a sus necesidades y preferencias individuales, y más respetuosos de su autonomía. Al principio, la idea chocó contra la viva oposición de los servicios sociales -que consideraban que era una fórmula elitista-, la de la izquierda -que veía en esta alternativa una forma de privatización totalmente contraria al modelo sueco de bienestar-, la de los sindicatos -que temían la explotación de los profesionales de asistencia personal-y la de las asociaciones de usuarios de corte más tradicional -que abogaban por una extensión de la cobertura y de la diversidad de la red de servicios existente-. Siendo ésas las primeras reacciones, durante los primeros años sólo algunos municipios optaron por esta vía y dieron su apoyo económico a algunas iniciativas de esta naturaleza, pero, para el año 1993, el movimiento había alcanzado tal fuerza que, rompiendo con la tradición sueca de las leyes marco aplicables al conjunto de la ciudadanía, se aprobó una ley sectorial, la Ley sobre Apoyo y Servicios a Personas Afectadas por Incapacidades Funcionales (Lag 1993:387 om stöd och service för vissa funktionshindrade, LSS), que impuso a las administraciones locales la obligación de garantizar a estas personas unas condiciones de vida dignas, ofreciéndoles el apoyo y la ayuda que requirieran, pero también la posibilidad real de participar directamente en las decisiones sobre los tipos de servicios ofrecidos. La medida faro de este dispositivo era la asistencia personal, que se definía como un apoyo individualizado para la realización de las actividades básicas de la vida diaria (incluida la comunicación), que debía estar disponible en todo momento para garantizar realmente la posibilidad de llevar una vida autónoma, y en cuya articulación debía garantizarse que la persona con discapacidad pudiera tomar parte activa en la elección de sus asistentes personales, en la definición de sus horarios y de los tipos de apoyo requeridos.

En el Reino Unido, las cosas empezaron a moverse a mediados de los ochenta por la confluencia de dos importantes factores:

- Por un lado, la llegada, procedente de Estados Unidos, del movimiento de vida independiente, con su defensa de una posición más activa y autónoma para las personas con discapacidad. Aquí también, su deseo era que las personas con discapacidad pudieran elegir la forma en que deseaban ser atendidas y ejercer un control directo sobre la atención que recibían, y para ello proponía la introducción de un sistema de prestaciones económicas. Inicialmente, las principales dudas u objeciones que planteaba esta cuestión se centraron en si las prestaciones económicas eran o no eficientes en términos de coste y en las dificultades asociadas a la responsabilidad sobre el uso de fondos públicos que, por estas vías, quedaba diluida. Los muy positivos resultados de la evaluación de las experiencias desarrolladas a escala local y la constatación del nivel de satisfacción de sus usuarios en comparación con el de quienes acudían al sistema por la vía tradicional, así como, sobre todo, las conclusiones de un estudio encargado en 1994 por el British Council of Disabled People -que comprobó que esta vía resultaba, de media, entre un 30\% y un $40 \%$ más económica que la organización de la prestación de servicios en especie- calmaron los ánimos y fueron decisivas para la introducción formal de las prestaciones económicas.

- El segundo factor determinante de la introducción de estas fórmulas fue la normativa reguladora de la atención comunitaria de 1990, que puso el énfasis en la necesidad de promover las posibilidades reales de elección para las personas usuarias y, en consecuencia, defendió una mayor diversidad en la red de servicios y en las formas de atención y, sobre todo, promovió la permanencia en el domicilio.

Sobre esta base, seis años más tarde, la Community Care (Direct Payments) Act de 1996, otorgaba carta de naturaleza a las prestaciones económicas para la adquisición de cuidados, ofreciendo a las administraciones locales, competentes en materia de servicios sociales, la posibilidad -no la obligación- de ofrecer a las personas con discapacidad una prestación económica (direct payment) en sustitución de la oferta de servicios en especie. 
Con el tiempo, la fórmula ha evolucionado en muchos aspectos: en forma, pasando de ser una prestación económica a integrarse en fondos personales; en ámbito, extendiéndose, en el año 2000, a todos los colectivos; y en 'imperatividad', pues hasta 2001 su aplicación o su propuesta a las personas usuarias dependía de la discrecionalidad de las administraciones locales, pero a partir de esa fecha se les impuso la obligación de ofrecer a todas las personas a las que la valoración de necesidades de los servicios sociales municipales abriera el acceso a los servicios comunitarios la posibilidad de hacerlo por la vía de la prestación económica, en lugar de hacerlo por la vía de la prestación en especie.

En los países continentales -y sin perjuicio de que, en algún caso, también pudieran jugar un importante papel factores como la promoción de la autonomía y del derecho de elección, y la permanencia en el domicilio-, los factores determinantes de la introducción de las fórmulas de asignación económica individual tuvieron más que ver con la composición de la red de atención: con la red de atención formal, para compensar sus insuficiencias; con la red de atención informal, bien con el fin de retener a la red natural y de promover la asunción de funciones de atención en el marco familiar, bien con el fin de formalizar situaciones de trabajo que tendían a desarrollarse en el marco de la economía sumergida.

Así, en Austria, la introducción de la prestación económica, como elemento nuclear del sistema de cuidados de larga duración creado en 1993, obedeció a tres objetivos estratégicos básicos:

- favorecer la permanencia en el domicilio habitual;

- proporcionar un incentivo económico a la atención informal en el entorno familiar, dada la marcada insuficiencia de la red formal de servicios de asistencia domiciliaria y de asistencia personal;

- contener el gasto público dedicado a la atención de las personas con necesidades de cuidados de larga duración.

En Alemania, la prestación económica, enmarcada en el seguro de cuidados de larga duración que, desde 1995, se constituye en el quinto pilar de la Seguridad Social, y que se destina, sobre todo, a la adquisición de cuidados de ayuda a domicilio o asistencia personal, preferentemente prestada por cuidadores familiares, se introdujo con objetivos básicos muy similares a los austríacos:

- facilitar la permanencia en su domicilio de las personas con necesidades de cuidados de larga duración;

- garantizar la protección social de los cuidadores familiares informales, con la doble finalidad de reconocer su contribución y de incentivar la asunción de este tipo de funciones;

- compensar la insuficiencia de la red de servicios para responder a las necesidades de atención y promover su extensión;
- promover la competencia entre proveedores de servicios, con el fin de reducir los costes.

En Holanda, la prestación económica se sumó, en 1995, al sistema de cuidados de larga duración y, desde entonces, se ha conformado en uno de sus elementos constitutivos. Inicialmente, la prestación se diseñó para posibilitar sólo la contratación, por parte de la persona dependiente, de cuidadores profesionales o de servicios formales de asistencia domiciliaria, con el fin de diversificar y ampliar la red de servicios y de generar empleo; fue la presión social la que llevó, en 1997, a hacer posible la utilización de la prestación económica para compensar económicamente al cuidador familiar.

Éstos también fueron los principales objetivos perseguidos por el modelo de dependencia introducido en Francia, tanto por la prestación de autonomía para las personas mayores dependientes como por la prestación compensatoria de la discapacidad: compensar la insuficiencia de la red de servicios y, a la vez, generar 'empleos de proximidad', mediante una prestación económica que garantizaba la rentabilidad de la formalización de muchas actividades desarrolladas en los domicilios en el marco de la economía sumergida.

En realidad, la mayoría de los objetivos mencionados - promover la autonomía y el derecho de elección, favorecer la permanencia en el domicilio, diversificar la red de servicios, compensar su insuficiencia, aflorar situaciones de economía sumergida y crear empleo, retener a la red informal, y contener el gasto público- están presentes, en mayor o menor medida, en todos los sistemas. La diferencia entre unos y otros países estriba en el peso que los distintos objetivos tuvieron realmente, en lo determinantes que fueron para optar por estas vías.

La diferencia también está, por supuesto, en la importancia que se otorgó en cada caso al objetivo de contención del gasto. Fue decisivo en muchos países en los que estas fórmulas se vislumbraban como alternativas de atención más baratas que la prestación de servicios en especie: fue determinante en el Reino Unido, pero también había tenido mucho peso en Estados Unidos, y lo tuvo, más tarde, en el diseño del modelo de seguro que se puso en marcha en Alemania en 1995. Con posterioridad, este objetivo económico ha adquirido protagonismo en países en los que no actuó como principal propulsor del cambio. La única excepción, hasta ahora, ha sido Suecia, en donde el modelo de asistencia personal, sólo destinado a personas con discapacidad, está económicamente muy bien dotado y alcanza costes elevadísimos, pero no es imposible que esto cambie, porque estos costes han sido ya objeto de duras críticas por parte del Tribunal de Cuentas del país nórdico y es posible que esto augure una próxima reforma. 


\subsection{La orientación de los modelos}

Las finalidades principales para la introducción de las prestaciones económicas no siempre fueron las mismas, ni tampoco lo fue la orientación general con la que se han ido desarrollando. Su distinta evolución revela la muy distinta utilización y las muy diversas utilidades que pueden darse a un mismo instrumento. Al margen de las diferencias específicas y del volumen o el peso real que tienen, de momento, en los diferentes sistemas, se observa, en los modelos filosóficos defendidos, en las estrategias aplicadas y, sobre todo, en el mayor o menor potencial que ven en la generalización de estas medidas, una línea divisoria clara entre dos orientaciones básicas.

La orientación más firmemente favorable a las prestaciones económicas que, sobre todo, ve en estas vías una solución posibilista ante las previsiones de crecimiento del gasto público en cuidados de larga duración, y una alternativa que, basada en la promoción de la autonomía y del derecho de elección, parece generar mayor satisfacción en las personas usuarias que las fórmulas tradicionales de acceso a la prestación de servicios en especie. Los países que se suman a esta orientación tienden a generalizar estas fórmulas:

- Las aplican a los diferentes grupos de población con necesidades de apoyo personal para la realización de las actividades de la vida diaria: personas con discapacidad (física, sensorial e intelectual), personas mayores y personas con enfermedad mental, principalmente.

- Permiten su utilización para la adquisición de una gama amplia de servicios, unas veces al conjunto de los servicios comunitarios -domiciliarios, diurnos, nocturnos, de respiro, etc.-, otras incluso a los de carácter residencial.

Esta orientación se observa principalmente en dos tipos de sistemas: los que ponen mucho énfasis en las fórmulas de asignación económica individual como instrumento de autonomía de los usuarios y de contención del gasto -por ejemplo, Reino Unido, pero también Estados Unidos y Holanda - y los que disponen de una red formal de servicios muy poco desarrollada y que utilizan estas prestaciones para compensar esta insuficiencia -es el caso, sobre todo, en algunos países europeos continentales, como Austria y Francia-. Con su nueva fórmula de planes personales, Alemania, que en su modelo inicial -todavía vigente- optaba por una introducción modesta de estas vías tanto en su cuantía como en su ámbito de actuación, parece cambiar de rumbo y alinearse con sus vecinos.

En contraste con esa orientación, está la opción de los países en los que la introducción de estas fórmulas respondió, y sigue respondiendo, casi exclusivamente a los deseos de autonomía, autodeterminación y empoderamiento manifestados por los colectivos de personas con discapacidad. Son siste- mas también con una fuerte tradición de protección social universal, que cuentan con una red formal de servicios sociales muy amplia y que, globalmente, defienden un sistema de prestación en especie frente a un sistema de prestaciones económicas. Los países nórdicos son el claro exponente de este posicionamiento, como se observa claramente en el modelo sueco. Desde esta visión, las fórmulas de asignación económica individual, muy desarrolladas y generosas en el ámbito de la discapacidad a través de las prestaciones económicas de asistencia personal, son totalmente residuales en relación con los demás colectivos, y se aplican sólo con carácter excepcional.

\section{Características básicas de los diferentes sistemas prestacionales}

La orientación general por la que optan unos y otros países, y las razones de su elección, tienen un claro reflejo en las características de los modelos prestacionales que han diseñado e implementado. Veamos las principales.

\subsection{La naturaleza optativa u obligatoria de las medidas}

Las fórmulas de asignación económica individual son una forma de ejercer un derecho. De hecho, en buen número de casos estas fórmulas constituyen, para la persona usuaria, una opción frente a la alternativa tradicional de acceder a los servicios en especie que los servicios sociales públicos consideren más idóneos, y la disyuntiva de orientarse hacia una u otra fórmula -o, incluso, hacia una combinación de ambas- se plantea una vez que los resultados de la valoración abren el acceso al sistema. En algunos casos, sin embargo, el acceso a la fórmula de asignación económica individual no se da como opción entre dos alternativas de ejercicio de un derecho, sino que constituye la forma primera y única de ejercicio de ese derecho: es el caso en Austria, en Francia, y en Suecia en el caso de la prestación económica para asistencia personal a personas con discapacidad cuando la necesidad de apoyo supera las veinte horas semanales.

\subsection{Las modalidades}

Las medidas prestacionales para la adquisición de atención pueden articularse en dos modalidades:

- La concesión en forma de prestación económica es la más habitual: es la opción de Austria, Alemania, Francia, Reino Unido y Suecia.

- Los fondos personales -traducción aproximada de lo que, en el ámbito internacional, suele recogerse bajo la denominación de personal budget o individual budget- se dan en Estados Unidos, Holanda y Reino Unido, y suelen valorarse en horas de atención, diferenciando a veces los dife- 
rentes tipos de atención requeridos. En Estados Unidos, lo más habitual es que esa valoración en horas y en tipos de apoyo no se traduzca en una valoración económica: la persona contrata a los cuidadores, los servicios y las adaptaciones que desee, siendo la Administración quien se encarga de abonar el coste de unos y otros apoyos directamente al proveedor, sin que medie la concesión de ninguna prestación económica a la persona usuaria. En los últimos años, no obstante, a partir de algunos proyectos de carácter experimental, se está extendiendo la posibilidad de asignar el fondo en forma de prestación económica a la persona usuaria, para que sea ella quien, directamente 0 a través de un asesor, se encargue del conjunto de las gestiones de diseño, contratación y organización de la atención.

En Europa, es Holanda el país representativo de la modalidad de fondos personales. Desde su introducción en 1995, adopta esta forma: se valoran las necesidades de la persona usuaria y si de dicha valoración se concluye que la mejor alternativa es la permanencia en el domicilio, se le asigna un fondo personal de atención valorado en horas. La persona beneficiaria puede optar entre acceder a los servicios en especie, es decir, a los servicios a los que le orienten los servicios sociales, o solicitar su cobro en metálico, y en este caso, queda en su mano la organización de los apoyos que requiere. Una tercera opción es combinar las dos alternativas anteriores, accediendo en parte a servicios en especie, y en parte a la cuantía en metálico.

Otros dos países europeos están ensayando fórmulas similares a la holandesa en su diseño. El Reino Unido inició esta tendencia en 2006, cuando, en su libro blanco sobre servicios comunitarios (Department of Health, 2006), el ejecutivo anunció su deseo de introducir en el sistema de prestaciones económicas la modalidad de fondos individuales y lanzó poco después trece proyectos piloto en diferentes municipios. En la actualidad, siguen extendiéndose.

En el modelo británico, la estructura de un fondo obedece a la idea de pool de financiación, consistente en reunir en un fondo único, de carácter individual, las cuantías a las que cada persona tendría derecho en los diferentes servicios y prestaciones públicas. Desde su introducción, se han barajado dos modalidades:

- El fondo personal (personal budget) consiste en la asignación a la persona de un importe equivalente a la suma de las cuantías que la Administración le destinaría desde los servicios sociales para atender sus necesidades. Incluye:

- una cuantía equiparable al coste de los servicios comunitarios en especie, en particular de la ayuda a domicilio y de la asistencia personal, calculada según el nivel de apoyo que requiere;
- cuantías derivadas de otras prestaciones 0 servicios propios del ámbito de los servicios sociales comunitarios (ayudas técnicas, adaptación del medio, otras prestaciones económicas, servicio de respiro, servicio de atención diurna, etc.).

- El fondo individual (individual budget) es, como el fondo personal, la asignación a la persona de un importe equivalente a las cuantías que la Administración le destinaría, pero, contrariamente a aquél, no reúne únicamente cuantías procedentes del ámbito de los servicios sociales, sino también las previstas en otros ámbitos: inclusión laboral, apoyo educativo, vivienda u otros.

Las dificultades inherentes a la confluencia de fondos procedentes de diferentes administraciones ha determinado que la segunda modalidad no se aplique como tal, de modo que, en la actualidad, aunque siguen utilizándose ambos términos, se hace indistintamente, para referirse a lo que, en sentido estricto, se conoce como fondos personales, es decir, los que reúnen las diferentes cuantías disponibles para una determinada persona dentro del ámbito de los servicios sociales. Al igual que en el modelo holandés, la persona tiene varias opciones: puede decidir cobrar su importe en forma de prestación económica (direct payment), puede decidir acceder a servicios en especie, o puede combinar ambas opciones.

También Alemania se ha lanzado, desde 2005, a ensayar esta fórmula, mediante proyectos piloto aplicados en siete Länder. Desde el año 2008, este modelo se ha incorporado al dispositivo de cuidados de larga duración, aunque siga vigente la prestación económica de ayuda a domicilio inicialmente implantada. El fondo obedece, como en el Reino Unido, a la idea de pool de financiación. La gama de servicios contratables es más variada que la gama de servicios cubierta por la prestación económica de ayuda a domicilio o, incluso, por la prestación en especie de ayuda a domicilio vigentes en la actualidad; en efecto, actualmente van siempre orientadas a cubrir los gastos originados por la ayuda requerida para la realización de las actividades básicas e instrumentales de la vida diaria, mientras que, con los fondos individuales, es posible organizar un paquete de cuidados más variado, adquiriendo los servicios que la persona estime que mejor se ajustan a sus necesidades, lo que está dirigido a incentivar a las entidades prestadoras de servicios a desarrollar una gama de servicios más variada.

\subsection{Utilización: diversidad en los tipos de apoyo}

Las prestaciones económicas y los fondos personales asignados a la persona usuaria para la adquisición de atención están pensados y diseñados, en los diferentes sistemas, para muy diversos usos. Atendiendo a la amplitud de la gama de servicios que pueden adquirirse por la vía de las medidas prestacionales 


\begin{tabular}{|c|c|c|}
\hline País & Denominación & Naturaleza \\
\hline Austria & $\begin{array}{l}\text { Prestación económica de cuidados de larga } \\
\text { duración (Pflegegeld) }\end{array}$ & Prestación económica \\
\hline \multirow[t]{2}{*}{ Alemania } & $\begin{array}{l}\text { Prestación económica de cuidados de larga } \\
\text { duración (Pflegegeld) }\end{array}$ & Prestación económica \\
\hline & Tragerubergreifendes Persönaliches Budget & Fondo personal integral de cuidados de larga duración \\
\hline \multirow{2}{*}{ Francia } & $\begin{array}{l}\text { Prestación personalizada de autonomía } \\
\text { (Allocation personalisée d'autonomie, APA) }\end{array}$ & Prestación económica destinada a personas mayores \\
\hline & $\begin{array}{l}\text { Prestación compensatoria de la discapacidad } \\
\text { (Prestation de compensation du hándicap) }\end{array}$ & Prestación económica destinada a personas con discapacidad \\
\hline Holanda & $\begin{array}{l}\text { Prestación económica del fondo personal de } \\
\text { cuidados de larga duración (Persoonsgebonden } \\
\text { budget) }\end{array}$ & $\begin{array}{l}\text { Fondo personal valorado en horas de atención que la persona } \\
\text { beneficiaria puede utilizar: } \\
\text { - En metálico } \\
\text { - En especie } \\
\text { - Combinando ambas alternativas }\end{array}$ \\
\hline \multirow[b]{2}{*}{ Reino Unido } & $\begin{array}{l}\text { Prestación económica de atención comunitaria } \\
\text { (Direct Payment) }\end{array}$ & Prestación económica \\
\hline & Fondo personal (Personal Budget) & $\begin{array}{l}\text { Fondo personal valorado en horas de atención que la persona } \\
\text { beneficiaria puede utilizar: } \\
\text { - En metálico } \\
\text { - En especie } \\
\text { - Combinando ambas alternativas }\end{array}$ \\
\hline \multirow[t]{2}{*}{ Suecia } & $\begin{array}{l}\text { Prestación económica de asistencia } \\
\text { personal para personas con discapacidad } \\
\text { (Assistansersättning) }\end{array}$ & Prestación económica \\
\hline & $\begin{array}{l}\text { Prestación económica de apoyo en el domicilio } \\
\text { para personas mayores (Anhörigbidrag) }\end{array}$ & Prestación económica \\
\hline Estados Unidos & $\begin{array}{l}\text { Programas de atención dirigida por la persona* } \\
\text { (Consumer-directed care programs) }\end{array}$ & $\begin{array}{l}\text { - Fondo personal valorado en horas de atención } \\
\text { - En los últimos, se está probando en algunos estados una } \\
\text { formula de fondo personal valorada en dinero y concedido en } \\
\text { formastación económica }\end{array}$ \\
\hline
\end{tabular}

* La denominación genérica varía según los estados (otra muy extendida es self-directed care) y dentro de ese marco general, cada Estado introduce denominaciones específicas para sus programas.

Fuente: SIIS Centro de Investigación y Estudios, 2011, pág. 48.

para la adquisición de atención, cabe diferenciar entre:

- Sistemas que permiten el acceso a toda la gama de servicios, incluidos los residenciales, como es el caso en Austria y en Francia, y también, desde fechas más recientes, en Alemania, con la nueva modalidad de fondos integrales personales de cuidados de larga duración.

- Sistemas que abren el acceso al conjunto de los servicios no residenciales, es decir, a los servicios domiciliarios, pero también al resto de los servicios que contribuyen, directa o indirectamente, al mantenimiento en el domicilio (ayudas técnicas, adaptación del medio, servicios de respiro, así como atención diurna y nocturna). Ejemplo de esta modalidad sería el fondo personal aplicado en el Reino Unido y la prestación económica de asistencia personal aplicada en Suecia, así como también las prestaciones aplicadas en algunos estados norteamericanos.

- Sistemas que destinan estas prestaciones fundamentalmente a la adquisición de atención o asistencia personal en el domicilio (incluidas actividades de acompañamiento), como es el caso de Holanda, del Reino Unido, pero esta vez en su modalidad de prestación económica, y de Alemania, también en su modalidad de prestación económica.

El uso más generalizado es, sin duda, el de la adquisición de atención y asistencia personal, es decir, de apoyos para realizar las actividades básicas e instrumentales de la vida diaria en el domicilio. Estos apoyos pueden adquirirse de tres tipos de proveedores: entidades prestadoras de servicios de asistencia domiciliaria o de asistencia personal; cuidadores profesionales que trabajan por cuenta propia; y cuidadores informales que, casi siempre, son familiares. Todos los países prevén y dan cobertura a las tres alternativas, en unas $u$ otras de las medidas que articulan, pero con especificidades:

- En el caso de la contratación de entidades, todos admiten que puedan ser sin ánimo de lucro o mercantiles, siendo la oferta la que determina que se recurra más a unas u otras opciones. La contratación de servicios prestados por las administracio- 
nes públicas, en cambio, sólo es posible en Suecia -una gran proporción de personas con discapacidad utilizan la prestación económica de asistencia personal para contratar servicios públicos-y en el Reino Unido, que prevé esta posibilidad en la modalidad de fondos personales, pero la excluye de la modalidad de prestación económica; otros países -Alemania, Holanda, Austria o Francia- no la prevén, bien porque no existen servicios públicos de ayuda a domicilio y de asistencia personal, bien porque el acceso a éstos queda reservado a quienes optan por la prestación en especie.

- La contratación de cuidadores profesionales autónomos se contempla en todos los modelos. En algunos casos -Francia y Holanda son ejemplos paradigmáticos-, esa contratación era, además, uno de los principales objetivos que perseguía la introducción de las prestaciones y los fondos personales, pues su fin era hacer aflorar contrataciones no declaradas: la prestación económica o el fondo individual sólo podría utilizarse para abonar esa atención si se demostraba la contratación laboral de la persona trabajadora, lo que fomentó la progresiva legalización de situaciones hasta entonces mantenidas en el marco de la economía sumergida.

En el extremo opuesto, se encuentra el sistema menos regulado y, por lo tanto, el más flexible de los modelos europeos, a saber, el austríaco. En Austria, la prestación económica está contribuyendo, dicen sus críticos, al sostenimiento de un mercado de trabajo paralelo, conformado principalmente por personas procedentes de países fronterizos (Hungría, Chequia y Eslovaquia), que trabajan por salarios inferiores al mínimo correspondiente al sector y sin protección social, viven en casa de la persona atendida, permanecen disponibles de forma continuada y realizan las tareas que se les encarguen, tanto de cuidado y atención personal como domésticas.

En el caso de utilizar la prestación económica o el fondo individual para retribuir o compensar la atención prestada por cuidadores familiares -posibilidad abierta en todas las modalidades, salvo en el fondo personal integral alemán-, existen, entre los modelos, dos criterios diferenciadores importantes:

- El primero, es la obligatoriedad o no de formalizar un contrato de trabajo entre la persona atendida y la persona cuidadora. En algunos países, efectivamente, se condiciona la posibilidad de utilizar la prestación o el fondo individual para compensar económicamente al familiar cuidador a la formalización de la relación mediante un contrato laboral; así lo hacen Francia, Holanda y Suecia; también Estados Unidos opta por esta vía. En otros países, la formalización contractual es una posibilidad, pero no una condición: es el caso en Austria, Alemania y en el Reino Unido.

- El segundo criterio diferenciador es la existencia o no de exclusiones en función de criterios como la convivencia o el grado de parentesco.
La mayoría de los países no aplican ninguna exclusión, de modo que cualquier familiar, de cualquier parentesco, conviva o no conviva con la persona usuaria, puede ser retribuido o compensado económicamente con la prestación económica o el fondo individual. Es el caso en Austria, Alemania (en su modalidad de prestación económica), Holanda, Reino Unido (en su modalidad de fondos personales) y en Suecia, si bien con algunas especificidades. Por ejemplo, en Holanda, la posibilidad de compensar económicamente al cónyuge sólo se aplica cuando la intensidad de los apoyos requeridos supera la intensidad de los cuidados habituales que se supone van implícitos en la naturaleza de la relación (la definición de estos cuidados habituales se establece en Holanda a través de directrices que, sin ser obligatorias, actúan como criterios generales comunes).

Otros países, en cambio, sí establecen exclusiones: Francia establece una exclusión para el cónyuge o la pareja de hecho siempre que haya convivencia entre ambos, lo que, en tales supuestos, fuerza a la contratación de un cuidador profesional o de un servicio formal; también lo hace así el Reino Unido, en su modalidad de prestación económica, y Alemania, en su nueva modalidad de fondo personal.

\subsection{Los requisitos de acceso: intensidad mínima de apoyo, duración, edad y nivel de recursos}

Al ser las prestaciones económicas y los fondos personales para la adquisición de atención una modalidad de ejercicio de un derecho, los requisitos de acceso son, básicamente, los requisitos de acceso al sistema de atención en el que se enmarcan, aunque, a veces, se apliquen requisitos complementarios. Dejando al margen los requisitos de carácter administrativo, como nacionalidad, residencia, empadronamiento o cotización previa-demasiado condicionados por encuadres administrativos generales, en los que no cabe entrar aquí-, interesan, en términos comparativos, aspectos muy específicos: la intensidad mínima de apoyos requerida para considerar que la persona tiene acceso al sistema, el carácter duradero o permanente de la necesidad de apoyos y la consideración otorgada al nivel de ingresos.

\subsubsection{Intensidad mínima de apoyos requerida para acceder al sistema}

Los países adoptan diferentes vías para la determinación de la intensidad mínima de apoyos requerida, muy en relación, por lo general, con el tipo de valoración que aplican:

- Algunos la definen en número de horas de apoyo. Así, en Austria, sólo permiten el acceso al sistema a las personas que requieren, como mínimo, 50 horas mensuales de apoyo para la realización de las actividades básicas e instrumentales de la vida diaria (en la actualidad se está debatiendo 
subir el límite a 60 horas semanales). En Suecia, para la atribución de la prestación de apoyo a domicilio a las personas mayores también se aplica este criterio, siendo el límite más comúnmente utilizado por las administraciones municipales el de 17 horas semanales (68 horas mensuales).

- Otros países definen la intensidad mínima en relación con el número de actividades de la vida diaria para las que se requiere apoyo. En Alemania, es necesario requerir ayuda, por lo menos, para la realización de dos actividades básicas y una instrumental. En Suecia, para acceder a la prestación de asistencia personal destinada a las personas con discapacidad, es necesario requerir apoyo para la realización de, al menos, una actividad básica de la vida diaria o de comunicación. Francia opta por este sistema en relación con la prestación compensatoria de la discapacidad, exigiendo presentar bien una dificultad absoluta para realizar una actividad básica de la vida diaria, bien una dificultad grave para desarrollar, por lo menos, dos actividades básicas de la vida diaria. También en Estados Unidos, muchos estados se unen a esta fórmula (es el caso de Michigan, Oregon y Washington).

- Una tercera vía para la determinación de la intensidad mínima consiste en establecer el límite con el propio instrumento de valoración de la dependencia. Esto es lo previsto en Francia, en relación con la prestación personalizada de autonomía destinada a las personas mayores, que abre el acceso a las personas que se sitúan, como mínimo, en el nivel 4 de la escala AGGIR -el instrumento oficial de valoración de la dependencia-, quedando excluidas las que quedan clasificadas como dependencia ligera, en los niveles 5 y 6 de la escala. También en Estados Unidos, algunos estados (Colorado y Maine, entre otros) optan por esta vía.

- Holanda es el caso más peculiar y, desde esta perspectiva, el más generoso: no establece ningún requisito mínimo de acceso: si la persona requiere algún apoyo para la realización de las actividades de la vida diaria, accede al sistema.

\subsubsection{Duración de la necesidad de apoyo}

Dado que, en muchos casos, las fórmulas de asignación económica individual se enmarcan en sistemas de cuidados de larga duración, en algunos casos se establecen previsiones en relación con la duración de la necesidad de apoyos:

- Ninguno de los modelos analizados exige, para el acceso a la prestación económica o al fondo personal, que la necesidad exista con carácter permanente, en el sentido de definitivo, sino que es suficiente que sea previsible que se prolongue durante un periodo más o menos largo. Algunos países establecen claras previsiones al respecto: en Alemania y Austria, es necesario, para acceder al sistema, que se prevea que la situación de necesidad se va a mantener, por lo menos, durante un periodo de seis meses; en Francia, ese periodo se extiende a un año.

- Otros modelos, en cambio, no establecen ninguna previsión en este sentido: en el Reino Unido, al no enmarcarse en un sistema de cuidados de larga duración, sino en el sistema de servicios sociales, y más concretamente, en el de atención comunitaria, parece lógico que así sea, y también es comprensible en Estados Unidos, en donde estas fórmulas no se enmarcan necesariamente en el ámbito de los cuidados de larga duración; resulta más llamativo en Holanda, en donde el sistema, en principio, sí obedece a esa finalidad, pero da cobertura a cualquier situación de necesidad de apoyo a domicilio.

\subsubsection{Nivel de ingresos}

- El nivel de ingresos constituye un requisito de acceso a la financiación pública en los países que se acogen a un sistema selectivo, a saber, Reino Unido y Estados Unidos, que sólo dan cobertura a las personas con bajo nivel de ingresos.

- En otros países -Alemania, Francia y Holanda-, el nivel de ingresos influye en la cuantía de la prestación, en la medida en que, al igual que los servicios en especie, la prestación está sujeta a copago.

- En el extremo opuesto, la prestación económica austriaca y la prestación sueca de asistencia personal para personas con discapacidad no quedan sujetas a copago, de modo que la determinación de la cuantía queda únicamente sujeta al nivel de apoyo requerido.

\subsection{La cuantía de las prestaciones}

Destacan aquí, en términos comparativos, dos cuestiones importantes: los criterios que intervienen en la determinación de la cuantía y las cuantías propiamente dichas.

\subsubsection{Criterios de determinación de la cuantía}

Respecto a los criterios de determinación de la cuantía, los países optan entre dos fórmulas básicas:

- La primera alternativa consiste en establecer límites máximos, expresados en cuantía económica o en horas de atención. Puede optarse por establecer varios límites máximos, relacionados, en su caso, con los grados de dependencia o los niveles de necesidad de apoyo. A esta fórmula se apuntan Alemania, en su modalidad de prestación económica, que diferencia tres cuantías máximas mensuales, correspondientes a los tres niveles de apoyo en los que se clasifica a las personas en el 
marco de la valoración; Austria, que procede del mismo modo, pero de forma más gradual, diferenciando siete niveles; Francia, que, en el caso de la prestación personalizada de autonomía, diferencia cuatro niveles, y en el de la prestación compensatoria de la discapacidad, establece máximos aplicables a diferentes tipos de apoyo (asistencia personal, ayudas técnicas, adaptación de la vivienda o del vehículo, entre otros gastos); $\mathrm{y}$, finalmente, algunos modelos estadounidenses que, por lo general, establecen un único límite máximo.

- La segunda fórmula consiste en no establecer límites, de modo que la cuantía de la prestación se determina en función de la intensidad de los apoyos requeridos. Ésta es la vía por la que optan, desde un principio, Holanda, Reino Unido y Suecia en la regulación de su prestación de asistencia personal a personas con discapacidad, y la vía a la que se ha sumado Alemania en su nueva modalidad de fondos personales integrales:

- En Holanda, este criterio se ve minorado por el hecho de que la prestación económica equivale siempre a un $75 \%$ del coste que tendría para la Administración ofrecer el mismo nivel de apoyo en especie.

- En el Reino Unido, la cuantía de la prestación económica se determina en función del nivel de apoyo personal que necesita la persona y se cuantifica en función del coste que tendría ese nivel de apoyo si se prestara mediante servicios en especie. No existe ningún mínimo y ningún máximo legal, aunque, por lo general, el máximo se sitúe en 31 horas semanales, lo que asciende a 363 euros semanales. En el caso de las personas con discapacidad que requieran un apoyo de mayor intensidad, pueden recurrir, según su nivel de ingresos, al Fondo de Vida Independiente, quien puede completar la prestación económica concedida por los servicios sociales, hasta alcanzar un máximo semanal, entre ambas prestaciones, de 927 euros semanales.

- En Suecia, la ausencia de límites ha llevado a unos niveles de intensidad elevadísimos, que se computan teniendo en cuenta todas las necesidades de la persona usuaria, tanto para las actividades básicas e instrumentales de la vida diaria como para su integración social. El número de horas concedido varía considerablemente en función del tipo de deficiencia que origina la dependencia, pero ronda $-y$, en algunos casos, supera- las 100 horas semanales de apoyo. Con tales cifras, el gasto medio de la prestación se sitúa en 10.935 euros mensuales.

\subsubsection{Cuantías}

Los datos no permiten una comparación fiable de la cuantía media de las prestaciones aplicadas en los diferentes países, de modo que, con el fin de facilitar alguna aproximación, se ha optado por comparar el gasto medio por prestación, resultando dichas cuantías de dividir el gasto anual total por el número de beneficiarios. Lógicamente, las cuantías resultantes se ven determinadas por las minoraciones aplicadas en los casos de compatibilización de la fórmula de asignación económica individual con la prestación de servicios en especie, y también por el número de meses que cada usuario permanece en la prestación en el año de referencia, de modo que la comparación que puede realizarse por esta vía es menos exacta que la que podría hacerse en caso de disponer del gasto medio mes a mes. Con todo, siendo el único dato al que se puede acceder para el conjunto de los países -y no siempre para el mismo año de referencia-, se ha preferido incluir esta información, con todas sus limitaciones, a no ofrecer ningún elemento de comparación.

Con esas cautelas, puede decirse que se observan considerables diferencias entre los países analizados, pero es importante tener presente que no resultan del todo significativas, o no siempre, porque no se destinan a la cobertura de los mismos gastos. De ahí que resulte más acertado comparar los países en tres grupos, en función de los servicios a los que dan cobertura:

- Sistemas integrales. Resultan comparables, por lo menos en lo esencial, las prestaciones que, como la austriaca, tienen un objetivo integral, es decir, sirven para adquirir cualquier tipo de servicio, por cuanto que ésa es la cuantía que, desde el sistema de cuidados de larga duración, se pone a disposición del usuario para que adquiera ayuda a domicilio o asistencia personal, pero también para que acceda a otros apoyos que considere necesitar. En este grupo estarían Austria y Francia (sólo se dispone de datos de gasto en relación con la prestación personalizada de autonomía), que tienen un gasto medio por prestación bastante similar: 405,08 y 421,86 euros mensuales respectivamente. También cabría incluir en este grupo la nueva modalidad de fondo personal integral introducida en Alemania, aunque con respecto a esta última, no se dispone de datos.

- Un segundo grupo sería el de los países que permiten la utilización de las fórmulas de asignación económica para la adquisición de los servicios habitualmente incluidos o complementarios de la atención domiciliaria o de la asistencia personal: atención personal y doméstica, pero también teleasistencia, ayudas técnicas, adaptación del medio, atención diurna o nocturna, y servicios de respiro. El caso representativo es el Reino Unido, así como también Suecia en lo referente a su prestación de asistencia personal para personas con discapacidad, en donde la extrema generosidad de la prestación desvirtúa cualquier comparación.

- Un tercer grupo estaría formado por los países en los que las fórmulas de asignación económica individual sólo pueden destinarse a la adquisición de atención o asistencia personal, en el que se incluirían Alemania y Holanda. 
En la Tabla 1, partiendo del gasto medio mensual correspondiente a las diferentes prestaciones, se indica el gasto medio en paridad de poder adquisitivo, con el fin de disponer de datos comparables, una vez eliminadas las diferencias entre los niveles de precios de cada país.

Tabla 1. Gasto medio en prestaciones y fondos personales para la adquisición de atención (2009)

\begin{tabular}{|c|c|c|c|}
\hline Países & $\begin{array}{l}\text { Prestaciones } \\
\text { económicas y fondos } \\
\text { personales para } \\
\text { la adquisición de } \\
\text { atención }\end{array}$ & $\begin{array}{l}\text { Gasto } \\
\text { medio } \\
\text { mensual } \\
\text { (euros) }\end{array}$ & $\begin{array}{c}\text { Gasto } \\
\text { medio } \\
\text { mensual } \\
\text { (euros } \\
\text { PPA) }\end{array}$ \\
\hline Alemania & $\begin{array}{l}\text { Prestación económica } \\
\text { de cuidados de larga } \\
\text { duración }\end{array}$ & 325 & 300,09 \\
\hline Austria & $\begin{array}{l}\text { Prestación económica } \\
\text { de cuidados de larga } \\
\text { duración }\end{array}$ & 446 & 405,08 \\
\hline Francia & $\begin{array}{l}\text { Prestación } \\
\text { personalizada de } \\
\text { autonomía }\end{array}$ & 494 & 421,86 \\
\hline Holanda & $\begin{array}{l}\text { Prestación económica } \\
\text { del fondo personal } \\
\text { de cuidados de larga } \\
\text { duración }\end{array}$ & 1.400 & $1.254,48$ \\
\hline $\begin{array}{l}\text { Reino } \\
\text { Unido }\end{array}$ & $\begin{array}{l}\text { Prestación económica } \\
\text { de atención } \\
\text { comunitaria }\end{array}$ & 895 & 919,83 \\
\hline Suecia & $\begin{array}{l}\text { Prestación de } \\
\text { asistencia personal } \\
\text { para personas con } \\
\text { discapacidad }\end{array}$ & 10.935 & $9.931,88$ \\
\hline
\end{tabular}

Fuente: Elaboración propia a partir de los indicadores de paridad de poder adquisitivo (PPA) proporcionados por Eurostat para el año 2009.

\subsection{Cobertura: un peso relativo pero creciente}

La comparación de los datos de cobertura presenta límites similares a los de la comparación de las cuantías: las fórmulas prestacionales de los sistemas de carácter integral, es decir las que pueden destinarse a la adquisición de toda la gama de servicios sociales, incluidos los residenciales, tienen lógicamente una cobertura más amplia que las que se destinan única o principalmente a la compensación económica de la atención informal; para que la cobertura de estas últimas fuera comparable con la de las primeras, habría que sumar la cobertura de los demás servicios a los que, siendo beneficiario de la prestación económica, es posible acceder, es decir, a los servicios compatibles con las prestaciones económicas. A esto se añade un sesgo suplementario: si la prestación económica es optativa, como alternativa a la prestación en especie, la cobertura de dicha prestación no da la medida del esfuerzo público, sino la medida de la opción individual. Con todo, y teniendo en cuenta esas limitaciones, es posible hacer algunos apuntes comparativos de carácter orientativo:

- Por un lado, los datos del sistema austríaco, que cubre tanto a la población con discapacidad como a la población mayor, son comparables con los datos globales del sistema francés, es decir, con la suma de las poblaciones atendidas por las prestaciones vigentes en Francia, incluida, como en el caso anterior, su precedente directo, la prestación por ayuda de tercera persona, que si bien no está abierta a nuevos usuarios, tras la entrada en vigor de las nuevas prestaciones se ha mantenido, como opción, para quienes ya eran beneficiarios de ella. Y aquí, las diferencias son importantes: en Austria, la cobertura es del 4,95\% de la población, mientras que en Francia se sitúa en un $2 \%$.

- Si se comparan los datos de Alemania con los de Holanda, en los que la prestación económica tiene una finalidad no idéntica pero sí similar, se observa también una considerable diferencia de cobertura: en Alemania alcanza el 1,26\% de la población (y representa a un $46 \%$ del total de personas beneficiarias del seguro de cuidados de larga duración), mientras que en Holanda se sitúa, en $\mathbf{2 0 0 6}$, en un 0,54\% de la población.

- En el grupo de los países que orientan la prestación a la adquisición de servicios de atención comunitaria, el Reino Unido es el país en donde menor cobertura alcanza este grupo de medidas. Aunque los sucesivos Gobiernos han tratado de potenciar y favorecer el recurso a estas vías, y a pesar de un rápido crecimiento en los últimos años, su volumen total es muy bajo, en parte debido a importantes reticencias para su aplicación desde las administraciones locales y desde los cuerpos profesionales, y en parte también debido a la escasez, hasta fechas recientes, de servicios de asesoramiento y apoyo destinados a facilitar la asunción de la gestión de la prestación por parte de las personas usuarias que pudieran optar por estas fórmulas. En Suecia, la cobertura total de las prestaciones económicas alcanza un $0,27 \%$.

En términos de evolución, algunos datos resultan significativos:

- En Alemania, entre 1996 (fecha de su introducción) y 1999, la población beneficiaria del seguro de cuidados de larga duración creció en más de 250.000 personas, un impacto claramente asociado a la fase de implantación y afianzamiento del seguro de dependencia. Entre 1999 y 2006, en cambio, el número de beneficiarios aumentó en un total de 150.000 personas, con un ritmo anual de crecimiento muy estable, del 1,1\%, directamente asociado a la evolución demográfica. En ese periodo, se observa un progresivo cambio en la utilización de la prestación: la proporción de beneficiarios que optan por la prestación económica frente a su alternativa en especie, que en 1996, representaba el $60 \%$ de la población beneficiaria, en 2007 representaba menos del $50 \%$ y la tendencia sigue a la baja, aunque a un ritmo más lento. Parte de la explicación está, sin duda, en el hecho de que la financiación prevista para las modalidades de atención en especie 
prácticamente duplica las cuantías previstas para la prestación económica. Esta tendencia de vuelta a los servicios en especie es, según la literatura especializada, la que ha llevado al ejecutivo alemán a introducir una nueva modalidad en forma de fondo personal integral, más flexible y versátil, susceptible de volver a invertir la tendencia.

- La evolución en Suecia también es reseñable: la prestación de asistencia personal para personas con discapacidad ha superado todas las previsiones 5 . Si en 1992, las estimaciones iniciales preveían 7.000 beneficiarios, doce años más tarde, en 2004, las cifras alcanzaban los 12.300 y siguieron creciendo a un ritmo acelerado hasta alcanzar, en 2009, los 19.210 usuarios de la prestación.

- Por último, interesa apuntar, por su cercanía y similitud, la evolución del modelo francés, que, según datos de 2009, se caracteriza por una estabilización de la evolución de la prestación personalizada de autonomía, destinada a las personas mayores de 60 años, con un incremento, entre 2008 y 2009 , del $2,1 \%$, muy inferior al $4,4 \%$ que se dio en el ejercicio anterior. En fuerte contraste con esta estabilización, la prestación compensatoria de la discapacidad, más tardía en su incorporación al sistema, se dispara y sufre en el mismo año un fortísimo incremento del $67 \%^{6}$, que empieza a generar mucha preocupación a las administraciones que intervienen en su financiación.

\section{Medidas de supervisión, control y garantía de calidad en los modelos prestacionales}

Uno de los principales problemas que plantean, en la práctica, los dispositivos prestacionales viene dado por la dificultad existente para supervisar el uso que la persona beneficiaria hace realmente de esa prestación y para garantizar la calidad de la atención adquirida por esa vía.

Algunos sistemas optan por obviar esta cuestión, asumiendo que constituye un riesgo inherente al modelo. Así, la prestación económica de cuidados de larga duración vigente en Austria o la prestación económica aplicada en el sistema alemán, anterior a la introducción de la fórmula de fondos personales integrales, son cuantías concedidas para que la persona

${ }^{5} \mathrm{El}$ aumento progresivo del número de beneficiarios se asocia a diferentes factores: el desmantelamiento de las instituciones para personas con discapacidad intelectual y de los hospitales psiquiátricos; la disminución de la prestación para niños con discapacidad menores de 16 años; la progresiva reducción de la ayuda a domicilio tradicional; la emancipación de personas con discapacidad que vivían con sus padres y que optan por llevar una vida autónoma; el envejecimiento de la población y el mantenimiento de la prestación después de los 65 años (aprobada en 2001).

${ }^{6}$ Según datos de la Direction de la Recherche, des Études, de l'Évaluation et des Statistiques (DREES), Ministère du Travail, de l'Emploi et de la Santé. haga el uso que le parezca, siempre que consista en la adquisición de servicios o apoyos; la supervisión sobre el uso real que la persona usuaria da a la prestación es muy ligera y no permiten articular vías orientadas a garantizar la calidad de la atención y el bienestar efectivo de la persona usuaria.

Esta orientación obedece a una tendencia que, en el origen de estas fórmulas, era bastante común, no sólo en estos sistemas poco regulados, sino en la filosofía subyacente a estas alternativas: la de considerar que cuando el usuario asume la responsabilidad de adquirir, por su cuenta, la atención que requiere, asume a la vez la responsabilidad de que la atención adquirida responda a sus necesidades y tenga la calidad suficiente para satisfacerlas en condiciones adecuadas. Parte así de la figura del usuario como consumidor plenamente competente y capaz de establecer los límites, y las condiciones de su relación de cuidado con los servicios y los profesionales que contrata, y con los familiares a los que retribuye o compensa por su atención.

No obstante, la evolución de las fórmulas de asignación económica individual que, cada vez más, abre su aplicación a colectivos susceptibles de sufrir importantes dificultades y limitaciones para la toma de decisiones, para la gestión de una prestación y para la organización de los apoyos que requieren, está llevando, progresivamente, a muchos países europeos a alejarse de ese planteamiento originario y a considerar la necesidad de establecer mecanismos de control, de supervisión y de garantía de la calidad de la atención prestada, necesidad que otros países -en particular, Estados Unidos- habían integrado en sus dispositivos, en mayor o menor medida, desde el inicio de su implantación.

Efectivamente, en la actualidad, casi todos los sistemas coinciden en reconocer que una de las principales preocupaciones de las administraciones públicas en relación con las fórmulas de asignación económica individual es la dificultad para idear y aplicar medidas orientadas a cuatro objetivos complementarios:

- garantizar que la atención se presta efectivamente, con la intensidad suficiente, y que la calidad de la atención así prestada es adecuada;

- garantizar que las personas cuidadoras ejercen sus funciones en condiciones adecuadas;

- responder de un uso adecuado de los fondos públicos;

- responder de la seguridad de las personas.

Estas inquietudes se plantean fundamentalmente en relación con la atención prestada en el domicilio de la persona usuaria, dado que los servicios de día y residenciales suelen estar sujetos, en todos los sistemas, a mecanismos de control -autorización, homologación e inspección- que, si se diseñan bien y se aplican adecuadamente, permiten asegurar 
ciertos estándares de atención (también es cierto que el simple hecho de ser servicios abiertos a las visitas de familiares, amigos y voluntarios favorece una supervisión informal y plural, que también contribuye a garantizar cierta calidad asistencial).

Por otra parte, y si bien es cierto que la cuestión puede plantearse en todas las modalidades de atención domiciliaria y de asistencia personal, incluso cuando se presta desde entidades de servicios, también lo es que las entidades que se dedican a este tipo de funciones quedan sujetas a una serie de dispositivos de control de carácter obligatorio que, en principio, conllevan ciertas garantías: las autorizaciones de funcionamiento para la prestación de servicios sociales, la homologación o la acreditación de las entidades cuando conciertan o contratan con entidades públicas, los sistemas de acreditación de la calidad a los que se someten cada vez más habitualmente las entidades, unidas a los requisitos de cualificación profesional, constituyen, de por sí, un marco más supervisado y, por lo tanto, a priori, más garantista.

La preocupación se centra, pues, especialmente en los casos en los que las prestaciones económicas o los fondos individuales son utilizados para contratar, en el domicilio, a cuidadores profesionales por cuenta propia, o para compensar económicamente a cuidadores informales. Por su naturaleza misma, por desarrollarse en la esfera privada, plantea dificultades evidentes de control o supervisión: es difícil saber, cuando se trata de atención informal, si efectivamente la prestación económica se utiliza como contraprestación o compensación a la persona cuidadora; es difícil conocer la intensidad y la calidad de la atención realmente prestada a la persona beneficiaria de la prestación; es difícil saber si la persona cuidadora se encuentra realmente en condiciones de asumir esa función o de hacerlo con la intensidad requerida. Y ese conocimiento es fundamental, tanto en términos de protección -finalidad inherente al sistema de atención-, como en términos de control sobre el uso del dinero público y sobre la consecución de las finalidades del sistema y, en consecuencia, de la eficacia de estos instrumentos como fórmula alternativa o complementaria de la utilización de servicios domiciliarios y diurnos, o como fórmula preventiva de situaciones de mayor dependencia y de uso de servicios de mayor coste.

De ahí que muchos países hayan otorgado importancia al desarrollo de una batería de medidas de control. Si bien, en términos generales, todas ellas persiguen, como objetivo último, garantizar la calidad de la atención y la calidad de vida de la persona usuaria y de la persona cuidadora, en la consecución de esas metas pueden responder a finalidades más específicas:

- garantizar que la persona cuidadora dedicará efectivamente parte de su tiempo a la atención de la persona que requiere apoyos;
- garantizar la capacidad física, psicológica y mental de la persona cuidadora, así como su cualificación para responsabilizarse de la atención;

- garantizar la capacidad de la persona beneficiaria para dar su consentimiento y tomar decisiones y para asumir las funciones de gestión y utilización de las prestaciones económicas o de los fondos personales;

- garantizar la disponibilidad de apoyos destinados a la persona cuidadora, con el fin de facilitar el ejercicio de sus funciones de atención;

- garantizar la disponibilidad de servicios de asesoramiento y apoyo para realizar las funciones asociadas a la gestión de la prestación económica o del fondo personal;

- controlar la adecuación de la atención desde el sistema público de servicios sociales, garantizando el contacto, el seguimiento y la supervisión de la situación en el domicilio y de la relación de cuidado;

- realizar el control económico de la utilización de la prestación;

- garantizar la protección y la seguridad de la persona usuaria y de la persona cuidadora.

- garantizar el respeto de los derechos de la persona cuidadora y de la persona atendida.

Del análisis de los modelos aplicados en el ámbito internacional y de la revisión de la literatura especializada -particularmente preocupada por esta materia, pero, paradójicamente, poco desarrollada-, se deduce un conjunto de medidas orientadas a estas finalidades7. Pueden actuar antes o después de acceder a la prestación y, en función de dicha temporalidad, se diferencia entre:

- Medidas ex ante, que se aplican antes de conceder la prestación y que, en ese sentido, constituyen condiciones de acceso a la propia prestación o a alguna de sus ventajas:

- Exigir la dedicación de un número mínimo de horas de atención.

- Establecer límites a la dedicación laboral, formativa o educativa.

- Establecer límites al número de personas atendidas.

- Determinar el impacto del factor de convivencia en el cómputo de los apoyos.

- Exigir la formalización de la relación de cuidado.

- Establecer una edad mínima y/o máxima a la persona cuidadora.

- Exigir la autonomía funcional de la persona cuidadora.

- Aplicar una valoración formal de la capacidad y de las necesidades de la persona cuidadora.

7 Por razones de espacio, no se incluye aquí la descripción de cada una de estas medidas y las finalidades a las que cada una responde, pero puede consultarse el informe comparativo que sirve de fuente al artículo para una descripción detallada (SIIS, 2011). 
- Aplicar una valoración de la capacidad de gestión y toma de decisiones de la persona atendida.

- Aplicar una valoración del riesgo de abuso.

- Exigir la previsión de mecanismos de sustitución del cuidador.

- Regular la intervención de los servicios sociales en el diseño del paquete de apoyos.

- Establecer un sistema de acreditación y registro de trabajadores domiciliarios o asistentes personales.

- Medidas ex post, que se aplican una vez concedida la prestación económica o el fondo personal, durante su disfrute, y que funcionan como mecanismos de supervisión de la calidad de la atención prestada y del mantenimiento de las condiciones que sirvieron de base al acceso a la prestación:

- Realizar una valoración periódica de la situación de la persona dependiente.

- Realizar visitas y entrevistas de seguimiento.

- Realizar visitas domiciliarias sin previo aviso.

- Realizar un control económico del uso de la prestación o del fondo personal.

- Exigir la intervención de servicios de asesoramiento y apoyo a la gestión de la prestación cuando la persona usuaria presenta limitaciones en su capacidad para la toma de decisiones, para la gestión de la prestación y para la organización de los apoyos que requiere.

- Articular medidas de formación personalizada domiciliaria para cuidadores.

- Articular medidas de respiro domiciliario para cuidadores.

- Evaluar la calidad de la atención.

Ningún sistema prevé y aplica todas estas medidas; más bien, lo habitual es que sólo integren algunas y que su implementación resulte, todavía hoy, poco sistemática.

\section{En nuestro ámbito, una reflexión pendiente}

El estudio de las fórmulas de asignación económica individual en otros países, de los objetivos a los que obedecen y de su evolución muestra que, a pesar de su peso, todavía muy relativo en los sistemas de atención a la dependencia y, en general, en los sistemas de servicios sociales, estas vías de acceso a la atención parecen estar aquí para quedarse. Que constituyan un avance para los sistemas depende de la finalidad con la que se introduzcan, del papel que se les conceda y del peso que se les atribuya en el sistema: si se calibra bien su aplicación y se definen bien sus objetivos, puede ser una vía de modernización, una opción más en la gama de alternativas, capaz de contribuir a una mejor adecuación del modelo a las necesidades y preferencias de las personas; si se calibra mal, puede suponer un riesgo real para el modelo de responsabilidad pública.
Por lo tanto, a la hora de diseñar la o las fórmulas aplicables, el factor decisivo es definir bien los objetivos que se persiguen y hacerlo en relación con diferentes dimensiones:

- Objetivos estructurales y filosóficos. En relación con el sistema, es imprescindible determinar si estas fórmulas tienen, en su marco, un carácter accesorio -configurándose como una opción más dentro de la gama de alternativas integradas en el dispositivo asistencial-, o un carácter definitorio - configurándose como un elemento nuclear del acceso a los principales apoyos-, lo que marca el mayor o menor peso o protagonismo que puedan adquirir.

- Objetivos asistenciales. Es necesario determinar qué fines se persiguen en términos de atención a la población con necesidades de apoyo, mediante la introducción de estas fórmulas: por ejemplo, ofrecer mayores posibilidades de permanecer en el domicilio, sobre todo en el caso de personas que, por su grado de dependencia, o porque viven solas, no podrían hacerlo si sus alternativas de atención sólo fueran en especie; ofrecer mayores posibilidades de elección y de autonomía a la hora de determinar quién le atenderá (posibilidad de contratar un servicio formal, pero también de contratar a un cuidador profesional autónomo o de compensar económicamente a un familiar), así como en la organización de los diferentes apoyos (en particular, en la determinación de los horarios de atención).

- Objetivos sociales. También es imprescindible determinar qué fines sociales quieren alcanzarse mediante la introducción de estas prestaciones. Por ejemplo, el reconocimiento social de las funciones de atención informal mediante la compensación o retribución económica por el desarrollo de unas tareas que, si bien se dan en la esfera privada, tienen un componente de responsabilidad social y pública; el reconocimiento del valor social de la profesión de atención y asistencia personal, promoviendo, en ese caso, la mejora en la cualificación de las y los profesionales, la formalización contractual de situaciones irregulares de trabajo en los domicilios y la creación de empleo.

- Objetivos económicos. Es necesario determinar si, a los objetivos asistenciales y sociales, se añaden objetivos económicos, en particular, si las fórmulas de asignación económica individual se van a utilizar como una vía de contención del gasto público en cuidados de larga duración, o si, por el contrario, el abaratamiento de los costes no es un fin en sí mismo, en cuyo caso, las cuantías de las prestaciones deberían aproximarse al coste que tendría la prestación de la misma intensidad de apoyo si se ofreciera en especie.

En nuestro ámbito, está pendiente una reflexión seria y serena en relación con esta materia. Desde la puesta en marcha, en 2006, del Sistema para Autonomía y Atención a la Dependencia, las prestaciones 
económicas integradas en su catálogo de apoyos - prestación económica vinculada al servicio, prestación económica para cuidados en el entorno familiar y prestación económica de asistencia personal- han ido creciendo en protagonismo, con una evolución particularmente llamativa de la segunda.

Aún pendientes de conocer su evolución futura, la tendencia que han mostrado hasta la fecha resulta lo suficientemente significativa como para pararse a valorar el objetivo genuino de su existencia y el papel que realmente interesa asignarles, tratando de garantizar un equilibrio sostenible que combine las contrastadas ventajas de un modelo de responsabilidad pública que, como el nuestro, se estructura en torno a la prestación de servicios, con los atractivos que, en términos de flexibilidad y personalización, pueden presentar, en determinados supuestos, las fórmulas de asignación económica individual, siempre que, bien diseñadas y bien implementadas, se integren como una alternativa más dentro del dispositivo asistencial. 
ARKSEY, H.; y GLENDINNING, C. (2007): “Choice in the context of informal care-giving", Health and Social Care in the Community, vol. 15, $\mathrm{n} \div \mathbf{0}$, págs. 165-175.

CLEVNERT, U.; y JOHANSSON, L. (2007): “Personal Assistance in Sweden", Journal of Aging and Social Policy, vol. 19, nº 3, págs. 65-80.

DA ROIT, B.; LE BIHAN, B.; y ÖSTERLE, A. (2007): “Longterm care policies in Italy, Austria and France: Variations in cash-for-care schemes", Social Policy and Administration, vol. 41, no 6, págs. 653-671.

DEPARTMENT OF HEALTH (2006): Our Health, Our Care, Our Say: A New Direction for Community Services, Londres, Stationery Office [«http:// www.official-documents.gov.uk/document/ cm67/6737/6737.pdf 〉].

GILBERT, N. (2004): Transformation of the Welfare State. The Silent Surrender of Public Responsibility, Nueva York, Oxford University Press.

GLASBY, J.; GLENDINNING, C.; y LITTLECHILD, R. (2006): "The future of direct payments", en LEECE, J.; $y$ BORNAT, J., Developments in Direct Payments, Bristol, Policy Press.

GLENDINNING, C.; y KEMP, A. (2006): Cash and Care. Policy Challenges in the Welfare State, Bristol, Policy Press.

GREVE, B. (ed.) [2010]: Choice. Challenges and Perspectives for the European Welfare States, serie Broadening Perspectives on Social Policy, Chichester, John Wiley and Sons.

GSTREIN, M.; MATEEVA, L.; y SCHUH, U. (2007): Workcare. Social Quality and the Changing Relationships between Work, Care and Welfare in Europe, Aberdeen, University of Aberdeen [rhttp:// www.abdn.ac.uk/socsci/research/nec/ workcare/documents/working_paper2_ trends_150908_workcare.doc>].

KEEFE, J. (2007): “To pay or not to pay: Examining underlying principles in the debate on financial support for family caregivers", Canadian Journal on Aging, nํㅜ 26 , supl. 1, págs. 77-90.

KNIJN, T.; y VERHAGEN, S. (2007): “Contested professionalism. Payments for care and the quality of home care", Administration and Society, vol. 39, págs. 451-475.

LUNDSGAARD, J. (2005): Consumer Direction and Choice in Long-term Care for Older Persons, Including
Payments for Informal Care: How Can it Help Improve Care Outcomes, Employment and Fiscal Sustainability?, serie Health Working Papers, París, Organización para la Cooperación y el Desarrollo Económico [«http://www.oecd.org/ dataoecd/53/62/34897775.pdf>].

PIJL, M. (2000): "Home care allowances: Good for many but not for all”, Practice, vol. 12, no 2, págs. 55-65.

- (1994): "When private care goes public. An analysis of concepts and principles concerning payments for care", en EVERS, A.; PIJL, M; y UNGERSON, C. (eds.), Payments for Care. A Comparative Overview, serie Public Policy and Social Welfare, vol. 16, Aldershot, Avebury.

ROULSTONE, A.; y MORGAN, H. (2009): “Neo-liberal individualism or self-directed support: Are we all speaking the same language on modernising adult social care?", Social Policy and Society, vol. $8, n^{\circ} 3$, págs. 333-345.

SCOURFIELD, P. (2007): "Social care and the modern citizen: Client, consumer, service user, manager and entrepreneur", British Journal of Social Work, nํㅜ 37, págs. 107-122.

SIIS CENTRO DE DOCUMENTACIÓN Y ESTUDIOS (2011): Prestaciones económicas y otras formulas de asignación económica individual en los sistemas de atención a la dependencia. Panorama comparativo internacional, DonostiaSan Sebastián, Diputación Foral de Gipuzkoa [khttp://www.siis.net/documentos/informes/ Informeprestacioneseconomicas.pdf $\rangle$ ].

TIMONEN, V.; CONVERY, J.; y CAHILL, S. (2006): “Care revolutions in the making? A comparison of cash-for-care programmes in four European countries", Ageing and Society, nํ26, págs. 455-474.

UNGERSON, C. (2004): "Whose empowerment and independence? A cross-national perspective on "cash and care' schemes", Ageing and Society, vol. 24, págs. 189-212.

WATERPLAS, L.; y SAMOY, E. (2005): “L'allocation personnalisée: le cas de la Suède, du RoyaumeUni, des Pays-Bas et de la Belgique", Revue Française des Affaires Sociales, nํㅡㄹ 2, págs. 61-101 [<http://www.sante.gouv.fr/IMG/pdf/ rfas200502-arto4.pdf)].

YEANDLE, S.; y BUCKNER, L. (2007): Carers, Employment and Services: Time for a New Social Contract?, Leeds, University of Leeds [http://www. carersnet.org.uk/documents/r6.pdf>]. 


\section{El papel de las organizaciones empresariales y sindicales en la política social de atención a la dependencia.}

\section{Vicente Marbán Gallego}

Dpto. de Fundamentos de Economía, Historia Económica y Sociología.

Universidad de Alcalá

<vicente.marban@uah.es>

Espainiako gizarte-politikaren baitan, mendetasunegoeran dauden pertsonen zaintzarako egungo erreformak bideratu izandako kultura, gizarte eta instituzioen aldaketaren analisia burutzen da, eta horren ostean, gizarte-eragileen (sindikatu eta enpresarioak) rolak aztertzen dira berauen egitekoa ezagutzearren. Partikularki, erantzuna eman nahi izan zaie honako galdera hauei: zein izan da gizarte-eragileen rolaren eragina egungo mendetasun-egoerako pertsonen artatzerako gizarte-politikaren itxuratzean, eta, modu berezian, Mendetasunaren Legean?; edota zein estrategia edo eragiteko gaitasun erabili dituzte erreforma hori burutzeko? Analisia osatzeko, berriz ustiatu dira Mendetasun Legea lantzeko partaide izandako zenbait gizarte-eragile estrategikori modu sakonean eginiko hamazazpi elkarrizketa. Besteak beste, galdegindako hauek hartu dituzte kontuan: sindikatuak eta enpresaburuak, irabazi-asmo gabeko erakundeak, alderdi politikoak, autonomiaerkidegoak eta adituak.

\section{HITZ-GAKOAK:}

Mendetasun Legea, epe luzeko zaintza, enpresaburuen elkarte, sindikatuak, hirugarren sektorea.
En este texto se parte del análisis de los cambios culturales, sociales e institucionales que han propiciado la actual reforma de la política social de atención a la dependencia en España para, a continuación, centrarse en el papel que los agentes sociales (sindicatos y empresarios) han desempeñado en dicha reforma. En particular, se pretende responder a preguntas como ¿cuál ha sido el papel de los agentes sociales en la actual configuración de la política social de atención a la dependencia y, en concreto, en la Ley de Dependencia?, 0 ¿cuáles han sido sus estrategias y capacidades de acción en dicha reforma? Este análisis se ha basado en una reexplotación de diecisiete entrevistas en profundidad realizadas a actores sociales estratégicos en la elaboración de la Ley de Dependencia, como los propios sindicatos y la patronal, así como entidades no lucrativas, partidos políticos, comunidades autónomas y expertos.

\section{Palabras Clave:}

Ley de Dependencia, cuidados de larga duración, organizaciones empresariales, sindicatos, tercer sector.

${ }^{1}$ Una versión preliminar de este artículo se presentó en el III Congreso Anual de la Red Española de Política Social, celebrado del 24 al 26 de noviembre en Pamplona. Esta versión ha sido mejorada gracias a las aportaciones de los asistentes al panel en el que se presentó la ponencia. 


\section{Introducción}

El 1 de enero de 2007 comenzó a aplicarse en España la Ley 39/2006, de Promoción de la Autonomía Personal y Atención a las Personas en Situación de Dependencia (LAPAD), conocida como Ley de la Dependencia, que crea un nuevo sistema de protección social, conocido como Sistema de Autonomía y Atención a la Dependencia (SAAD). Esta reforma es fruto de un conjunto de cambios institucionales, sociológicos e ideológicos que coinciden progresivamente a lo largo de casi quince años (entre 1992 y 2006), y actúa de manera desigual y con distinta intensidad (Rodríguez Cabrero, 2009; Rodríguez Cabrero y Marbán, en prensa).

Se trata de una reforma compleja, que pretende dar respuesta al mismo tiempo a varios objetivos:

- Asistenciales: cubrir un riesgo tradicional, garantizando un mínimo de protección en todo el territorio del Estado; apoyar a la familia cuidadora mediante prestaciones sociales, a la vez que facilitar la incorporación de la mujer al mercado de trabajo; mejorar la calidad de los servicios; promover la autonomía personal; o crear una red pública de servicios sociales de gestión mixta en todo el Estado.

- Institucionales: impulsar la cooperación institucional entre administraciones; promover la participación de los agentes sociales y económicos en el SAAD; garantizar las condiciones de igualdad en todo el territorio; o conciliar la vida familiar, los cuidados informales y el empleo.

- Económicos: crear empleo en servicios sociales, reforzar la cooperación financiera entre administraciones, impulsar la participación de los beneficiarios en la financiación (copago).

Esta multiplicidad de objetivos ha producido no escasos conflictos institucionales y financieros (entre administraciones), entre prestaciones y servicios (voto mayoritario a favor de las prestaciones económicas frente a los servicios) y entre los proveedores privados y el Estado (por el coste de los servicios y el escaso impulso al desarrollo de los servicios sociales). También ha producido una confluencia inercial de intereses entre los distintos actores sociales implicados (comunidades autónomas, corporaciones locales, partidos políticos, organizaciones del tercer sector del ámbito de los mayores y las personas con discapacidad, y sindicatos y organizaciones empresariales).

En este texto analizaremos tanto los factores culturales, sociales e institucionales que subyacen a la política social de atención a la dependencia, como el proceso de negociación y consenso entre los agentes sociales implicados. Para este análisis, nos hemos apoyado en una reexplotación de los resultados de diecisiete entrevistas en profundidad realizadas a agentes sociales y actores sociales estratégicos (entidades no lucrativas de acción social, partidos políticos, comunidades autónomas y expertos) entre octubre de 2007 y julio de 2008 , centrándonos en el análisis específico que estos actores hacen del papel desempeñado por los sindicatos y la patronal en el desarrollo de la LAPAD.

\section{Factores de cambio subyacentes a la política social de atención a la dependencia}

En la puesta en marcha del Sistema Español de Atención a la Dependencia, se entrecruzan varios conjuntos de intereses que han dado lugar a una ley compleja, basada en la necesaria cooperación institucional o administrativa entre el Estado y las comunidades autónomas. Detrás de esta rama de protección social, subyacen distintas cuestiones: el proceso de europeización cognitiva de las políticas sociales; la necesaria racionalización de los programas de atención existentes en la Seguridad Social, las comunidades autónomas y Ayuntamientos; la creciente demanda social de las familias; o la importancia del diálogo social, a través del cual se han canalizado las demandas de los sindicatos (en pro de nuevos nichos de empleo) y de los empresarios (en pro de nuevos ámbitos de gestión privada de los servicios sociales).

El principal episodio de la reforma de la política social de atención a la dependencia es la Ley 39/2006, de Promoción de la Autonomía Personal y Atención a las Personas en Situación de Dependencia. Su existencia y configuración no pueden explicarse sin atender al contexto cultural, social e institucional, los cuales, a su vez, han ejercido gran influencia en la postura de los diferentes actores sociales respecto el modelo español de atención a las personas dependientes, así como a las coaliciones entre dichos agentes.

\subsection{El contexto europeo y las inercias socioculturales e institucionales en el ámbito sociosanitario}

Un factor de cambio fundamental en la definición del actual sistema de atención a la dependencia español son las reformas políticas y las inercias institucionales, tanto internas como externas, en el ámbito sociosanitario.

En el plano externo, no podemos obviar el 'efecto llamada' que han tenido las reformas europeas en el debate sobre la atención a la dependencia en España. En particular, la incardinación del debate español en las políticas de la UE sobre esta materia ha supuesto la dinamización de un debate incipiente desde la década de 1990 (Marbán, 2011b). En la Unión Europea, la extensión y diversificación de los cuidados de atención a la dependencia se produjeron a distintas velocidades. A principios de los ochenta, los países nórdicos ampliaron y diversificaron su sistema de cuidados en respuesta a unos cambios sociodemográficos precoces en el contexto europeo (en especial, en Suecia, donde en el año 1980, 23 de cada 100 ciudadanos eran mayores de 65 años). 
Tales cambios todavía no se habían manifestado con una acusada intensidad en los países con sistemas contributivos de Seguridad Social hasta entrados los noventa. Los países nórdicos optaron, a principios de los ochenta, por integrar progresivamente las necesidades de atención a la dependencia en el extenso sistema de prestaciones y servicios sociosanitarios existentes. Una década después, mientras en los países nórdicos el debate latente sobre el sistema giraba en torno a su redimensionamiento, en el Reino Unido se discutía en torno a la búsqueda de soluciones para resolver el conflicto existente entre un sistema sanitario universal y unos servicios sociales asistenciales de atención a la dependencia.

En los sistemas de seguros sociales continentales, empezaron a gestionarse sistemas de seguros públicos para la cuidados de larga duración (Austria en 1993, Alemania en 1995, Luxemburgo en 1998 , Flandes en 2001, o Francia en 2002), en respuesta, además de a factores sociodemográficos, a un sistema que contaba con un alto nivel de copago -sobre todo en cuidados institucionales-, baja cobertura de prestaciones, disminución en la oferta de cuidadores familiares, y servicios de atención muy medicalizados y costosos (Pacolet, 1998).

Debe apuntarse, por lo tanto, cómo las experiencias europeas, en particular las de los países nórdicos y centroeuropeos (Pacolet, 1998, 2006), supusieron un acicate más en la definición de una política integral de atención a la dependencia en España (Pavolini y Ranci, 2008). Por ejemplo, tales experiencias se reflejan desde 2007 en los informes conjuntos de la Comisión Europea (2009, 2007a, 2007b, 2007c).

En el plano interno, nuestra reforma de la política social de atención a la dependencia también se construye a partir de un sistema de servicios sociales que ha ido aumentando considerablemente las ratios de cobertura en los últimos años, y también a partir de los siguientes hitos y reformas políticas de calado en la actual configuración de la política de atención a la dependencia (Rodríguez Cabrero, 2004; Rodríguez Rodríguez, 2006):

- La Constitución Española de 1978, en particular, sus artículos 49 y 50, que se refieren a la protección, por parte de los poderes públicos, de las situaciones de discapacidad y de las personas mayores, respectivamente.

- La Ley 13/1982, de 7 de abril, de Integración Social de los Minusválidos (LISMI). En virtud del artículo 49 de la Constitución, la LISMI contemplaba (artículo 16) un subsidio de ayuda por tercera persona, que fue suprimido en 1994, y al cual podían acceder quienes tuvieran 18 o más años, y no desarrollaran actividad laboral, tuvieran un grado de discapacidad igual o superior al $75 \%$ y la necesidad de asistencia de otra persona para realizar los actos más esenciales de la vida.

- El Plan Concertado para el Desarrollo de Prestaciones Básicas de Servicios Sociales de las Comu- nidades Locales, aprobado en 1988. En 1993, la Federación Española de Municipios y Provincias (FEMP) aprobó un catálogo que atribuía mayores competencias a las corporaciones locales en materia de servicios sociales, lo que implicó la extensión de servicios sociales como la ayuda a domicilio, una apuesta de los ayuntamientos hacia los cuidados de proximidad, y una incipiente dotación de profesionales municipales.

- La aprobación del Plan Gerontológico en 1992 supuso que, por primera vez, se abordaran de manera integral toda una serie de políticas en materia de envejecimiento, más allá de sus efectos sobre las pensiones, abriéndose camino la importancia de su atención sociosanitaria. Por entonces, el plan ya contemplaba medidas como alcanzar ratios suficientes en los principales servicios de atención, un complemento de pensión para pensionistas en situación de dependencia funcional, o mapas sociosanitarios y unidades específicas para coordinar los servicios sociales y sanitarios. Sin embargo, en su mayoría estas medidas no se implementaron por la falta de financiación e impulso político y por la fragmentación de competencias entre las administraciones públicas (Rodríguez Rodríguez, 2006). De haberse llevado a cabo, habrían supuesto un importante avance en la atención de situaciones de dependencia de personas mayores (Sancho y Rodríguez, 2002).

- Ley General de la Seguridad Social (texto refundido de 1994). El artículo 136, capítulo V del título II regula la incapacidad permanente, entre las cuales está la gran invalidez, definida como "la situación del trabajador afecto de incapacidad permanente y que, por consecuencia de pérdidas anatómicas o funcionales, necesita la asistencia de otra persona para los actos más esenciales de la vida, tales como vestirse, desplazarse, comer o análogos”. Asimismo, el artículo 181.a reconoce una asignación económica por cada hijo menor de 18 años a cargo del beneficiario, ayuda que también pueden cobrar las personas mayores de edad afectadas por una discapacidad en un grado igual o superior al $65 \%$.

- Las leyes autonómicas de servicios sociales -ya sean de primera generación (reguladas durante la década de 1980 y parte de la de 1990) como de segunda- en comunidades autónomas como Galicia, País Vasco, Comunidad de Valencia, La Rioja, Principado de Asturias, Madrid y Murcia (Guillén, 2005; Guillén y Vilá, 2007) han ido configurando, junto con diversos programas sociosanitarios y planes de atención a personas mayores, un mapa autonómico de servicios sociales cada vez más extenso. Aunque "se proclaman como universales, es decir, accesibles a cualquier persona en situación de necesidad [...], se trata de un derecho puramente retórico, que no puede compararse de ninguna manera al derecho subjetivo que tienen los sistemas de protección ya consolidados" (Rodríguez Rodríguez, 2006: 50). 
- Son igualmente reseñables otras medidas contempladas desde el ámbito sanitario, como la Ley General de Sanidad (1986), la práctica universalización de la atención sanitaria, y la Ley 16/2003, de Cohesión y Calidad del Sistema Nacional de Salud. Esta última regula, por primera vez, la prestación llamada sociosanitaria, que, si bien no se remite exclusivamente a la dependencia, es relevante para ella, pues incluye prestaciones de cuidados de larga duración, atención sanitaria durante la convalecencia y la rehabilitación en pacientes con déficit funcional recuperable. Según su artículo 14, tales prestaciones estarían destinadas a "aquellos enfermos, generalmente crónicos, que, por sus especiales características, puedan beneficiarse de la actuación simultánea y sinérgica de los servicios sanitarios y sociales para aumentar su autonomía, paliar sus limitaciones o sufrimientos, y facilitar su reinserción social".

- Finalmente, se deben mencionar otros hitos, como la creación, en 1988, del Ministerio de Asuntos Sociales, para tratar los servicios sociales de manera diferenciada a otros ministerios, y que supuso un cambio simbólico y representativo del creciente peso asignado a este pilar del Estado del bienestar; o la entrada en la agenda internacional con la celebración en España de la II Asamblea Mundial de Envejecimiento de Naciones Unidas (2002).

\subsection{Cambio cultural en torno a la responsabilidad de los cuidados}

Un segundo factor que hay que considerar es el cambio cultural producido en torno a la responsabilidad de los cuidados. Se trata de una transformación progresiva, que no implica un retroceso del modelo de atención familiar de cuidados, sino una profunda restructuración social interna.

Ese cambio cultural viene desencadenado, en primer lugar, por procesos sociodemográficos que afectan a la dinámica y los roles familiares tradicionales, como el menor tamaño de las familias o la creciente participación de la mujer en el mercado laboral. Tales cambios están precipitando una crisis de la red de cuidados de la que disponían las personas dependientes en décadas anteriores, $y$ han puesto de manifiesto la fragilidad e insuficiencia de un modelo de atención como el actual, sustentado en las mujeres cuidadoras: en el $22,5 \%$ de los casos, el cuidador principal suele ser el cónyuge y, fundamentalmente, las hijas (39,3\% frente al 9,15\% de los hijos) [Centro de Investigaciones Sociológicas, 2006].

En cierto modo, como consecuencia de esas transformaciones sociodemográficas, se ha registrado una creciente demanda de socialización de los cuidados, es decir, de asunción de responsabilidades colectivas en los cuidados. Así, en 2004, el 10,6\% de los mayores de 65 años creían que las familias debían asumir toda la responsabilidad de los cuidados, mientras que dos años después, esa opinión la sostenía el $5,5 \%$. Del mismo modo, el porcentaje de personas que opinaba que la familia debía ser responsable de los cuidados con ayuda de las administraciones públicas pasó del 38\% en 2004 al 43\% en 2006 (Centro de Investigaciones Sociológicas, 2006; Imserso, 2004).

Parte de este cambio en la cultura de los cuidados viene también desencadenado por un factor menos visible, pero que ha operado de manera latente y gota a gota en el imaginario colectivo: la creciente densidad de conciencia con respecto a la dependencia. Dicho factor parte, en los años ochenta, de un movimiento ilustrado encabezado por las clases profesionales provenientes del ámbito de la Seguridad Social, y de la geriatría y la gerontología, así como de expertos y académicos que trasladan esas inquietudes a las administraciones públicas, las cuales reaccionan, no obstante, con retraso a las demandas sociales planteadas. Se trataba de profesionales y expertos que, en muchos casos, conocían las experiencias de otros países en el campo de la dependencia, la geriatría y la gerontología. Contribuyeron a crear incipientes cambios en la cultura sobre la responsabilidad de los cuidados, una especie de 'conciencia por goteo' sobre dicho fenómeno, y sus conocimientos y experiencias posteriormente se pusieron relieve en el libro blanco (Rodríguez Castedo, 2005).

Dicho 'movimiento ilustrado' consiguió que, desde finales de los ochenta y principios de los noventa, la dependencia se incorporarse a la 'agenda de asuntos pendientes' de nuestro Estado del bienestar, hecho en cierto modo también propiciado porque, en esos años, el principal debate sobre protección social girara en torno a la viabilidad del sistema de pensiones y sus posibles reformas. No sería hasta iniciada la primera década de 2000 cuando la demanda social creciente de un buen número de familias 'desbordadas' por un aumento de la esperanza de vida con elevados años de discapacidad y plenamente concienciadas del problema fuera canalizada por los sindicatos y las organizaciones sociales de la discapacidad y de personas mayores, a través de consejos estatales y plataformas de entidades (Plataforma de ONG de Acción Social, Consejo Estatal de Personas Mayores, Consejo de ONG de Acción Social, Comité Español de Representantes de Personas con Discapacidad).

\subsection{La provisión de cuidados a la dependencia}

En tercer lugar, la reforma de la política social de atención a la dependencia no puede explicarse sin atender a la organización y la insuficiente provisión de los cuidados en las esferas pública y privada para sostener o impulsar un sistema de atención a la dependencia de amplia cobertura, como se pretende en nuestro recién estrenado sistema. 
En este sentido, el caso español participa de algunos de los rasgos comentados a escala de la UE: alta feminización de los cuidados y significativa prevalencia de los cuidados informales; creciente colaboración público-privada en la provisión de los servicios, con un peso creciente de la iniciativa privada lucrativa y no lucrativa; gestión descentralizada de la provisión de servicios; creciente regulación de la provisión privada de los servicios; y (re)definición de los estándares de evaluación, seguimiento y control de la calidad de las prestaciones.

Estos rasgos son consustanciales a nuestro sistema de cuidados, de trayectoria asistencial y sustentado por las familias, las entidades no lucrativas, las empresas privadas (fundamentalmente en el ámbito de los servicios residenciales, donde el índice de cobertura de las residencias privadas es del 2,28, superior al de las residencias públicas $(2,04), y$ donde el $80 \%$ de las residencias son de titularidad privada (Imserso, 2008) y con una participación multinivel de perfil asistencialista de las administraciones públicas, en especial las comunidades autónomas y las corporaciones locales.

Efectivamente, se constata cómo las familias son las primeras proveedoras de cuidados y cómo recaen sobre ellas de manera muy significativa los principales cuidados de las personas mayores. Así se ponía de manifiesto en la Encuesta de condiciones de vida de los mayores 2006 (Centro de Investigaciones Sociológicas, 2006), ya que, mientras que los cuidadores principales familiares (cónyuge, hijas e hijos) se ocupaban, por término medio, del $71 \%$ de los cuidados principales, los servicios sociales públicos o las empresas de servicios sociales privadas tan sólo lo hacían en el 2,5\% y el 0,2\% de los casos, respectivamente.

En cuanto al papel de las administraciones públicas, existe un amplio mapa de prestaciones y ventajas fiscales para atender a la dependencia. Se trata de prestaciones que, si bien han aumentado significativamente en oferta y cobertura en los últimos años, son insuficientes y están desequilibradas territorialmente en tasas de cobertura, requisitos de acceso y en aportaciones del usuario (Marbán, 2009).

En definitiva, con la organización y provisión de los cuidados previa a la LAPAD, los servicios y las prestaciones seguían siendo insuficientes, y la sobrecarga de los cuidadores familiares, excesiva, lo cual, junto a la inmediata demanda de necesidades de atención, justifica plenamente la puesta en marcha de la reforma y responde a nuestra pregunta de por qué era necesaria una política integral de atención a la dependencia en España como la implementada hace cinco años con la LAPAD.
2.4. La atención a la dependencia: una reforma gradual, pero con interrupciones

Como ya hemos puesto de manifiesto (Marbán, 2011a), este recorrido por los factores de cambio subyacentes a la política social de atención a la dependencia apunta a que la LAPAD no constituye un episodio de cambio o una reforma radical, sido una reforma gradual, dependiente de una senda (path dependency) acumulativa de factores socioeconómicos e institucionales acaecidos desde los años ochenta, que amplía y complementa la acción protectora que ya venía realizando el Estado y el sistema de Seguridad Social.

No obstante, en esa senda acumulativa de factores, la política social de atención a la dependencia también ha estado sometida, hasta iniciado el siglo XXI, a una sucesión de procesos interrumpidos, debido a que los sucesivos Gobiernos, y también otros agentes sociales, han ido posponiendo la atención a la dependencia como una prioridad en ciernes. Podríamos apuntar varias circunstancias que avalarían esta fundamentación.

En primer lugar, conviene recordar de nuevo cómo el Plan Gerontológico, de haberse implementado plenamente desde 1992, habría supuesto un importante avance en la atención a situaciones de dependencia de personas mayores, que se vio, en cierto modo, 'interrumpido' por la falta de financiación e impulso político y por la fragmentación de competencias entre las administraciones públicas.

Igualmente, sucede que durante el segundo mandato del Partido Popular, entre 2000 y 2004, tanto la creación de una Comisión sobre Dependencia -denominada también Comisión Zaplana- como el Acuerdo Social de 2001 y la situación económica de elevado crecimiento económico del momento indujeron a pensar que la Ley de la Dependencia la haría el Partido Popular en ese mandato. Sin embargo, eso no sucedió, probablemente por razones presupuestarias, como apunta en su entrevista uno de nuestros informantes.

En tercer lugar, en lo que respecta a los sindicatos, la dependencia tardó en entrar en su agenda, en la medida en la que se priorizaron aspectos como la dignificación de las pensiones o la protección al desempleo (debido, en buena medida, a las altas tasas de paro de la década de 1990). En cuanto a las organizaciones empresariales, no participaron de esta preocupación -más allá de su posible efecto en los seguros privados de cuidados de larga duraciónhasta que no empezaron a constatar el posible espacio de negocio de la dependencia -especialmente en la atención a personas mayores-y el clima favorable hacia la protección social de esta contingencia. 


\section{El papel de los sindicatos y las organizaciones empresariales en la reforma de la política social de atención a la dependencia}

Además de por la acumulación de los factores mencionados, la LAPAD también es el resultado de la importancia central, que no determinante, de la confluencia inercial de intereses entre los distintos actores sociales implicados (comunidades autónomas, corporaciones locales, partidos políticos, organizaciones del tercer sector del ámbito de los mayores y las personas con discapacidad, y sindicatos y organizaciones empresariales).

En síntesis, la gestación de la Ley de Dependencia arrancó con la elaboración del Libro blanco de la dependencia (Rodríguez Castedo, 2005) en mayo de 2004, por iniciativa del Gobierno del PSOE, a través del Imserso, y se publicó a principios de enero de 2005. Sobre la base de dicho documento, el contenido de la futura ley fue debatido desde inicios de ese año por patronal, sindicatos y Gobierno. En diciembre de 2005, se alcanzó un acuerdo social entre el Gobierno, los sindicatos UGT y CC.00., y las patronales CEOE y CEPYME, mediante el cual se acordaron los principios básicos del modelo (financiación, prevalencia de servicios sobre prestaciones, desvinculación de la Seguridad Social y sistema universal).

¿Cuál ha sido el papel de los agentes sociales en la actual configuración de la política social de atención a la dependencia y, en particular, en la Ley de Dependencia? ¿Cuáles han sido sus estrategias y capacidades de acción en dicha reforma? La respuesta a estas cuestiones requiere diferenciar dos escenarios:
- Un escenario de consenso (Figura 1) articulado en torno a una serie de aspectos básicos de la ley sobre los cuales existió un relativo acuerdo -aunque por razones e intereses distintos- entre los actores sociales, como la universalidad y la igualdad de acceso, el reconocimiento de los derechos de los cuidadores en la Seguridad Social, la importancia concedida a la prevención, la formación, la calidad en la prestación de servicios o la importancia del apoyo a las familias.

- En lo relativo a la universalidad y la igualdad de acceso al sistema, los sindicatos perseguían la consolidación de la oferta pública de servicios; y la patronal, la consolidación de la oferta privada. En el caso de las organizaciones empresariales, aunque cabía esperar que abogaran por un seguro privado de dependencia, finalmente optaron por un sistema universal, no sólo por el alto consenso sociopolítico en torno a dicho sistema, sino sobre todo por la necesidad de contar con un marco jurídico estable que garantizara la provisión mixta de los servicios de atención a la dependencia y, por ende, la posibilidad de dar salida a sus excedentes de plazas residenciales.

- Los agentes sociales también coincidían en la preferencia por un modelo de prestaciones en servicios sobre un modelo de prestaciones monetarias. Con ello, los sindicatos pretendían potenciar la creación de empleo y la integración laboral femenina, al objeto de que hubiera servicios de respiro suficientes que facilitan el tránsito de las mujeres cuidadoras al mercado laboral. Las organizaciones empresariales querían consolidar la demanda de servicios, la gestión privada de los servicios sociales, la capacidad instalada en servicios residenciales y de ayuda a domi-

Figura 1. Aspectos básicos de consenso entre los agentes sociales respecto a la Ley de Dependencia

Gestión mixta

de la red de

servicios sociales

$\uparrow$

Sindicatos: creación de empleo de calidad, integración laboral femenina.

Patronal: consolidación de la capacidad instalada en servicios residenciales y ayuda a domicilio, absorción de excedentes de plazas residenciales.

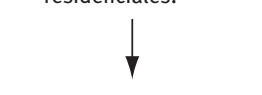

Prevalencia de servicios sobre prestaciones económicas
Sindicatos: consolidación de la oferta pública de servicios, gestión pública de los servicios sociales de responsabilidad pública.

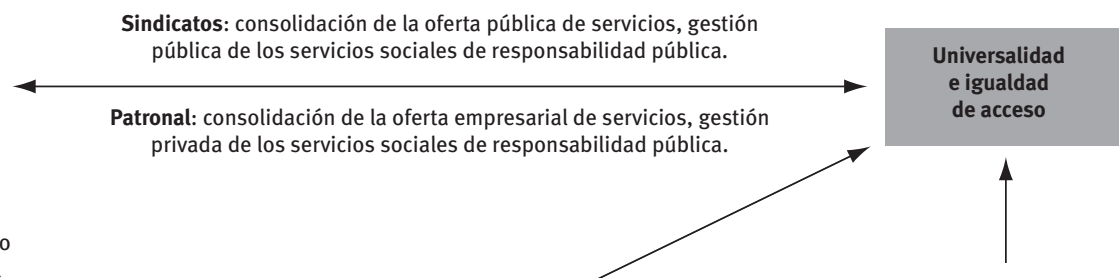

Sindicatos: creación de empleo de calidad, integración laboral femenina. Patronal: consolidación de la capacidad instalada en servicios residenciales y de ayuda a domicilio, absorción de excedentes de plazas residenciales.
Sindicatos: oferta de formación. Patronal: mejora de la calidad del servicio.

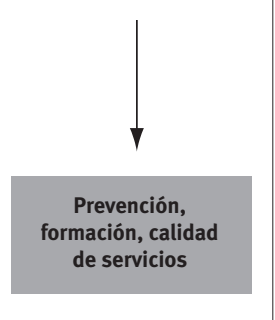

Fuente: Elaboración propia. 


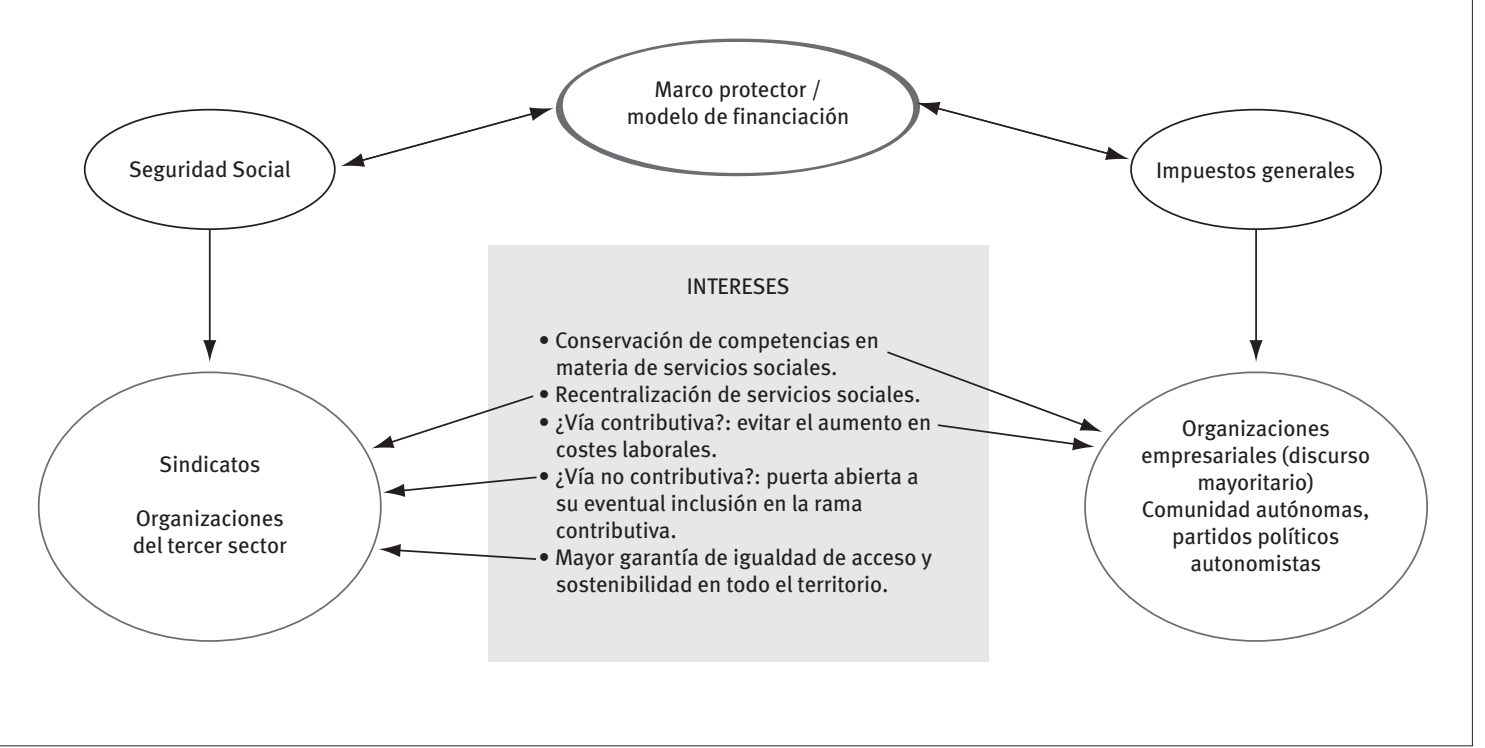

Fuente: Elaboración propia.

cilio, y la absorción de excedentes de plazas residenciales.

- Un escenario de disenso (Figura 2), en torno a aspectos como el marco protector y el ámbito competencial, que fueron objeto de intenso debate.

Con respecto al marco protector y el ámbito competencial, el principal debate surgió en torno a dos cuestiones: a) si la LAPAD debía incluirse en el marco de la Seguridad Social, o bien dejarse fuera de ella; y b) la consiguiente financiación vía impuestos. La primera posibilidad podría suponer un aumento en las cotizaciones (en el caso de ir por la vía contributiva), así como la transferencia de más competencias en servicios sociales a la administración central, en detrimento de las comunidades autónomas.

A este respecto, la patronal, gran parte de las comunidades autónomas y los partidos políticos de corte más autonomista se oponían a la inclusión de la Ley de Dependencia en el marco de la Seguridad Social y defendían la financiación vía impuestos:

- Para las organizaciones empresariales, enmarcar la LAPAD en la Seguridad Social por la vía contributiva implicaría un aumento en sus costes laborales (en cotizaciones sociales), lo cual lastraría su crecimiento organizativo, mientras que hacerlo por la vía no contributiva habría supuesto una puerta abierta a su inclusión en algún momento en la rama contributiva.

- Para la mayoría de las comunidades autónomas y los partidos políticos de corte más autonomista, incluir la LAPAD en el sistema de la Seguridad Social afectaba de pleno al ámbito competencial autonómico, pues conferiría al Gobierno central una legitimidad y una capacidad imperativa que invadía las competencias de las comunidades autónomas en el ámbito de servicios sociales, y les restaba legitimidad para intervenir en la práctica.

Ésa fue la posición prevalente de las organizaciones empresariales, lo cual no impidió que abogaran por un sistema de amplia cobertura que estableciera un marco estable de ordenamiento jurídico y de financiación para la atención a la dependencia. Más bien todo lo contrario: un marco jurídico estable y la definición de un sistema universal de amplia cobertura y de gestión mixta como el que se proponía en la LAPAD podría suponer, como hemos afirmado anteriormente, la consolidación de la capacidad instalada en servicios residenciales y de ayuda a domicilio, así como la absorción de excedentes de plazas residenciales del sector privado mercantil.

No obstante, hubo un debate interno en el seno de la CEOE -fruto de la desfragmentación del sector-, articulado en torno a la siguiente dualidad de discursos (Figura 3):

- Por un lado, el discurso sostenido por las grandes organizaciones empresariales y por el sector empresarial en general. Dicho discurso, mayoritario, considera la atención a la dependencia como un sector asistencial generador de gasto y donde el rechazo al modelo de Seguridad Social se fundamenta en la contención de costes laborales que supondría, desconsiderándose los efectos positivos de tal modelo, en términos de financiación estable y existencia de un marco regulador homogéneo, que evitaría incertidumbres en la acreditación de centros entre las diferentes comunidades autónomas. 


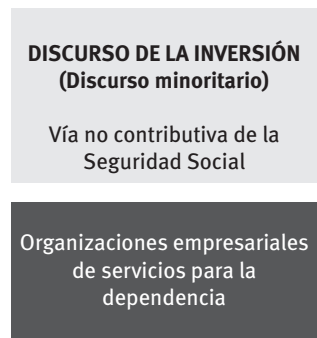

Sostenibilidad financiera

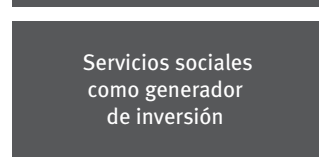

DISCURSO DEL GASTO

(Discurso mayoritario)

Desvinculación de la

Seguridad Social:

financiación vía impuestos

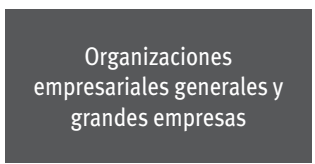

Contención de costes laborales

Servicios sociales

como sector asistencia

generador de gasto

Fuente: Elaboración propia a partir del análisis de las entrevistas.

El discurso sostenido por las organizaciones empresariales de servicios para la dependencia, que conciben la atención a esta contingencia como un espacio generador de inversiones y de creación de empleo no deslocalizable. En dicho discurso, prevalecen la seguridad jurídica y económica que les aportaría el marco regulador de la Seguridad Social, más estable y homogéneo, para evitar los elevados costes de transacción que, para estas organizaciones, tienen aspectos como la acreditación de centros.

Por el contrario, las organizaciones del tercer sector y los sindicatos eran proclives a incluir los derechos y las prestaciones en el ámbito de la Seguridad Social, y a una participación más activa de la administración central en los servicios sociales, fundamentalmente porque, con ellos, se respondía con mayor fidelidad a la igualdad de acceso en todo el territorio, a la extensión de los servicios públicos, o a la extensión de los servicios privados no lucrativos de responsabilidad pública.

La postura inicial de los sindicatos con respecto al marco protector de la LAPAD fue situar la dependencia dentro del ámbito de la Seguridad Social, aunque no necesariamente en la parte contributiva; de hecho, se contempló la posibilidad de incluir el sistema en la vía no contributiva de la Seguridad Social, pero gestionada por las comunidades autónomas. En este aspecto, fueron moderando sus posiciones hasta aceptar la vía impositiva, en especial por dos razones:

- Porque la integración de los mecanismos de protección de la dependencia en la Seguridad Social podría implicar un replanteamiento del Pacto de Toledo, que dejaba al margen del sistema contributivo todo lo que no fueran prestaciones econó- micas puras, teniendo en cuenta que el texto de la Ley de Dependencia prioriza las prestaciones en servicios sobre las económicas.

- Por la presión de las comunidades autónomas, las cuales "en el caso de que se incluyese dentro del ámbito de la Seguridad Social, iban a presentar un recurso de inconstitucionalidad" (UGT), lo cual podría retrasar en exceso la universalización de esta contingencia.

En definitiva, según las entrevistas realizadas, el hecho de no enmarcar el nuevo sistema en el ámbito de la Seguridad Social pudo deberse al rechazo de la patronal, los partidos políticos más autonomistas - los cuales poseían una mayor presencia parlamentaria durante la legislatura en que se aprobó la ley-, pero, sobre todo, a la oposición de las comunidades autónomas, respaldadas por su capacidad instalada en los servicios sociales y por las amenazas de inconstitucionalidad de algunas de ellas, que, de producirse, habrían podido retrasar la aprobación de una ley en un contexto socioeconómico propicio.

\section{Conclusiones}

La Ley de Dependencia representa un hito moderno en la configuración actual del Estado del bienestar. Su impacto, tanto en la economía (Montserrat, 2011; Sosvilla Rivero, 2010) como en el número de personas beneficiarias, está siendo cada vez más significativo. Como explica el recientemente publicado informe de evaluación de la Ley 39/2006 (Imserso, 2011), elaborado por un equipo de investigación independiente, a 1 de noviembre de 2011 hay más de 740.000 beneficiarios que reciben prestaciones, frente a un 
total de 914.373 que tienen reconocido ese derecho. En términos de empleo, los puestos de trabajo vinculados a la atención a la dependencia durante 2009 y 2010 han supuesto un total de 248.000 , y se han creado 165.000 nuevos empleos como resultado del nuevo gasto implementado con la LAPAD. El gasto sobre el PIB se ha doblado entre 2003 y el 2010, pasando del $0,32 \%$, a casi el $0,64 \%$, cifra que supone unos retornos fiscales de casi el $20 \%$.

Hemos puesto de manifiesto que, en su actual configuración, la LAPAD tiene su referente en una serie de factores culturales, sociodemográficos e institucionales que han ejercido gran influencia en el modelo vigente de atención a las personas dependientes. Entre otros, han resultado determinantes los siguientes factores: los cambios en la cultura sobre la responsabilidad de los cuidados, desencadenados por cambios sociodemográficos y una creciente demanda de socialización de esta contingencia; la insuficiente provisión de los cuidados en las esferas pública y privada, donde las familias son las primeras proveedoras de cuidados; así como las reformas políticas y las inercias institucionales tanto internas (reformas como el Plan Gerontológico o el Plan Concertado) como externas (europeización cognitiva de las políticas sociales).

Con ello, se evidencia que la LAPAD supone una reforma gradual dependiente de una senda acumulativa (path dependency) de factores socioeconómicos e institucionales acaecidos desde los años ochenta. En realidad, podría considerarse al nuevo sistema como el perfeccionamiento del sistema anterior, que se transforma en un sistema de cobertura universal, basado en un derecho subjetivo (como la sanidad o la educación) y en la cooperación entre el Estado y las comunidades autónomas o regiones, y financiado con impuestos, cotizaciones sociales y copago de los usuarios.

Por otro lado, la LAPAD también es el resultado de la confluencia inercial de intereses entre los distintos actores sociales implicados (comunidades autónomas, corporaciones locales, partidos políticos, organizaciones del tercer sector del ámbito de los mayores y las personas con discapacidad, y sindicatos y organizaciones empresariales). Aunque el debate comenzó antes, desde una perspectiva institucional el punto de partida fue el acuerdo social de diciembre de 2005 entre las organizaciones empresariales, los sindicatos y el Gobierno, en el que se acordaron los principios básicos del modelo (financiación, prevalencia de servicios sobre prestaciones, desvinculación de la Seguridad Social y universalidad del sistema).

Hubo cierto grado de acuerdo en torno a una serie de aspectos básicos de la ley, como la universalidad y la igualdad de acceso, la gestión mixta de la red de servicios sociales, el reconocimiento de los derechos de los cuidadores en la Seguridad Social, y la importancia concedida a la prevención, la formación o la calidad en la prestación de servicios. El consenso se produjo porque incorporar estos aspectos en la ley favorecía las expectativas de ambos agentes sociales de contar con un marco jurídico estable que garantizara la provisión mixta de los servicios de atención a la dependencia. Para los sindicatos, ello podría suponer consolidar la oferta pública de servicios y favorecer la creación de empleo y la integración laboral femenina. Para las organizaciones empresariales, representaba consolidar la oferta y la demanda de los servicios ofertados por las empresas del sector, y mayores posibilidades a la gestión privada de los servicios sociales de responsabilidad pública.

El principal punto de desacuerdo giró en torno al marco protector y el ámbito competencial, en particular, a la inclusión o no de la LAPAD en el marco de la Seguridad Social. Entre las organizaciones empresariales, prevaleció - no sin debate interno- la estrategia de rechazar la inclusión en la Seguridad Social tanto en la vía contributiva -por cuanto ello implicaría un aumento en sus costes laborales- como por la vía no contributiva -en la medida en que ello habría dotado a la Administración de mayor margen de maniobra para incluirla, en un futuro, en la rama contributiva-. En cuanto a las organizaciones sindicales, aunque su estrategia inicial fue la de apoyar la inclusión de la Ley de Dependencia en el marco de la Seguridad Social, finalmente aceptaron su financiación vía impuestos, no sólo por la negativa de las organizaciones empresariales al acuerdo social -con la connivencia del Ministerio de Economía y Hacienda-, sino sobre todo por la amenaza latente de que algunas comunidades autónomas plantearan un recurso de inconstitucionalidad, lo que, de haberse producido, habría podido retrasar en exceso la universalización de esta contingencia.

Con la perspectiva de los cinco años trascurridos desde la puesta en marcha de la LAPAD, cabría afirmar, no obstante, que el resultado final para las organizaciones empresariales no ha sido del todo satisfactorio en lo que se refiere a sus principales objetivos (Figura 4). Por un lado, han logrado excluir la ley del ámbito de la Seguridad Social (con el inestimable apoyo de las comunidades autónomas) y dar mayor visibilidad a ciertos productos de financiación privados (por ejemplo, la hipoteca inversa). Por otro, no han conseguido que el peso de la iniciativa privada en el conjunto de la ley sea especialmente significativo, sobre todo si lo comparamos con el asignado a las organizaciones del tercer sector, ni tampoco han podido dar salida a los excedentes de plazas en los servicios residenciales, debido, entre otras razones, a la prevalencia de las prestaciones económicas sobre las prestaciones en servicios.

En lo relativo a los sindicatos (Figura 4), aunque finalmente la LAPAD no se incluyera en el marco de la Seguridad Social, su papel fue significativo en la consecución de una ley de carácter universal que consolida un derecho subjetivo. Sucede, empero, que sus otros objetivos prioritarios -crear empleo, favorecer el trabajo femenino, reducir la precariedad laboral y mejorar la formación de los cuidadores profesiona- 


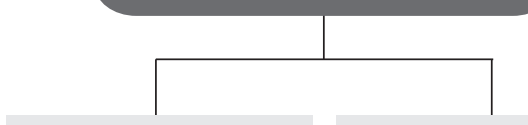

LAPAD fuera del ámbito de la Seguridad Social.

Mayor visibilidad a ciertos productos de financiación privados.
DEBILIDADES

Limitado reconocimiento de la iniciativa privada en el conjunto de la LAPAD.

Baja cobertura de excedentes de plazas en los servicios residenciales.

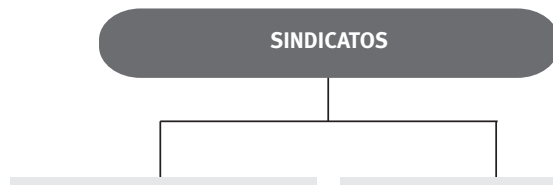

FORTALEZAS

Consolidación de un derecho subjetivo.

Reconocimiento de los derechos de los cuidadores.
DEBILIDADES

Resultados por debajo de expectativas en:

- Creación de empleo (330.000 para 2010, según el libro blanco).

- Precariedad laboral de los cuidadores profesionales

(en bajos salariosy temporalidad).

- Formación de cuidadores.

- Perpetuación de la mujer como cuidadora.

Fuente: Elaboración propia a partir del análisis de las entrevistas.

les- se han saldado, hasta la fecha, por debajo de las expectativas. En términos de empleo, los puestos de trabajo vinculados a la atención a la dependencia durante 2009 y 2010 han ascendido a 248.000 y se han creado 165.000 nuevos empleos como resultado del gasto nuevo implementado con la LAPAD (Imserso, 2011). Una cifra, que si bien queda por debajo de las previsiones de generación neta de puestos de trabajo del libro blanco -más de 330.000 en el horizonte de 2010 (Rodríguez Castedo, 2005)-, es de gran relevancia, habida cuenta de la importante destrucción de empleo en la mayoría de los sectores de la actividad.

La precariedad laboral de los cuidadores profesionales es todavía un hecho, debido a la existencia de unos márgenes muy ajustados en la concertación y los convenios con los centros residenciales y de ayuda a domicilio, lo que desemboca en bajos salarios y mayor temporalidad en relación a otros sectores. Del mismo modo, a pesar de los avances conseguidos, ya reflejados en distintos informes de evaluación de la LAPAD (Agencia Estatal de Evaluación de las Políticas Públicas y la Calidad de los Servicios, 2008; Barriga et al., 2009, 2010; Cervera et al., 2009; Imserso, 2011), las carencias existentes en la formación de cuidadores (Imserso, 2011), o la perpetuación de la mujer como cuidadora-debido a la significativa prevalencia de las prestaciones económicas- son todavía asignaturas pendientes. 
AGENCIA ESTATAL DE EVALUACIÓN DE LAS POLÍTICAS PÚBLICAS Y LA CALIDAD DE LOS SERVICIOS (2008): "La participación de la administración general del Estado en el Sistema para la Autonomía y Atención a la Dependencia”, Madrid, Agencia Estatal de Evaluación de las Políticas Públicas y la Calidad de los Servicios, [<http://www.aeval.es/comun/pdf/ evaluaciones/E13.pdf〉].

BARRIGA, L.; et al. (2010): Desarrollo e implantación territorial de la Ley de Promoción de la Autonomía Personal y Atención a las Personas en Situación de Dependencia. $V$ Dictamen, Asociación Estatal de Directoras y Gerentes en Servicios Sociales [<http:// www.directoressociales.com/documentos/ libroVdictamenjulio.pdf〉].

- (2009): Desarrollo e implantación territorial de la Ley de Promoción de la Autonomía Personal y Atención a las Personas en Situación de Dependencia. III Dictamen, Asociación Estatal de Directoras y Gerentes en Servicios Sociales [<http:// www.imsersomayores.csic.es/documentos/ documentos/barriga-dictamen-02.pdfs].

CENTRO DE INVESTIGACIONES SOCIOLÓGICAS (2006): Encuesta de condiciones de vida de los mayores, serie Estudios, no 2.647 [rhttp:// www.cis.es/cis/opencm/ES/1_encuestas/ estudios $/$ ver.jsp? estudio $=7740 \&$ cuestionario $=$ $8954 \&$ muestra $=14065$ >].

CERVERA, M. et al. (2009): Informe final del grupo de expertos para la evaluación del desarrollo y efectiva aplicación de la Ley 39/2006, de 14 de diciembre de Promoción de la Autonomía Personal y Atención a las Situaciones de Dependencia, Madrid, Imserso [<http://www. imserso.es/groups/imserso/documents/ binario/informesaadgexpertos.pdf $>$ ].
COMISIÓN EUROPEA (2009): Joint Report on Social Protection and Social Inclusion 2009, Luxemburgo, Oficina de Publicaciones de la Unión Europea [shttp://dx.doi. org/10.2767/51562>].

- (2007a): Comunicación de la Comisión al Consejo, al Parlamento Europeo, al Comité Económico y Social Europeo y al Comité de las Regiones. Propuesta de informe conjunto sobre protección social e inclusión social 2007 , Bruselas, Comisión Europea [rhttp://eur-lex. europa.eu/LexUriServ/site/es/com/2007/ com2007_0013es01.pdf〉].

- (2007b): Informe conjunto sobre protección social e inclusión social 2007. Perfiles de países, Bruselas, Comisión Europea.

- (2007c): Joint Report on Social Protection and Social Inclusion. Supporting Document, Bruselas, Comisión Europea [<http://ec.europa.eu/ employment_social/social_inclusion/ docs/2007/joint_report/sec_2007_329_ en.pdf>].

GUILLÉN, E. (comp.) [2005]: Sobre problemas y respuestas sociales, Barcelona, Hacer.

GUILLÉN, E.; y VILÀ, A. (2007): “Impacto de la Ley de Promoción de la Autonomía Personal y Atención a las Personas en Situación de Dependencia en los servicios sociales de las comunidades autónomas", en CASADO, D.; y FANTOVA, F. (coords.), Perfeccionamiento de los servicios sociales en España: informe con ocasión de la ley sobre autonomía y dependencia, Madrid, Fundación FOESSA; Cáritas, págs. 177-208.

IMSERSO (2011): Informe del Gobierno para la evaluación de la Ley 39/2006, de 14 de diciembre, de Promoción de la Autonomía Personal y Atención 
a las Personas en Situación de Dependencia (2007-2010), Madrid, Ministerio de Sanidad, Política Social e Igualdad [<http://www. dependencia.imserso.es/InterPresent1/ groups/imserso/documents/binario/ie_2011_ informeevaluacion.pdf $>$ ].

- (2008): Las personas mayores en España. Informe 2008, Madrid, Ministerio de Trabajo y Asuntos Sociales [rhttp://www.imsersomayores.csic. es/estadisticas/informemayores/informe2008/ index.html>].

- (2004): Encuesta de condiciones de vida de los mayores, Madrid, Imserso [<http://www. imsersomayores.csic.es/estadisticas/ encuestas/index.html>].

Ley 39/2006, de 14 de diciembre, de Promoción de la Autonomía Personal y Atención a las Personas en Situación de Dependencia [<http://www. boe.es/boe/dias/2006/12/15/pdfs/A4414244156.pdf >].

MARBÁN, V. (2011a): “Actores sociales y desarrollo de la Ley de Dependencia en España”, Revista Internacional de Sociología [<http:// revintsociologia.revistas.csic.es/index.php/ revintsociologia/article/view/428/451>].

- (2011b): "Los actores sociales en el sistema de dependencia español", Cuadernos de Relaciones Laborales, vol. 29, $\mathrm{n}-1$ 1, págs. 69 91 [hhttp://revistas.ucm.es/index.php/CRLA/ article/view/36186/35052〉].

- (2009): "La atención a la dependencia”, en MORENO, L. (coord.), Reformas de las políticas del bienestar en España, Madrid, Siglo XXI, págs. 207-238.

MONTSERRAT, J. (2011): Evaluación económica del SAAD, Barcelona, Mimeo.

PACOLET, J. (2006): “Protección social de las personas mayores dependientes: sostenibilidad de Estado del bienestar y ámbito del seguro de cuidados de larga duración", Revista Española del Tercer Sector, no 3, págs. 111-160 [<http://www.fundacionluisvives.org/rets/3/ articulos/6368/index.html s].

- (1998): Social Protection for Dependency in Old Age in the 15 EU Member Status and Norway, Bruselas, Comisión Europea.

PAVOLINI, E.; y RANCI, C. (2008): "Restructuring the Welfare State: Reforms in long-term care in Western
European countries", Journal of European Social Policy, vol. 18, no -3 , págs. 246-259 [<http://rszarf.ips.uw.edu.pl/welfare-state/ ranci.pdf $\rangle]$

RODRÍGUEZ CABRERO, G. (2009): "El desarrollo de la política social de promoción de la autonomía y atención a las personas en situación de dependencia en España (2007-2009)", Gestión y Análisis de Políticas Públicas, nํ2, págs. 33-58.

- (2004): "Protección social de la dependencia en España", serie Documentos de Trabajo, no 44, Madrid, Fundación Alternativas [<http://www.falternativas.org/content/ download/5708/163686/version/1/ file/431d_12-09-05_44_2004.pdf)].

RODRÍGUEZ CABRERO, G.; y MARBÁN, V. (en prensa): “Longterm care in Spain: A hybrid system of informal family care tradition and the institutionalisation of risk", en RANCI, C.; y PAVOLINI, E., Reforms in Long-term Care Policies in EU Countries, Nueva York, Springer.

RODRÍGUEZ CASTEDO, Á. (dir.) [2005]: Libro blanco de atención a las personas dependientes en situación de dependencia en España, Madrid, Imserso. [<http://www. imsersomayores.csic.es/documentos/ documentos/libroblancodependencia/mtaslibroblancodependencia-01.pdf〉].

RODRÍGUEZ RODRÍGUEZ, P. (2006): El sistema de servicios sociales español y las necesidades derivadas de la atención a la dependencia, serie Documentos de Trabajo, no 87, Madrid, Fundación Alternativas [rhttp:// www.falternativas.org/en/content/ download/5833/166791/version/1/ file/4cb8_04-07-06_27atencionDependencia. pdf>].

SANCHO CASTIELLO, M.; y RODRÍGUEZ RODRÍGUEZ, P. (2001): "Envejecimiento y protección social de la dependencia en España. Veinte años de historia y una mirada hacia el futuro", Intervención Psicosocial, vol. 10, nº 3, págs. 259-275 [khttp://www.copmadrid.org/ webcopm/publicaciones/social/76317.pdf)].

SOSVILLA RIVERO, S. (2010): Estimación del efecto del establecimiento del Sistema de Autonomía y Atención a la Dependencia sobre el empleo en España, Madrid, Mimeo. 


\title{
Códigos deontológicos e ideología en trabajo social
}

\author{
Rogelio Gómez García \\ Universidad de Valladolid \\ <rgomga@soc.uva.es>
}

Artikulu honetan, langintzan betetako rola ulergarriagoa gertatzearren, saiakera jasotzen da gizarte-langileen berauen irudiaz eta langintzaren idealen mailako gaiez hautemandakoaren berri izateko. Izan ere, oinarriko gertatzen da balioen sistemaz jakitea edonolako langintzaren izaera ezagutzeko. Hori lortzeko, oso erabilgarria da ideologiaren kontzeptua aztertzea. Horrela, gizartelangileen ikuspegi ideologikoa ezagutzearren, aztertu egin da estatu eta nazioarte-mailan erabilitako zenbait kode etiko. Aztergai hartzen dira honako hauek: kode etiko horiek bilatu izandako helburuak; profesional gisara, gizarte-langintzaren oinarriko helburuen nolakotasunak; lanbide gisara, jokaera-arauak bideratzeko lanbidearen baitan errotutako balioak, printzipioak eta oinarriko arauak; eta, azkenik, kontuan hartzen dira gizartelangintzaren alor batzuetan azaldutako ohiko gai arazotsu eta konponbiderako baliabide gisako balizko metodoak. Ondorio gisara, ohartarazi dezakegu oinarriko ideologia-iturria langintzaren instituzioaren kolektiboa berau dela, eta horrek betetzen duela hautemandako idealen bateratasuna.

\section{HITZ-GAKOAK:}

kode deontologikoak, ideologia, balioak, jokabide profesionala, gizarte-langintza.
Este artículo trata de analizar la imagen y el ideal de la profesión que tienen los trabajadores sociales, de cara a comprender mejor su papel social. Los sistemas de valores son elementos fundamentales para entender las profesiones. Un concepto de gran utilidad para ello es el de ideología. Para estudiar la visión ideológica de los trabajadores sociales, se examinan diferentes códigos de ética en el ámbito estatal e internacional. Se estudian los objetivos que pretenden alcanzar estos códigos; la finalidad del trabajo social como actividad profesional; los valores, los principios y las normas fundamentales que guían la conducta de los profesionales; $y$ finalmente algunas de las áreas problemáticas que pueden aparecer en el ejercicio profesional y algunos de los posibles métodos de decisión para tratar de afrontarlas. Como conclusión, podemos señalar que la institución profesional colectiva actúa como primera fuente de ideología, contribuyendo a la percepción de la unidad de los ideales profesionales.

\section{Palabras Clave:}

códigos deontológicos, ideología, valores, conducta profesional, trabajo social. 


\section{Introducción}

Para entender una profesión no es suficiente el análisis de sus características estructurales. La imagen y el ideal de profesión que tienen los trabajadores sociales permiten entender mejor algunas de esas situaciones estructurales y, especialmente, sus posicionamientos ante los problemas o las alternativas planteadas. Los sistemas de valores son elementos fundamentales para entender las profesiones y su papel social (Rodríguez, 2008: 42). El trabajo social se desarrolla en un espacio profesional donde las organizaciones profesionales crean un contexto en el que los trabajadores sociales laboran, producen y reflejan las visiones particulares de los ideales profesionales. Estas visiones se refieren al papel que tiene la profesión en la organización del trabajo, el entorno de la práctica profesional.

Un concepto de gran utilidad a la hora de analizar las interrelaciones entre el conflicto y el consenso es el de ideología: los valores y las creencias que ayudan a asegurar la posición de grupos más poderosos a expensas de los más débiles. Poder, ideología y conflicto están siempre íntimamente ligados. Muchos de los conflictos que surgen son acerca del poder, debido a las gratificaciones que brinda. Los que disponen de mayor poder pueden depender básicamente de la influencia de la ideología para mantener su dominación, pero, por lo general, pueden además emplear la fuerza si se considera necesario (Giddens, 1994: 759).

\section{Códigos deontológicos e ideología en trabajo social}

Para estudiar de manera interna la visión ideológica del profesionalismo de los trabajadores sociales, utilizamos sus códigos deontológicos. Éstos, como nos indica Grazziosi (1978: 31), reflejan las conductas deseables de los trabajadores sociales como profesionales 0 , por decirlo con palabras de Salcedo (2003: 321), expresan el compromiso del bien público que representa la actividad profesional y, al mismo tiempo, legitima a la profesión ante la opinión pública, al quedar regulada la actividad profesional de los trabajadores sociales, cumpliendo de este modo con las garantías institucionales. Por ello, tal como nos indica Bermejo en su obra Ética del trabajo social (2002: 155), un código deontológico representa un modo en que aparece definido en la profesión lo que es ético y lo que no lo es:

Quieren expresar la pretensión de un colectivo de prestar un servicio competente y cualificado que les otorgue credibilidad y prestigio ante los usuarios y el conjunto social, para lo cual hacen públicos los criterios de calidad y las normas por las que se rigen.

El primer código deontológico de trabajo social tiene su origen en 1950, en Francia, dos años después de la Declaración Universal de los Derechos
Humanos (1948). Veintiséis años después, la Asamblea de la Federación Internacional de Trabajo Social (FITS) aprueba en Puerto Rico el Código de Ética en Trabajo Social Internacional, que es ratificado por Europa en 1985. En 1994, en Oslo, se actualiza bajo el título de The Ethics of Social Work: Principles and Standards. La Asamblea General de la FITS, celebrada en Ginebra en julio de 2002, acuerda reemplazar este último documento para adaptarlo a la nueva definición de trabajo social, aprobada por la FITS en julio de 2000. La propuesta encargada a la comisión es considerada en la asamblea celebrada en septiembre de 2004, después de un proceso de dos años de consultas, debates y escuchas a diversos organismos de la FITS. La referencia para la reflexión parte de un concepto común de trabajo social, adoptado en la asamblea general de Montreal (Canadá), en julio de 2002. Ya entonces, se pone el énfasis en los principios que constituyen las dimensiones de la ética en trabajo social: los derechos humanos, la justicia social y la conducta profesional. Estas dimensiones se mantienen como referencias en el nuevo documento de 2004 .

En España, el primer código de ética publicado es el elaborado en 1989 por el Colegio Oficial de Diplomados en Trabajo Social y Asistentes Sociales de Cataluña. En 1999, la asamblea general de Colegios Oficiales de Diplomados en Trabajo Social y Asistentes Sociales aprobó el Código Deontológico de la Profesión de Diplomados en Trabajo Social.

\section{Análisis de diferentes códigos deontológicos de la profesión de trabajo social}

En este trabajo, analizaremos el Código Internacional de Trabajadores Sociales $(1996,2004)$ y algunos otros de ámbito estatal que son especialmente interesantes para el asunto que nos ocupa: el Código Deontológico de la Profesión de Diplomado en Trabajo Social de España, elaborado por el Consejo General de Colegios Oficiales de Diplomados en Trabajo Social y Asistentes Sociales (1999); el Código de Ética de los Asistentes Sociales del Colegio Oficial de Diplomados en Trabajo Social y Asistentes Sociales de Cataluña (1989); el Código de Ética para el Trabajo Social de la Asociación Británica de Trabajo Social (1996); el Código de Deontología de la Asociación Nacional de Asistentes Sociales de Francia (1994); y el Código de Ética de la Asociación Nacional de Trabajadores Estadounidense (1996).

Algunos de los objetivos que pretenden alcanzar estos códigos aparecen sintéticamente recogidos en el código estadounidense (National Association of Social Workers, 1999: finalidad):

- Identificar el núcleo de valores en los que se basa la finalidad del trabajo social.

- Resumir los principios éticos generales que refleja el núcleo de valores profesionales y establecer un 
conjunto de normas éticas que deberían ser utilizadas como guías de la práctica del trabajo social.

- Ayudar a los trabajadores sociales a identificar las consideraciones relevantes cuando hay obligaciones profesionales en conflicto, o surgen incertidumbres éticas.

- Proporcionar normas éticas para que el público en general pueda exigir responsabilidades a la profesión de trabajo social.

- Iniciar a los nuevos profesionales en la finalidad, los valores, los principios y las normas éticas del trabajo social.

- Articular las normas éticas que el trabajo social puede utilizar para valorar si los trabajadores sociales están comprometidos con conductas no éticas.

En la mayor parte de estos países, ha habido una reflexión constante, en el seno de sus organizaciones y a lo largo de los años, respecto a la dimensión ética de esta práctica profesional y al modo más adecuado de responder a los retos de unas sociedades en continua transformación moral y social. El código de la Federación Internacional de Trabajo Social lo declara expresamente en su prólogo, al referirse a que el objetivo, en materia de ética, de la Asociación Internacional de Escuelas de Trabajo Social (AIETS) y de la propia FITS es promover una reflexión y un debate en las organizaciones miembros, entre los trabajadores sociales de los países miembros, así como en las escuelas de trabajo social y entre los estudiantes de Trabajo Social ${ }^{1}$ (International Federation of Social Workers, 2004: antecedentes).

Estos códigos reflexionan sobre el fin de esta actividad profesional, sobre el servicio específico que se propone prestar. Todos ellos suelen coincidir en señalar el bienestar social como el objetivo prioritario de esta profesión, si bien cada uno lo expresa con distintos matices. El código francés, por ejemplo, habla de participar en el desarrollo social, de prevenir las dificultades sociales y de mejorar la calidad de $v^{\text {vida }}{ }^{2}$. El código inglés se refiere al intento de aliviar y prevenir las adversidades y sufrimientos ${ }^{3}$. El catalán pone el acento en la búsqueda de los medios más

1 También la Asociación Nacional de los Asistentes Sociales franceses se refiere a este tema en los siguientes términos: "La Asociación Nacional de Asistentes Sociales, en tanto que asociación profesional, lleva a cabo desde su creación, en 1945, una reflexión constante sobre la deontología, concretada en la edición de dos códigos: en 1949 y en 1981" (Association Nationale des Assistants de Service Social, 1994: preámbulo).

2 Según este código, "el asistente social está al servicio de la persona humana en la sociedad y, con su intervención, aspira al florecimiento y la autonomía de personas, grupos y comunidades; al desarrollo de las potencialidades de cada uno para que se haga actor de su propio cambio y a la adaptación recíproca de los individuos y la sociedad en evolución" (Association Nationale des Assistants de Service Social, 1994: preámbulo).

3 "Los trabajadores sociales tienen la responsabilidad de ayudar a los individuos, las familias, los grupos y las comunidades mediante la prestación y realización de servicios apropiados, y contribuyendo a la planificación y la acción social" (British Association of Social Workers,1996: artículo 7). adecuados para solucionar los problemas que afectan a la organización de la vida social ${ }^{4}$. El internacional afirma que el trabajo social promueve el cambio social, la resolución de problemas en las relaciones humanas, y el fortalecimiento y la liberación de la persona para incrementar el bienestar ${ }^{5}$. Pero es tal vez el código estadounidense el que se refiere a la finalidad del trabajo social de una forma más precisa, aludiendo a que el cometido principal de esta profesión es mejorar el bienestar humano y contribuir a satisfacer las necesidades humanas básicas de todas las personas, con especial atención a las necesidades y la emancipación de las personas vulnerables, oprimidas o que viven en la pobreza (National Association of Social Workers, 1997: preámbulo).

Otro de los objetivos de los códigos es presentar los valores, principios y normas fundamentales que sirven para guiar la conducta de los profesionales. Se trata de un conjunto de disposiciones para favorecer su independencia, credibilidad, honestidad e intervención respetuosa, correcta y adecuada a las características y necesidades de los usuarios, que les permita utilizar los servicios con las debidas garantías. Tales garantías permiten, además, que los profesionales cuenten con un marco legal delimitado para apoyar su actuación profesional, frente a posibles injerencias o alteraciones en su labor (Consejo General de Colegios Oficiales de Diplomados en Trabajo Social y Asistentes Sociales, 1999: preámbulo).

Asimismo los diferentes códigos señalan algunas de las áreas problemáticas que pueden aparecer en el ejercicio profesional y algunos de los posibles métodos de decisión para tratar de afrontarlas. El código no pretende ofrecer reglas claras para cada una de las situaciones que se le puedan presentar a cada trabajador social. En último término, éste, a la luz de los valores, los principios y las normas, y teniendo en cuenta el contexto en el que se desarrolla su labor, habrá de dar la respuesta que considere más adecuada dadas las circunstancias. En general, los códigos ni siquiera especifican la jerarquía que ha de establecerse entre los distintos criterios normativos existentes. Por tanto, será el profesional (o el grupo de profesionales) responsable quien habrá de decidir cuál es la mejor forma de actuar, apoyado, únicamente tal vez, en sus cualidades personales y en algún procedimiento de resolución de casos. Francisco J. Bermejo (2002: 163-174) señala que,

${ }^{4}$ Según este código, algunas de las funciones del trabajo social son "ayudar a las personas a desarrollar sus capacidades de manera que les permitan resolver los problemas sociales, individuales y colectivos; promover la facultad de libre elección, de adaptación y desarrollo de las personas; abogar por la adopción de políticas sociales justas y por el establecimiento de servicios o alternativas a los recursos socioeconómicos existentes" (Col-legi Oficial de Diplomats en Treball Social i Assistents Socials de Catalunya, 1988: introducción).

5 "El trabajo social promueve el cambio social, la resolución de problemas en las relaciones humanas y el fortalecimiento y la liberación de las personas para incrementar el bienestar. Mediante la utilización de teorías sobre comportamiento humano y los sistemas sociales, el trabajo social interviene en los puntos en los que las personas interactúan con su entorno. Los principios de derechos humanos y justicia social son fundamentales para el trabajo social" (International Federation of Social Workers, 2004: artículo 2). 
aunque la dimensión deontológica ${ }^{6}$ suele estar dividida en dos partes fundamentales -los principios inspiradores de la profesión y las normas que traducen tales principios en la práctica concreta-, algunos códigos insisten previamente en la importancia que tiene para esta profesión inspirarse en un conjunto de valores que sirvan de marco de referencia ético para la conducta de los profesionales.

\section{El código de la National Association of Social Wor-}

kers, por ejemplo, deriva directamente sus principios y normas de conducta de un conjunto de valores que explicita claramente. En concreto, del valor 'servicio' se deriva el principio que enuncia que "el objetivo principal de los trabajadores sociales es ayudar a las personas que están en situaciones de necesidad, y atender a los problemas sociales"; del valor "justicia social', se deriva el principio de que "los trabajadores sociales están en contra de las injusticias sociales"; del valor 'dignidad y valor de la persona', se deriva el principio de que "los trabajadores sociales respetan la dignidad y el valor intrínseco de la persona"; del valor 'importancia de la relaciones humanas', se deriva el principio de que "los trabajadores sociales reconocen la importancia esencial de las relaciones humanas"; del valor 'integridad', se deriva el principio de que "los trabajadores sociales se comportan de una manera que asegura la confianza"; del valor 'competencia', se deriva el principio de que "los trabajadores sociales ejercen dentro de sus áreas de competencia, y desarrollan y mejoran su pericia profesional”(1999: principios éticos).

El término 'valores' aparece en varias ocasiones en el código internacional y es también muy importante en el catalán, el cual señala cómo todas las profesiones tienen una manera de actuar que las diferencia de

${ }^{6}$ Francisco J. Bermejo (2002: 16-18) considera que la ética profesional incluye tres dimensiones inseparables que la constituyen como tal: la dimensión teleológica, la dimensión deontológica y la dimensión pragmática. La dimensión teleológica lleva a preguntarse por el fin de la actividad de la profesión. Son muchas las formulaciones que se han hecho sobre los principios que fundamentan y orientan el trabajo social. Todos ellas tratan de reflejar la concepción fundamental sobre lo que es el mundo, el hombre, la vida. Constituyen estos principios los presupuestos, las razones últimas, los motivos más profundos que orientan y dan sentido a lo que se hace. Podemos decir que tales fundamentaciones giran en torno al valor de la dignidad de la persona humana, el valor de la libertad, de la individualidad y del respeto, el derecho a la participación, la libre autodeterminación, la autorrealización y a la integridad. Así se recoge en el documento de la Asamblea General de la Federación Internacional de Trabajadores Sociales, celebrada en Colombo en 1994. La dimensión deontológica entra de lleno en el terreno de los deberes. Los trabajadores sociales, desde los valores de emancipación humana, libertad, justicia social, solidaridad y participación, en función de su autonomía como profesionales, orientan su práctica profesional de acuerdo a unas normas que se convierten en deberes profesionales. Ello da lugar a los principios operativos básicos que podemos resumir en los siguientes: defensa de los derechos humanos, apoyo a la integración y al acceso a los bienes materiales y culturales, promoción de la responsabilidad social y la participación, respeto a la autodeterminación, ejercicio profesional competente, respeto a las diferencias y garantía de pluralismo, y fiscalización del ejercicio profesional. La dimensión pragmática se ocupa de analizar la eticidad de las actuaciones concretas, sobre todo cuando existen conflictos de perspectivas o intereses entre los usuarios, los profesionales o la propia entidad desde la que se interviene. En esta dimensión hay que ubicar las actuaciones de los comités de ética. otras actividades semejantes, entre otras cosas, por un conjunto de valores que la profesión transmite como propios y que la hace evolucionar en sintonía con los valores socioculturales del momento presente de una sociedad determinada (Col-legi Oficial de Diplomats en Treball Social i Assistents Socials de Catalunya, 1988: introducción). Otros códigos, como el británico, los considera implícitos en su práctica, y señalan, como uno de sus propios objetivos, hacer explícitos tales valores (British Association of Social Workers, 1996: nํㅜ 1).

Los principios del trabajo social nacieron con los precursores de la disciplina, especialmente con el filósofo humanista español Juan Luis Vives (s. XVI). Hoy aparecen formulados de modo diferente ${ }^{7}$. Vamos a señalar algunos de los principios explícitamente enumerados por los códigos que estamos viendo, dividiéndolos temáticamente:

- Respecto a los clientes: todos coinciden en señalar la trascendencia del respeto al valor y la dignidad de las personas, sin tener en cuenta su género, cultura, religión, lengua, ideas políticas, clase social, inclinación sexual, edad, capacidad, color o raza ${ }^{8}$. Ésta sería, de algún modo, la base sobre la que se apoya el resto de los principios, como el derecho a la autorrealización, y el respeto a la autodeterminación y la participación de los usuarios en la resolución de sus propios problemas, una vez informados de las ventajas e inconvenientes de las posibles líneas de actuación y teniendo siempre en cuenta los derechos de las demás personas involucradas. En este sentido, algunos señalan que los trabajadores sociales han de evitar, en lo posible, cualquier decisión de carácter impositivo sobre sus clientes. Por el contrario, esperan, generalmente, que éstos se hagan en cierto modo corresponsables de la intervención profesional, en la medida en que pueda afectar a su vida. Los procedimientos coercitivos constituyen un último recurso del que sólo se hará uso después de una cuidadosa evaluación de los argumentos de las partes en conflicto (Consejo General de Colegios Oficiales de Diplomados en Trabajo Social y Asistentes Sociales, 1999: artículo 13).

- Desde el punto de vista del trabajador social, todos señalan la relevancia del secreto profesional y del respeto a la intimidad, de velar por el mantenimiento e incremento de la competencia, la eficacia, la responsabilidad y la independencia profesional, y de asegurar que no primen sus intereses personales. Su obligación principal es poner sus conocimientos teóricos y sus habilidades técnicas al servicio de los usuarios y de la sociedad en general.

7 Son muchos los autores que presentan diversas tablas de principios orientadores de la práctica de trabajo social (Moix, 1991: 275 y ss.; Zamanillo y Gaitán, 1991: 60-65; Kisnerman, 1970: 75-90; Grazziosi, 1978: 55-61).

${ }^{8}$ Tal vez sea el código francés el más contundente en este sentido, al referirse a que el respeto a la dignidad de las personas es lo que fundamenta la intervención profesional en todas las circunstancias (Association Nationale des Assistants de Service Social, 1994: artículo 1). 
- Desde el punto de vista de la sociedad, señalan la importancia de trabajar para mejorar el bienestar social, para implantar la justicia, para denunciar y erradicar, en lo posible, las discriminaciones basadas en diversos motivos (raza, creencias, edad, sexo, género, incapacidad mental o física, entre otras), para que se respeten los derechos humanos universales, sin negar, por ello, las legítimas diferencias existentes en las costumbres de individuos y comunidades.

Una de las declaraciones más antiguas y conocidas, en relación con los servicios sociales, es la de la ONU de 1958. La proponemos como un ejemplo del tipo de principios que aún hoy inspiran la práctica del trabajo social:

Reconocer el valor del ser humano como individuo, cualquiera que sean sus circunstancias, condición, raza, religión, opinión pública o conducta, y hacer lo posible por fomentar en el individuo un sentimiento de dignidad y respeto propio; respetar las diferencias entre los individuos, grupos y comunidades, tratando al mismo tiempo de conciliarlas con el bienestar común; fomentar el propio esfuerzo como medio de desarrollar en el individuo el sentimiento de confianza en sí mismo y su capacidad para afrontar responsabilidades; promover oportunidades para una vida más satisfactoria en las circunstancias particulares en que se encuentran los individuos, los grupos o las comunidades; aceptar el deber profesional de trabajar en pro de la aplicación de medidas sociales compatibles con los principios y los conocimientos del Servicio Social, acerca de los anhelos y las necesidades humanas, con objeto de brindar a toda persona la posibilidad de hacer el mejor uso posible de su medio y de sus propias aptitudes; respetar la índole confidencial de la relación profesional; utilizar esta relación para ayudar a sus clientes (individuos, grupos o comunidades) a alcanzar un grado mayor de libertad y de confianza en sí mismos, y no tratar de manejarlos para que se adapten a un sistema preconcebido; hacer un uso responsable de la relación profesional con miras a promover, lo más objetivamente posible, el mayor bien para el individuo y los mejores intereses de la sociedad (Kisnerman, 1970: 7$)^{9}$.

9 Otro ejemplo de tabla de principios más reciente es el elaborado por la Federación Internacional de Trabajadores Sociales en 1976:

a) todo ser humano posee un valor único, con independencia de su origen, edad, creencias, etnia, condición socioeconómica, o de su contribución a la sociedad; b) todo individuo tiene el derecho a realizar su potencial, siempre que no perjudique los derechos de los demás; c) toda sociedad, cualquiera que sea, debe funcionar con miras a proporcionar el máximo de beneficio a la totalidad de sus miembros; d) el trabajador social profesional tiene la responsabilidad de encauzar sus conocimientos y capacidades hacia la ayuda de individuos, grupos, comunidades y sociedades, en el desarrollo de sus posibilidades y la resolución de conflictos humano sociales y sus consecuencias; e) y el trabajador social profesional tiene como obligación suprema el servicio a los demás, lo cual debe primar sobre cualquier otro interés o ideología particular (International Federation of Social Workers, 1976).
Junto a tales principios, habría tal vez que señalar algunos otros aspectos que aparecen en los códigos consultados, como la aceptación del otro, la contribución al bien común o la opción preferencial por los más necesitados. En cualquier caso, los criterios anteriormente señalados presentan un cuadro bastante completo de lo que serían los principios básicos de la ética del trabajo social, y servirán de orientación para formular pautas normativas más concretas.

\section{Conclusión}

El profesionalismo de los trabajadores sociales refleja la visión ideal de la profesión que afecta de diversas formas a la organización de la vida y la práctica diaria. Las múltiples visiones forman el comportamiento de los trabajadores sociales, que se refleja en las distintas áreas de la práctica profesional. La institución profesional colectiva actúa como primera fuente de ideología, contribuyendo a la percepción de la característica unitaria de los ideales profesionales.

El ideal de la profesión es un ideal de servicio, que constituye un sistema de valores que es consecuencia de su pacto social con la sociedad, y que se configura en:

- El respeto y la promoción de la autonomía de las personas, los grupos y las comunidades, con especial atención y sensibilidad a sus diferencias sociales por razón de raza, etnia, origen nacional, color, sexo, orientación sexual, edad, estado civil, creencias políticas, religión o minusvalías psíquicas y físicas.

- El deber de promover la igualdad en la propia relación profesional y en las relaciones entre los clientes y las instituciones o la sociedad.

- El deber de defender a los clientes de la injusticia social y de aplicar con equidad las normas de distribución de los beneficios de la cooperación social, así como de emprender acciones que las transformen hacia formas más justas.

En la posición de los trabajadores sociales, confluyen elementos valorativos -como la mayor satisfacción, la mayor importancia, y el mayor prestigio asociado al servicio (ayuda a los demás, trabajo interesante)-, así como otros elementos asociados -la innovación que mejora la intervención, la dedicación que asegura esa intervención y la ética que asegura la corrección en la intervención-. La ética es fundamental como mecanismo de control del trabajo, que asegura la buena práctica. 
ASSOCIATION NATIONALE DES ASSISTANTS DE SERVICE SOCIAL (1994): Code de Déontologie [rhttp:// anas.travail-social.com/code.htm〉].

BERMEJO, F. J. (2002): Ética de las profesiones. Bilbao, Desclée de Brouwer.

BRITISH ASSOCIATION O F SOCIAL WORKERS (2002): The Code of Ethics for Social Work [shttp://www. celticknot.org.uk/links/baswcode.html/].

COL.LEGI OFICIAL DE DIPLOMATS EN TREBALL SOCIAL I ASSISTENTS SOCIALS DE CATALUNYA (1989): Codi d'ètica dels assistents socials, Barcelona, Col-legi Oficial De Diplomats en Treball Social I Assistents Socials De Catalunya.

CONSEJO GENERAL DE COLEGIOS OFICIALES DE DIPLOMADOS EN TRABAJO SOCIAL Y ASISTENTES SOCIALES (1999): Código deontológico de la profesión de diplomado en Trabajo Social [rhttp://dtsss. ua.es/es/documentos/practicas-externas/ codigo-deontologico-de-la-profesion-dediplomados-en-trabajo-social.pdfs].

GIDDENS, A. (1994): Sociología, Madrid, Alianza.

GÓMEZ, R. (2008): La profesionalización de los trabajadores sociales en Castilla y León, Madrid, Universidad Pontificia de Salamanca. Tesis doctoral inédita.

GRAZZIOSI, L. (1978): Códigos de ética del servicio social, Buenos Aires, Humanitas.

INTERNATIONAL FEDERATION OF SOCIAL WORKERS (1994): The Ethics of Social Work. Principles and Standards [versión en español: 〈http:// www.ifsw.org/p38000454.html〉].

INTERNATIONAL FEDERATION OF SOCIAL WORKERS; e INTERNATIONAL ASSOCIATION OF SCHOOLS OF SOCIAL WORK (2004): Ethics in Social Work, Statement of Principles, Berna, International Federation of Social Workers; International Association of Schools of Social Work [versión en español: 〈http://www.ifsw.org/p38000400. htmls].

KISNERMAN, N. (1970): Ética para el Servicio Social, Buenos Aires, Humanitas.

MOIX, M. (1991): Introducción al trabajo social, Madrid, Trivium.

NATIONAL ASSOCIATION OF SOCIAL WORKERS (1999): Code of Ethics, Washington DC, National Association of Social Workers [versión en español: 〈http:// www.naswdc.org/pubs/code/code.asp?c=sp〉].

RODRÍGUEZ, N. (2008): Manual de sociología de las profesiones, Barcelona, Edicions Universitat de Barcelona.

SALCEDO, D. (2003): "La ética del trabajo social en la época postmoderna”, en FERNÁNDEZ GARCíA, T.; y ALEMÁN, C. (coords.): Introducción al trabajo social, Madrid, Alianza Editorial, págs. 313-339.

ZAMANILLO, Mํㅡ. T.; y GAITÁN, L. (1991): Para comprender el trabajo social, Estella, Verbo Divino. 


\section{Dinámicas relacionales entre servicios sociales comunitarios y entidades sociales. Un estudio de caso}

\section{Germán Jaraíz Arroyo}

Universidad Pablo de Olavide

<gjararr@upo.es>

\author{
Auxiliadora González Portillo \\ Universidad Pablo de Olavide

\section{Guadalupe Cordero Martín} \\ Universidad Pablo de Olavide
}

Artikulu honetan, harremanen dinamismoaren zernolakoak ezagutzeko, aztergai hartzen da hiri handi bateko auzune zaurgarri batean esku-hartzeen gunea partekatutako Komunitateko Gizarte Zerbitzuen Zentro baten eta auzo bereko gizarte-erakundeen arteko lotura. Gaiaren inguruko ezagutza hedatzeko asmo berariazkoarekin, honako hauek aztertzen dira: a) ezagutu nahi dira gizarte-erakunde horien bidez jasotako estrategiak auzuneko gizarte-mailako eskuhartze programa nagusietan; b) deskribatu nahi dira GKE, administrazioa eta hiritarrek osatutako erakundeen arteko harreman praktikoak; c) ebaluatu nahi dira bai erakunde horien guztien arteko eskuhartze moduen bidez lortutako eraginak bai berauen hobetzerako aukerak.

\section{HITZ-GAKOAK:}

Komunitateko Gizarte Zerbitzuak, auzune zaurgarriak, gizarte esku-hartzeak, hirugarren sektorea, gizarte-erakundeak.
Este artículo trata sobre las dinámicas relacionales establecidas entre un centro de servicios sociales comunitarios ubicado en un barrio vulnerable de una gran ciudad, y el tejido de entidades sociales con las que comparte espacio interventor. Se pretende de modo expreso: a) identificar las diversas estrategias de incorporación de las entidades sociales a los principales programas de intervención social en el barrio; b) describir las prácticas relaciones que ONG, administraciones y organizaciones ciudadanas llevan a cabo; y c) valorar los efectos generados por estas dinámicas de intervención mixta, así como su posible mejora.

\section{PALABRAS ClaVe:}

servicios sociales comunitarios, barrios vulnerables, intervención social, tercer sector, entidades sociales. 


\section{Objeto de estudio y metodología}

Este trabajo se preocupa por las relaciones entre servicios sociales comunitarios y entidades del tercer sector en sentido amplio. De modo concreto, se detiene en la descripción densa (Geertz, 1973) de estas relaciones en un tipo específico de espacio interventor: el barrio vulnerable.

El comentado aporte descriptivo surge como resultado parcial de dos investigaciones llevadas a cabo por el Grupo de Investigación Social y Acción Participativa (GISAP) entre 2006 y $2011^{1}$. Ambas tienen un hilo argumental y un diseño metodológico común; son aproximaciones cualitativas, de lógica participada, en las que investigadores e interventores han compartido un espacio de reflexión y discusión centrado en el estudio de dos aspectos concretos: las formas interventoras y las percepciones sobre éstas. Los dos trabajos pretenden, por tanto, investigar las prácticas incorporando a sus protagonistas al proceso investigador y, al mismo tiempo, devolver la observación en clave de reformulación y mejora de la acción. Dicho proceso ha consistido en:

1. Observar prácticas y recoger discursos sobre ellas (de diferentes actores).

2. Codificar y sistematizar la información mediante procedimientos explícitos y reconocidos.

3. Analizarla, con el debido contraste teórico, en el equipo de investigación.

4. Devolver el conocimiento a los protagonistas, para discutir y reformular participadamente el análisis.

5. Identificar criterios y vías de aplicación.

La primera de las investigaciones se centró en las prácticas y percepciones de los profesionales de servicios sociales comunitarios de cuatro barrios clasificados como zonas con necesidades de transformación social (ZNTS) ${ }^{2}$. El segundo trabajo, surgido en conexión con el anterior, se detuvo en el estudio de uno de estos centros de servicios sociales, atendiendo a las prácticas y los discursos del conjunto de actores que inciden en su red de relaciones (profesionales del centro y de entidades sociales, beneficiarios, vecinos, voluntarios).

\section{Espacio y configuración de la morfología interventora}

En este apartado, describimos el conjunto de acontecimientos que han conformado la actual morfología del tejido interventor, como cuestión previa para explicar posteriormente las relaciones entre los servicios sociales comunitarios y las entidades sociales. Conviene, sin embargo, detallar antes algunas características del espacio interventor.

\subsection{Algunas pinceladas sobre el espacio interventor}

El barrio objeto de estudio está ubicado en la periferia de una gran ciudad andaluza. Se ajusta a los perfiles de lo que Alguacil et al. (1997) denominan un barrio-ciudad, al disponer de una determinada densidad poblacional (en torno a 21.000 habitantes), una alta uniformidad social, un conjunto de equipamientos básicos de referencia, y una red de organizaciones y entidades que concentran su intervención específica sobre ese espacio.

En este lugar los problemas existen desde hace tiempo; algunos están aquí desde su origen. Fue uno de esos barrios construidos con el primer desarrollismo franquista. A finales de la década de 1950, las administraciones del momento tienen un problema importante: la creciente obrerización de la ciudad. Este hecho requerirá de actuaciones urbanísticas masivas ajustadas al criterio de 'mucha población en poco espacio' (Cáritas, 2007) 3 , con el que se construyen las diferentes barriadas que conforman este barrio desde inicios de los sesenta a finales de los ochenta (Torres Gutiérrez, 2011).

En sus orígenes, éste es un lugar de 'gente pobre, pero honrada'. Sin embargo los cambios urbanísticos de finales de los setenta van a intensificar la situación de vulnerabilidad, como consecuencia del proceso de vaciado y rellenado de la población, que queda expresado de modo nítido en el siguiente testimonio:

En los años setenta, empezaron a construirse barrios mejores, más modernos que éste. Pero se los daban a gente que estaba peor que nosotros y no podían pagar la vivienda. Entonces los vecinos de aquí hicieron cambalaches. Se fue la mejor gente y vino gente con problemas. Antes aquí todos sabíamos quién era el padre y la madre; la gente que venía estaba más desestructurada (Vecina).

Este hecho activa una lenta pero imparable dinámica en la que la honra de la conciencia obrera entra en conflicto con la nueva marginalidad. En la década de los ochenta, el barrio vive un segundo proceso de de la intervención de los servicios sociales comunitarios en entornos vulnerables. No han sido diseñadas para un análisis exclusivo del tercer sector, aunque sí se ha contemplado este aspecto como uno de los aspectos particulares de estudio.

${ }^{2}$ La zona con necesidades de transformación social es una figura administrativa activada en el ámbito andaluz al amparo del Decreto $202 / 89$, de 3 de octubre. Hace referencia a barrios con elevados indicadores de exclusión social.
3 Para comprender el proceso urbanístico que origina este barrio, por Cáritas Diocesana de Sevilla, con la colaboración de la Plataforma Vecinal. es recomendable la consulta del diagnóstico participativo elaborado 
degradación que guarda no pocos paralelismos con otras zonas urbanas. A principios de esa década, el paro se intensifica y cronifica, al tiempo que emergen con fuerza las problemáticas de la droga y el sida. Tales sucesos asientan de forma definitiva el estigma de marginalidad, que, unido a la ausencia de un proyecto serio de reactivación social, traerá consigo el refuerzo del uso del barrio como lugar para el acceso barato y sin condiciones a la vivienda, para la economía ‘sumergida' y para la 'desviada'. Éstas son algunas de las principales funciones que han sido asignadas a este espacio en las dos últimas décadas: una historia conocida en otras ciudades del Estado.

\subsection{Configuración del entramado interventor}

La formación del tejido de entidades dedicadas a la intervención social ha seguido un inevitable paralelismo con la historia del barrio. Pueden identificarse cuatro 'movimientos' que han conformado la actual morfología interventora.

\subsubsection{Primer 'movimiento': de la vecindad a las primeras formas de intervención organizada}

En sus inicios, el rasgo más definitorio de las formas de acción se encuentra en el componente vecinal desde el que se van a articular las primeras iniciativas de intervención, a partir de la década de 1960. Los efectos provocados en 1961 por el desbordamiento del arroyo que separaba al barrio de la ciudad (hoy avenida) ejercen de desencadenante de estas primeras actuaciones institucionalizadas para la atención social a los damnificados. Las parroquias, atendidas con la participación de vecinos (hoy serían voluntarios/as sociales), se convierten en un referente visible que promueve ayuda de carácter asistencial a las familias afectadas y a otras familias con necesidades (alimentos y ayuda económica). De aquí surgirán las diversas Cáritas parroquiales de la zona. En este tiempo, nace también la Asociación de Vecinos (1967), que tomará parte en diversas iniciativas de ayuda mutua (la creación de una cooperativa de consumo para los vecinos es la más relevante). También se fundará el colegio (concertado), primer equipamiento específicamente social. Este centro educativo, gestionado en sus inicios por el obispado, va a permitir también la incorporación de los primeros profesionales de lo social (el equipo de maestros y maestras). Son iniciativas distintas, dispersas, altamente espontáneas, pero que activan la intervención.

En los años siguientes, la transición política trae consigo el florecimiento de las asociaciones de vecinos y, con ello, el despliegue de una intervención de lógica más reivindicativa, que demanda nuevos servicios para el barrio. Durante las décadas de 1970 y 1980 , se producen diversos movimientos liderados por las asociaciones vecinales en demanda de mejoras en la atención sanitaria, apertura del comedor escolar, o de reconstrucción de viviendas y equipamientos.
Este dinamismo hace posible la puesta en marcha, en los ochenta, de la Coordinadora Cívica, una primera red vecinal en la que estará integrada la práctica totalidad de organizaciones sociales del barrio. Con ella, se pretende el encuentro de las entidades para aumentar las fuerzas a la hora de demandar los servicios públicos básicos. La dispersión e informalidad de los inicios se torna ahora en una estructura más organizada y en un primer intento de conexión en red de naturaleza estrictamente vecinal.

\subsubsection{Segundo 'movimiento': la aparición de los servicios públicos para el bienestar}

La evolución de la situación social, de la que no puede sustraerse la aportación reivindicativa hecha por el movimiento vecinal en torno a la necesidad de más equipamientos y servicios públicos, dará lugar a un segundo 'movimiento', caracterizado por la aparición de la intervención pública. Este despliegue se va a realizar, sobre todo, desde finales de la década de 1980 y a largo de la de $1990^{4}$. En esta etapa, se instalan en el barrio la mayoría de recursos sociales públicos: se construye el centro de salud, los tres nuevos centros educativos (ahora públicos) y el centro de servicios sociales. Aparecen también algunas ofertas formativas específicas, como la escuela-taller. Ocurrirá aquí, como en otros barrios periféricos, que paralelamente a la expansión de lo público, se produce un debilitamiento de lo cívico-vecinal: el dinamismo de las asociaciones que lideraron la demanda de servicios se reduce; algunos de sus dirigentes promocionan políticamente, otros se irán a vivir a otras zonas.

\subsubsection{Tercer 'movimiento': la 'tercersectorización' del tejido vecinal}

El tercer momento de expansión del entramado interventor se caracteriza por la aparición de un nuevo y peculiar tejido asociativo que, en cierto modo, reactiva desde otras claves las energías cívicas que antes tuvo el movimiento vecinal 'clásico'. Aparece aquí un grupo de organizaciones del barrio en las que se da una presencia simultánea de voluntarios y profesionales, pero que, en lugar de tener un enfoque generalista (como las entidades vecinales clásicas), se centran en la intervención social ante problemas concretos. Especialización y profesionalización conviven así con participación vecinal y voluntariado. Buena parte de los cuadros de estas entidades (dirigentes, voluntarios y profesionales) han participado o participan aún del movimiento vecinal primero.

Será después de diferentes movilizaciones vecinales en demanda de una respuesta al acuciante problema de la droga cuando surja, en 1990, la primera de estas organizaciones: la Asociación de Lucha Contra

${ }^{4} \mathrm{Si}$ bien es cierto que existe una percepción vecinal colectiva de que la presencia de lo público siempre fue aquí muy débil. Esta percepción aparece en la mayoría de discursos de gentes del barrio. 
la Droga. Nace como entidad voluntaria, promovida por un grupo de vecinos del barrio sensibilizados por la problemática, pero poco después incorporará a trabajadores sociales, psicólogos y educadores, profesionales 5 que son contratados gracias, sobre todo, al acceso a subvenciones públicas.

Un proceso similar vive el centro juvenil. Se había fundado por iniciativa de una de las parroquias, pero en 1990 se refunda como asociación civil, con el objetivo de generar servicios de apoyo escolar y educación en el tiempo libre a los niños y niñas del barrio. Está formado, en un primer momento, por voluntarios que viven en el barrio, pero más tarde la asociación se irá implicando en diversos programas públicos para acabar 'liberando' (contratando) a alguno de sus integrantes, que cambian el rol de voluntarios por el de trabajadores remunerados con cargo a subvenciones. Más tarde, la creciente implantación de nuevas iniciativas por parte de esta entidad ha obligado a contratar a nuevos profesionales y a gente de fuera del barrio.

También las tres Cáritas parroquiales de la zona, entidades formadas por voluntarios que viven en el barrio, van a promover, a partir de la década de 1990, diferentes iniciativas de captación y formación. Esta renovación afectará a sus modos organizativos: pasan a estructurarse por proyectos y a contar con el apoyo de una trabajadora social, contratada para realizar labores de acompañamiento.

\subsubsection{Cuarto 'movimiento': la instalación de entidades sociales especializadas y externas al barrio}

La proliferación de cauces de financiación va a permitir también la 'instalación en el barrio’ de nuevas entidades del tercer sector, más próximas al terreno de la economía social que al del voluntariado vecinal; entidades que, sin ser del barrio, acuden para intervenir en él. Son frecuentemente organizaciones dedicadas a problemáticas concretas (menores, minorías étnicas) que generalmente vinculan su acción a subvenciones del sector público. Aparece así en la 'fauna' interventora un tercer tipo de agentes, distinto a las entidades vecinales ‘clásicas' y a las entidades 'regeneradas' (con carácter vecinal, especializado e integradas por voluntarios y profesionales): son entidades de carácter especializado, más profesionalizadas y no necesariamente vinculadas al tejido vecinal. A menudo, estas entidades acuden por la llamada de los propios servicios públicos. Son los servicios sociales, sanitarios o educativos quienes invitan a estas entidades a desplegar su intervención en el barrio, al prestar éstas servicios que complementan en un alto grado actuaciones llevadas a cabo por actores públicos.

\subsection{Estrategias de despliegue y factores condicionantes}

La narración de este proceso de conjunto nos permite identificar tres estrategias de despliegue del tercer sector de acción social en este espacio (Jaraíz Arroyo, 2009), entendiendo a tal actor como el conjunto de entidades que, careciendo de ánimo de lucro, articulan servicios y programas de servicios sociales en sentido amplio (Cabra y De Lorenzo, 2005). En cada una estas estrategias persiste, como se verá después, una lógica particular de intervención social y de presencia en el territorio:

- La primera de las estrategias ha consistido en la renovación funcional de entidades del tejido vecinal. Una parte importante de las entidades sociales que participan en las redes de prestación de servicios en el barrio son organizaciones que se han reconvertido de la estricta acción vecinal a la gestión de programas y servicios sociales.

- La segunda estrategia de despliegue ha sido por generación. A ésta se acogen organizaciones sustentadas en las dinámicas internas del barrio, pero surgidas ya en un escenario de tercer sector en el sentido descrito, pensadas, por tanto, como entidades dedicadas desde su origen a la prestación de servicios. Son organizaciones que, sin perder el vínculo vecinal, han sido diseñadas en clave de intervención social.

- Por último, la tercera de las estrategias la hemos llamado aquí de instalación. Se refiere al conjunto de organizaciones externas, sin vinculación inicial con el tejido local, especializadas en la atención a problemáticas concretas (inmigración, drogodependencia, menores, mayores), generalmente ubicadas fuera del barrio y predominantemente profesionalizadas 6 .

Estas tres estrategias inciden en la formación del tejido del tercer sector local, configurando una percepción heterogénea de éste por parte de los diversos actores. Esta heterogeneidad se torna en algunos momentos en una visión diferenciadora entre entidades:

- De un lado, aparecen las entidades 'reconvertidas' o 'generadas', que reivindican el valor de la conexión cívica y vecinal, y se conciben, al mismo tiempo, como interventoras y portadoras legitimadas de los intereses del barrio (aunque no siempre son evidenciadas las vías que acreditan tal legitimidad).

- De otro, las entidades 'instaladas', más decantadas hacia la intervención (generalmente de naturaleza especializada). En torno a éstas, emergen en el barrio dos tipos de percepciones: unas entidades son vistas como 'paracaidistas', que acuden cuando hay recursos económicos; otras

\footnotetext{
${ }^{6}$ En otros trabajos hemos abordado esta descripción de estrate-
} gias con mayor detalle y profundidad (Jaraíz Arroyo, 2009: 110 y ss.) 
tienen, sin embargo, una imagen más 'asentada' $\mathrm{y}$, aunque venidas 'de fuera', han tendido lazos (colaboraciones con entidades del barrio; integración en las redes vecinales; ubicación de algún espacio físico, como una sede o algo similar; contratación de personal de la zona; incorporación de voluntariado autóctono). Todo ello ha contribuido a la mejora de su percepción por parte de los actores del barrio.

\section{Las dinámicas de colaboración entre servicios sociales comunitarios y entidades sociales}

\subsection{Inicio de los servicios sociales comunitarios: un proyecto imposible}

Nos preocupamos ahora por el papel de los servicios sociales comunitarios y, de modo especial, por su vinculación respecto a las entidades del tercer sector local. Aunque los servicios sociales comunitarios ya existían antes ${ }^{7}$, el centro de servicios sociales comunitarios comienza a operar de modo directo en este barrio en 1997. En ese tiempo, se organiza en torno a los cuatros contenidos básicos: el Servicio de Información y Valoración (SIVO), que canaliza y orienta el acceso de todo beneficiario al centro; el Servicio de Ayuda a Domicilio (SAD), encargado gestionar la atención domiciliaria a persona mayores y discapacitadas con dificultades de autonomía; el Servicio de Convivencia y Reinserción (CORE), centrado en la problemática que afecta a menores y familias en situación de riesgo social; y el Servicio de Cooperación Social (COSO), dedicado principalmente a las relaciones con las entidades y asociaciones que operan en el barrio.

En su organización primera, predomina la idea de generar un ente con un conjunto de prestaciones técnicas delimitadas y diferenciadas (servicios), que funcionarían con una cierta autonomía respecto al contexto comunitario local. Este patrón de intervención toma su asiento en la idea de que los servicios sociales, como ente de responsabilidad pública, son los encargados principales de promover, por sus propios medios y vías, el bienestar en la comunidad. Por ello, la relación con las entidades sociales presentes en el barrio no es, ni muchos menos, un aspecto central en la práctica, al considerarse éstas como meras colaboradoras subsidiarias. La sinergia con el resto de entidades interventoras, que podría haber sido entendida como un eje transversal en la articulación de su proyecto de intervención en este primer momento, queda relegada, en la práctica, a la categoría de función o cometido específico de uno de los servicios, el de Cooperación Social, que se conforma como el servicio comunitario de los comunitarios.

${ }^{7}$ En sus inicios, los servicios sociales comunitarios atienden a todos los barrios de la zona desde la junta de distrito. Posteriormente, se irán generando centros que atienden a varios barrios a un tiempo.
Sin embargo este esquema no va a sostenerse, entre otras cosas, porque la intensidad de las problemática social desbordará la capacidad de intervención autónoma de servicios sociales comunitarios Además, su incorporación al barrio será vista como una especie de alivio para otros recursos públicos ya instalados (colegios, centro de salud), que van a delegar sobre el nuevo dispositivo una parte importante de las problemáticas que aparecen en su entorno. Esta misma senda de derivaciones la van a seguir otras instituciones públicas (fiscalía de menores, hospitales, entidades de tutela). Todo ello va a provocar un inmediato desborde de la capacidad de acción autónoma de los servicios sociales comunitarios, que, nada más instalarse sobre el terreno, se ven abocados al rol de entidad solucionadora de 'rotos y descosidos'.

La evidente falta de condiciones de los servicios sociales comunitarios para afrontar en solitario los múltiples cometidos propios y delegados obliga a revisar la intención primera, y a reconsiderar la conveniencia de fortalecer la colaboración con las entidades sociales, hecho este que, como veremos ahora, va a ir tomando un peso creciente.

\subsection{Dinámicas de colaboración táctica}

Esta relación no surge de manera planificada. Es una reconexión más bien espontánea, guiada con frecuencia por el pragmatismo de algunos de sus profesionales. De hecho, no suele aparecer registrada en las evaluaciones escritas, ni en las memorias. Estas prácticas de colaboración entre el centro de servicios sociales comunitarios y las entidades sociales se orientan, al principio, en torno a problemas concretos que frecuentemente requieren una solución urgente:

Buscamos mucho la colaboración de las Cáritas parroquiales, nos coordinamos cuando estamos ayudando a una familia (económicamente sobre todo), incluso recurrimos a ellos para que adelanten dinero a la familia, ya que nosotros, por la burocracia interna, somos más lentos (Profesional de servicios sociales comunitarios).

Es a esto a lo que hemos denominado una 'colaboración táctica', ya que la relación entre servicios sociales comunitarios y entidades sociales se guía aquí más por una conveniencia puntual que por una convicción y una percepción compartida sobre la acción.

Las dinámicas de colaboración bilateral van a mejorar después con el surgimiento de algunas vías directas de financiación de los servicios sociales municipales a las entidades sociales. Aparece aquí el programa Ciudad Solidaria, una iniciativa gestionada desde el Servicio de Cooperación Social, que apoya económicamente a las entidades del tercer sector que colaboran en los distintos programas de 'los comunitarios'. Aunque la cuantía de las ayudas es reducida (en 2010, el montante total se elevó a 50.000 euros), van a permitir el tránsito de una colaboración espontánea 
a una relación más asentada, aunque no desaparece el enfoque táctico. En 2010, esa convocatoria sirvió para financiar catorce entidades ${ }^{8}$, que recibieron fondos para siete proyectos dirigidos a menores y adolescentes (apoyo escolar y psicosocial), personas mayores (actividades ocupacionales y ayuda domiciliaria) y voluntariado social. La mayoría de proyectos financiados incorporan al barrio un conjunto de actuaciones que complementan la atención de los servicios sociales comunitarios. Se financia, por ejemplo, el proyecto de apoyo escolar a menores, por el interés que tiene contar con tal recurso para derivar a familias atendidas por 'los comunitarios'.

Más allá de la limitada colaboración económica, esta iniciativa va a incorporar un valor añadido superior, ya que un sector importante de las entidades beneficiarias utilizan este aporte como un complemento financiero que, unido a subvenciones de otras administraciones ${ }^{9}$, permite poner en marcha programas de intervención más ambiciosos en el barrio. En otros casos, la aportación económica, aunque insuficiente, permite a algunas asociaciones disponer de una partida de cofinanciación con la que cumplir los requisitos básicos de acceso a convocatorias de ayuda mejor dotadas.

\subsection{Prácticas de colaboración dialógica}

La declaración del barrio como zona con necesidades de transformación social en 2003 incorpora un elemento renovador en las relaciones entre el centro de servicios sociales comunitarios y las entidades sociales. La clasificación como zonas con necesidades de transformación social (ZNTS) aporta tres cuestiones relevantes:

- Se mejora la dotación de profesionales del centro de servicios sociales comunitarios, cuestión que permitirá dedicar tres técnicos del equipo como apoyo para mejorar las relaciones de coordinación con las entidades sociales.

- Mejoran también las condiciones de financiación a entidades sociales.

- Por último, hace posible el establecimiento de un sistema explícito y planificado de relaciones entre los servicios sociales comunitarios y las entidades sociales.

Tal sistema se ordena en torno a distintas Mesas Temáticas de Coordinación (Salud, Educación, Mayores y Vivienda), todas lideradas por el centro de servicios sociales comunitarios. Sus profesionales asumen la coordinación y se convoca a ellas al conjunto de entidades que intervienen en cada una de las temáticas.

\footnotetext{
${ }^{8}$ Diez ONG, dos asociaciones cívicas del barrio y dos entidades de economía social.

${ }^{9}$ EL 0,52 del IRPF y la Convocatoria de Ayuda Pública Unificada de la Junta de Andalucía, entre otras.
}

Sin embargo, aunque en un principio esta iniciativa tiene un considerable dinamismo, pronto irá disipándose en la mayoría de mesas. Este hecho ocurre por dos motivos. De un lado, una parte de las entidades sociales, las más arraigadas, se descuelgan, disconformes con el carácter meramente informativo y de coordinación formal ("sólo nos vemos para contarnos lo que hacemos, al principio está bien, pero luego hay que ir más allá"). De otro, se producen cambios operativos en los tiempos de trabajo: en un principio, se reunían por la tarde para facilitar la participación de voluntarios y dirigentes de entidades, pero poco a poco, las convocatorias van a ir pasando a horario de mañana, ajustándose a los intereses de los profesionales. Esto hará que pasen de ser un espacio cívicotécnico a ser un espacio exclusivamente profesional.

A pesar del pronto 'agostamiento' de la iniciativa de coordinación, son reseñables tres aportes de este momento:

- Se trascienden las formas de relación bilateral hacia una relación multilateral.

- Se establece una estructura formalizada de encuentro.

- Se genera alguna práctica significativa, como el trabajo en torno al absentismo escolar (sobre la que nos detendremos a continuación).

\subsubsection{El trabajo en torno a la problemática de absentismo escolar como modelo de práctica dialógica}

Aunque las mesas temáticas no desaparecen, sus convocatorias se espacian y su funcionamiento general parece obedecer más a una necesidad del guión, a un requisito para acceder al complemento financiador de las ZNTS, que a una convicción compartida. La Mesa de Educación constituye, sin embargo, una salvedad. En ella trabajan de manera conjunta 25 entidades públicas, cívicas y del tercer sector. El trabajo en ella se inicia con un diagnóstico compartido de la situación socioeducativa. Una vez realizado, las entidades identifican un problema concreto sobre el que intervenir, el absentismo escolar, que en algunos centros educativos se aproxima al $50 \%$ del alumnado.

De la coordinación inicial, se pasará después a articular, en el seno de la mesa, un planteamiento unificado de intervención. Los diferentes programas que llevaban a cabo los colegios, los servicios sociales, la Delegación de Educación y las ONG se ponen en común para ser discutidos. De este momento surgirá una herramienta integrada de intervención ante el absentismo escolar, en la que, a grandes rasgos:

- Se concreta y explicita el proceso general de intervención, determinando los cometidos de cada actor.

- Se establecen los instrumentos de derivación y comunicación de la red. 
- Se apuesta por concentrar la oferta de apoyo en menos ONG, pero mejorando su capacidad de intervención. La mesa selecciona a dos entidades que considera solventes y ajustadas a los criterios. De este modo, las entidades pasan de ofertar proyectos particulares a las convocatorias públicas, a asumir la demanda generada desde un espacio reticular surgido desde el territorio.

- Finalmente, la mesa logra el compromiso de que las cuatro convocatorias públicas que financian proyectos de intervención socioeducativas en el barrio, apoyen un único plan de actuación integrado, poniendo, para ello, de acuerdo a diferentes administraciones de ámbito local y autonómico.

El conjunto de actores percibe que, de las actuaciones puestas en marcha tras la declaración de ZNTS, ésta es la más relevante, hecho que se objetiva en el efecto del nuevo modelo de intervención sobre el problema: el absentismo se reduce de modo considerable en el primer año de trabajo en red ${ }^{10}$. Más allá del resultado, este modo de actuar aporta tres elementos a la renovación relacional:

- Reduce la dinámica fragmentadora que ha provocado la diferenciación y especialización creciente de los dispositivos de bienestar.

- Racionaliza energías y recursos.

- Consolida dinámicas horizontales de actuación con agentes de distintas esferas (pública, cívica y del tercer sector).

\subsection{De lo dialógico a lo estratégico. El trecho pendiente}

Por estas aguas ha venido navegando la relación entre los servicios sociales comunitarios y las entidades sociales. En la dinámica general, ha primado la lógica espontánea sobre la planificación expresa, las necesidades tácticas sobre la articulación de una estrategia de construcción común. Pero también es cierto que, como se ha visto, se han generado algunos espacios de renovación en la referida senda dialógica. Aun así, es claro que no se ha sacado el debido partido al valor añadido que la práctica narrada aporta como recurso para mejorar la intervención de conjunto.
La puesta en marcha, a finales de 2009, del Plan Comunitario Integral ${ }^{11}$ para esta zona parece inaugurar un nuevo momento. Esta iniciativa de planificación apuesta por un impulso integrador al conjunto de políticas del barrio. Operativamente, se establece una estructuración en cuatro ejes (urbanismo, seguridad, sociocomunitario y empleo, y economía). Para el impulso del plan, se crea una Oficina con un pequeño grupo de personal 'liberado', que habrá de dinamizar la marcha general (el eje transversal). La idea, a diferencia de otros planes integrales más ambiciosos, es disponer de personal de apoyo, pero que luego sean los propios dispositivos del barrio lo que lideren estos ejes temáticos.

La mayoría de actores entiende que el liderazgo del mencionado eje sociocomunitario ha de corresponder, en su mayor parte, a los servicios. Se espera que el plan suponga un renovado impulso al trabajo en red, que sustituya la debilidad presente de las mesas temáticas. Sin embargo, aunque hace ya más de un año que el plan está oficialmente en marcha, a febrero de 2011 (fecha en que terminó el trabajo de campo) no se había producido movimiento significativo alguno que ajustara esa expectativa a la realidad. En los discursos que fundamentan este desajuste, aparecen distintas argumentaciones:

- “Desde la Oficina no nos dicen con claridad lo que tenemos que hacer".

- "Las entidades sociales están negociando al margen de los servicios sociales comunitarios y nos preguntamos para qué estamos nosotros aquí”.

- "El Plan Comunitario ha quedado siempre en la esfera de dirección del centro, a nosotros no ha trascendido esto; simplemente nos han informado a veces".

- "Hemos invitado a la gente [a los profesionales] a que se impliquen, a que participen en la gestación del plan, pero ha sido poca gente la que se ha animado...".

Los discursos de los agentes de servicios sociales comunitarios ponen de manifiesto la dificultad de este dispositivo para trascender los enfoques meramente tácticos de cooperación hacia formas de hacer en las que lo dialógico se extienda a todas sus dimensiones (esto sería aquí lo estratégico). El diagnóstico lo realiza con precisión milimétrica una profesional:
${ }^{10}$ Entidades sociales y servicios sociales están de acuerdo en que este nuevo enfoque ha mejorado la intervención sobre el fenómeno del absentismo y el conjunto de problemas asociados a él (desajustes familiares, fracaso escolar o abandono prematuro, entre otros). No existe, sin embargo, un diagnóstico unificado sobre su efecto real. Para servicios sociales, es próximo al $90 \%$, ya que se han reducido de manera drástica los expedientes de absentismo derivados de los colegios al centro de servicios sociales. En cambio, para las entidades sociales su repercusión es mucho menos (algunos informantes la sitúan en torno al $25 \%$ ), ya que, aunque los expedientes son menos, la problemática asociada persiste en un alto grado.

\footnotetext{
${ }^{11}$ La Plataforma Cívica que se crea en 2003 tiene en su agenda operativa dos reivindicaciones. Una ya ha sido citada aquí, la declaración del barrio como ZNTS. La segunda consistía en la puesta en marcha de un plan comunitario integral para el barrio. Aunque no entraremos en detalle en este punto, dicho plan se empezó a gestar en un espacio de trabajo mixto, donde participaban administraciones (autonómica y local), entidades vecinales y entidades sociales. Una vez elaborado el plan, se inicia la fase de puesta en marcha, que en el momento actual -marcado por los cambios políticos y el contexto de crisis- parecen encontrarse en punto muerto.
} 
Los servicios sociales comunitarios no hemos sido pensados para esto [para la dinamización], sino para la atención a problemas, para gestionar recursos para la gente con problemas. Estamos organizados como oficina que gestiona recursos. A los profesionales, ni se nos forma para ello, ni se nos pide desde arriba; a mí lo único que me controlan, en realidad, es lo que tardo en dar de baja un expediente; tampoco nosotros [los profesionales] tenemos a veces un especial interés por ello. Todos nos hemos acomodado a todo esto.

En el anterior discurso, se atisba el conjunto de factores que contienen el avance en la dinámica relacional en este caso: escasa prioridad (esfera política), ausencia de contenidos explícitos (esfera directiva), déficits de capacidades para la gestión de dinámicas relacionales (instituciones formativas), alejamiento real de los profesionales respecto a este tipo de contenidos interventores (esfera profesional). Estos factores, además, se refuerzas mutuamente, llegando a 'enrocarse' en forma de 'coartada' justificadora del inmovilismo de cada actor, mediante 'casuísticas' ajenas.

\section{4. ¿Qué nos enseña el caso? Los servicios sociales comunitarios en clave de red}

A pesar de todo, la propia realidad tiene también capacidad para cuestionarse, para desmentirse a sí misma. Es cierto que, en la relación entre los servicios sociales comunitarios y las entidades sociales, las prácticas reticulares dialógicas no son aquí una prioridad en el sentido político formal; no se ha instaurado un hábitus (Bourdieu, 2008) consistente en esta línea. Pero sí lo son en el sentido político cívico, al ser demandadas por las organizaciones ciudadanas; también son reconocidas como enfoque idóneo por profesionales de base y personal directivo. Por todo esto, cuando han surgido iniciativas, aunque no han venido impulsadas 'desde arriba' en sus inicios, sí han sido acogidas. Este hecho muestra las potencialidades que los enfoques de gestión 'de abajo arriba’ tienen para la renovación de los servicios sociales.

La praxis profesional o los modos organizativos están pensados para la atención individualizada, incluso fragmentadora. Pero cuando se adquiere la capacidad de articular nuevos modos de hacer, razonables y eficientes, suelen ser aceptados en la estructura de la organización con cierta fluidez. Por último, es también cierto que estos modos de hacer sacan al profesional de ‘su guión'. Parecen enfrentar a los técnicos del lado público a retos de difícil gestión (dinamizar redes, negociar o discutir en espacio horizontales). Sin embargo, cuando se inicia un camino así, parece comprobarse que la mayor dificultad está, antes que en saber dar respuestas, en la búsqueda de preguntas compartidas. El proceso, al ser abierto, requiere de elevadas dosis de autoaprendizaje en la práctica totalidad de casos, de generación de dinámicas de apoyo mutuo (entre actores de uno y otro lado). La mayor dificultad, por el lado de la práctica profesional, está precisamente en lo que Silvia Navarro (2004) llama 'dar el salto', en decidir enfocar la intervención cotidiana desde la conexión dialógica.

Este caso nos muestra cómo el principal límite se concentra aquí en el modo de 'conocer-se'. Los servicios sociales comunitarios se han concebido a sí mismos, tanto en la esfera política como en la técnica, como un actor institucional prestador. Incluso las propias entidades sociales los perciben como un dispositivo inserto en un sistema público, en el más formal de los sentidos. Pero esta construcción, que tiene una base teórica, jurídica y organizativa, refleja hoy sólo una parte de la 'realidad real'. Los servicios sociales comunitarios en este barrio son, cada día más, una red de interacciones interventoras múltiples que una institución en el sentido clásico. La ayuda a domicilio corresponde al Servicio de ayuda a Domicilio, pero es posible gracias a conciertos con cooperativas, con empresas, con ONG. Los talleres ocupacionales para mujeres o personas mayores los gestiona el centro de servicios sociales, pero los llevan a cabo distintas asociaciones. La atención a familias corresponde al Servicio de Cooperación Social, pero el acompañamiento familiar es posible gracias a un concierto con una cooperativa, y el trabajo con menores, a la colaboración con una ONG. Los servicios sociales comunitarios en este barrio son, hoy día, la institución pública municipal con sus recursos profesionales y programas, y además el conjunto de recursos y actuaciones que, en conexión con tal institución, desarrollan cerca de treinta entidades sociales de distinta naturaleza.

La red, que existe implícitamente, no ha trascendido, sin embargo, a categoría de trabajo explícita, a esquema articulador global. Éste es, a nuestro juicio, el factor condicionante central. Además, una parte del propio tejido de entidades ha adoptado también una posición adaptativa, renunciado también al trabajo de conjunto. Este hecho, menos relevante en las entidades surgidas por estrategias de 'renovación' o 'generación', sí aparece de modo más acusado en el grupo de entidades 'instaladas', aunque tampoco en todas. Son, con frecuencia, entidades más vinculadas a la atención especializada a problemas que al contexto comunitario, más interesadas en conexiones concretas que en procesos de conjunto.

Los criterios de renovación habrían de transitar, en este caso, por diferentes rutas no recorridas por servicios sociales (García Roca, 2006). La primera de ellas atiende a la explicitación de lo reticular. Ello precisaría de la renovación de los espacios y las herramientas de diagnóstico, planificación y evaluación de la realidad. Un ejemplo de renovación lo encontramos en la planificación. La herramienta que ordena este proceso suele ser el plan de centro, que se elabora de puertas adentro, con el aporte de profesionales de base y personal directivo. Esta orientación no se ajusta, sin embargo, a la realidad de la acción, ya que muchos de los contenidos que se planifican dependen luego de conexiones con terce- 
ros. Parecería más lógico trabajar en clave de planes de red, de forma que el proceso fuera compartido con el conjunto de actores con los que se opera en la práctica. Esto es, en realidad, lo que se hizo con el problema del absentismo escolar.

La segunda línea de renovación tiene que ver con los objetivos de intervención. Con frecuencia, la parte más relevante de las energías relacionales se concreta en la solución de problemas concretos, de demandas puntuales. En este sentido, servicios sociales y entidades sociales intervienen a menudo con los mismos sujetos (familias, personas), pero cada cual desarrolla una especie de proceso paralelo de atención que, en ocasiones, se entrecruza en intercambios de información o apoyos mutuos. Parece que la vía de renovación habría de venir marcada por un replanteamiento, también más reticular, del proceso de intervención. La exploración en torno a metodologías de acompañamiento (Navarro, 2004) compartidas, como el trabajo por itinerarios dirigidos a la activación (Pérez Eransus, 2009), puede servir para revisar el enfoque de acción.

El tercer ámbito de renovación pone la mirada en lo cívico, en los espacios en los que se despliega la cotidianidad de la comunidad objeto de intervención. Aquí se hace necesario que tanto servicios sociales como una parte de entidades del tercer sector refuercen sus relaciones con el tejido estrictamente comunitario. Sobre este particular, resulta interesante el esfuerzo de presencia vecinal que han realizado algunas ONG especializadas, orientado a la implicación creciente del vecindario en los espacios de cotidianidad. Sin embargo, este tipo de conexiones es, en general, insuficiente. A menudo, tiende a entenderse que 'lo comunitario' en servicios sociales se circunscribe a la relación con las entidades sociales colaboradoras: ahí termina la 'cosa'. En el discurso profesional analizado en este estudio, esa percepción aparece de modo consistente. Esta dinámica que simplifica ‘lo comunitario’ en las entidades colaboradoras resulta, a la larga, empobrecedora para servicios sociales comunitarios.
El último de los ámbitos de renovación atiende a los modos de conocer la realidad. El conocimiento es el más relevante recurso de la práctica profesional (Ruiz Ballesteros, Jaraíz Arroyo y Cordero, 2009). En el caso estudiado, el conocimiento se canaliza principalmente mediante herramientas predefinidas (cursos formativos, documentos). Esto suele ocurrir tanto en el ámbito de servicios sociales como en el de las entidades sociales. Además de predefinida, la mayor parte de la 'oferta' de conocimiento suele ser externa (se sale del centro de servicios sociales y del barrio para la formación, por ejemplo). Este esquema vincula el nuevo conocimiento necesario a dos dinámicas (Ruiz Ballesteros, Jaraíz Arroyo y Cordero, 2009): la informativa (novedades legislativas) y la formativa (cursos, lecturas). Pero el recurso a la experiencia y a la propia práctica como herramientas de conocimiento y de renovación suele tener un peso mucho menor.

Es cierto que, en el caso estudiado, el centro de servicios sociales ha puesto en marcha un seminario permanente, de carácter interno; una experiencia interesante, la única en este sentido en toda la ciudad. Esta iniciativa ha supuesto un avance, porque permite el que los profesionales tengan un espacio de intercambio de saberes, si bien lo que se intercambia en este seminario son, sobre todo, habilidades para la atención directa (se comparte información sobre recursos sociales, técnicas de intervención o sobre herramientas concretas).

Siendo relevante este paso, la vía que apuntamos aquí sitúa la meta un poco más allá. La renovación en las formas de conocer precisará de una apertura en torno a dos líneas: compartir las prácticas entre los diferentes actores que operan sobre la realidad y vincular los espacios de conocimiento con los procesos de diagnóstico/planificación/intervención/ evaluación. En este sentido, nos parecen interesantes enfoques como el de comunidad de práctica ${ }^{12}$ (Wenger, 1999). Tal vez éste sea el reto estratégico que esta red de servicios sociales tenga frente a sí: re-conocerse como comunidad de práctica.

${ }^{12}$ Este tipo de planteamientos, de amplía aplicación en ámbitos como el educativo, se sostiene sobre la base de que los diferentes actores inmersos en un contexto de intervención establecen herramientas explícitas sobre las que compartir y co-generar conocimiento. 


\section{Referencias bibliográficas}

ALGUACIL, J.; et al. (1997): La ciudad de los ciudadanos, Madrid, Ministerio de Fomento.

BOURDIEU, P. (2008): El sentido práctico, Barcelona. Siglo XXI.

CABRA, M. A.; y DE LORENZO, R. (2005): "El tercer sector en España: ámbito, tamaño y perspectivas", Revista Española del Tercer Sector, nํㅜ 1, págs. 95-134 [ [http://www.fundacionluisvives.org/ rets/1/articulos/1731/>].

GARCÍA ROCA, J. (2006): "Memorias silenciadas en la construcción de servicios sociales", Cuadernos de Trabajo Social, no 19, págs. 197-212 [<http:// revistas.ucm.es/index.php/CUTS/article/ viewFile/CUTSo606110197A/7568>].

GEERTZ, C. (1973): The Interpretation of Cultures, Nueva York, Basic Books.

JARAÍZ ARROYO. G. (2009): "El tercer sector de acción social en la intervención comunitaria”, Revista Española del Tercer Sector, nํㅜ12, págs. 101-129 [<http://www.fundacionluisvives.org/rets/12/ articulos/39528/index.html>].
NAVARRO, S. (2004): Redes sociales y construcción comunitaria. Creando (con) textos para una acción social ecológica, Madrid, CCS.

PÉREZ ERANSUS, B. (2009) "La activación como criterio político para la intervención social en el ámbito de la exclusión”, en VV.AA., Actuar ante la exclusión: análisis, políticas y herramientas para la inclusión social, Madrid, FOESSA, págs. 281-298.

RUIZ BALLESTEROS, E.; JARAÍZ ARROYO, G.; y CORDERO MARTÍN, G. (2009) "Gestión del conocimiento en servicios sociales", Sociología del Trabajo, nำ 66, págs. 3-30.

TORRES GUTIÉRREZ, J. (2011): Segregación urbana y exclusión social en Sevilla, Sevilla, Focus Abengoa.

WENGER, E. (1999): Communities of Practice. Learning, Meaning and Identity, Cambridge, University Press. 


\title{
El papel de los observatorios en el conocimiento de los procesos de exclusión social
}

\author{
Isabel Serrano Rodríguez
}

Dpto. de Sociología y Política Social, Universidad de Murcia

\section{Juan Benito Martínez}

Dpto. de Teoría e Historia de la Educación, Universidad de Murcia

\section{Manuel Hernández Pedreño}

Dpto. de Sociología y Política Social, Universidad de Murcia

<manuel@um.es>

\begin{abstract}
Gizarte-bazterketaren behatokiak aztertu dira testu honetan, eta azpimarratzen da behatoki horien rola, nagusiki, hiritarren gizarteratze edo bazterkeria-prozesuak ezagutzeko garaian. Gizarte-bazterketaren testuingurua eta teoriamailako hurbiltzea egiten da, lehenik. Azterlana burututako hiru ikerleak partaide diren Murtziako Unibertsitateko Gizarte Bazterketaren Behatokiaren kasua aztertu da xeheki, bestetik. Aztergai bi horietaz gain, konparazioa burutu da abian diren behatokien artean, dela Europako eremukoa, dela nazionala, eskualdekoa edota tokiko behatokia. Azkenik, gogoeta egiten da zaurgarritasunaren eta gizarte-bazterketaren jakintza hedatu eta ikertzen jarraitzeko erakunde horien lorpen eta ahalezko baliabideez.
\end{abstract}

\section{HITZ-GAKOAK:}

gizarte-behatokiak, bazterkeria, zaurgarritasuna, gizarte garatuak, ekonomia-krisialdia.
En este trabajo se analizan los observatorios de exclusión social, destacándose el importante papel que pueden desempeñar de cara al conocimiento de los procesos de inclusión/exclusión de la ciudadanía. En primer lugar, se realiza una aproximación teórica y contextual al fenómeno de la exclusión social. A continuación, se profundiza en el caso concreto del Observatorio de la Exclusión Social de la Universidad de Murcia, al que pertenecen los tres firmantes de este trabajo. En tercer lugar, se hace un análisis comparativo de algunos de los diversos observatorios sociales existentes, ya sean de ámbito europeo, nacional, regional o local. Por último, se reflexiona sobre los logros alcanzados por estas organizaciones y su potencial en el estudio y conocimiento de los fenómenos de vulnerabilidad social y de exclusión.

\section{Palabras ClaVe:}

observatorios sociales, exclusión, vulnerabilidad, sociedades desarrolladas, crisis económica. 


\section{La exclusión social en las sociedades desarrolladas}

La superación de la sociedad industrial y el advenimiento de la sociedad postindustrial han dado lugar a la aparición de nuevas bases generadoras de pobreza y marginación social. Como han señalado diversos autores (Subirats y Gomà, 2003; Subirats, 2005; Laparra et al., 2007; Brugué, Gomà y Subirats, 2002; Santos Ortega, Montalbá y Moldes, 2004; Hernández Pedreño, 2008b), las principales causas se encuentran en los importantes cambios acaecidos en la estructura socioeconómica, en el mercado de trabajo y en los niveles de cobertura del Estado del bienestar, factores que conforman un nuevo contexto social con un gran potencial de vulnerabilidad y precariedad.

Nuestro país no ha sido ajeno a estas transformaciones socioeconómicas - desempleo y precarización laboral, déficits del Estado del bienestar, envejecimiento demográfico, diversidad étnica, restructuración del modelo familiar, entre otras-, las cuales han hecho aflorar nuevas manifestaciones de riesgo social. No es tanto una mera cuestión de desigualdad económica, consecuencia de la pobreza monetaria, sino que, con estos desequilibrios, emergen otras formas de desigualdad. Aparecen una serie de procesos estructurales que afectan cada vez a más colectivos y desde muy diversos ámbitos -económico, laboral, formativo, sociosanitario, residencial, relacional y participativo-. Se trata de la exclusión social, fenómeno que limita la capacidad integradora que, tiempos atrás, se asentaba en los derechos de ciudadanía que propugnaban los Estados de Derecho. El concepto de exclusión social pretende definir y explicar las nuevas situaciones de pobreza y desarraigo social que se están produciendo en las sociedades más desarrolladas (Hernández Pedreño, 2008a: 9).

La exclusión es entendida como un fenómeno que deviene de causas estructurales, y no meramente individuales o causales, es decir, deviene de las transformaciones económicas y sociales que caracterizan a las sociedades del conocimiento. Estos cambios han minado la capacidad integradora de la sociedad, cuestionando la completa ciudadanía (Hernández Pedreño, 2008a: 18). La generalización de la expresión 'exclusión social' y su creciente uso en la definición de políticas sociales ha fomentado los esfuerzos por dotar a este concepto de mayor precisión. Los elementos comunes que presentan la mayor parte de las aproximaciones realizadas (Subirats, 2004, 2005; Tezanos, 1999; Cabrera, 1998; Raya Díez, 2006; Brugué, Gomà y Subirats, 2002:, Laparra et al., 2007; Hernández Pedreño, 2008b) la caracterizan como un fenómeno estructural, dinámico, multifactorial, multidimensional y heterogéneo, que incluye un componente individual y que es abordable desde las políticas públicas.

La exclusión social es el resultado de una determinada estructura social, política, cultural y económica. Por tanto, es relativa, depende del contexto. Como han señalado diversos autores (Tezanos, 2001: 204; Bauman, 2000: 11), el significado y las consecuencias de ser pobre o excluido son distintos según cada contexto específico, es decir, según el contenido social que se dé a la pobreza y a la exclusión social en un espacio-tiempo determinado.

Distintas voces han destacado el carácter dinámico, y no estático, de la exclusión (Castel, 1992, 1995; Subirats, 2005, 2006; Estivill, 2003; Moriña, 2007; Laparra et al., 2007; Raya Díez, 2006, Hernández Pedreño, 2008b). La exclusión es un conjunto de procesos más que una situación estable. Es un proceso que se va forjando a través de un itinerario en el que se suele pasar por fases distintas, en el que hay avances y retrocesos, rupturas y cambios de ritmo (Moriña, 2007: 14). Como señala Estivill (2003: 37), se trata de un itinerario que tiene un principio y un final, y en el que se pasa por fases distintas, si bien no lineales (inicio, recuperación, deterioro y cronificación). Entender la exclusión como un proceso conlleva aceptar la existencia de un continuo inclusión-exclusión, en el cual se sitúan las personas según su situación en un momento concreto. Una de las concepciones más referidas sobre este proceso es la desarrollada por Castel (1997), a partir de su análisis sobre la "metamorfosis de la cuestión social”. Según él, la quiebra del modelo de integración social, basado en el empleo asalariado y en las relaciones de solidaridad familiares y comunitarias, ha conllevado la generación de tres espacios sociales diferenciados (Castel, 1992, 1995, 2004), que surgen de la combinación de los ejes integraciónexclusión laboral e integración-exclusión en el entorno social, y en los que se distribuyen los riesgos de exclusión de forma desigual. Esta característica de la exclusión dificulta su medición, pues requiere el empleo de indicadores dinámicos, y no sólo de medidas estáticas (Hernández Pedreño, 2008a: 20).

La relevancia que ha adquirido la exclusión social en España se ha puesto de manifiesto en multitud de foros académicos y científicos, fruto de los cuales se ha producido una importante evolución conceptual y metodológica, que está permitiendo avanzar en el estudio y análisis de este fenómeno complejo. A ello han contribuido, sin duda, los abundantes trabajos de investigación realizados desde distintas instituciones. Es de destacar, en este sentido, la tendencia a conformar equipos de trabajo interdisciplinares, justificada por el carácter multidimensional y multifactorial de la exclusión. En este contexto se inscriben los estudios realizados en varias comunidades autónomas, como Andalucía (Pérez Yruela et al., 2002), Asturias (Pérez Yruela et al., 2004), Murcia (Hernández Pedreño, 2008a) o el VI Informe FOESSA (Renes, 2008). Asimismo, cada vez es más frecuente emplear distintas y complementarias técnicas de aproximación a la exclusión social, al objeto no sólo de cuantificar, sino también de alcanzar una mayor comprensión de los procesos de acumulación de desventajas sociales.

La exclusión social no debe entenderse como una realidad fatalista e irremediable en las sociedades 
más avanzadas. Cada sociedad es responsable de sus riesgos de exclusión, de sus déficits de inclusión, de la gestión de su bienestar social. Como han señalado Subirats y Gomà (2003: 30), la exclusión social es susceptible de ser abordada desde medidas colectivas y desde la práctica institucional. Puesto que es un fenómeno estructural, es posible encararla de forma estratégica, a través de políticas efectivas que promuevan las prácticas de inclusión, ya que, en muchos casos, la exclusión social es consecuencia de políticas ineficaces (Moriña, 2007: 15). A partir de actuaciones integrales que repercutan en los diferentes ámbitos (laboral, formativo, económico o social) y en los múltiples colectivos, se puede reducir la cantidad e intensidad de la vulnerabilidad. En esta línea se inscriben las recientes iniciativas comunitarias instadas desde la política europea de inclusión, desde los planes nacionales de acción, e incluso desde planes regionales y locales. Además, es necesario destacar la labor que vienen realizando las ONG en la aplicación de las medidas públicas de inserción, ya que, en las últimas décadas, han pasado de tener un papel subsidiario a desarrollar un rol cooperador (Serrano Rodríguez, 2008).

Todo ello requiere abordar la exclusión desde su complejidad, ya que uno de los desafíos más difíciles es el de modificar nuestro pensamiento de manera que haga frente a dicha complejidad -así como a la rapidez de los cambios y la imprevisibilidad que caracteriza nuestra sociedad-, de modo interdisciplinar y desde el compromiso social tanto de la sociedad civil como de la sociedad científica. Porque cuando tratamos sobre igualdad, justicia o inclusión social, estamos ante una cuestión de derechos, que son la base de una ciudadanía activa, ya que la desigualdad, la pobreza y la exclusión social ponen en tela de juicio las condiciones del ejercicio de los derechos fundamentales de las personas (Benito, 2008). Este hecho entronca con la dimensión político-ciudadana de participación de la exclusión social, un ámbito fundamental de la inclusión y la participación social de pleno derecho que recoge algunas de las situaciones más explícitas de exclusión, tales como la negación o restricción del acceso de la ciudadanía a los derechos económicos, sociales y políticos más fundamentales.

En esta línea, debe hacerse referencia a las fortalezas y debilidades de las ONG, como agentes activos en la lucha contra la exclusión social. Entre los puntos fuertes que tienen las organizaciones del tercer sector, se encuentran el robustecimiento de la vida democrática, la motivación y el compromiso como factores de identidad, así como la capacidad de integración social para generar soluciones eficientes dentro de una orientación social. Por el contrario,

Tabla 1. Tipología de los observatorios sociales, según sus características

\begin{tabular}{|c|c|c|c|c|}
\hline Denominación & Ámbito & Promoción y Financiación & Componentes & $\begin{array}{l}\text { Periodo de } \\
\text { actividad }\end{array}$ \\
\hline $\begin{array}{l}\text { Observatorio de las Comunidades Europeas } \\
\text { sobre Políticas Nacionales para Luchar } \\
\text { contra la Exclusión Social }\end{array}$ & Europeo & - Unión Europea & - Expertos & 1990-1993 \\
\hline Observatorio Social de España & Nacional & - Universidad Pompeu Fabra & $\begin{array}{l}\text { - Expertos } \\
\text { - Universidades }\end{array}$ & 2004-hoy \\
\hline $\begin{array}{l}\text { Observatorio de la Exclusión Social y los } \\
\text { Procesos de Inclusión en la Comunidad de } \\
\text { Madrid }\end{array}$ & Regional & $\begin{array}{l}\text { - Empresas de inserción de } \\
\text { la Comunidad de Madrid } \\
\text { - Caja Madrid }\end{array}$ & $\begin{array}{l}\text { - Empresas de inserción de } \\
\text { la Comunidad de Madrid } \\
\text { - Tercer sector } \\
\text { - Expertos } \\
\text { - Universidades }\end{array}$ & 2008-hoy \\
\hline $\begin{array}{l}\text { Observatorio de Procesos de Exclusión e } \\
\text { Incorporación Social (Sartu) }\end{array}$ & Regional & $\begin{array}{l}\text { - Fondo Social Europeo } \\
\text { - Federación Sartu }\end{array}$ & $\begin{array}{l}\text { - Tercer sector } \\
\text { - Expertos } \\
\text { - Universidad }\end{array}$ & 2001-2006 \\
\hline $\begin{array}{l}\text { Observatorio Permanente de la Inmigración } \\
\text { en Asturias }\end{array}$ & Regional & $\begin{array}{l}\text { - Consejería de Bienestar } \\
\text { Social y Vivienda del Princi- } \\
\text { pado de Asturias }\end{array}$ & - Tercer sector & 200o-hoy \\
\hline $\begin{array}{l}\text { Observatorio de la Exclusión Social de la } \\
\text { Universidad de Murcia }\end{array}$ & Regional & - Universidad de Murcia & $\begin{array}{l}\text { - Tercer sector } \\
\text { - Expertos } \\
\text { - Universidad }\end{array}$ & 2005-hoy \\
\hline $\begin{array}{l}\text { Observatorio de la Inserción Ocupacional y } \\
\text { la Diversidad Social }\end{array}$ & Regional & $\begin{array}{l}\text { - Servicio de Empleo y } \\
\text { Formación de la Región de } \\
\text { Murcia }\end{array}$ & $\begin{array}{l}\text { - Técnicos de la } \\
\text { Administración }\end{array}$ & 2008-hoy \\
\hline Observatorio de la Exclusión Social & Local & $\begin{array}{l}\text { - Ayuntamiento de Santa } \\
\text { Coloma de Gramenet } \\
\text { (Barcelona) }\end{array}$ & $\begin{array}{l}\text { - Técnicos de la } \\
\text { Administración }\end{array}$ & 2006-hoy \\
\hline $\begin{array}{l}\text { Observatorio sobre Exclusión Social y } \\
\text { Políticas de Inclusión (Granada) }\end{array}$ & Local & - Fondo Social Europeo & $\begin{array}{l}\text { - Expertos } \\
\text { - Universidad }\end{array}$ & 2003-2004 \\
\hline $\begin{array}{l}\text { Observatorio Municipal de la Igualdad de } \\
\text { Oportunidades de Albacete }\end{array}$ & Local & - Ayuntamiento de Albacete & $\begin{array}{l}\text { - Técnicos de la } \\
\text { Administración }\end{array}$ & $2007-2011$ \\
\hline $\begin{array}{l}\text { Observatorio de las Migraciones y la } \\
\text { Convivencia Intercultural de la Ciudad de } \\
\text { Madrid }\end{array}$ & Local & - Ayuntamiento de Madrid & - Expertos & 2005-hoy \\
\hline
\end{tabular}

Fuente: Elaboración propia. 
como reto o amenaza estaría la compatibilidad del espíritu crítico y reivindicativo con el de la corresponsabilidad y la cooperación constructiva con los poderes públicos (Serrano Rodríguez, 2008: 384).

Los observatorios de la exclusión social pueden cumplir con estas condiciones, al acoger la complejidad, la interdisciplinariedad y el compromiso social civil y universitario. Un ejemplo modesto, y que tiene casi siete años de experiencia, es el Observatorio de la Exclusión Social de la Universidad de Murcia (OES-UMU), constituido a partir de una demanda de la sociedad civil comprometida con la inclusión social y que requería la colaboración de la comunidad universitaria. Como miembros del equipo coordinador de ese dispositivo, podemos exponer que la experiencia ha confirmado, teniendo en cuenta los resultados obtenidos hasta ahora, la pertinencia de impulsar observatorios de la exclusión social al menos desde las premisas enunciadas, ya que, en última instancia, los ciudadanos debemos aprender que tenemos un compromiso muy estrecho con la comunidad más próxima, y que los problemas de los que integran nuestra sociedad son también nuestros problemas.

\section{El Observatorio de la Exclusión Social de la Universidad de Murcia}

\subsection{Origen, finalidad, objetivos y áreas de trabajo}

La propuesta de creación de un Observatorio de la Exclusión Social en la Universidad de Murcia surge como resultado de la asamblea de la Plataforma contra la Exclusión Social celebrada el 14 de febrero de 2005, donde se acordó proponer a la Universidad de Murcia el compromiso con los objetivos por los que aquélla venía trabajando. El proyecto de observatorio comenzó a gestarse en febrero de 2005 , y al principio se ubicó dentro del Vicerrectorado de Extensión Cultural y Proyección Universitaria.

El observatorio nace, pues, a iniciativa conjunta de la Plataforma contra la Exclusión Social y la Universidad de Murcia, y participan inicialmente en él una veintena de profesoras y profesores universitarios de distintas facultades y áreas de conocimiento (economía, educación, Derecho, historia, sociología, psicología o trabajo social), miembros de la plataforma y de la Comisión Técnica de Personas sin Hogar, representantes de asociaciones no adscritas a la plataforma y otras asociaciones que, estando en esta última, participan individualmente. También se incorporan diversos profesionales a título individual.

La finalidad del observatorio es llenar el vacío existente en el estudio de la exclusión social, profundizando en el conocimiento de las distintas realidades de exclusión en el ámbito de la Región de Murcia, y promover la investigación, la divulgación y el debate sobre los procesos sociales y las distintas intervenciones de lucha contra la pobreza y la exclusión social. Estos fines se concretan en seis objetivos:
- Contribuir al conocimiento y el análisis de los fenómenos de exclusión social, especialmente de las problemáticas menos conocidas.

- Realizar y promover estudios e investigaciones sobre estos fenómenos, así como evaluar las intervenciones sociales, públicas o privadas, de lucha contra la pobreza y la exclusión social.

- Recopilar datos relativos a las situaciones de pobreza, precariedad y exclusión en la Región de Murcia.

- Difundir las informaciones recogidas y los resultados de sus trabajos para el conocimiento de las administraciones públicas y la sociedad en general.

- Promover el debate público sobre los procesos sociales más relevantes en la producción de las situaciones de exclusión, así como sobre las políticas sociales en favor de la igualdad y la justicia.

- Favorecer la participación de las personas que viven en situación de exclusión, reconociendo la importancia de su presencia en la actividad del observatorio.

Dichos objetivos se llevan a cabo mediante el desarrollo de tres grandes proyectos o áreas de trabajo:

- El Seminario Permanente tiene como finalidad proporcionar un foro abierto y continuo de debate teórico sobre la conceptualización del fenómeno de la exclusión social, de reflexión y análisis sobre los instrumentos más adecuados de actuación, así como de evaluación participativa de las intervenciones en temas relacionados con la exclusión social. Uno de los marcos para este fin es el desarrollo de las Jornadas anuales sobre Exclusión Social, ya que constituyen un ámbito privilegiado para el intercambio de información, experiencias, análisis e instrumentos de evaluación entre investigadores, asociaciones y entidades, profesionales de la intervención social, y ciudadanos interesados en los procesos de exclusión y las políticas sociales de intervención. Asimismo, son un ámbito adecuado para promover el debate público, y difundir los trabajos y estudios realizados por el observatorio.

- El Centro de Recursos tiene como objetivo desarrollar tareas de difusión, publicación, formación, asesoramiento y documentación relativos a la exclusión social y las políticas sociales en la Región de Murcia.

- El Centro de Investigación tiene como finalidad llevar a cabo investigaciones, proyectos e informes sobre la exclusión social de la Región de Murcia. El equipo de trabajo es mixto, pues al grupo de investigadores de la Universidad de Murcia se suman profesionales de la intervención social y miembros de las asociaciones y entidades de integración y lucha contra la pobreza y la exclusión en la Región de Murcia. 


\subsection{Composición y estructura}

Cada una de las áreas de trabajo mencionadas está coordinada por dos miembros del observatorio elegidos a tal efecto por la Asamblea General. De esos dos coordinadores/as, uno/a es miembro de la comunidad universitaria, y otro, de la parte civil.

En cuanto a la estructura organizativa o funcional del observatorio, se deben destacar las figuras del equipo coordinador y la asamblea. El equipo coordinador está formado por el/la director/a del observatorio, el/la secretario/a -miembros ambos de la comunidad universitaria-, otros cinco miembros de la comunidad universitaria y siete miembros de la sociedad civil, elegidos respectivamente -por separado- por los miembros de cada uno de esos dos grupos en la asamblea general. La asamblea es el órgano de mayor representación del observatorio, a la que pertenecen todos los socios o miembros de aquél.

\subsection{Actividades}

Respecto al tipo de informes, documentos e investigaciones que han surgido del observatorio, así como a la metodología empleada en ellos, se resume a continuación lo más destacado que se ha realizado. En los inicios de la formación del observatorio (febrero de 2005), se crea un equipo mixto, cuyos miembros pertenecían tanto a la comunidad universitaria como a asociaciones u ONG de la Región de Murcia. Este grupo realiza la primera actividad investigadora: un informe que analiza la infravivienda y las personas sin hogar en la Región de Murcia. Este primer estudio sirve como presentación del observatorio ante la comunidad universitaria y la murciana en general, y se hace coincidir con la conferencia de Joan Subirats "La exclusión social en España. El papel de la Universidad", el 14 de diciembre de 2005, fecha oficial del nacimiento del observatorio como institución.

En enero de 2006, se crea el grupo de investigación interdisciplinar "Exclusión social y desigualdad" formado entonces por trece investigadores de distintas áreas de conocimiento (sociología, economía, Derecho, educación y trabajo social). Este grupo de investigadores nace vinculado directamente al observatorio y solicita un proyecto de I+D a la Fundación Séneca de la Región de Murcia, proyecto realizado durante 2007-2008 y publicado con el título Exclusión social en la Región de Murcia. Aproximación cuantitativa y cualitativa (Hernández Pedreño, 2008a). Este proyecto sirvió para consolidar la metodología de trabajo del observatorio, que se puede dividir en dos herramientas complementarias de aproximación a la realidad social de la exclusión en la región: el Registro de Usuarios de ONG colaboradoras del observatorio y las reuniones periódicas con los técnicos de aquéllas.

El Registro de Usuarios de ONG surge en 2006, cuando el observatorio realiza un cuestionario/ficha común para homogeneizar la información recabada sobre los usuarios de las ONG regionales. Los principios que rigen la confección de la ficha común fueron: utilizar como base el cuestionario empleado en la encuesta de Personas sin Hogar del INE en 2005, con el fin de poder comparar los resultados de ambos estudios; recoger información de los distintos colectivos usuarios de las ONG; hacer sencilla su cumplimentación por parte de los técnicos o voluntarios de las ONG, procurando que fuera clara y, a la vez, no demasiado extensa; $y$, sobre todo, incluir aspectos del mayor número de dimensiones o áreas vitales de exclusión que fuera posible (ingresos, trabajo, educación, salud, vivienda, relaciones sociales y participación). La estructura del cuestionario se divide en ocho bloques, que incluyen las siguientes cuestiones en cada dimensión:

- Datos de identificación personal: edad y sexo.

- Dimensión participativa: país de procedencia.

- Dimensión relacional: estado civil y personas a su cargo.

- Dimensión formativa: nivel de estudios alcanzado.

- Dimensión ingresos: volumen total de ingresos mensuales.

- Dimensión laboral: situación laboral y fuente principal de ingresos.

- Dimensión vivienda: residencia habitual.

- Dimensión salud: consumo de alcohol y de drogas, y padecer enfermedad física/psíquica.

Aunque la mayoría de preguntas son objetivas, las relacionadas con la salud (física y psíquica) de los usuarios deben ser contestadas según la observación de la persona que cumplimenta la ficha, que habitualmente es un técnico o voluntario de la ONG. Al tratarse de un cuestionario de carácter anónimo, se utiliza un código de identificación, consistente en las iniciales del nombre, el primer apellido y la fecha de nacimiento. Con este código, se pretende identificar a la persona y poder detectar su trayectoria por los diversos centros, evitando contabilizar al mismo usuario varias veces.

Tras realizar una prueba piloto con un borrador de la ficha/cuestionario en una de las ONG colaboradoras, a finales de 2006 , se realizaron algunas modificaciones del cuestionario, de forma que quedó corroborada su idoneidad para ser cumplimentado por las catorce ONG que empezaron a colaborar en el proyecto a partir de enero de 2007. Las fichas se recogen semestralmente -bien directamente, bien mediante correo electrónico- en una base de datos en Access. La explotación de los datos se realiza mediante el programa SPSS. La principal ventaja de cumplimentar una ficha común en las ONG es la posibilidad de agregar los datos de todas ellas. La ficha incorpora un conjunto amplio de cuestiones y se formula de forma idéntica en todas las ONG colaboradoras, que han consensuado la herramienta. 
Las dieciséis ONG que han proporcionado sus datos de usuarios ofrecen servicios de muy diversa índole (acogida, asesoramiento, inserción laboral, entre otros) y a grupos sociales en precariedad/exclusión de distinto perfil (personas sin hogar, mujeres, familias, inmigrantes, por ejemplo). Como zona de actuación, predomina el municipio de Murcia, si bien varias de ellas prestan servicios a escala regional. Las ONG colaboradoras son: Apramu, Asociación Neri, Asociación Beniram, Asociación Traperos de Emaús, Asprosocu, Cáritas, Centro Beto, Cepaim, Colectivo La Huertecica, Columbares, Cruz Roja, Fundación Patronato Jesús Abandonado, Fundación Rais, Hermanas Oblatas del Santísimo Redentor, Murcia Acoge y Proyecto Abraham.

Es necesario matizar, no obstante, las siguientes limitaciones del Registro de Usuarios del observatorio para obtener una completa visión del perfil de las personas en situación de vulnerabilidad o exclusión social en la Región de Murcia:

- No recoge a los usuarios de los centros públicos, ni se aplica en el total de las ONG de la Región de Murcia.

- Hay formas de exclusión cuyos sujetos no son usuarios de los centros de apoyo social, sean públicos o privados.

- La ficha no puede recoger aspectos subjetivos o personales de la exclusión (cómo se vive o cómo se llega a ella), metas sólo alcanzables a partir de metodologías cualitativas, como la entrevista en profundidad, el grupo de discusión o la historia de vida.

En 2007, se obtuvieron 1.095 fichas; en 2008, 1.139; y en $2009,1.101$. Una vez eliminadas las de usuarios repetidos, el número de usuarios únicos por año se sitúa en 916 en 2007, 1.083 en 2008 y 1.077 en 2009. Estos registros obtenidos se analizan tanto desde la perspectiva de género como desde la diferenciación entre usuarios españoles y extranjeros. Se ha dejado para un análisis posterior (2007-2011) la cuestión de la duplicidad de los sujetos como usuarios -ya sea en el mismo centro o en centros distintos-, que permitirá realizar un seguimiento de los usuarios y estudiar los itinerarios seguidos por las ONG.

Por último, cabe decir que también se realiza anualmente una clasificación de los usuarios en los tres espacios sociales definidos por Castel (1997) -integración, vulnerabilidad y exclusión- y en cada una de las siete dimensiones sobre las que contiene información la ficha de usuario. La graduación de estos tres espacios se lleva a cabo teniendo en cuenta diversos estudios revisados por Esther Raya Díez (2006), así como los resultados del tallerseminario realizado en la Universidad de Murcia, en diciembre de 2008, entre los miembros del Centro de Investigación del observatorio, y varios profesores y expertos en el estudio de la exclusión social de otras universidades (Esther Raya Díez, de la Universidad de la Rioja; Rosa Martínez, de la Universidad Rey Juan
Carlos I de Madrid; y Pedro Cabrera, de la Universidad Pontificia Comillas de Madrid).

En ese seminario, ejemplo de los desarrollados tras las conferencias organizadas por el observatorio, se realizó la graduación de los tres espacios sociales en las siete dimensiones, partiendo de las respuestas registradas en la ficha común que habían cumplimentado los usuarios de las ONG colaboradoras. En este proceso, se observó que la graduación debía considerarse solamente aproximada en algunas dimensiones, debido a la complejidad de medir estos espacios y a la ausencia en la ficha de algunos datos fundamentales. Éste es el caso de las dimensiones 'relaciones sociofamiliares' y ‘participación'. No obstante, se considera que la graduación realizada puede ser útil para aproximarnos a la influencia y casuística de las distintas áreas vitales de exclusión, según el perfil de los usuarios.

Es preciso destacar que, como resultado de ese seminario, se produjeron modificaciones en la ficha de usuarios de ONG utilizada en 2009, con el fin de obtener una información más precisa respecto a la graduación social. Asimismo, cada año, en la reunión periódica del observatorio con las ONG colaboradoras, se revisa y adapta la ficha a las peculiaridades o casuísticas que comentan las ONG, para asegurar que se incluyen todas las opciones de respuesta posibles y para obtener mayor información de las siete dimensiones de la exclusión social.

La segunda herramienta metodológica son las reuniones periódicas con técnicos de las ONG colaboradoras. Varios miembros del área de investigación del observatorio llevan a cabo grupos de discusión con esos técnicos, en los que, sobre todo, se ponen en común los perfiles sociales de los usuarios que solicitan sus servicios, y se verifican así los cambios de perfil de los usuarios en el plano cualitativo.

Con estas dos herramientas, el observatorio viene elaborando dos productos de forma periódica:

- Informe anual del perfil de los usuarios de los servicios de las ONG de la Región de Murcia, realizado desde 2007. Los perfiles se analizan desde la perspectiva de género, por nacionalidades y teniendo en cuenta la graduación de usuarios en los tres espacios de inserción social (integración, vulnerabilidad y exclusión) y en las siete dimensiones de la exclusión consideradas y sobre las que se tiene información.

- Perfiles sociales de exclusión emergentes en la Región de Murcia. Se obtienen a partir de los grupos de discusión con técnicos de ONG (también de ayuntamientos el primer año, 2007). En los grupos de discusión, no sólo se evalúa la tipología de colectivos que son usuarios de los centros de apoyo social en su conjunto y los servicios que demandan, sino que también se identifican las tendencias seguidas por éstos. Se clasifica a los colectivos en tres tipos: los usuarios habituales que mantienen su situación de exclusión/vulne- 
rabilidad, los que aumentan su presencia y riesgo de exclusión, y los que son emergentes o de reciente entrada como usuarios.

Otras actividades reseñables -además de la elaboración de informes e investigaciones- son la realización de siete cursos formativos durante 2010 , o la organización de conferencias periódicas, que suelen ser impartidas por representantes de universidades o centros de investigación. Los ponentes invitados realizan también un taller-seminario, al día siguiente de la conferencia, al que asisten los distintos miembros del observatorio interesados en la investigación y en el aspecto o colectivo concreto sobre el que versa el seminario.

Recientemente se ha presentado el Boletín del OES (〈http://edit.um.es/boes/〉), que recoge periódicamente información sobre investigaciones, entrevistas y fichas de ONG, entre otros contenidos vinculados con la exclusión social, sus procesos y sus colectivos en la Región de Murcia. Por último, está la iniciativa de 2011 en materia de formación para los técnicos de las ONG colaboradoras; en concreto, se trata del curso Gestión de ONG de Apoyo a la Inclusión Social, de 150 horas, realizado en colaboración con el Servicio de Proyección Social y Voluntariado de la Universidad de Murcia y financiado por el Vicerrectorado de Estudiantes y Empleo, dentro del cual se ubica el observatorio desde abril de 2011. Toda la actividad realizada por el observatorio desde su nacimiento se puede consultar en su sede electrónica [<http://www. um.es/vic-estudiantes/observatorio/১].

\section{Otros observatorios sociales}

En el análisis no exhaustivo de otros observatorios sociales (Tabla 1), en especial de aquellos que tienen relación con las desigualdades y la exclusión social, se ha de indicar que la mayoría surgen a lo largo de los primeros años del siglo XXI.

\subsection{Observatorio de las Comunidades Europeas sobre Políticas Nacionales para Luchar Contra la Exclusión Social}

A finales de la década de 1980, la Comunidad Europea -hoy día, Unión Europea- ve la necesidad de identificar los problemas de desigualdad y exclusión social en los Estadios miembros, mediante la creación del Observatorio sobre Políticas Nacionales para Luchar Contra la Exclusión Social, financiado por el Fondo Social Europeo. El Observatorio nace en 1990, intentando dar respuesta a tres necesidades políticas:

- Incrementar el conocimiento de las características de los menos privilegiados.

- Estudiar las medidas adoptadas por los Estados miembros para combatir la exclusión social.
- Analizar las medidas que la Comunidad Europea estaba adoptando para promover una cohesión económica y social en el contexto del desarrollo del mercado único.

De este modo, el observatorio recoge anualmente, a través de expertos independientes, información de cada uno de los países de la Comunidad Europea (estadísticas, textos y normas legislativas). Desarrolla su labor entre 1990 y 1993, un periodo en el que realiza informes anuales y un informe final (Roldán, 1993).

\subsection{Observatorio Social de España}

El Observatorio Social de España nace en 2004, ante las inquietudes de una red de académicos e investigadores de diversas universidades y centros de investigación españoles, en especial, la Universidad Pompeu Fabra de Barcelona. Su función principal es documentar y analizar las intervenciones públicas que, en materia de bienestar social y calidad de vida, se desarrollan a escala estatal, autonómica y local, estableciendo comparaciones tanto de la situación de España respecto al resto de países de la Unión Europea y otros países del contexto internacional, como de las diecisiete comunidades autónomas entre sí, indagando igualmente en las consecuencias de tales intervenciones en las condiciones de vida de la población. Los principales objetivos del observatorio son:

- Mejorar el conocimiento de la situación de los ámbitos sociales que componen el Estado del bienestar en España.

- Generar debate público e informar en torno a las políticas sociales, la calidad de vida y el bienestar social de la población.

- Fomentar que las cuestiones sociales tengan más y mejor visibilidad mediática y, por otro lado, reciban más atención política.

- Proponer intervenciones para mejorar la calidad de vida de la ciudadanía.

Mediante metodología cuantitativa, se explotan bancos de datos de fuentes oficiales a escala nacional en materia económica, de desigualdades y pobreza, inmigratoria, de protección social, de Seguridad Social, así como datos demográficos, sociopolíticos, educativos, del mercado de trabajo, de salud y sanidad, y de vivienda. Aunque la financiación inicial del observatorio provino del Ministerio de Trabajo e Inmigración, en la actualidad procede de la Universidad Pompeu Fabra. Durante su trayectoria, el Observatorio ha editado varias publicaciones: El Estado de bienestar en España (2004); La situación social de España (2005); La situación social de España, volumen II (2007); La situación social de España, volumen III (2009). 
3.3. Observatorio de la Exclusión Social y los Procesos de Inclusión en la Comunidad de Madrid

El Observatorio de la Exclusión Social y los Procesos de Inclusión en la Comunidad de Madrid se crea en 2008. Está integrado por empresas de inserción de la Comunidad de Madrid, asociaciones del tercer sector y expertos. Intenta obtener información de los aspectos que rodean a las empresas de inserción -haciendo especial hincapié en las normas, las ayudas, las políticas sociales o los beneficiarios-, con el propósito de analizarla con técnicas cualitativas y cuantitativas.

Este observatorio pretende plasmar los efectos laborales y socioeconómicos que producen las empresas de inserción, y fundamentar esta metodología de intervención como modelo sostenible y rentable de inserción social. Así pues, el objetivo principal del observatorio es aportar nuevas ideas de cara a la adecuación de contenidos y metodologías que mejoren las intervenciones de esas empresas, reforzándolas como herramienta privilegiadas de inserción social y laboral de las personas pertenecientes a colectivos en exclusión social.

\subsection{Observatorio de Procesos de Exclusión e Incorporación Social de Sartu}

En 2001 surge el Observatorio de Procesos de Exclusión e Incorporación Social de Sartu, con el objetivo de medir los factores de exclusión; comparar los cambios en relación con el sistema de indicadores de exclusión; identificar las trayectorias de incorporación social desarrolladas por las personas, estableciendo itinerarios tipo, de acuerdo a la posición inicial, la movilización de recursos sociales y personales, y la posición social final; y por último, explorar los elementos presentes en los procesos de incorporación social (Sartu, s/f). Las técnicas utilizadas para alcanzar dichos objetivos han sido cuantitativas (2002-2005) y cualitativas (2006). La financiación del observatorio proviene de un convenio de colaboración entre la Unidad Administradora de Fondo Social Europeo (UAFSE) y la Federación Sartu. Durante el periodo 2001-2006, cofinancian la iniciativa el Gobierno Vasco (Departamentos de Justicia, Empleo y Seguridad Social, y Vivienda y Asuntos Sociales) y la BBK Gazte Lanbidean Fundazioa. No obstante, las dificultades de financiación en 2007 provocan el cierre del observatorio.

\subsection{Observatorio Permanente de la Inmigración en Asturias}

El Observatorio Permanente de la Inmigración en Asturias nace en 2001 dentro de un proyecto promovido por Accem y financiado por la Consejería de Bienestar Social y Vivienda del Principado de Asturias. Su finalidad es estructurar y desarrollar un dispositivo permanente de observación cooperativa sobre la situación socioeconómica del colectivo de las personas inmigrantes que residen en dicha comunidad. Las entidades promotoras del observatorio son Accem, la Consejería de Asuntos Sociales y la Plataforma Pro-Inmigrantes de Asturias. Desde su creación hasta la actualidad, han realizado diagnósticos (locales y autonómicos), seminarios, y publicaciones. Las herramientas del observatorio son tres:

- Acompañamiento, Diagnóstico y Evaluación: esta herramienta permite conocer las necesidades, y construir los perfiles y tipologías del colectivo inmigrante.

- Repertorio de Actores y de Acciones para la Inserción: con esta herramienta, se estructura la información sobre los recursos sociales existentes en el territorio y las acciones propuestas por los distintos actores, entidades, instituciones y organismos, según sus campos, áreas de intervención y servicios.

- Base de Datos Contextuales: contiene una veintena de indicadores socioeconómicos estratégicos, armonizados con los datos de seguimiento del colectivo, suministrados por las fuentes externas o colectivos cercanos a los actores, para así permitir realizar fichas estadísticas contextuales y mapas, según las zonas que se tengan que definir.

\subsection{Observatorio de la Inserción Ocupacional y la Diversidad Social (Región de Murcia)}

El Observatorio de la Inserción Ocupacional y la Diversidad Social es un proyecto cofinanciado por el Servicio de Empleo y Formación de la Comunidad Autónoma de la Región de Murcia, y abierto a la participación de las diferentes entidades de la región que trabajan en el ámbito de la inserción ocupacional. Surgido en 2008, es una plataforma que tiene como objetivo facilitar el trabajo de organizaciones y profesionales de entidades sociales de la Región de Murcia que trabajan en el ámbito de la inserción ocupacional con grupos sociales en situación de desigualdad social. Para ello, el observatorio lleva a cabo, entre otras, las siguientes actuaciones: recopilación y difusión de información actualizada y convocatorias de interés; edición de un boletín semanal; realización de un inventario de los servicios de orientación, formación y empleo; elaboración de un informe semestral con los datos de empleo relacionados con los grupos sociales en situación de desigualdad; desarrollo de un sistema de indicadores relacionados con el empleo y los diversos grupos sociales en situación o en riesgo de exclusión; elaboración de un manual de orientación; y, finalmente, publicación de informes, planes, estudios o guías.

\subsection{Observatorio de la Exclusión Social (Ayuntamiento de Santa Coloma de Gramenet, Barcelona)}

En 2006, el Ayuntamiento de Santa Coloma de Gramenet (Barcelona) crea el Observatorio de la 
Exclusión Social como una herramienta para medir el alcance y la evolución de las desigualdades sociales y de los recursos que se pueden articular para hacerles frente. El observatorio dispone de dos fuentes de datos: una cuantitativa, el sistema de información sobre exclusión social, propio de la Administración; y otra cualitativa, un buscador de actividades inclusivas. El sistema de información sobre exclusión social es un programa informático que recoge la información cuantitativa más actualizada sobre los colectivos que se encuentran en riesgo social, el tipo de dificultades que sufren y la atención que reciben por parte de las administraciones. Entre los organismos públicos que suministran dicha información, se encuentran el Instituto Catalán de las Mujeres, y el Departamento de Bienestar Social y Familia. Con la información facilitada por el buscador de actividades inclusivas, se ha realizado un Mapa de la Inclusión, que contiene fichas informativas sobre los recursos y servicios de la ciudad que se dirigen directamente a prevenir o a paliar la situación de colectivos con especiales dificultades.

\subsection{Observatorio sobre Exclusión Social y Políticas de Inclusión (Granada)}

Mediante el desarrollo de un proyecto EQUAL en Granada, entre 2003 y 2004, surgió el Observatorio sobre Exclusión Social y Políticas de Inclusión, con el fin de crear un dispositivo de investigación, evaluación, formación y documentación que permitiera sensibilizar tanto a la administración pública como al sector asociativo y al entorno social beneficiario de éste. En sus inicios, pretendía un acercamiento entre la Universidad de Granada, el Ayuntamiento y otras agencias públicas, con el fin de trabajar en cinco proyectos de investigación:

- Estudio de políticas y dispositivos de inserción en la ciudad de Granada.

- Dinámicas de acceso y exclusión del empleo en el sector hostelero en Granada.

- Fracaso escolar.

- Informes sobre la vulnerabilidad y la exclusión en Granada.

- Centro Virtual de Documentación Social.

Su amplio objetivo general fue incitar al debate público y profesional, en especial en torno a lo relacionado con las políticas y los dispositivos de inserción; estudiar qué relaciones se establecen entre el concepto de 'empleo' y el de 'políticas de inserción' en la práctica social e institucional; y analizar el funcionamiento de distintos mecanismos de inserción social en la ciudad de Granada, en particular las acciones de la administración pública local y el tercer sector que la acompaña/complementa.
3.9. Observatorio Municipal de Igualdad de Oportunidades de Albacete

El Observatorio Municipal de Igualdad de Oportunidades de Albacete surge en 2007, como una herramienta de la administración local para contribuir a una mayor igualdad, en términos de ciudadanía, entre las personas que viven en Albacete, independientemente de su sexo, edad, procedencia étnica o religión. Su objetivo general es analizar y evaluar la situación de igualdad de oportunidades, identificar los desequilibrios existentes y proponer medidas de actuación (Partido Socialista Obrero Español, s/f). El observatorio, que deja de actuar en 2011, se regulaba a través de un convenio con la delegación castellano-manchega de la Red Europea de Lucha contra la Pobreza y la Exclusión social (EAPN-CLM), al coincidir los objetivos de esta asociación con los del Ayuntamiento de Albacete, en lo concerniente a la detección, prevención y lucha contra las bolsas de pobreza.

El trabajo del observatorio utiliza dos perspectivas complementarias: por un lado, la investigación en sí misma y, por otro, la evaluación de las políticas públicas, que pasa por verificar que las iniciativas que se llevan a cabo son realmente efectivas y contribuyen a una mayor igualdad para la ciudadanía.

\subsection{Observatorio de las Migraciones y la Convivencia Intercultural de la Ciudad de Madrid}

En 2005, el Ayuntamiento de Madrid crea el Observatorio de las Migraciones y la Convivencia Intercultural de la ciudad de Madrid, con la finalidad de conocer la realidad de la inmigración en la localidad y potenciar el diálogo intercultural, a través de la divulgación, la formación y la participación ciudadana. El observatorio cuenta con una serie de publicaciones cuyo propósito es difundir textos especializados entre estudiosos, profesionales y otros agentes sociales vinculados o interesados en las migraciones, la convivencia y la interculturalidad. Entre estas publicaciones, se encuentran una revista cuatrimestral, una encuesta sobre la convivencia-que persigue obtener una radiografía de la sociedad madrileña-, una guía de recursos para la atención a la población de origen extranjero, una guía de convivencia y datos de la población extranjera.

\subsection{Algunos comentarios}

En definitiva, comprobamos que los observatorios colaboran, en distinta medida, con asociaciones; que no en todos interviene la administración pública; que las fuentes de financiación son variadas y que, en algunos casos, su financiación proviene de un proyecto determinado, como ocurre con el Observatorio de Granada.

Sirva esta exposición para conocer las aportaciones de los diversos observatorios de exclusión social, los 
cuales responden a premisas ideológicas, premisas metodológicas y a compromisos plurales. Desde nuestro punto de vista, los observatorios no sólo deben 'observar', sino también realizar propuestas fundamentadas, y en su caso, incluso desarrollarlas para favorecer procesos de inclusión social en condiciones de igualdad, equidad y justicia, tomando como referencia los derechos humanos y el desarrollo humano (en los términos expuestos por el Plan de Naciones Unidas para el Desarrollo). Para ello, se precisa de la contribución de todos, ya sea desde la condición de ciudadanos, profesionales o universitarios.

\section{Importancia de los observatorios de la exclusión social en época de crisis}

Quizá es ahora cuando los observatorios de exclusión social son más importantes y necesarios que nunca, no ya sólo porque ha aumentado cuantitativa y cualitativamente el riesgo de exclusión social de más número de personas, sino porque es 'en época de crisis' cuando se hace más oportuno el conocimiento de los procesos de vulnerabilidad y exclusión, debido a la mayor afluencia de personas en situación de riesgo social, como consecuencia de los cambios socioeconómicos emergentes. No podemos olvidar que estas circunstancias sirven también de excusa para prescindir, generalmente por la vía de no apoyarlas, de iniciativas que, con sus estudios y propuestas, denuncien las decisiones que agudicen los procesos de exclusión. Por consiguiente, con el aliento de la ciudadanía, de los profesionales y de la universidad y los universitarios, los miembros de los observatorios de exclusión social tenemos un importante compromiso moral, social y científico en la lucha por la cohesión y la integración social de toda la ciudadanía, sin distinción por nacionalidad, etnia, sexo, edad o ideología; un compromiso en la defensa de los derechos humanos, porque la exclusión social es evitable.

De la revisión realizada de los distintos observatorios sociales, se pueden destacar importantes avances en el conocimiento del perfil social de los sujetos que viven el fenómeno de la exclusión social, de los itinerarios que siguen en dichos procesos, así como de las políticas llevadas a cabo. Los logros alcanzados por los observatorios sociales y el potencial de estos dispositivos para el conocimiento de la exclusión social los podemos sintetizar en los siguientes puntos:

- Aproximación al perfil de los sujetos que viven la exclusión social. En concreto, el Observatorio de la Exclusión Social de la Universidad de Murcia viene realizando un seguimiento de los usuarios que acuden a las distintas ONG, y analizando su evolución.

- Seguimiento de los nuevos usuarios y de las nuevas necesidades/demandas de éstos, a través de reuniones periódicas con los técnicos de centros de apoyo social, ya sean de ONG, ayuntamientos u otras administraciones.

- Análisis de las trayectorias de vulnerabilidad/ exclusión de los usuarios y de los distintos recursos de apoyo social que demandan en cada fase del itinerario seguido. Ello permite detectar la eficacia de las medidas de apoyo social, así como determinar en qué espacio social se ubicarían los usuarios (exclusión, vulnerabilidad, integración).

- Evaluación de la oferta (pública y privada) de recursos de apoyo social. Analizan los recursos existentes destinados a personas en riesgo social y la contrastan con la demanda existente, es decir, con el perfil de los usuarios de los centros de apoyo social.

- Colaboración en el diseño, la implantación y la puesta en marcha de los planes de inclusión social regionales o locales. Éste es un potencial que pueden desarrollar los observatorios sociales, gracias a los equipos mixtos que suelen integrarlos (Universidad, ONG, Administración, expertos).

- Además, estos equipos suelen ser interdisciplinares, peculiaridad que les cualifica para analizar los procesos de exclusión desde distintas esferas científicas (economía, sociología, Derecho, psicología, trabajo social), hecho bastante recomendable, teniendo en cuenta la mulitidimensionalidad de la exclusión social.

- Vinculado con el hecho anterior, es de destacar las ventajas de complementar diversas técnicas para el estudio y análisis de la exclusión, ya sean cuantitativas -como la encuesta o la ficha de usuarios- o cualitativas -como la entrevista en profundidad, la historia de vida o el grupo de discusión-. Todas ellas han sido utilizadas en el estudio realizado en 2008 por el Observatorio de la Exclusión Social de la Universidad de Murcia (Hernández Pedreño, 2008a).

- Avance en procedimientos metodológicos y herramientas de aproximación al estudio de los procesos de exclusión-integración -por ejemplo, a través de representaciones gráficas-, ahondando en los puntos críticos de las trayectorias vitales de los sujetos, es decir, detectando los momentos de inflexión de las personas que se mueven en el continuo integración-vulnerabilidad-exclusión.

- Los observatorios ponen de manifiesto que la complementariedad entre la Universidad y el tercer sector no se limita exclusivamente a la investigación, sino que también se relaciona con la docencia y con la práctica social. Los profesores universitarios que colaboran en los observatorios pueden transmitir a su alumnado los resultados de las distintas investigaciones, a la vez que, a través del prácticum universitario, el alumnado puede tener contacto con las distintas ONG e, incluso, con sus usuarios, quienes son objeto de estudio de los observatorios. En especial, resultan de interés para el alumnado de ciertos títulos universitarios, como Trabajo Social, Sociología o 
Educación Social. De esta manera, los estudiantes quedan también integrados en la estructura de los observatorios.

- Contribuyen a reivindicar la función social de la Universidad. El desarrollo pleno de las sociedades democráticas requiere, inexorablemente, ciudadanos con valores éticos, responsabilidad social y competencias cívicas, con la plena conciencia de los problemas culturales, ambientales y sociales que nos afectan. En este ambicioso reto, las universidades deben ser entes creadores de cultura, espacios para la participación y motor de innovación (Benito, 2011: 227).

Como se ha visto, los observatorios sociales vienen aglutinando a un amplio y diverso número de agentes sociales (públicos/privados, profesorado/alumnado, investigadores/técnicos) provenientes de distintas áreas de trabajo (economía, sociología, trabajo social), hecho que permite realizar un amplio espectro de informes y estudios relativos al fenómeno de la exclusión social.

Aunque la continuidad de algunos observatorios se ha visto truncada por la ausencia de financiación, la realidad es que, en los últimos años, han surgidos nuevos proyectos de observatorios, lo cual debe interpretarse como un creciente interés por los procesos de exclusión, así como una creciente confianza en estas instituciones. No obstante, por todos es conocido, por un lado, el aumento cuantitativo de personas en situación de riesgo social -desde el inicio de la crisis económica-, y por otro, las importantes reducciones presupuestarias (recortes) que están realizando los diferentes Gobiernos regionales y el nacional. Este último factor actúa, sin duda, en detrimento de los nuevos colectivos vulnerables (parados, jóvenes, extranjeros), a la vez que puede incidir negativamente en la continuidad de algunos observatorios de reciente implantación.

No obstante, la situación actual de crisis puede ser una oportunidad para la labor de los observatorios, en lugar de un inconveniente, ya que el análisis de la afluencia de nuevos usuarios antes normalizados puede permitir comprender la fragilidad de la integración social, sobre todo cuando ésta se asienta sobre unas bases pocos estables, como ha pasado en nuestro país en los últimos años. El mayor conocimiento de las causas y los factores que influyen en los procesos que alejan a los ciudadanos de la integración social permitirá realizar propuestas de intervención más eficaces. Asimismo, los momentos de crisis pueden servir para aumentar las colaboraciones solidarias entre distintos agentes sociales, $\mathrm{y}$ hacer surgir, por ejemplo, nuevas instituciones $u$ organismos que analicen y estudien las consecuencias sociales de la crisis. En consecuencia, tenemos la oportunidad de seguir avanzando, y realizar otros estudios y otras propuestas, para progresar en el conocimiento de la situación de los colectivos con mayores necesidades, y en la mejora de sus condiciones sociales. 
BAUMAN, Z. (2000): Trabajo, consumismo y nuevos pobres, Barcelona, Gedisa.

BENITO, J. (2011): “Ciudadanía, universidad y derechos humanos", Revista Electrónica Interuniversitaria de Formación del Profesorado, vol. 14, ํㅡ 1, págs. 227-241 [rhttp://www.aufop.com/aufop/uploaded files/articulos/1301669285.pdf)].

- (2008): “Educación social para la igualdad”, en HERNÁNDEZ PEDREÑO, M. (coord.), Exclusión social y desigualdad, Murcia, Editum [rhttp:// edit.um.es/library/docs/books/exclusionsocial-y-desigualdad.pdf $>$.

BRUGUÉ, Q.; GOMÀ, R.; y SUBIRATS, J. (2002): “De la pobreza a la exclusión social. Nuevos retos para las políticas públicas", Revista Internacional de Sociología, nํㅜ 33, págs. 7-45.

CABRERA, P. (1998): Huéspedes del aire. Sociología de las personas sin hogar en Madrid, Madrid, Universidad Pontificia Comillas.

CASTEL, R. (2004): “Encuadre de la exclusión”, en KARSZ, S., La exclusión: bordeando sus fronteras. Definiciones y matices, Barcelona, Gedisa.

- (1997): Metamorfosis de la cuestión social. Una crónica del salariado, Buenos Aires, Paidós.

- (1995): "De la exclusión como estado a la vulnerabilidad como proceso", Archipiélago, nํ21, págs. 27-36.

- (1992): "La inserción y los nuevos retos de las intervenciones sociales", en ÁLVAREZ URÍA, F. (ed.), Marginación e inserción, Madrid, Endymion.

ESTIVILL, J. (2003): Panorama de lucha contra la exclusión social: conceptos y estrategias, Ginebra, Oficina Internacional del Trabajo.
HERNÁNDEZ PEDREÑO, M. (dir.) [2008a]: Exclusión social en la Región de Murcia. Aproximación cuantitativa y cualitativa, Murcia, Editum [<http://edit. um.es/library/docs/books/9788483718117. pdf〉].

- (2008b): "Pobreza y exclusión en las sociedades del conocimiento", en HERNÁNDEZ PEDREÑO, M. (coord.), Exclusión social y desigualdad, Murcia, Editum [<http://edit.um.es/library/ docs/books/exclusion-social-y-desigualdad. pdf>].

LAPARRA, M. et al. (2007): “Una propuesta de consenso sobre el concepto de exclusión. Implicaciones metodológicas", Revista Española del Tercer Sector, no 5 , págs. 15-57 [rhttp:// www.fundacionluisvives.org/rets/5/ articulos/16553/>].

MORIÑA, A. (2007): La exclusión social: análisis y propuestas para su intervención, Madrid, Fundación Alternativas [<http://www.falternativas.org/ content/download/5901/168251/version/2/ file/1e45_07-05-07_EP\%252026.pdf)].

PARTIDO SOCIALISTA OBRERO ESPAÑOL (s/f): “El Observatorio Municipal de Igualdad de Oportunidades de Albacete", en Banco de Buenas Prácticas de Gestión Municipal Socialista, Madrid, Partido Socialista Obrero Español [<http://experiencias.psoe.es/pagina. php?cs_id_pagina $=3 \& c s \_i d \_c o n t e n i d o=5311$ )]

PÉREZ YRUELA; et al. (2004): Pobreza y exclusión social en el Principado de Asturias, Córdoba, Consejo Superior de Investigaciones Científicas; Instituto de Estudios Sociales Avanzados.

- (2002): Pobreza y exclusión social en Andalucía, Córdoba, Consejo Superior de Investigaciones Científicas; Instituto de Estudios Sociales Avanzados. 
RAYA DÍEZ, E. (2006): Indicadores de exclusión social. Una aproximación al estudio aplicado de la exclusión social, Bilbao, Universidad del País Vasco.

RAYA LOZANO, E. E. (2004): Exclusión/Inclusión social en la Ciudad de Granada. Estudios y propuestas del Observatorio sobre Exclusión Social y Políticas de Inclusión (2003-2004): Sintesis, Granada, Editorial Maristan.

RENES, V. (coord.) [2008]: VI Informe sobre exclusión social y desarrollo social en España, Madrid, Fundación FOESSA.

SANTOS ORTEGA, A.; MONTALBÁ, C.; y MOLDES, R. (2004): Paro, exclusión y políticas de empleo. Aspectos sociológicos, Valencia, Tirant lo Blanch.

SARTU (s/f) Observatorio de Procesos de Exclusión e Incorporación Social de Sartu. De la exclusión social a la ciudadanía. Madrid, 27 de enero [cfr. <http://grunyon.rosybotero.com/observatorio/ images/ct_observatorio_sartu.pdf〉].

SERRANO RODRÍGUEZ, I. (2008): “El papel de las ONG en la inclusión social. El caso concreto de Murcia Acoge", en HERNÁNDEZ PEDREÑO, M. (coord), Exclusión social y desigualdad, Murcia, Editum [<http://edit.um.es/library/docs/books/ exclusion-social-y-desigualdad.pdf].

SUBIRATS, J. (dir.) [2006]: Fragilidades vecinas. Narraciones biográficas de exclusión social urbana, Barcelona, Icaria.

- (dir.) [2005]: Análisis de los factores de exclusión social, serie Documentos de Trabajo, Bilbao, Fundación BBVA [<http://www.fbbva.es/TLFU/ dat/exclusion_social.pdf`].

- (dir.) [2004]: Pobreza y exclusión social. Un análisis de la realidad española y europea, col. Estudios Sociales, $\mathrm{n}^{0} \mathbf{1 6}$, Barcelona, Fundación La Caixa [rhttp://obrasocial. lacaixa.es/StaticFiles/StaticFiles/ f28d31d9615d5210VgnVCM1000000e8 cf10aRCRD/es/vol16_es.pdf>].

SUBIRATS, J.; y GOMÀ, R. (dirs.) [2003]: Un paso más hacia la inclusión social. Generación de conocimiento, políticas y prácticas para la inclusión social, Madrid, Plataforma de ONG de Acción Social [<http://www.plataformaongs. org/upload/88/94/un_paso_mas_hacia_la_ inclusion_social.pdf $>$ ].

TEZANOS, J. F. (2001): La sociedad dividida. Estructura de clases y desigualdades en las sociedades tecnológicas avanzadas, Madrid, Biblioteca Nueva.

- (1999): "Tendencias de dualización y exclusión social en las sociedades avanzadas. Un marco para el análisis", en TEZANOS, J. F. (ed.), Tendencias en desigualdad y exclusión social. Tercer Foro sobre Tendencias Sociales, Madrid, Sistema.
Sedes electrónicas de los

\section{observatorios analizados}

Observatorio de la Exclusión Social (Ayuntamiento de Santa Coloma de Gramenet, Barcelona) 〈http://www.grame.net/es/principal/elayuntamiento/serveis/servicios-sociales/ plan-local-por-la-inclusion-social/observatoride-lexclusio-social.htmls.

Observatorio de la Exclusión Social de la Universidad de Murcia 〈http://www.um.es/vic-estudiantes/ observatorio/s.

Observatorio de la Exclusión Social y los Procesos de Inclusión en la Comunidad de Madrid 〈http://grunyon.rosybotero.com/observatorio/ observatorio.html>.

Observatorio de la Inserción Ocupacional y la Diversidad Social (Región de Murcia) 〈http://www.ceisintegra.com/basico. php?sub=170>

Observatorio de las Migraciones y la Convivencia Intercultural de la Ciudad de Madrid 〈http://goo.gl/MgkNf〉.

Observatorio Municipal de Igualdad de Oportunidades de Albacete 〈http://www.albacete.es/es/ayuntamiento/ observatorio-de-la-igualdad/s.

Observatorio Permanente de la Inmigración en Asturias 〈http://www.odina.info/〉.

Observatorio Social de España 〈http://www.observatoriosocial.org/〉. 



\title{
Infancia y exclusión social en España: realidades y retos a partir de la crisis.
}

\author{
Mònica Clua-Losada
}

Departamento de Ciencias Políticas y Sociales, Universitat Pompeu Fabra

<monica.clua@upf.edu>

\author{
Albert Sesé i Ballart \\ Observatorio Social de España, Universitat Pompeu Fabra \\ Marta Tur i Tur \\ Observatorio Social de España, Universitat Pompeu Fabra
}

\begin{abstract}
Artikulu honetan, xede hartu da haurtzaro eta gaztetako pobrezia eta gizarte-bazterketa, eta bertan aurkezten dira krisialdiaren eraginei aurre egiteko nola aritu diren gaiari erantzuten gizarte, arlo publiko eta arlo pribatuko erakundeak. Azterlana burutzeko, oinarritzat hartu da Espainiako Gizarte Behatokiko ikerleek bideratutako diseinua. Xedea betetzeko, testigantzak jaso dira pobrezia eta gizarte-bazterketa pairatzeko arriskuan diren haur eta gazteen kolektiboen eguneroko laguntzan administrazio eta hirugarren sektoreko erakundeei galdeginda. Tamainaren arabera mugatu ahal izateko, Espainiako hiri handienak hartu dira; eta berariaz aztertu dira Bartzelona, Madril eta Bilbon jasotako datuak. Internet bidez galdegin zaie sektore publiko nahiz pribatuko erakundeei, eta horietatik guztietatik 300 inkesta bildu dira. Bestetik, teknika kualitatiboak erabiliz, Bartzelonako erakunde publiko zein pribatuko 15 goi-arduradun elkarrizketatu dira. Azterlanak nabarmen ondorioztatzen duenez, ezinbestekoa da pobrezia eta bazterkeria bizitzeko arriskuan dauden haur eta gazteen hezkuntza eta gizarte-zerbitzuak erabat berregituratzea.
\end{abstract}

\section{HITZ-GAKOAK:}

krisia, gizarte-bazterketa, haurtzaroa, pobrezia, hirugarren sektorea.
Este artículo presenta los resultados de un estudio diseñado por investigadores del Observatorio Social de España que analiza el efecto de la crisis y las consecuentes respuestas llevadas a cabo por las organizaciones sociales, públicas y privadas, sobre la pobreza y la exclusión social infantil y juvenil. Para elaborarlo, se han recogido los testimonios de diferentes administraciones y entidades del tercer sector que trabajan a diario con colectivos de infancia y juventud en riesgo de exclusión social o pobreza. Se ha tomado como base territorial las principales ciudades españolas según su tamaño, haciendo especial hincapié en los datos obtenidos de Barcelona, Madrid y Bilbao. El estudio se ha realizado a través de más de 300 encuestas en línea con organizaciones públicas y privadas del sector, y 15 entrevistas cualitativas con altos representantes de tales organizaciones en la ciudad de Barcelona. En nuestro estudio, resulta evidente la necesaria reestructuración de los servicios sociales y educativos que trabajan con grupos de infancia en riesgo de exclusión social y pobreza.

\section{PALABRAS CLAVE:}

crisis, exclusión social, infancia, pobreza, tercer sector.

\footnotetext{
${ }^{1}$ Este estudio se ha desarrollado gracias a la financiación de la Obra Social de La Caixa. Agradecemos la participación de todos y todas aquellas profesionales que nos han ayudado respondiendo nuestra encuesta, e invitándonos a visitar sus organizaciones.
} 


\section{Introducción}

El presente artículo analiza la situación actual de la infancia en riesgo de exclusión social o pobreza en España. A través de las experiencias de los profesionales que trabajan con infancia en colectivos de riesgo de exclusión social, se intenta mostrar un esbozo de la realidad en la que se encuentran tanto los menores como las organizaciones, públicas y privadas, que trabajan con ellos. El estudio pretende obtener una aproximación de cómo ha cambiando (y continúa cambiando) esta situación a raíz de la crisis global financiera que empieza en EE.UU. en 2007 y que se manifiesta en España de manera clara a partir de 2008 y 2009. Por lo tanto, los resultados de este estudio presentan una realidad dinámica y que tan sólo considera la experiencia acumulada en los primeros dos o tres años de esta crisis. Como nuestro trabajo de campo ha demostrado, los cambios políticos y económicos actuales ocurren de manera rápida, sin periodos de negociación, e incluso de manera inesperada. Esta incertidumbre, que está marcando nuestra época, afecta de forma todavía más acentuada a aquellos sectores y ciudadanos que ya viven una situación de incertidumbre o precariedad aun sin crisis.

De hecho, hay ciertos factores cruciales que afectan de manera negativa a la infancia en riesgo de pobreza o exclusión social, tanto en épocas de crisis como en estabilidad económica. En un estudio realizado en Gran Bretaña ${ }^{2}$ en perspectiva comparada, el profesor de la Universidad de York Jonathan Bradshaw (2002), experto en infancia y pobreza reconocido internacionalmente, mantiene que hay tres tipos de factores clave:

- Económicos: la calidad del trabajo y la retribución que se percibe por él son factores económicos muy importantes. El paro (sobre todo cuando afecta a más de un adulto en la unidad familiar), la inseguridad e inestabilidad laborales, y los salarios generalmente bajos percibidos por los trabajadores no cualificados afectan negativamente a la infancia.

- Demográficos: el aumento de las familias monoparentales y la dificultad de éstas para acceder al mercado laboral y permanecer en él. De manera añadida, los ingresos de estas familias suelen ser más bajos, y su inestabilidad financiera, más alta (algo lógico si consideramos que sólo hay posibilidad de que entre un sueldo en el hogar, y que toda responsabilidad económica, afectiva, y de cuidados y tareas del hogar recae sobre un único adulto).
- Políticos: según Bradshaw, estos factores son los más importantes ${ }^{3}$. Es precisamente a través de políticas y programas diseñados de manera adecuada como podemos incidir en los dos tipos de factores anteriores. Por lo tanto, y a modo ilustrativo, no es el paro lo que determina el bienestar, sino la falta de prestaciones sociales cuando un individuo se encuentra en tal situación; no es el sueldo bajo el principal problema de una familia monoparental, sino la falta de alquileres asequibles para estas familias, o de otras ayudas públicas.

Por lo tanto, este estudio considera precisamente que los factores económicos y demográficos encuentran (o no) respuesta en los factores políticos (entendidos de una manera amplia, e incluyendo tanto las políticas y los programas de las administraciones públicas como aquellos diseñados y llevados a cabo por entidades del tercer sector).

El artículo está dividido en tres secciones principales, además de una final con las conclusiones. Primero, presenta la relación entre las características del Estado del bienestar español y las políticas públicas sobre la infancia que se desarrollan en este marco. En este apartado, se consideran tanto el papel de la administración pública como el del tercer sector en el diseño y la implementación de políticas y programas orientados hacia la infancia. A partir de esta introducción teórica, se desarrollan las tres hipótesis que han guiado el estudio. Este primer apartado termina presentando brevemente las metodologías cuantitativas y cualitativas utilizadas en el estudio.

La segunda parte del artículo muestra los resultados de la investigación. Éstos son considerados a partir de dos ejes diferenciadores. Por un lado, se analiza la situación actual y cómo ha variado a raíz de la crisis financiera, es decir, cómo han evolucionado los servicios de asistencia a la infancia en riesgo de pobreza o exclusión social. Este análisis se organiza a partir de las tres hipótesis propuestas en el apartado anterior. Por otro lado, se identifican tres retos básicos que hemos encontrado en este tipo de servicios sociales, educativos y de ocio: la prevención, la coordinación y la formación de profesionales en materias relativas a la infancia en situaciones de vulnerabilidad social o económica.

La tercera parte presenta nuestras propuestas de futuro a partir de nuestra investigación. Remarcando algo intrínsecamente positivo, los profesionales de este sector que han aceptado colaborar con nuestro estudio han mostrado una gran capacidad de reflexión y autocrítica. Esto ha facilitado la tarea de identificar tanto los retos actuales como las posibles vías de mejora para los servicios a la infancia.

\footnotetext{
${ }^{2}$ Cabe recordar que Gran Bretaña lleva sufriendo tasas de pobreza infantil muy elevadas desde la década de 1980. De hecho, Unicef remarca que en 2000 era el país con la tercera tasa más elevada de pobreza infantil, tan sólo superada por Rusia y EE.UU.
}

3 De hecho, el último informe publicado por FOESSA (Renes y Lorenzo, 2011) también apunta hacia el argumento de Bradshaw. 


\section{El Estado del bienestar español y la infancia}

La Comisión Europea, en su Informe conjunto sobre la protección y la inclusión social 2009 resalta que "España no informa de manera explícita de las estrategias a grandes rasgos enfocadas a niños/as y familias" (2009: 41). Esto se manifiesta de dos maneras claras. Primero, no existe transversalidad o visibilidad de la infancia en el diseño y la implementación de las políticas públicas españolas (tanto a escala estatal, como autonómica o municipal). Esto se traduce en políticas de infancia de carácter reactivo y con finalidades asistencialistas específicas. En segundo lugar, cuando existen políticas relacionadas con la infancia, éstas se orientan más hacia las familias que hacia la infancia.

La transversalidad ha recibido un gran empuje en el ámbito de las políticas por la igualdad entre hombres y mujeres ${ }^{4}$. En España, este concepto se materializó en la creación del Ministerio de Igualdad en 2008 -durante el segundo Gobierno de Zapatero-, que se integró en el Ministerio de Sanidad, Política Social e Igualdad a partir de la crisis (2010). Aunque el Ministerio tuvo una vida muy corta, y cargada de acusaciones y cuestionamientos sobre su relevancia y eficiencia, quería demostrar la voluntad política de avanzar hacia la transversalidad de las políticas de género. Sin entrar en cuestiones sobre la adecuación de esta iniciativa a sus objetivos fundacionales, es evidente que la infancia nunca ha conseguido tal visibilidad política. Por ejemplo, los observatorios de la infancia, aunque necesarios, no contribuyen a conseguir una mayor transversalidad de las políticas, precisamente porque no son instituciones políticas.

Las Naciones Unidas definen la transversalidad de las políticas de género como "una estrategia aceptada globalmente para promover la igualdad entre géneros. [...] Requiere asegurar que las perspectivas de género y la atención a los objetivos de igualdad entre géneros son centrales a todas las actividades -desarrollo de políticas, investigación, presión y diálogo, legislación, distribución de recursos, y planificación, implementación y seguimiento de programas y proyectos-" (ONU Mujeres, sede electrónica, traducción propia). La transversalidad para la infancia es igualmente necesaria y requiere considerar cómo cualquier política afecta a la infancia; incluso políticas de infraestructuras deberían tener en cuenta cómo afectan a la infancia.

La segunda manifestación del subdesarrollo de las políticas de infancia en España va completamente ligada al carácter del Estado del bienestar español, cuyo desarrollo asistencialista ha dado paso a un sistema mixto de provisión de servicios. Como ya han

${ }^{4}$ La transversalidad de las políticas de género (conocida en inglés como gender mainstreaming) ha suscitado interés entre políticos, investigadores y expertos internacionales. A día de hoy, cuenta con una literatura científica extensa y unos procesos claros dentro del diseño de políticas públicas de los países desarrollados. apuntado en detalle diversos especialistas (Arriba y Moreno, 2005; Esping-Andersen, 1993; Ferrera, 2005), el Estado del bienestar español se caracteriza por un énfasis en la familia como red de apoyo al individuo. Las políticas que se desarrollan en este marco olvidan a la infancia, la cual queda, incluso, olvidada por los propios expertos, como muestra una mirada rápida a trabajos importantes publicados en nuestro país sobre el Estado del bienestar (Adelantado, 2000; Gallego, Gomà y Subirats, 2003; Navarro, 2006; Moreno, 2009).

Este énfasis da paso a unas políticas de familia (y de infancia) insuficientes y, en ocasiones, inexistentes. El carácter de estas políticas ayuda a explicar por qué encontramos a las familias monoparentales y a las numerosas en situaciones más vulnerables. Como apunta Parella, "la voluntad universalizadora de las prestaciones económicas es tan reducida que, en la práctica, es la participación de la familia [...] en el mercado de trabajo la que determinará su capacidad para satisfacer las necesidades económicas familiares" (2000: 429).

El rasgo distintivo de las políticas públicas dirigidas a la infancia en España es, precisamente, que no se dirigen a la infancia, sino a las familias. Por ejemplo, implementar guarderías públicas se ve como una necesidad para favorecer la participación laboral de las madres, no como un elemento socializador e integrador de los menores. En cualquier manual básico de políticas públicas, se trata el efecto que la definición de un problema tiene en el diseño de una política pública (Parsons, 1995). En el caso de los menores, encontramos programas públicos dirigidos a capacitar a los adultos como actores de mercado, no necesariamente a garantizar los derechos sociales de los niños. Si esto último ocurre -la garantía de los derechos de los menores-, es de manera accidental, no por el diseño de la política pública.

Aunque ésta no es una característica esencialmente española, sí parece estar presente en aquellos Estados del bienestar con tasas más altas de pobreza infantil. El problema, como apunta la experta Aletha Huston (1991: 20), es que el diseño y análisis de políticas públicas suelen hacerse en planos analíticos relacionados con cuestiones socioeconómicas: se asume que las políticas diseñadas para reducir la pobreza de los padres también solventarán los problemas de la pobreza en la infancia. Aunque esta afirmación es indudable en muchos casos, los intereses de los niños no son siempre idénticos a los de sus padres.

\subsection{El papel de la administración pública en la provisión de bienes y servicios}

La regulación sobre los derechos y servicios disponibles para la infancia corresponde a diversas administraciones territoriales -locales, autonómicas y estatales-. A su vez, está dividida por ámbitos (salud, educación, servicios sociales), siendo única- 
mente los departamentos de servicios sociales los que tienen suborganizaciones dedicadas exclusivamente a la infancia. La tradición asistencialista y caritativa del Estado del bienestar español queda en evidencia en situaciones de crisis. La falta de cohesión social en nuestra sociedad aumenta en una situación como la actual, debido precisamente a esas dos características.

Un aspecto en el que la administración pública ha avanzado en la provisión de bienes y servicios para la infancia es en el desarrollo de planes marco. A partir de la Estrategia de Lisboa de 2000, la Comisión Europea ha incentivado la coordinación de políticas y programas sociales en sus Estados miembros, desde un enfoque de soft-law ${ }^{5}$. La idea principal es garantizar un conocimiento y una coordinación mínimos para poder evaluar las necesidades básicas de las poblaciones que se ha de atender. Los mecanismos son variados y parten de una base de gobernanza multinivel, donde están implicados desde los ayuntamientos hasta la misma Comisión.
Esta coordinación, más conocida como Método Abierto de Coordinación, ha sido utilizada de manera ordenada en diversos aspectos de las políticas sociales, sanitarias y educativas de los Estados miembros. Pero lo que nos concierne aquí son algunos de sus efectos en otras políticas. En España, distintas comunidades autónomas han llevado estas ideas algo más lejos, para diseñar planes en áreas más específicas. Es a partir de ahí que se desarrollan los planes de atención a la infancia y la adolescencia. En el Cuadro 1 se presenta una comparativa entre los planes de la Comunidad de Madrid, Cataluña y el País Vasco.

Esta comparativa nos ofrece una aproximación a la complejidad de las políticas y los programas relacionados con la infancia. Aun considerando que los tres planes tenían el objetivo explicito de coordinar programas, podemos referirnos a la dificultad básica apuntada anteriormente: la falta de transversalidad. Precisamente, es el Gobierno Vasco, con sus planes interinstitucionales, el único que se acerca a este concepto. No es quizás una coincidencia que, de hecho, tenga la tasa de pobreza infantil más baja de España, junto con Navarra.

Cuadro 1. Comparativa de planes de atención a la infancia y la adolescencia. Madrid, Cataluña y País Vasco

\begin{tabular}{|c|c|c|c|}
\hline & Madrid & Cataluña & País Vasco \\
\hline Impulsor & $\begin{array}{l}\text { Instituto Madrileño del Menor y la } \\
\text { Familia (Consejería de Familia y } \\
\text { Asuntos Sociales) }\end{array}$ & $\begin{array}{l}\text { Secretaría de Infancia y } \\
\text { Adolescencia (Departament de } \\
\text { Benestar Social) }\end{array}$ & $\begin{array}{l}\text { Dirección de Política Familiar y } \\
\text { Comunitaria (Departamento de } \\
\text { Empleo y Asuntos Sociales) }\end{array}$ \\
\hline $\begin{array}{l}\text { Coordinación de } \\
\text { leyes, políticas y } \\
\text { programas }\end{array}$ & $\begin{array}{l}\text { - Programa de Protección de } \\
\text { - Pronores } \\
\text { - No Biológicas } \\
\text { - Programa de Adopciones } \\
\text { - Programa de Atención Precoz } \\
\text { - Programa de Intervención Integral } \\
\text { - Puntos de encuentro familiar } \\
\text { - Programa de Vacaciones en Familia } \\
\text { - Inserción sociolaboral de jóvenes }\end{array}$ & $\begin{array}{l}\text { - Ley de Servicios Sociales } \\
\text { - Ley de Derechos y } \\
\text { Oportunidades de la Infancia y } \\
\text { Adolescencia de Cataluña } \\
\text { - Convención de los Derechos de } \\
\text { los Menores (1989) } \\
\text { - Directrices y recomendaciones } \\
\text { europeas e internacionales }\end{array}$ & $\begin{array}{l}\text { - Ley de Atención y Protección } \\
\text { a la Infancia y Adolescencia } \\
\text { (2005) } \\
\text { - I y II Plan Interinstitucional de } \\
\text { Apoyo a las Familias (2005, } \\
\text { 2006-2010) } \\
\text { - Observatorio de la Infancia y } \\
\text { Adolescencia (2007) }\end{array}$ \\
\hline $\begin{array}{l}\text { Coordinación } \\
\text { administrativa }\end{array}$ & $\begin{array}{l}\text { Cofinanciado por la Consejería y el } \\
\text { Fondo Social Europeo } \\
\text { (168 proyectos, desarrollados por } 128 \\
\text { entidades) }\end{array}$ & $\begin{array}{l}\text { - Interdepartamental (entre } \\
\text { departamentos de la } \\
\text { Generalitat) } \\
\text { - Local (por pueblos y ciudades) } \\
\text { - Sectorial (empresas privadas } \\
\text { y entidades que realizan } \\
\text { actuaciones en infancia y } \\
\text { adolescencia) }\end{array}$ & $\begin{array}{l}\text { A través de los Planes } \\
\text { Interinstitucionales de Apoyo a las } \\
\text { Familias del Gobierno Vasco. }\end{array}$ \\
\hline
\end{tabular}

Fuente: Elaboración propia a partir de los planes autonómicos de atención a la infancia y adolescencia.

\footnotetext{
${ }^{5}$ Es decir, su participación es voluntaria y no hay mecanismos directos de coerción si la 'ley’ no se cumple.
} 


\subsection{El papel del tercer sector}

El tercer sector se ha ido convirtiendo en un factor clave en la restructuración del Estado del bienestar en España. Aunque la existencia de organizaciones caritativas, sobre todo ligadas a la iglesia católica, ha sido consustancial a la historia del país, su desarrollo como proveedoras de servicios del Estado del bienestar se ha intensificado a partir de la década de 1990 , y consolidado en la primera década del siglo XXI. Diversas iniciativas europeas, estatales, autonómicas y municipales han trabajado de manera directa por incluir al tercer sector en la restructuración del Estado del bienestar. Esa incorporación se ha visto claramente reforzada por la elaboración de planes de políticas (por ejemplo, los planes por la inclusión social, o los planes de familia, infancia y adolescencia), que intentan identificar todas las actuaciones que se realizan en ámbitos específicos, con el objetivo de crear actuaciones más acertadas y eficientes.

La irrupción del tercer sector en las políticas sociales es subrayada por varios expertos, como uno de los entrevistados para esta investigación:

El tercer sector, para nosotros, es, desde mi punto de vista, extraordinariamente importante, porque [...] emergiendo desde la [iniciativa] privada con fines no lucrativos, se convierte realmente en un pilar de lo que es el desarrollo del Estado de bienestar. De hecho, esto ha cambiado en España en, yo creo, muy poco tiempo, en diez años. Hace diez años, cuando decías: ‘¿el tercer qué?'. Claro que había entidades, gestión cedida de las administraciones... (Entrevista 11).

\subsection{Tres hipótesis}

En este trabajo nos planteamos tres hipótesis:

\subsubsection{Hipótesis 1: a partir de la crisis, encontraremos nuevos colectivos atendidos por la administración pública y las entidades del tercer sector}

La pobreza, tanto si es una situación que se convierte en permanente como si se consigue temporalizar, tiene consecuencias a largo plazo para la infancia. Hudson (1991) ya encontró que, aun considerando que la pobreza temporal comporta menos riesgos sociales que la crónica, también tiene efectos negativos en el desarrollo de los niños. A partir de una situación de crisis, la familia, como es lógico, recorta gastos. Inicialmente se trata de gastos considerados 'extra' (campamentos de verano, actividades extraescolares), pero esos 'gastos extra' son los que tienen un efecto más grande en el bienestar de los niños. Como destaca Cantó (2006), Huston “subraya que la volatilidad del ingreso familiar puede provocar también estrés emocional en los padres" (1991: 186). Podemos, incluso, ampliar esta afirmación y considerar que ese estrés emocional puede también aumentar entre los menores.
En el caso de España, Gradín y Cantó han encontrado que "la incidencia de la pobreza crónica en España en individuos compartiendo hogares con niños es más del doble que la de aquellos que viven en hogares sin niños" (2009: 8). Aunque los datos presentados por estos autores son del periodo 19942000, muestran grandes diferencias entre países. Por ejemplo, en Dinamarca un hogar con hijos tenía menos posibilidades de ser pobre, sobre todo debido a las transferencias y los servicios que tal familia percibiría. Precisamente, esto refuerza la teoría de Bradshaw, expuesta con anterioridad, de que no son determinantes los factores demográficos o económicos, sino las acciones que realizan los entes públicos ante estos factores.

\subsubsection{Hipótesis 2: la crisis ha provocado una reducción de los recursos que la administración pública y las entidades del tercer sector reciben y, en cuyo contexto, dedican servicios y transferencias a la infancia}

Es bien sabido que una de las consecuencias de la crisis financiera ha sido la reestructuración de las finanzas públicas (y privadas). Esta reestructuración se ha caracterizado por ideologías que premian una menor intervención del Estado en la economía y en la sociedad. Por lo tanto los servicios sociales y educativos que trabajan con infancia en riesgo de exclusión social pueden estar sufriendo esos recortes.

\subsubsection{Hipótesis 3: los colectivos en riesgo de pobreza o exclusión social presentan nuevas necesidades, que están apareciendo a consecuencia de la crisis actual}

A partir de la crisis, las necesidades de los colectivos en riesgo de pobreza o exclusión social no solamente han aumentado, sino que han cambiado. Han aparecido nuevas necesidades, fundamentalmente relacionadas con aspectos materiales.

\subsection{Metodología}

Para elaborar este estudio, se ha utilizado una aproximación metodológica mixta. Por un lado, se han recogido (y analizado) datos cuantitativos, mediante una encuesta a 300 profesionales de 198 entidades y administraciones públicas en cuya realización se han considerado los principales territorios urbanos españoles. La encuesta se ha distribuido a través de Internet, para llegar directamente a los profesionales que trabajan con la infancia. Se mandaron correos electrónicos a las entidades y también se difundió a través de grupos específicos dentro de las redes sociales más utilizadas (como Facebook). Además, se han llevado a cabo quince entrevistas cualitativas. 


\subsubsection{Encuesta}

El uso de encuestas para entender la pobreza es tan antiguo como las propias encuestas. De hecho, una de las primeras utilizaciones de esta técnica de investigación en Gran Bretaña data de finales del siglo XIX y estuvo a cargo de filántropos como Charles Booth y Seebohm Rowntree (Burnham et al., 2004: 84). Estos pioneros de las encuestas sociales estaban muy preocupados por cuestiones de representatividad de aquellos que respondían sus encuestas, hasta el punto que Rowntree encuestó a toda la población. En el siglo XXI, el debate sobre la representatividad de las encuestas siguen abierto, pero ya no se espera hacer encuestas tipo censo, no sólo por el coste prohibitivo que acarrean, sino también porque hay otras maneras de buscar tanto representatividad como resultados válidos. En nuestro caso, elegimos un muestreo no aleatorio, específicamente conocido como bola de nieve. Aunque este método presenta limitaciones a la hora de generalizar los resultados, tiene la ventaja que es "una estrategia muy valiosa para generar una muestra de personas o grupos a los que sería difícil o imposible de acceder de otros modos" (Burnham et al., 2004: 91). En nuestro caso, nos pareció la metodología más apropiada, aunque la combinamos con aspectos del muestreo por cuotas.

En realidad, se han realizado dos encuestas distintas: una a personas que trabajan en órganos de dirección y coordinación de sus organizaciones (en adelante, grupo o colectivo A) y otra a personas que trabajan directamente en la atención directa a la infancia (en adelante, grupo B). Esta distinción se ha considerado importante, ya que las percepciones de ambos grupos pueden ser muy distintas. De hecho, una de las conclusiones diferenciadoras de la encuesta del grupo A frente a la del grupo B es la percepción y visibilización de los resultados de su trabajo: puede observarse cómo la frustración aparece en los profesionales del grupo $B$, quienes expresan en mayor medida (un $11,7 \%$, frente a un $5,3 \%$ en el grupo A) que su trabajo pocas veces se traduce en resultados visibles.

La distribución geográfica de las respuestas obtenidas se puede comprobar en la Figura 1. Barcelona, Madrid, Murcia y Bilbao son las provincias con más respuestas, seguidas por las Baleares y Valencia. El perfil de los encuestados responde, en su gran mayoría, a personal de tipo laboral ( $85 \%$ en el grupo A y $90 \%$ en el grupo B) que lleva más de tres años en su actual puesto de trabajo ( $86 \%$ en el grupo A y $55 \%$ en el grupo B), lo cual es fundamental para que puedan aportar una perspectiva evolutiva de la crisis económica.

\subsubsection{Entrevistas cualitativas}

Además, se han realizado quince entrevistas cualitativas a actores clave en la ciudad de Barcelona y su área metropolitana, a partir de las encuestas (la última pregunta de la encuesta daba la oportunidad a la persona que respondía de dejar sus datos para futuros contactos).
1-5 respuestas

6-10 respuestas

11-15 respuestas

16-20 respuestas

$>20$ respuestas

Total: 300

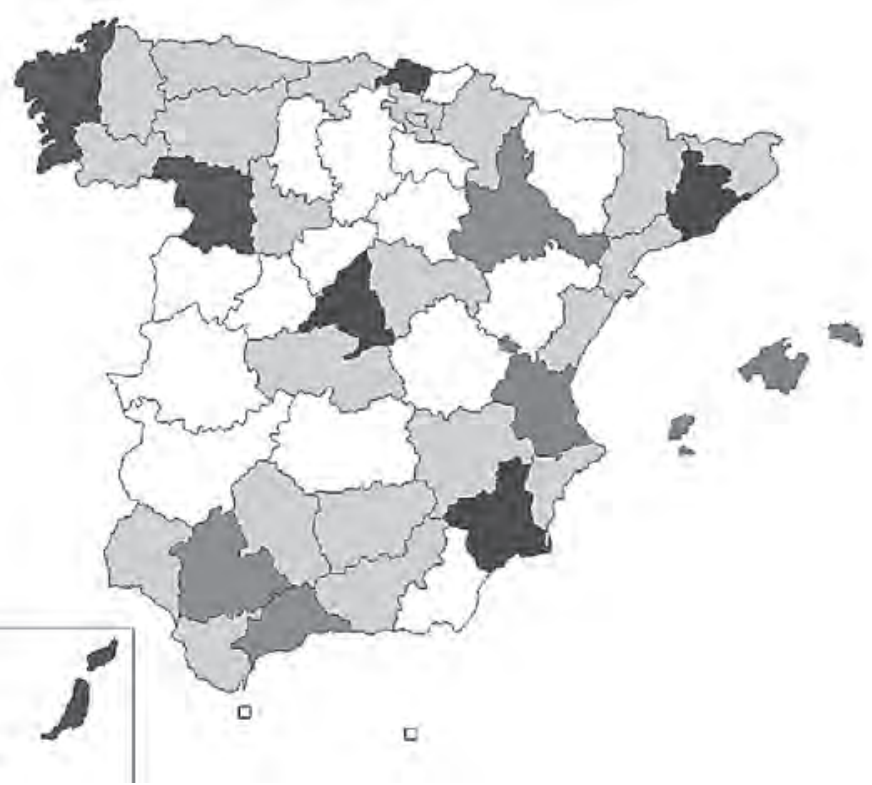

Fuente: Elaboración propia. 


\begin{tabular}{|c|c|c|c|}
\hline Entrevista & Entidad & Colectivo & $\begin{array}{l}\text { Edad de la población } \\
\text { atendida }\end{array}$ \\
\hline $\mathrm{E}_{1}$ & Administración pública & Equipos de Atención a la Infancia y Adolescencia (EAIA) & 0-18 años \\
\hline E2 & Administración pública & Centros de Desarrollo Infantil y Atención Precoz (CDIAP) & $0-6$ años \\
\hline E3 & Administración pública & Justicia Juvenil & 14-21 años \\
\hline E4 & Tercer sector & Acogida & 0-18 años \\
\hline$E_{5}$ & Tercer sector & Infancia & 3-25 años \\
\hline E6 & Tercer sector & Pueblo gitano & General \\
\hline E7 & Tercer sector & Inserción laboral & Adolescentes \\
\hline E8 & Experto & Infancia & General \\
\hline E9 & Tercer sector & Abuso sexual a la infancia & General \\
\hline E10 & Tercer sector & Atención psicológica & $0-18$ años \\
\hline E11 & Experto & Infancia & General \\
\hline $\mathrm{E}_{12}$ & Tercer sector & Educación en el ocio & $0-35$ años \\
\hline E13 & Experto & Infancia y juventud & $0-25$ años \\
\hline E14 & Experto & Infancia e inclusión social & General \\
\hline E15 & Tercer sector & Educación en el ocio & 0-18 años \\
\hline
\end{tabular}

El análisis de las entrevistas cualitativas se ha hecho a partir de lo que se denomina análisis de temas o de marcos. Esto nos ayuda a crear tipologías y a analizar los datos cualitativos recogidos de manera sistemática, es decir, con criterios científicos y rigurosos. Una de las grandes ventajas de la investigación cualitativa es la riqueza de los datos obtenidos, que es prácticamente imposible de reducir de manera agregada. Por lo tanto, como apunta Harrison, "la utilización efectiva de entrevistas cualitativas significa trabajar con citas directas y extensas, para conseguir evidencia ilustrativa de los temas o las tipologías generadas por la investigación" (2001: 103, traducción propia).

\section{Situación de la infancia en riesgo de pobreza o exclusión social, según los profesionales que trabajan en este ámbito}

Esta segunda parte del artículo analiza los resultados del estudio. Aquí, tanto los resultados cuantitativos como los cualitativos son presentados a partir de nuestras tres hipótesis, y de los retos presentes y futuros que aparecen en nuestra investigación: la formación, la coordinación y la prevención.

\subsection{Situación actual y evolución}

Una de las consecuencias de la crisis económica ha sido forzar el cambio de las políticas y los planes de acción de los profesionales del sector. Este cambio (secundado por el $53 \%$ de los encuestados) ha ido dirigido a la reducción del fracaso escolar y a la mejora de las redes sociales de los menores $(46 \%$ y $39 \%$, respectivamente). La encuesta evidencia que, con la crisis, el rendimiento escolar de los menores ha bajado, así como su participación social, lo cual es un claro factor de exclusión social. Cabe destacar también que el cambio de las acciones llevadas a cabo, en el $27 \%$ de los casos, también va en el sentido de cubrir las necesidades vitales de los niños.

El $53 \%$ de las organizaciones no han modificado las acciones que ya venían realizando a raíz de la crisis económica, puesto que el $47 \%$ de las entidades ya trabajaban para reducir el fracaso social, y el $32 \%$, para mejorar las redes sociales de los menores. Uno de los cambios principales se encuentra en los usuarios: un $77 \%$ de los profesionales afirman que se ha incrementado la demanda, lo cual ha aumentado la ratio profesional/personal atendido en el $47 \%$ de los casos. 


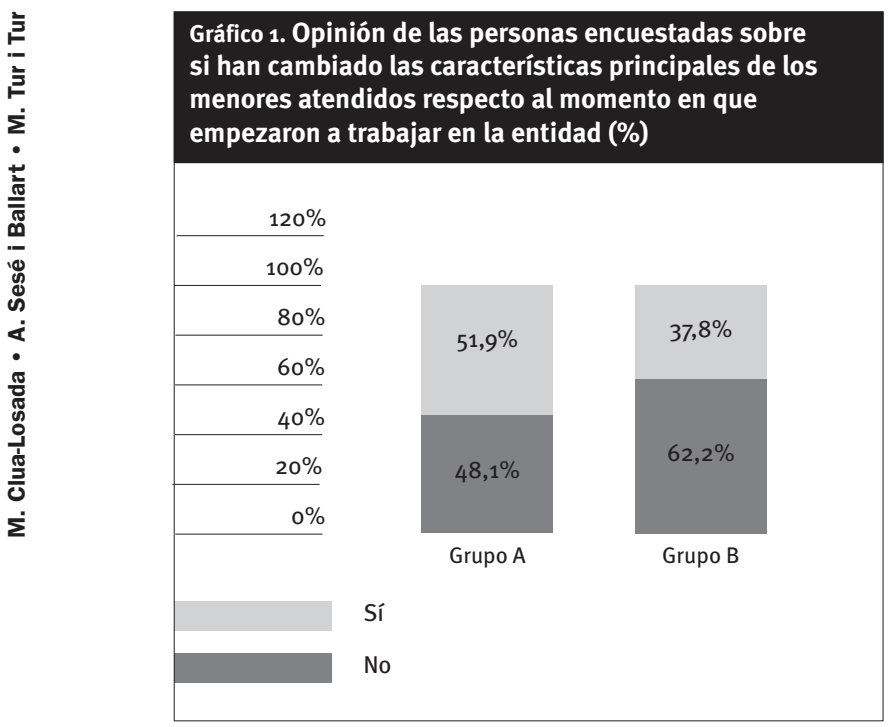

Fuente: Elaboración propia.

Los datos presentados en el Gráfico 1 denotan una distinción entre los profesionales del colectivo $\mathrm{A}$ (cargos con puestos más altos en la jerarquía de su organización) y los del colectivo B (profesionales que trabajan directamente con los niños). Las razones pueden ser diversas, pero es posible que se deba al tipo de información a la que tienen acceso unos y otros profesionales. Tal vez las necesidades aparentes o las características visibles de los menores no han cambiado tanto como sus necesidades objetivas (niveles de renta, situación de desempleo en el hogar).

\subsubsection{Hipótesis 1: existen nuevos colectivos atendidos}

Los resultados de la encuesta a los trabajadores del grupo B muestran que el $41 \%$ de las familias han sufrido un empeoramiento de su economía como consecuencia de la crisis económica, aunque también revelan que la situación laboral de la mayoría de las familias se sostiene gracias a la economía sumergida, y a empleos temporales y precarios, y que la práctica totalidad se dedica a trabajos manuales, no cualificados.

Cuando se analizan las características de los menores con los que trabajan estos profesionales, cabe destacar que sólo el $6 \%$ tienen menos de 4 años, lo cual es una muestra de la invisibilidad de los niños más pequeños, debido a que no hay obligación de escolarizarlos y, por ello, resultan invisibles a ciertos mecanismos de detección de problemáticas relativas a la pobreza y la exclusión social. También cabe destacar los pocos servicios de atención precoz existentes en nuestro Estado del bienestar.

Considerando que la alimentación es una de las necesidades más básicas de un ser humano, y por tanto, la ultima en sufrir una situación de precarie- dad, un $20 \%$ de los encuestados del grupo B creen que los menores con los que trabajan no reciben una alimentación adecuada. Este elevado porcentaje apunta a que la crisis está afectando las necesidades materiales de la infancia. Mayor importancia tiene el hecho de que el $70 \%$ de los encuestados afirmen que estos niños y niñas no disponen de las habilidades motrices, físicas, intelectuales y cognitivas esperadas en niños y niñas de su edad. En esta misma línea, un $81 \%$ responde que el desarrollo escolar está por debajo del esperado y el $44 \%$ afirma que el absentismo escolar es reiterado.

Los profesionales que trabajan con infancia gitana señalan que la situación de este colectivo no ha empeorado con la crisis económica $(51 \%)$, pero que ello no es debido a que no sufran las consecuencias de la crisis, sino al hecho de que la situación que vivían antes de la crisis ya era muy difícil, y a que experimentaban unas condiciones similares a las actuales. Lo que más destaca en referencia a los menores del colectivo gitano son las peores ratios en rendimiento escolar (el $86 \%$ de los encuestados opinan que su rendimiento es inferior a la media) y el absentismo escolar grave (identificado por el $51 \%$ de los encuestados). Donde más se nota la diferencia en este colectivo es en las relaciones sociales, ya que el $71 \%$ de los profesionales que atienden a niños gitanos perciben que éstos únicamente se relacionan con personas e instituciones de sus redes sociales más cercanas.

Cabe añadir que las encuestas dejan un patrón claro de cambio en las nacionalidades de origen de los niños con los que trabajan (o la de sus familias). Se han reducido los niños procedentes de familias latinoamericanas, mientras que han ganado en importancia las familias procedentes del este de Europa. Es de vital importancia mencionar la ralentización en su llegada, aunque es fundamental poder entender las características de las familias llegadas de Europa del Este para poder atender correctamente a los niños y evitar posibles situaciones de exclusión social.

Resulta significativo que, pese a la incidencia de la crisis, el perfil del menor atendido en este tipo de organizaciones siga siendo bastante parecido al anterior a la crisis. Este hecho es percibido por la mayoría de profesionales encuestados de grupo $B$ y no así por la mayoría del grupo $A$, que piensan que sí ha cambiado el perfil. Esta disparidad en la descripción del perfil de los usuarios puede suponer un problema a la hora de realizar políticas y planes de actuación, así como en el momento de redistribuir los recursos entre los colectivos.

En esta misma línea, se ve también disparidad en las respuestas dadas por los colectivos de profesionales A y B a la pregunta de cómo han variado los criterios de acceso a los diferentes recursos existentes. La percepción de que los servicios están sobresaturados y que, por ello, han tenido que endurecerse los criterios es mucho más notoria entre los profesionales del grupo B que entre los del A; es decir, 


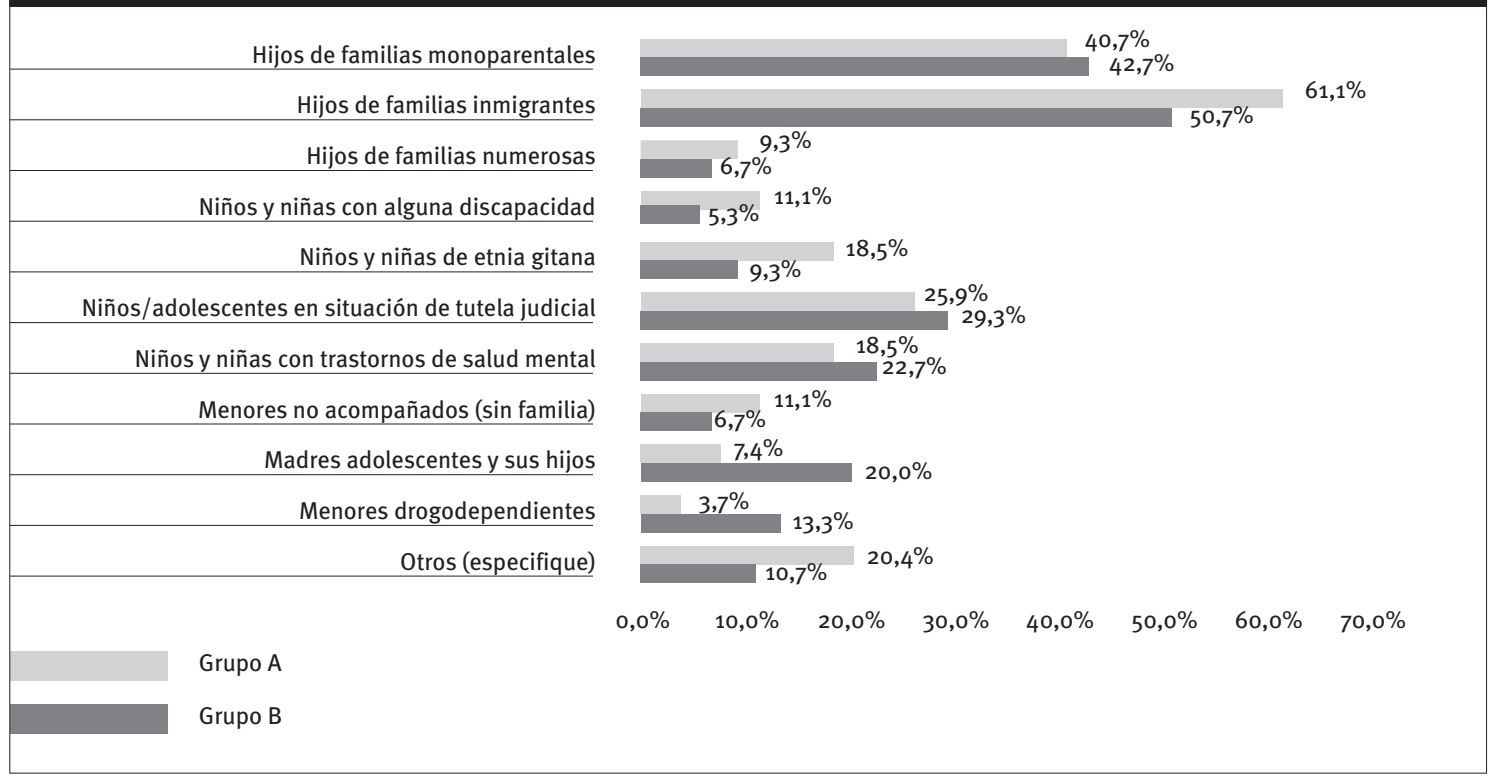

Fuente: Elaboración propia.

resulta más visible entre aquellos profesionales que trabajan directamente con los colectivos en riesgo de exclusión social. Así pues, se percibe una falta de coordinación en cuanto se refiere a la percepción de la realidad y a la aplicación de acciones.

\subsubsection{Hipótesis 2: han disminuido los recursos disponibles}

El último Anuario del tercer sector social de Cataluña (2011) ya apunta que "las entidades no tienen recur- sos propios acumulados para hacer frente a estos momentos de dificultad, hecho que provoca que las tensiones económicas se tengan que gestionar a partir de las cuentas de explotación en curso" (Vidal y Güell, 2011: 116). Esta situación se evidencia tanto en las entrevistas cualitativas como en la encuesta a los profesionales del colectivo $A$, y no sólo en Cataluña, sino que la situación se reproduce en el resto del Estado.

Aunque existe un acuerdo sobre la disminución de los recursos de los que disponen las organizaciones

\section{Gráfico 3. Opinión de las personas encuestadas sobre si han cambiado los presupuestos o los recursos de que disponen} para llevar a cabo su trabajo dentro de la organización (\%)

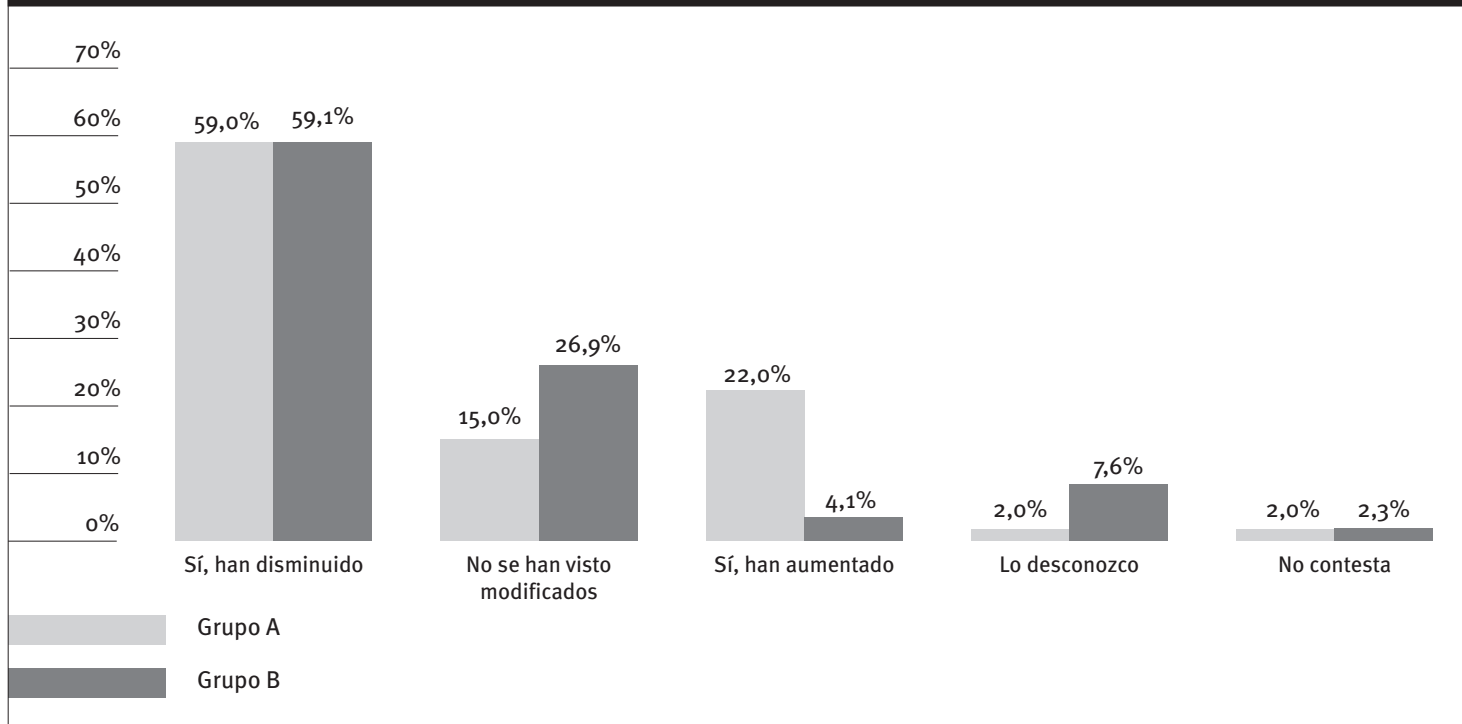

Fuente: Elaboración propia. 
y los profesionales para llevar a cabo sus labores, lo interesante es la percepción tan distinta sobre el aumento de recursos que los profesionales de los grupos $\mathrm{A}$ y $\mathrm{B}$. En el caso del grupo A, un $22 \%$ afirma que los recursos han aumentado a partir de la crisis, frente a tan sólo 4,1\% que responden lo mismo en la encuesta B. Hay dos posibles explicaciones lógicas para entender esta disparidad. Por un lado, los recursos pueden haber aumentado, pero al haberlo hecho también las necesidades, el aumento no se percibe como tal (ya que, en términos relativos, no es un aumento). Una segunda explicación podría relacionarse con los diseños presupuestarios y las fuentes de tales presupuestos. Algunas entidades están recibiendo ahora subvenciones solicitadas anteriormente, aunque con posibilidades limitadas e inciertas de continuidad en un futuro, como apuntan varias de nuestras entrevistas cualitativas.

Intentando profundizar un poco más en este punto, nuestro estudio ha considerado el origen de los recursos (público frente a privado), además de cómo dichos recursos están variando (o no) a partir de la crisis. Es interesante lo que nos apunta uno de los profesionales entrevistados:

Hay proyectos que son un $100 \%$ públicos, y otros un $100 \%$ privados. Pero realmente los fondos privados son los que nos permiten, y son los que..., sobre todo las donaciones libres totalmente, las que nos permiten innovar, tener una incidencia social, el poder decir.... 'empiezo un centro abierto para jóvenes sin hogar’ (Entrevista 12).

Es precisamente la libertad que dan los fondos privados lo que permite innovar, y es difícil mantener el equilibrio entre la libertad para innovar y la garantía de que los recursos son invertidos en programas efectivos. Uno de los problemas de la distribución de recursos son las necesidades regulativas, administrativas y evaluativas de las administraciones (e incluso de algunas entidades que aportan recursos). Es cierto que una distribución eficiente de recursos, bien administrada y capaz de evaluarse mediante criterios objetivos debe ser una prioridad de cualquier organización que aporte recursos. Pero unos criterios demasiado estrictos, con criterios de evaluación a corto plazo y poco compromiso de continuidad pueden perjudicar de manera directa justo a aquellos proyectos que requieren mayor flexibilidad y tiempo para conseguir incidir positivamente en los colectivos con los que se trabaja. Como apunta el siguiente profesional:

Tenemos un centro del Raval que hace las funciones de un centro abierto, hace el seguimiento individualizado del niño, con los profesionales necesarios, y están haciendo una labor. Pero no pueden ser un centro abierto, porque habitan en un campanario, porque son de la parroquia, y porque las salas del esplai [educación en el tiempo libre] están en un campanario, literalmente. ¿Podrán ser un centro abierto? No, si la Administración nos pide que los baños deben hacer tanto por tanto, y que... Es ideal, así debe ser. Tenemos que poder acondicionar los espacios lo mejor posible, pero claro, mientras acondicionamos los espacios... Es el pez que se muerde la cola. Mientras no haya recursos para habilitar el espacio, el espacio no se habilita; por lo tanto, no es un centro abierto; por lo tanto, nunca tendrá los recursos (Entrevista 15).

El gran reto de los recursos en la situación de crisis actual no afecta únicamente a las posibilidades de crear nuevos centros, sino también a cómo se pueden o no mantener los servicios actuales en una situación de recortes presupuestarios como la actual. Uno de los profesionales nos explica cómo están afectando los recortes presupuestarios de las administraciones públicas:

Los centros crecen, hay más demanda, pueden mantener las plantillas, pero claro, las mismas plantillas para ratios superiores. La ratio por profesional contratado aumenta, y el resto lo cubren con voluntariado; la ayuda tampoco aumenta. De recortes, ha habido; ahora, en becas, hay administraciones que nos han recortado las ayudas, porque no había suficiente para estas medidas. La relación con la Administración es buena, y el contraste que hacemos es bueno, pero tienes que picar piedra. [...] todo se sustenta con pinzas, la subsistencia de algunos de nuestros centros se resuelve en la inmediatez: tengo tanto dinero, y a final de mes, debo pagar tanto, y me quedo a cero. Un mes malo es un mes en que no cobran. Está colgando de un hilo, es débil; mientras no haya un mayor reconocimiento social y de la Administración, es débil (Entrevista 15).

La situación de muchas entidades cuelga de un hilo muy fino. Como apunta una de las personas entrevistadas, como mucho, se pueden mantener programas a un año vista:

Cuando vas viendo otras organizaciones que ya están con EREs [expedientes de regulación de empleo], que están con tal..., pero la verdad es que aquí la estructura..., como somos muy pequeños, o sea, que lo que destinamos a proyectos es la mayoría, no se ve afectado, aunque va constante. Pero si un financiamiento cae, te cae el proyecto, pero no cae la entidad, no tiembla todo. A pesar de esto, cada año todos los centros, como dependemos tanto de fondos públicos, hacemos el presupuesto, y todos los directores están temblando al decir: 'bueno, este año tal vez no llegamos, después termina el año y sí..., no será el 2011 el peor, no, es que el 2012 aún será peor’. De momento, vamos aguantando, pero estamos atentos, porque... (Entrevista 7). 
Cuadro 3. Indicadores de exclusión/integración utilizados en el estudio

\begin{tabular}{|c|c|c|c|}
\hline Ámbitos vitales & Grave & Moderado & Leve \\
\hline Empleo & Exclusión del mercado laboral & Acceso precario & Exclusión del empleo estable \\
\hline Situación económica & Carencia de gastos básicos & Dificultades con gastos básicos & Dificultades con otros gastos \\
\hline Vivienda & Exclusión del acceso a la vivienda & $\begin{array}{c}\text { Precariedad y gasto excesivo en } \\
\text { vivienda }\end{array}$ & $\begin{array}{c}\text { Privación de equipamientos } \\
\text { básicos }\end{array}$ \\
\hline Educación & Desescolarización & Acceso limitado & Deficiente cualificación \\
\hline Salud & Exclusión del acceso a la salud & $\begin{array}{l}\text { Precariedad por motivos } \\
\text { de salud }\end{array}$ & $\begin{array}{l}\text { Cronicidad por carencia de red } \\
\text { social }\end{array}$ \\
\hline Interacción social y familiar & $\begin{array}{l}\text { Carencia o conflictividad en } \\
\quad \text { relaciones primarias }\end{array}$ & $\begin{array}{l}\text { Carencia o conflictividad de red } \\
\text { de apoyo social }\end{array}$ & $\begin{array}{l}\text { Carencia o conflictividad de } \\
\text { alguna red de relaciones sociales }\end{array}$ \\
\hline Relaciones sociales & $\begin{array}{l}\text { Conductas delictivas } \\
\text { o antisociales }\end{array}$ & $\begin{array}{l}\text { Conductas asociales o } \\
\text { conflicto familiar }\end{array}$ & $\begin{array}{l}\text { Conductas delictivas, asociales o } \\
\text { conflicto familiar en el pasado }\end{array}$ \\
\hline
\end{tabular}

Fuente: Ministerio de Sanidad y Política Social (2009: 32).

\subsubsection{Hipótesis 3: existen nuevas necesidades}

El diseño del cuestionario se realizó a partir los indicadores de exclusión/integración del Plan de Lucha contra la Exclusión Social en Navarra 19982005, adaptados por el Observatorio de Procesos de Exclusión e Incorporación Social (Cuadro 3).

Una perspectiva como la señalada en el Cuadro 3, que no es solamente multidimensional, sino que también tiene en cuenta la intensidad de exclusión, permite avanzar en la prevención. Es decir, aunque es evidente que debemos actuar en situaciones de exclusión graves, se puede anticipar qué situaciones de exclusión leves pueden ser un buen punto de partida para la prevención. Por lo tanto, esta mirada nos ayuda a ver cómo las necesidades de la infancia en riesgo de exclusión social o pobreza se manifiestan a partir de distintas dimensiones e intensidades.

Para indagar en esta tercera hipótesis, se preguntó a los profesionales del grupo $B$, aquellos que atienden directamente a los colectivos de infancia que nos interesan para esta investigación. La primera pregunta que se les hacía a este respecto trataba de determinar el punto de partida de los colectivos con los que trabajan estos profesionales.

Como podemos comprobar, queda en evidencia que una gran parte de los niños atendidos por estas organizaciones se encuentran en una situación de exclusión moderada (70\%), y un $21 \%$, en exclusión social grave (recuérdese el Cuadro 3 ).

\section{2. ¿Nuevos y viejos retos?}

A través de esta investigación ( $y$, sobre todo, a través de los datos obtenidos en las entrevistas cualitativas) hemos identificado tres retos básicos en la lucha contra la exclusión social y pobreza infantil: la pre-

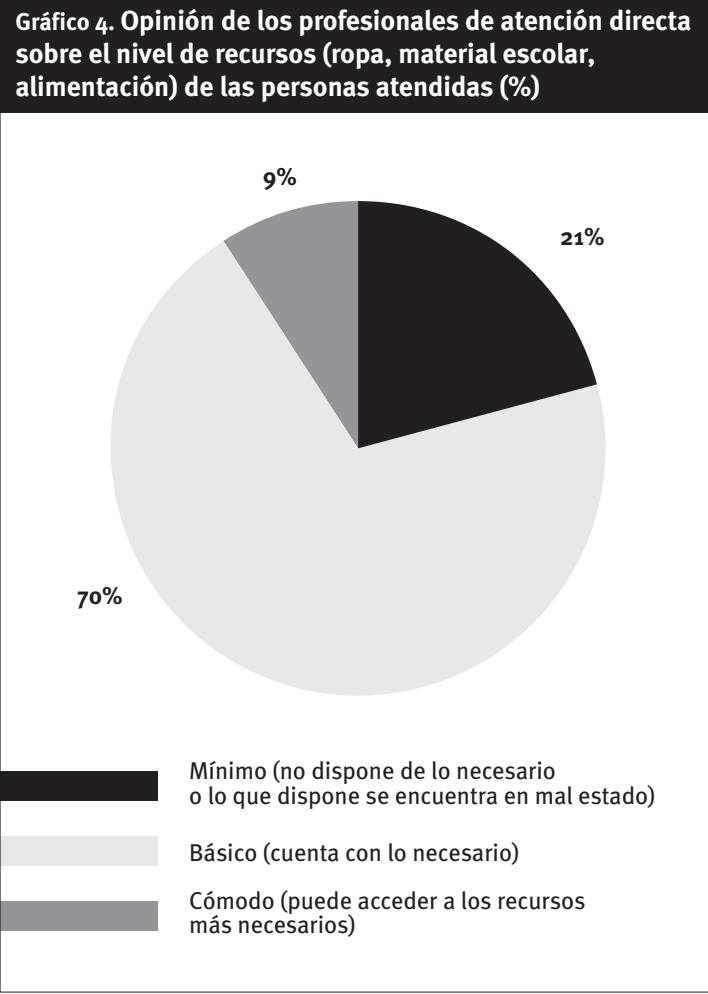

Fuente: Elaboración propia.

vención, la coordinación y la formación. No son retos que se excluyan mutuamente; al contrario, como se indicaba en una entrevista, van íntimamente ligados:

Una de mis grandes preocupaciones es que no puede ser que seas una criatura de 8 años, tengas un problema y la Administración intervenga porque tienes un problema determinado. Estoy de acuerdo [en] que es una lotería, que si en vez de esta familia te hubiera tocado otra..., pero lo que 
no puede ser es que la lotería también sea de jla problemática que tengas! Si se ocupa de ti una entidad u otra puede haber muchas diferencias: muchas veces pasa por el sueldo que pagan a los profesionales, su nivel de formación..., son muchos los elementos que afectan. Hay poca regulación de este tercer sector. [...] Esto se ha ido trabajando y se ha ido reduciendo con el tiempo, pero aún queda mucho trabajo por hacer. Tal y como está estructurado el sistema, al final siempre acaban sufriendo las consecuencias los mismos: aquellos a los que precisamente el sistema intenta dar respuesta. Esto no tiene sentido. El sistema está organizado de una manera que no da respuesta a quien debe dar respuesta. Si queremos cambios, debemos organizarnos de otra manera (Entrevista 8).

\subsubsection{Prevención}

Hay dos aspectos claves en la idea de la prevención relacionada con la infancia en riesgo de pobreza o exclusión social. De un lado, la prevención es necesaria a lo largo del ciclo vital, para evitar que personas en situaciones de riesgo terminen excluidas. Por otro lado, está la prevención entendida desde un punto de vista más individualizado, de una actuación temprana para evitar las dificultades en el desarrollo psicomotriz e intelectual en la infancia en riesgo; es decir, actividades y actuaciones relacionadas con la atención precoz a la infancia, tradicionalmente poco desarrolladas en el Estado del bienestar español. Esta actuación precoz es un ámbito crucial de prevención, como apunta la Unicef (2010: 27):

Los niños que se quedan atrás comienzan a hacerlo ya en las primeras fases de su vida. $Y$ en esta sencilla afirmación, nos encontramos frente a uno de los resultados que tienen mayor importancia, pero menos reacciones suscitan en nuestra época. Durante el embarazo y en las primeras semanas y meses de vida, se cumplen una tras otra, en rápida sucesión, etapas decisivas del desarrollo mental y físico del niño. Cada etapa sirve de base para la siguiente. Cualquier tropiezo en la primera infancia puede, por lo tanto, poner en peligro las etapas subsiguientes del crecimiento y el desarrollo. En otras palabras, la desventaja en las fases tempranas de la vida puede comenzar a modelar la neurobiología del niño en desarrollo y dar inicio a un proceso que, una vez empezado, tiende a reforzarse de por sí.

El problema es que aunque "una buena sociedad debe tener capacidad para un trabajo preventivo", en el caso español "casi todos los recursos se utilizan en programas para paliar o reducir situaciones de carencia" (Montagut, 2011: 46). Como se señalaba en la entrevista 1, aunque existen redes de prevención, acaban siendo ineficaces, ya que no están institucionalizadas.

\subsubsection{Coordinación}

Aunque se han hecho grandes avances en coordinación, y sobre todo, las entidades del tercer sector son cada vez más conscientes de la importancia de evitar duplicidades en servicios, todavía hay problemas en este ámbito. La coordinación es relativamente efectiva en los escalafones más elevados de la pirámide decisoria. Muchas organizaciones del tercer sector y administraciones públicas han creado foros donde representantes de cada entidad se reúnen para acordar acciones comunes y desarrollar programas más efectivos, intentando evitar duplicaciones. En Cataluña, por ejemplo, se han visto diversas iniciativas en los últimos años destinadas a mejorar la coordinación entre las entidades del tercer sector. Tres han sido las más exitosas a la hora de motivar a las entidades a coordinarse:

- Federació d'Entitats d'Atenció i d'Educació a la Infància i a l'Adolescència (FEDAIA): nació en 1994 y se ha ido convirtiendo en un referente para todas las entidades que trabajan con infancia y adolescencia en riesgo de exclusión social.

- Taula d’Entitats del Tercer Sector Social de Cataluña: esta mesa coordinadora nació en $\mathbf{2 0 0 3 ,}$ aglutina a todo tipo de entidades que trabajan en la acción social -en un sentido amplio- y también intenta influenciar la agenda política. Desde el 24-II-11, tiene además una plataforma de infancia.

- Entitats Catalanes d'Acció Social (ECAS): esta federación aparece el mismo año que la Taula, y aunque de carácter generalista, reúne a entidades que trabajan directamente con colectivos en riesgo de exclusión social (tanto en infancia, como con personas adultas).

La coordinación, incluso en los escalafones más altos de la pirámide, no es fácil. El problema se plantea, según la mayoría de entrevistas, en lo que afecta al niño o la niña. Ha habido grandes avances en la coordinación de entidades y programas con la administración pública, pero éstos no toman al niño como eje principal, sino la actuación social.

\subsubsection{Formación}

Muchos de los profesionales que han respondido a nuestra encuesta, y muchos de los que hemos entrevistado de manera cualitativa apuntan de manera clara a una falta de formación específica de los profesionales que trabajan con infancia: o bien son profesionales capacitados para trabajar con infancia, pero no en situaciones de riesgo, o bien son profesionales generalistas (por ejemplo, psicólogos) sin una formación específica para trabajar con infancia.

\section{Conclusión}

Este artículo presenta los resultados de un estudio diseñado para esbozar la situación de la infancia en 
riesgo de pobreza o exclusión social en España. Ese estudio se ha basado en la recogida de datos a través de una encuesta a 300 profesionales pertenecientes a 189 organizaciones que trabajan directamente con infancia en riesgo. Además se han realizado quince entrevistas cualitativas en Cataluña.

Se planteaban tres hipótesis. La primera afirmaba que, a partir de la crisis, encontramos nuevos colectivos atendidos por la administración pública y las entidades del tercer sector. En este caso, nuestro artículo señala una situación complicada. Por un lado, aquellos colectivos que estaban en riesgo siguen estándolo. Por otro, algunos colectivos han aumentado entre los que acuden a esos recursos, debido a que anteriormente vivían una situación de precariedad controlada (por ejemplo, algunos colectivos inmigrantes).

La segunda hipótesis, que sostenía que la crisis ha provocado una reducción de los recursos que la administración pública y las entidades del tercer sector reciben y, en cuyo contexto, dedican servicios y transferencias a la infancia, también recibe una respuesta ambivalente. Si bien se nota una gran inseguridad en cuanto a recursos, el efecto de los recortes todavía no se ha manifestado de manera directa. Pero el problema llegará, porque los programas actuales no cuentan con una financiación segura, ni con un proyecto de financiación futura, y sus posibilidades empiezan a verse como sujetas por un hilo.

En cuanto a la tercera hipótesis, que apuntaba hacia las nuevas necesidades que puedan presentar estos colectivos a raíz de la crisis actual, se observa que sí existe un aumento de las necesidades materiales de estos colectivos. Por último, se han considerado los principales retos en la lucha contra la pobreza o exclusión social de la infancia, y, a este respecto, han aparecido de manera inequívoca tres retos: la formación, la prevención y la coordinación de los servicios que atienden a estos colectivos.

Este estudio también nos ha ayudado a identificar necesidades de investigación futura. Es necesario invertir en investigaciones sociales donde el menor sea la unidad de análisis, no necesariamente su hogar o familia. Aunque en este estudio, nos hemos acercado a una aproximación al menor a través de los profesionales, se trata de un enfoque insuficiente. Los análisis de datos agregados todavía esconden más la situación del menor, ya que:

Partiendo de la información recogida en los hogares, se asigna a cada niño su participación en el total de ingreso o gasto del hogar. Esta consideración del hogar como unidad primaria de análisis, con independencia de si el interés final se centra o no en el individuo, tiene otras implicaciones [...], no todos los individuos tienen las mismas necesidades, y esto es especialmente importante cuando nos ocupamos de la pobreza infantil (Cantó, 2006: 190).

Por último, se debe reiterar que necesitamos una aproximación a la infancia que tome el niño o niña como eje vertebrador de cualquier política y programa. Únicamente a partir de un enfoque de derechos de la infancia, que supere la perspectiva familiar, las necesidades y los derechos de la infancia conseguirán no sólo visibilidad, sino también un avance en la dirección necesaria para el desarrollo de un Estado del bienestar. 
ADELANTADO, J. (coord.) [2000]: Cambios en el Estado del Bienestar. Políticas sociales y desigualdades en España, Barcelona, Icaria,

ARRIBA, A.; y MORENO, L. (2005): "Spain - poverty, social exclusion and 'safety nets", en FERRERA, M. (ed.), Welfare State Reform in Southern Europe. Fighting Poverty and Social Exclusion in Italy, Spain, Portugal and Greece, Abingdon, Routledge.

BRADSHAW, J. (2002): "Child poverty and child outcomes", Children \& Society, vol. 16, no2, págs. 131-140.

BURNHAM, P.; et al. (2004): Research Methods in Politics, Basingstoke, Palgrave Macmillan.

CANTÓ, O. (2006): “Pobreza y exclusión social de la infancia en España”, en VIDAL, F. (ed.), V Informe FUHEM de políticas sociales: la exclusión social y el Estado del bienestar en España, Madrid, FUHEM.

COMISIÓN EUROPEA (2009): Joint Report on Social Protection and Social Inclusion 2009, Luxemburgo, Oficina de Publicaciones de la Unión Europea [rhttp://dx.doi. org/10.2767/51562>].

ESPING-ANDERSEN, G. (1993): Los tres mundos del Estado del bienestar, Valencia, Edicions Alfons el Magnànim.

FERRERA, M. (2005): "Welfare states and social safety nets in Southern Europe: An introduction", en FERRERA, M. (ed.), Welfare State Reform in Southern Europe. Fighting Poverty and Social Exclusion in Italy, Spain, Portugal and Greece, Abingdon, Routledge.

GALLEGO, R.; GOMÀ, R.; y SUBIRATS, J. (eds.) [2003]: Estado de Bienestar y comunidades autónomas, Madrid, Tecnos.

GRADÍN, C.; y CANTÓ, O. (2009): Why are child poverty rates so persistently high in Spain?, serie Working paper, $\mathrm{n}-2009-123$, Society for the Study of Economic Inequality [<http://www.ecineq.org/ milano/WP/ECINEQ2009-123.pdf)].

HARRISON, L. (2001): Political Research: An Introduction, Londres, Routledge.

HUSTON, A. C. (1991): “Children in poverty: Developmental and policy issues", en HUSTON, A. C. (ed.):
Children in Poverty. Child Development and Public Policy, Cambridge, Cambridge University Press.

MINISTERIO DE SANIDAD Y POLÍTICA SOCIAL (2009): Pobreza y exclusión social de la infancia en España, Madrid, Instituto UAM-Unicef de Necesidades y Derechos de la Infancia y Adolescencia, Madrid [<http://www.observatoriodelainfancia.msps. es/productos/docs/pobrezaExcInfEspana. pdf>].

MONTAGUT, T. (2011): La funció del Tercer Sector en l'àmbit d'infància, adolescencia i famílies, Barcelona, CIIMU-Instituto de Infancia y Mundo Urbano [<http://ciimu.org/images/stories/CIIMU/ Estudios_y_Monografias/Estudi_final_funcio_ tercer_sector_MMontagut_2.pdf $\rangle$ ].

MORENO, L. (ed.) [2009]: Reformas de las políticas de bienestar en España, Madrid, Siglo XXI.

NAVARRO, V. (ed.) [2006]: La situación social en España, Madrid, Biblioteca Nueva.

ONU MUJERES (2011): Gender Mainstreaming [〈http:// www.un.org/womenwatch/osagi/ gendermainstreaming.htm>].

PARELLA, S. (2000): “Las políticas familiares", en ADELANTADO, J. (coord.), Cambios en el Estado del Bienestar. Políticas sociales y desigualdades en España, Barcelona, Icaria.

PARSONS, W. (1995): Public Policy: An Introduction to the Theory and Practice of Policy Analysis, Londres, Edward Elgar.

RENES, V.; y LORENZO, F. J. (2011): La acción frente a la pobreza infantil. Informe final, Madrid, FOESSA.

UNICEF (2010): Los niños dejados atrás. Una tabla clasificatoria de la desigualdad respecto al bienestar infantil en las naciones ricas del mundo, Florencia, Centro de Investigaciones Innocenti [<http://www.unicef-irc.org/ publications/pdf/rc9_spa.pdf)].

VIDAL, P.; y GÜELL, S. (coords.) [2011]: Anuari $2011 \mathrm{del}$ Tercer Sector Social de Catalunya. Una visió participativa dels reptes de les entitats socials catalanes. Taula d'Entitats del Tercer Sector Social de Catalunya; Observatori del Tercer Sector [rhttp://www.anuaritercersectorsocial. cat/doc/anuari_2011.pdfs]. 


\title{
Análisis de la calidad percibida en usuarios/as de servicios sociales comunitarios
}

\author{
Manuel E. Medina Tornero
}

Facultad de Trabajo Social, Universidad de Murcia

<memedina@um.es>

\section{Elvira Medina Ruiz}

Facultad de Trabajo Social, Universidad de Murcia

Erabiltzaileak zerbitzuan jasotako asebetetzea garrantzizko gaia da, eta kalitate-mailaren neurritzat ulertu izaten da. Horrela, gaiaren ikerketa bultzatzearen garrantzia nabarmentzen da erabiltzailearen behar eta nahietara moldarazteko. SERVQUAL eskala erabiliz, oinarrizko ongizate zerbitzuetako bi zentroetako erabiltzaileek hautemandako asebetetzea eta kalitatearen neurrien araberako aldeak aztertzen dira testuan. Gehienbat balioesten dute profesionalek transmititutako segurtasuna eta konfiantzaren arloa, eta puntuzenbatze baxuena jaso du erantzun ahal izateko gaitasunak, hau da, erabiltzaileen eskaeren aurrean profesionalen artean ematen diren zailtasunegoerak. 7 puntuko mailakatze batean 6,21 puntu jasotzen dira asebetetze-indizea aztertzean, eta, oro har, datua ontzat hartu daiteke bestelako zerbitzuen asebetetze-mailarekin erkatuz gero.

\section{HITZ-GAKOAK:}

kalitatea, hautemandako kalitatea, gizartezerbitzuak, ebaluazioa, SERVQUAL.
La satisfacción de las y los usuarios con la atención recibida se concibe como una medida de control de calidad, y su estudio es importante para conseguir una mejor adaptación a las necesidades y deseos de las y los usuarios. Utilizando la escala SERVQUAL, aquí se analizan algunos aspectos de medida de satisfacción y calidad percibida de los y las usuarias de dos centros de servicios sociales de base. El ámbito más valorado es el de la seguridad y la confianza que transmiten los profesionales en el trato, mientras que el aspecto que presenta menor puntuación es el de la capacidad de respuesta, entendida como la dificultad que tienen los profesionales para hacer frente a las demandas de las y los usuarios. El índice general de satisfacción alcanza 6,21 puntos en una escala de 7 , un buen dato si lo comparamos con otros análisis de satisfacción en prestación de servicios.

\section{Palabras Clave:}

calidad, calidad percibida, servicios sociales, evaluación, SERVQUAL. 


\section{Introducción}

En los últimos treinta años, se han producido importantes cambios sociales, culturales, económicos y tecnológicos que han afectado notablemente nuestra forma de vida y distintos ámbitos de la sociedad, entre ellos la forma en que los ciudadanos perciben las prestaciones de los servicios sociales. También podemos admitir que la población se ha vuelto más exigente hacia lo público, y no es de extrañar que demande prestaciones y considere que deben ser de calidad. Analizando con una cierta perspectiva histórica este proceso, puede afirmarse, sin dudarlo, que se han introducido cambios significativos en el número y la calidad de los recursos disponibles, y también que se han abordado cambios estructurales para satisfacer las nuevas demandas ciudadanas. La importancia que se atribuye ahora a la mejora de la calidad, sin ser nueva, es seguramente una de las transformaciones más llamativas.

Ahora bien, en el proceloso y difícil contexto de los servicios sociales, la calidad es, como señalan algunos teóricos y profesionales que la implementan, el fruto de una sabia receta en la que intervienen perspectivas cualitativamente diferentes, donde aproximar necesidades y expectativas a recursos y oferta sigue siendo la clave, aunque no siempre resulte fácil descifrarla. Es por ello por lo que la satisfacción del usuario o usuaria se ha abierto un hueco entre las medidas de resultado de las políticas sociales y, más concretamente, de los servicios sociales. Puede afirmarse, de este modo, que la puesta en marcha de métodos y canales para escuchar la voz de la persona usuaria constituye una revolución silenciosa, que paulatinamente irá introduciendo un cambio en la cultura de las organizaciones sociales.

La evaluación de las prestaciones y los servicios sociales por parte de las y los usuarios responde a las nuevas exigencias que deben reunir los servicios sociales, tal y como quedan reflejadas en las nuevas leyes de servicios sociales que se han ido aprobando en los últimos años, pero también al compromiso ético tradicional en las disciplinas de la intervención social. No obstante, adoptar modelos de gestión de calidad en ayuntamientos (en ciertos servicios o en su totalidad) implica ir más allá. Significa que la gestión en las organizaciones se hace por algo y, sobre todo, para alguien. Significa que prima la orientación hacia el cliente o usuario/a. Y es aquí, precisamente, donde se demuestra la validez y eficacia del despliegue de la calidad en las instituciones sociales.

\section{Contexto de la calidad}

\subsection{En busca de una definición de calidad}

Un planteamiento acerca de la calidad en las entidades prestadoras de servicios sociales parece que no pueda empezar de otro modo que ofreciendo una definición de qué se entiende por calidad. Pese a la dificultad que ello comporta y, hasta cierto punto, de la arbitrariedad de ofrecer cualquier definición, hemos creído conveniente 'enfrentarnos' a esta tarea, con el objeto de clarificar si existen elementos y argumentos constantes en el intento de definir qué es calidad.

Al término calidad le ocurre lo que a tantos otros a los que su amplia difusión ha terminado por desdibujar su significado, atribuyéndoseles tantos matices que los han convertido en expresiones que encierran sentidos diversos. La etimología remite al vocablo latino qualitas -atis. Nuestro diccionario de la Real Academia Española (1992) define calidad como "la propiedad o conjunto de propiedades inherentes a una cosa, que permiten apreciarla como igual, mejor o peor que las restantes de su especie". El mismo diccionario la define, también, en sentido absoluto, como "superioridad o excelencia".

Pero el enfoque actual de la calidad excede de la idea de un producto o servicio bien hecho o prestado. Tendiendo hacia un enfoque integrador de la gestión, la calidad total se concibe como la mejora continua de la gestión y de los resultados de la organización, de forma que se obtengan productos o servicios que den plena satisfacción al cliente, al menor coste económico posible, y con la participación e implicación de todo el personal de aquélla. Se trata, pues, de una mejora continua de la gestión y de los resultados, de buscar la satisfacción del cliente, y de conseguir la participación y responsabilidad de todos los miembros de la organización.

Según esto, los principios de la calidad total son:

- Mejora continua.

- Satisfacción del cliente.

- Compromiso de la dirección.

- Adhesión del personal.

- Eficiencia económica.

Así pues, la calidad puede ser vista como un resultado, una idea o un valor:

- La calidad es el resultado satisfactorio que se consigue cuando los productos o servicios se organizan y ofrecen de acuerdo con las necesidades y expectativas de los clientes, tanto externos como internos.

- Una idea amplia de calidad la encontramos en Morris (1992): “La calidad se alcanza cuando los servicios que se prestan, según los compromisos adquiridos, se adecuan a las necesidades reales de sus destinatarios y de la comunidad en general, y todo ello se hace de manera económica, efectiva, eficiente y equitativa".

- La calidad muestra el valor de las personas en el desempeño de sus tareas, su satisfacción con el trabajo bien hecho, siempre a la primera y con el empleo de los recursos estrictamente necesarios. 
Analizando las definiciones dadas en obras de carácter general, más que en documentos especializados, hallamos concepciones que pueden agruparse en función del elemento que priorizan, como 'la calidad en el diseño o de las características intrínsecas'; 'la calidad en el proceso o de la calidad como conjunto de maneras de proceder o de hacer'; y ‘la calidad centrada en el resultado o de la satisfacción de los clientes', siendo esta última la que nos interesa para este trabajo.

Existe en la actualidad sobrada evidencia empírica como para reconocer que el modelo de gestión de los centros públicos que opera en nuestro país, sean éstos del ámbito que sean, está sumido en una crisis, cuya influencia sobre la concepción de la gestión de calidad, aunque reclamada y conocida por los expertos su inexistencia, pasa a menudo inadvertida para la sociedad, entre otras razones, por la peculiar naturaleza del servicio que se proporciona -buena parte de cuyos efectos se advierten, principalmente, a medio y largo plazo- y por la escasa referencia a los resultados - a la medida de la eficiencia- y a la comparación, con fines evaluativos, que dicho sector presenta.

\subsection{Calidad de servicio}

La calidad de servicio es una variable de naturaleza compleja si lo pensamos desde la perspectiva que nos ofrece el análisis de sus características específicas. Esta complejidad aumenta si nos referimos a los servicios sociales, pues la prestación del servicio y su consumo, en unas ocasiones se producen simultáneamente, y en otras se retrasa, o nunca llega a producirse. De ahí que se deba estar atento a las emociones y sensaciones que se producen durante su prestación, ya que, a diferencia de otros servicios, son muy importantes para la implicación del profesional con las personas usuarias demandantes.

La conceptualización de la calidad de servicio ha sido un debate que ha suscitado un especial interés. Inicialmente se entendía desde una definición centrada en la realización de un servicio de acuerdo con las especificaciones técnicas fijadas por los prestatarios, abordándose el tema como si de un producto se tratara. Posteriormente, la definición empezó a desplazarse hacia el usuario o usuaria, viéndose desde la perspectiva subjetiva de éste. De esta manera, se pasó de una concepción más técnica y objetiva a otra más subjetiva y centrada en los requerimientos del usuario o usuaria. A partir de esta concepción última (la subjetiva), aparece el término calidad percibida frente al de calidad técnica (Carman, 1990). Sin embargo, Grönroos (1994) ya aportó la idea de que los y las usuarias comparan sus expectativas con el servicio que perciben que han recibido, siendo el resultado de este proceso la calidad percibida del servicio. Si se introduce la percepción, la definición pasa a entenderse desde la óptica del usuario o usuaria; por lo tanto, la única referencia de calidad real es la que existe en la mente de éste/a.

En la literatura sobre calidad de servicio, está ampliamente aceptada la concepción de que la calidad de servicio percibida depende de la comparación del servicio esperado con el servicio percibido y es, por esta razón, el resultado de un proceso de evaluación continuado. Es decir, se trata del resultado de la comparación evaluativa que el usuario hace de la experiencia percibida del servicio con las expectativas que tenía en el momento de la compra o el consumo. Esta definición se adapta al denominado paradigma no confirmatorio aplicado a la satisfacción, el cual establece que la satisfacción se relaciona con el tamaño y la dirección de una experiencia no confirmatoria, donde dicha experiencia es la diferencia entre las expectativas iniciales del individuo y el resultado actual del servicio. Así pues, las expectativas de un usuario/cliente son:

- Confirmadas cuando un servicio conforma las expectativas.

- Negativamente confirmadas cuando el servicio no resulta como se esperaba.

- Positivamente confirmadas cuando el servicio resulta mejor de lo esperado.

\section{Satisfacción del usuario/a}

La satisfacción ciudadana por la calidad de un servicio está relacionada con el conjunto de propiedades que debe tener ese servicio para atender, en primer lugar, las necesidades (explícitas e implícitas) de las personas a las cuales va destinado. Pero esto, aunque sea necesario, no es suficiente, porque la satisfacción va ligada también a la percepción que el ciudadano tiene de cómo se presta el servicio y a la expectativa que tenía respecto al servicio esperado. Esta situación nos lleva a un lugar conflictivo, como es la concepción del ciudadano como cliente de los servicios, y esto sí significa un enorme cambio en las bases políticas de las administraciones, especialmente la municipal. Como bien indica García Roca (1992: 31), “el Estado no se justifica por el respeto a las leyes, la división de poderes y los procedimientos de la toma de decisiones, sino por las prestaciones del Estado que exigen los ciudadanos". Las especiales características de las personas que son receptoras de servicios sociales han conducido a ciertos autores e investigadores a establecer una distinción funcional entre consumidor, usuario/a y cliente.

Para este estudio, nos interesa de forma especial el concepto de usuario/a que hace referencia al ciudadano contribuyente que usa el servicio que le ofrece la Administración -a través de funcionarios o empresas concertadas- de forma gratuita y en igualdad de condiciones. En estas circunstancias, el usuario o usuaria no suele ejercer el derecho a exigir calidad en la prestación. En el modelo de servicio público, cuentan más los intereses de los funciona- 
rios que las expectativas y necesidades de las y los usuarios, quienes normalmente no tienen plataformas de presión eficaces. Ball (1997) llama a este modelo burocorporativo.

Corresponde que nos preguntemos en este momento: ¿qué significa satisfacción del usuario o usuaria? Sobre este criterio se fundamenta gran parte de la filosofía de las organizaciones que muestran algún interés por la calidad. Es tan importante que se convierte en el núcleo de toda la actividad de la organización. Las instituciones que deciden trabajar con criterios de calidad, utilizando alguno de los modelos existentes, planifican, generan procesos, diagnostican, se autoevalúan, toman decisiones, producen servicios, crean estructuras y mecanismos de comunicación para el cliente y en función de éste. Por esta razón, es de gran importancia que podamos definir de forma operativa lo que significa satisfacción del usuario o usuaria. Siguiendo algunas de las reflexiones de Álvarez Fernández (1998), destacamos los dos puntos que tienen gran utilidad para nuestro argumento:

- Identificar los factores críticos de éxito que constituyen el núcleo de las expectativas del usuario o usuaria. Para ello, es fundamental conocer (escuchar) las necesidades y demandas de los y las usuarias, y solicitar su opinión sobre la satisfacción del servicio.

- Destacar la importancia del personal de primera línea (trabajador social, psicólogo, educador), que son las personas claves en el proceso interventivo, de manera especial, cuando surge una situación de conflicto o insatisfacción con el usuario o usuaria: para ello, es necesario conocer el mayor número de aspectos de estos profesionales, con el fin de calibrar el papel que auténticamente desempeñan en la prestación de los servicios.

Por lo tanto, el objetivo de cualquier estudio que desee determinar la percepción de calidad de los y las usuarias de un centro de servicios sociales deberá contemplar, además de los ámbitos ya considerados de cultura organizacional y clima, aspectos y variables actitudinales, como el nivel de satisfacción laboral, el burnout y el compromiso organizacional que presentan los profesionales, puesto que son las personas con mayor contacto con los y las usuarias y, como consecuencia, las responsables de influir sobre la percepción de calidad asistencial que éstos/as puedan tener.

\subsection{Medida de la satisfacción del usuario o usuaria en servicios sociales}

La satisfacción de las y los usuarios con la atención recibida es concebida como una medida de control de calidad, por lo que su estudio y valoración es importante para gestión y el trabajo de los profesionales de los servicios sociales en su conjunto, con la perspectiva de conseguir una mejor adaptación a las necesidades y deseos de las y los usuarios. Autores como Vuori (1982), Suñol (1987), Medina Tornero (1996) o Saturno (1991), además de organizaciones como la OMS, la Unesco y la Federación Española de Municipios y Provincias (Brezmes, 2010), han señalado la pertinencia de introducir la satisfacción de los y las usuarias con los servicios como parte y complemento de otras actividades de control de calidad. Desde nuestra perspectiva, el objetivo principal de conocer la satisfacción de los y las usuarias es obtener datos para llevar a cabo una intervención que permita mejorar las actuaciones profesionales.

La satisfacción del usuario o usuaria en relación al resultado de la asistencia, es decir, su opinión acerca de si el resultado obtenido era el mejor posible, no solía estar incluida en las medidas de satisfacción (Pallares y García, 1996). En las evaluaciones de calidad asistencial sanitaria, tales juicios los realizan normalmente los profesionales, porque no es probable que los pacientes tengan los conocimientos técnicos necesarios para emitir un juicio sobre los máximos beneficios alcanzables por la asistencia sanitaria. Todo esto ha cambiado lo suficiente, llegando, incluso, a la creación de organizaciones de consumidores que asesoran a los pacientes, y de otro tipo de organizaciones de defensa del consumidor que reclaman la participación del paciente en todo lo que tiene que ver con el proceso asistencial (Martínez del Olmo, 1994; Gómez y Saturno, 1997). Sin embargo, los y las usuarias del sistema de servicios sociales sí tienen criterio en muchas ocasiones, incluso los conocimientos necesarios para mantener una opinión definida (Medina Tornero, 1997a; 1997b).

Lo cierto del caso es que algunas medidas de satisfacción en términos de calidad percibida de los servicios se obtienen comparando las percepciones con las expectativas, con ciertas diferencias sutiles. La satisfacción compara las percepciones de los consumidores con lo que normalmente esperarían, mientras que la calidad percibida de los servicios compara las percepciones de los consumidores con lo que un consumidor debería esperar de una empresa que ofrece servicios de elevada calidad; es decir, tal como argumentan Hoffman y Bateson (2002: 324), "la calidad de los servicios parece medir un parámetro más alto de la prestación del servicio".

En este sentido, la calidad percibida de los servicios, por lo general, es más compleja de evaluar que las de los productos, principalmente las características distintivas (intangibilidad, variabilidad, caducidad, y que son producidos y consumidos simultáneamente), aunque éstas pueden variar con mayor o menor intensidad de un empleado a otro, o de un cliente a otro. Por consiguiente, diversos investigadores, entre ellos Hoffman y Bateson (2002), concuerdan en afirmar que la calidad de los servicios es un concepto escurridizo y abstracto, difícil de definir y medir; es por esta razón por la que se le ha dado importancia a la estandarización de los servicios para proveer una calidad consistente. 


\subsection{Calidad de servicio percibida}

Prestigiosos investigadores han estudiado científicamente la calidad de servicio percibida desde diferentes puntos de vista, manteniendo un debate interesante sobre el concepto, la dimensión y la medida de la calidad de servicio. En este apartado, se revisan de forma somera los principales modelos que han ayudado al desarrollo de este constructo (Medina Tornero, 2000).

\subsubsection{El modelo de Parasuraman, Zeithaml y Berry}

La calidad de servicio recibió un fuerte impulso para su aplicación en la gestión de las organizaciones a partir de los trabajos desarrollados, hace años, por Parasuraman, Zeithaml y Berry $(1985,1988,1993$, 1994), cuyo modelo es un punto de referencia obligado en el estudio y la gestión de la calidad.

Específicamente $(1985,1988)$, definen la calidad de servicio percibida como el juicio global del cliente acerca de la excelencia o superioridad del servicio, que resulta de la comparación entre las expectativas de los consumidores (lo que ellos creen que las empresas de servicios deben ofrecer) y sus percepciones sobre los resultados del servicio ofrecido. Indican que, a la hora de evaluar la calidad de servicio, y en ausencia de criterios de carácter objetivo, es necesario llevar a cabo un diagnóstico a partir del análisis de las percepciones de los o las clientes o usuarios/as con relación al servicio recibido (Parasuraman, Zeithaml y Berry, 1988). Por ello, la calidad del servicio queda definida, en este modelo, como la amplitud de las diferencias o brechas que existe entre las expectativas o deseos de los clientes y sus percepciones respecto a la prestación del servicio (Parasuraman, Zeithmal y Berry, 1993).

Teniendo en cuenta las conclusiones alcanzadas en sus investigaciones, estos autores desarrollaron un modelo conceptual de calidad del servicio y diseñaron un instrumento de medida, que identificaron como SERVQUAL (SERVice QUALity), para su evaluación (Parasuraman, Zeithaml y Berry, 1988). El SERVQUAL se fundamenta en la teoría de los gaps (the Gaps models of service quality), la cual explica las diferencias entre las expectativas de los clientes y aquello que realmente obtienen del servicio utilizado (Igami, 2005). El estudio exploratorio de estos investigadores ha sido considerado una innovación dentro del área de evaluación de servicios.

El modelo SERVQUAL se fundamenta en la premisa de que todas las usuarias y usuarios de servicios poseen una expectativa de calidad del servicio que se les oferta. La diferencia entre la expectativa y la percepción se denomina gap (falla), y en ella reside la oportunidad para la mejoría del servicio (Igami, 2005). Después de años de refinamiento de su escala, el SERVQUAL utiliza actualmente cinco dimensiones de abordaje, destinadas a medir la diferencia entre la expectativa del usuario o usuaria y la satisfacción con el servicio.

\subsubsection{El modelo de Grönroos}

En su modelo, Grönroos (1988) define la calidad de servicio percibida conectando las experiencias en calidad con las expectativas en calidad. El autor entiende que las expectativas son función de una serie de factores, tales como la comunicación de mercado, la comunicación boca a oído, la imagen corporativa/local y las necesidades del cliente.

\subsubsection{El modelo de Nguyen}

Nguyen (1991) se basa en el sistema de servucción ${ }^{1}$ para determinar su modelo, que se define a partir de las relaciones entre la imagen de la empresa, el resultado del personal en contacto con el cliente, la organización interna de la servucción, el soporte físico de la servucción, y la satisfacción del cliente. Así pues, según este autor, cuanto mayor sea la percepción del cliente en cada una de estas variables, mayor será su percepción de la calidad del servicio. Por tanto, las variables anteriores son consideradas como factores explicativos de la variable dependiente.

\subsubsection{El modelo de Bolton y Drew}

Bolton y Drew (1991a) presentan la calidad de servicio percibida como la resultante de la satisfacción/ insatisfacción a través de la no confirmación de expectativas, mediante las percepciones de niveles de resultado de los componentes. De su investigación, deriva que un determinante clave de la calidad de servicio global es el desajuste entre resultado y expectativas (Bolton y Drew, 1991b). Entienden que la calidad de servicio es una actitud frente a la empresa y todos sus servicios, mientras que la satisfacción se expresa con respecto al servicio ofrecido personalmente. También concluyen diciendo que es de la calidad de servicio percibida de la que se derivan las intenciones comportamentales.

\subsubsection{El modelo de Bitner}

Bitner (1990) define la calidad de servicio percibida como una consecuencia de la experiencia de satisfacción/insatisfacción. La autora indica que el

\footnotetext{
${ }^{1}$ De una manera sencilla, puede definirse la servucción como el proceso de elaboración de un servicio, es decir, toda la organización de los elementos físicos y humanos en la relación cliente-empresa que es necesaria para prestar de un servicio, y cuyas características han sido determinadas - desde la idea concebida hasta la obtención del resultado- como tal servicio. Resumiendo, podríamos decir que es todo el engranaje necesario que hay detrás de la prestación de un buen servicio. El usuario/cliente no ve la servucción, sino su resul-
} tado. 
paradigma no confirmatorio se da entre el resultado del servicio percibido en una transacción y las expectativas iniciales. Esto afecta a la experiencia de satisfacción/insatisfacción y, posteriormente, a la calidad de servicio percibida, de la cual se deriva la comunicación boca a oído, el cambio de servicio y la fidelidad.

\subsubsection{El modelo de Koelemeijer, Roest y Verhallen}

Koelemeijer, Roest y Verhallen (1983). Estos autores aportan un modelo con una estructura integradora, en la que el resultado y las expectativas se encuentran en tres planos:

- Macro: expectativas y percepciones de resultado respecto a clase-productos.

- Meso: expectativas y percepciones de resultado con respecto al proveedor de servicio.

- Micro: expectativas y resultado percibidos con respecto a una transacción individual.

\subsubsection{El modelo de Grönroos-Gummesson}

El modelo de Grönroos-Gummesson (Gummerson, 1987, cit. por Grönroos, 1994) se propone ayudar tanto a los fabricantes como a las empresas de servicios en la gestión de la calidad. Se basa en dos modelos con dos enfoques separados sobre la descripción de cómo se crea la calidad: a) el modelo 4 Q de Gummesson, basado en la noción de que todo el mundo contribuye a la calidad y de que existen diferentes fuentes de la calidad en una empresa; y b) el modelo de Grönroos de la calidad percibida en los servicios, que trata de la percepción de la calidad. Estos autores proponen cuatro fuentes de la calidad: el diseño, la producción, la entrega y las relaciones. La forma de gestionar y resolver estos aspectos afecta a la calidad percibida por el cliente. Tanto la calidad técnica del resultado de los bienes o servicios como la calidad funcional de los procesos interactivos que implican al comprador y al vendedor están influidas por estas fuentes de la calidad.

\subsection{La calidad y la satisfacción en la administración pública}

Como se ha podido observar, la calidad de servicio y la satisfacción son conceptos muy estudiados en la literatura del marketing. Este desarrollo de la investigación se ha centrado principalmente en el sector privado de la economía. En cambio, el sector público ha sido el que, hasta la fecha, menos ha podido beneficiarse de este tipo de estudios, debido sobre todo a la escasa sensibilidad de sus responsables por conocer las necesidades y expectativas de los ciudadanos.
Como afirma Gaona (2001), la implantación de la gestión de la calidad total en la administración pública, a través de cualquiera de los modelos existentes, suscita reacciones encontradas. Por una parte, se encuentran aquellos que entienden que implantar uno de estos sistemas será la solución a multitud de circunstancias y vaivenes en el servicio público. Y por otra parte se encuentra el escepticismo hacia estos sistemas y procesos de implantación de la calidad total en el sector público. Desde esta última perspectiva, se entiende que en la administración pública, la implantación del modelo de calidad europeo (EFQM) puede resultar un fracaso, debido a la idiosincrasia de las administraciones y de las relaciones que se establecen entre éstas y los ciudadanos. Tanto las acepciones de la calidad en la administración pública como las barreras a las que deben enfrentarse están, en parte, relacionadas con la evolución que ha sufrido, y aún está sufriendo, el modelo de administración pública.

Senlle (1996) indica que los sistemas de gestión de la calidad deben implantarse en la administración pública, no ya por conseguir votos, sino por converger con los países más avanzados de Europa, y aporta diez razones concretas:

- Para asegurar el futuro y la continuidad del equipo.

- Por economía y para reducir el déficit.

- Para mejorar el servicio al cliente interno.

- Para mejorar el servicio al cliente externo.

- Para integrar el cliente a la organización.

- Por mejorar la imagen.

- Para ser más competitivos.

- Para mejorar la gestión.

- Para obtener resultados en los objetivos y la economía.

- Para potenciar el estilo de liderazgo.

En definitiva, la administración pública está adquiriendo cada vez más responsabilidad en su atención al ciudadano, y fruto de ello son las numerosas iniciativas que se están desarrollando para implantar sistemas de certificación, control o de gestión de calidad. En definitiva, se trata de un lento proceso de modernización de las administraciones que se presenta como una necesidad urgente para los ciudadanos a los que sirve. Consecuentemente, las administraciones se enfrentan con el reto de conciliar la satisfacción de los derechos individuales con la atención a los intereses colectivos, de promover la cohesión social y de ejecutar las políticas públicas. Ello justamente en un periodo histórico en el que la globalización y la proliferación de entramados transnacionales de personas y de organizaciones trasladan a la Administración responsabilidades acrecentadas. 


\subsection{Situación actual del análisis de satisfacción en los servicios de base}

Son escasos los servicios sociales que elaboran de manera sistemática estudios de opinión de la satisfacción de las personas que los utilizan. En los casos en los que se realizan, se utilizan cuestionarios, metodologías y enfoques dispares que hacen muy difícil realizar comparaciones y agregar los resultados. Se trata, pues, de un ámbito en el que hay un amplio margen para el desarrollo. La experiencia en materia de evaluación de la satisfacción de las personas usuarias de los servicios sociales va adquiriendo relevancia en los últimos años. En el ámbito de los servicios sociales básicos, se han desarrollado diferentes experiencias de evaluación de la satisfacción de las personas usuarias ${ }^{2}$, aunque hemos de admitir que no con carácter empírico, en su mayoría.

Pero hemos de admitir que, aunque se hagan encuestas de satisfacción a los y las usuarias de servicios sociales, su trascendencia social es escasa, y prueba de ello es la ausencia de referencias en la literatura científica que las avalen o que, simplemente, sirvan para que se conozca su existencia, a diferencia de lo que ocurre en el campo sanitario, en el que hay cientos de artículos sobre análisis de satisfacción de pacientes y sobre aspectos de la calidad percibida, tanto en la sanidad comunitaria como en la hospitalaria.

En el campo general de los servicios municipales, existen algunas referencias publicadas sobre satisfacción percibida de las y los usuarios, por ejemplo, de instalaciones deportivas (Vila, Sánchez y Manassero, 2009; Morales Sánchez, 2003; Gálvez Ruiz y Morales Sánchez, 2011), recogida de residuos (Pérez Morote, 2001) o servicios socioculturales (Catalina, Palacios y Fulgueiras, 2002).

\section{El marco de la calidad en las administraciones públicas}

Cuando se traslada el concepto de calidad al ámbito de las administraciones públicas, no hay que olvidar que, en ellas, concurren una serie de circunstancias que deben tenerse en cuenta, principalmente la enorme variedad de sectores de la vida ciudadana en los que está presente la Administración y, en consecuencia, el elevado número y la gran heterogeneidad de los servicios prestados. Por ello, hablar de calidad

\footnotetext{
${ }^{2}$ En particular, nos referimos a: el estudio Servicios sociales y satisfacción del Ayuntamiento de Reus (2003), que se ha tenido en cuenta para elaborar el plan de calidad de los servicios sociales de ese municipio (2009); las encuestas de satisfacción entre personas usuarias de servicios de atención domiciliaria realizadas en el periodo 2002-2005 en diferentes municipios de Barcelona, con el apoyo de la Diputación de Barcelona; el estudio que la Fundación EDE realizó en el País Vasco sobre la implantación de sistemas de calidad en los servicios locales de la CAPV (2008), y que se refiere la realización de una serie de encuestas a las y los usuarios de servicios sociales; el trabajo de carácter metodológico de Cabrera et al. (2010) sobre la satisfacción de usuarios y usuarias de programas sociales; y la investigación de Sánchez Pérez (2010) sobre la mejora de los servicios sociales.
}

en las administraciones públicas significa, sobre todo, hablar de un nuevo enfoque en su actuación, considerando al ciudadano como cliente, consumidor individual de los servicios prestados.

La calidad debe constituirse en el nexo de unión que garantiza la coherencia de toda la actividad de la organización. Por un lado, trata de conseguir un funcionamiento armónico de la organización (coordinado y que consigue los resultados deseados) y, por otro, debe establecer las bases para la mejora, para la gestión del cambio y la continua adaptación de la organización al entorno. Para ello, aporta diversidad de herramientas y metodologías de trabajo. Por otro lado, la calidad se construye con un liderazgo político y profesional del más alto nivel, plenamente convencido de la necesidad de cambio y comprometido en ello, sobre cinco ejes básicos:

- La satisfacción de la ciudadanía: la prestación del servicio ha de estar claramente orientada al usuario o usuaria, conocer las demandas de la ciudadanía y sus prioridades, evaluar sus expectativas y su satisfacción con el servicio recibido, e incorporar estas opiniones en la planificación y el rediseño del servicio, para su mejora continua.

- Objetivos y compromiso de resultados ante la ciudadanía: deben planificarse las acciones para satisfacer aquellas necesidades, articulando objetivos a corto y largo plazo, explicitando claramente los compromisos que se adquieren ante la ciudadanía en cuanto a resultados en la prestación de servicios y cumpliendo los objetivos con el menor coste posible. Es importante el establecimiento de indicadores, la medición y la evaluación de resultados.

- Los procesos de producción de los servicios: deben identificarse y estudiarse los procesos de gestión de los diferentes servicios, conocerse sus costes, los tiempos de entrega del servicio, la productividad y la posición en relación con los otros municipios (los del entorno y los mejores).

- La satisfacción de las personas que trabajan en la Administración: hay que ser conscientes de la importancia de las personas y de lo necesario de la mejora continua en términos de satisfacción y compromiso. Debe explicitarse claramente a las personas del Ayuntamiento hacia dónde se quiere ir y con qué propósito, lo que da sentido al trabajo de los empleados y, por tanto, aumenta su motivación y compromiso.

- La participación de todos los grupos de interés en la mejora continua y toma de decisiones.

Se define, en consecuencia, la calidad total y la mejora continua como el marco más idóneo para el inicio de una intervención normalizadora y simplificadora de los procesos.

Es evidente que la puesta en marcha de sistemas de gestión de calidad está avanzando en las administraciones españolas, pero estamos aún lejos de poder 
hablar de su generalización. Como suele suceder, hay un grupo de administraciones que lideran la implantación de estos sistemas y son tomadas como referentes por los demás.

Con la publicación, en 1992, de la Ley de Régimen Jurídico de las Administraciones Públicas y del Procedimiento Administrativo Común, se produce un cambio en las relaciones de la Administración con la ciudadanía, al reconocérsele más derechos, hacerse más sencillos los procedimientos e instaurarse el uso de las tecnologías de la información, dentro de la perspectiva de la Administración como entidad prestadora de servicios.

Todos los niveles de la Administración española han realizado un gran esfuerzo por modernizarse y han desarrollado acciones diversas que obedecen, sin embargo, a objetivos comunes, entre los que se pueden destacar: acercar la Administración al ciudadano; mejorar la atención y el servicio prestado, implantando sistemas de calidad y midiendo la satisfacción de ciudadanía y usuarios/as; o lograr una Administración ágil y accesible. A este respecto, es necesario poner de manifiesto que implantar sistemas de gestión de calidad constituye un elemento más dentro de los procesos de modernización en que están incursas la administración general del Estado, las comunidades autónomas y una gran mayoría de entidades locales; unos procesos de modernización basados en la combinación de tres elementos básicos: la simplificación, la información y la tecnología.

\subsection{La calidad de los servicios sociales en las administraciones públicas}

La introducción, en el Sistema para la Autonomía y Atención a la Dependencia (SAAD), de la calidad como concepto y como mecanismo articulador que favorezca el control y la eficacia ha sido, sin duda, uno de los grandes aciertos de la denostada, $y$ al mismo tiempo esperada, Ley 39/20063. Pero ha tenido un efecto multiplicador, ha conseguido que nos interesemos por la aplicación práctica de la calidad y ha logrado que las leyes posteriores incluyeran la calidad como referencia y marco operativo (Medina Tornero y Medina Ruiz, 2011).

El desarrollo de los distintos estatutos de autonomía ha hecho que las comunidades autónomas sean las responsables de otorgar las correspondientes autorizaciones, así como de crear y actualizar los registros de centros y servicios, lo que ha facilitado el cumplimiento de los requisitos y estándares de calidad. También son las comunidades autónomas quienes establecen el régimen jurídico y las condiciones de actuación de los centros privados concertados, además de acreditar a los centros y servicios privados no concertados que prestan servicios a personas mayores en situación de dependencia. Con el fin de

${ }^{3}$ Ley de Promoción de la Autonomía Personal y Atención a la Dependencia. asegurar la calidad de esa atención, se gestiona y asegura la correcta acreditación de centros, y se definen criterios y parámetros como requisitos mínimos para obtener dicha acreditación. En estos momentos, algunas comunidades autónomas están llegando más lejos y han comenzado a elaborar planes de calidad, planes estratégicos y similares.

A partir de nuevas leyes y actuaciones, las comunidades autónomas quieren extender y sistematizar los desarrollos en materia de calidad a las prestaciones que ofrecen los sistemas públicos, con el fin de promover un proceso de mejora continua en la calidad que pueda ser evaluado objetivamente, tanto interna como externamente. Estos planes (se denominen de calidad, de servicios sociales, geriátricos o estratégicos), al igual que los requisitos para recibir la autorización y la acreditación, se han establecido de forma independiente por parte de cada comunidad autónoma, sin que haya un mínimo común. Esta falta de criterios comunes ha dado lugar a que, en cada comunidad, se hayan dado diferentes desarrollos, con distintos grados de complejidad y, por lo tanto, sea difícil establecer un estándar nacional.

Aquí utilizaremos, como marco referencial, la Ley Catalana de Servicios Sociales (Ley 12/2007, de 11 de octubre), que contempla, en el título VII, todo lo concerniente a la calidad y su operatividad en servicios sociales. La calidad viene definida en la ley desde dos perspectivas: por un lado, como principio rector de todo el Sistema Catalán de Servicios Sociales, y por otro, como un derecho de las personas usuarias en su relación con el sistema. Más adelante, se le dedica un capítulo, en el que se establece que el plan de calidad es la herramienta básica para asegurar el desarrollo y la aplicación de los principios de calidad, y se concreta que incluirá "los estudios de opinión y los resultados de los procedimientos de participación de los usuarios y de sus familias" (artículo 85.3c). Por otra parte, en el artículo 10e) de la misma ley, se establece que las personas tienen derecho a "presentar sugerencias, obtener información, poder presentar quejas y reclamaciones, $\mathrm{y}$ recibir respuesta dentro del periodo legalmente establecido". La ley ha dado lugar a un plan de calidad, en el que la calidad de servicio se define por el nivel de satisfacción que las personas usuarias muestran respecto a la actuación de los servicios sociales, particularmente respecto a la satisfacción de sus necesidades y expectativas (pág. 21-25). En consecuencia, la apreciación de la calidad del servicio corresponde a las personas a las que se dirige 0 , en un sentido más amplio, al conjunto de personas o entidades interesadas o afectadas, en una $u$ otra medida, por este servicio (grupos de interés).

El primer eje estratégico del plan de calidad es la mejora de la calidad de las prestaciones en su integridad, incluyendo tanto el proceso de acceso a la prestación como el de seguimiento una vez ésta ha sido concedida. Y el primer objetivo estratégico es, precisamente, el de evaluar la satisfacción de las personas usuarias de las prestaciones garantizadas provistas por el sistema público. 
Pero también debemos contemplar la calidad desde la óptica de los ayuntamientos, que son los últimos responsables de las prestaciones de los servicios sociales comunitarios. Aquí debemos hacer referencia a los esfuerzos de la Federación Española de Municipios y Provincias de aproximar la calidad a los ayuntamientos y de concienciar de su importancia en los procesos de modernización de las entidades locales (Brezmes, 2010). Es de resaltar que también contamos con la experiencia de la trayectoria de gestión de la calidad de un gran número de entidades locales ${ }^{4}$. De gran valor orientativo y documental es el trabajo realizado por la Fundación EDE en el País Vasco entre 2007 y 2009, impulsado por el Gobierno Vasco y con la colaboración de Euskalit, al objeto de fomentar la implantación de la calidad en los ayuntamientos vascos 5 .

En el sistema de servicios sociales, la tendencia parece imparable. La planificación y la gestión de la calidad se van convirtiendo en una exigencia para la contratación y concertación de servicios con la empresa privada. AENOR ya hace tiempo que estructuró la certificación de calidad para las organizaciones de servicios sociales en la Familia de Normas UNE 158000, a partir de unos requisitos mínimos y consensuados ${ }^{6}$ :

- UNE 158101: gestión de centros residenciales con centro de día o centro de noche.

- UNE 158201: gestión de centros de día y de noche.

- UNE 158301: gestión del servicio de ayuda a domicilio.

- UNE 158401: gestión del servicio de teleasistencia.

En 2005, se presentó una adaptación específica de la norma ISO a los Gobiernos locales (ISO IWA 4), cuyos ejes son:

- Desarrollo institucional para un buen gobierno7.

- Desarrollo ambiental sustentable.

- Desarrollo económico sostenible.

- Desarrollo social incluyente.

4 Véanse referencias en Escobar Rando y Gil Valenzuela (2004); Sánchez Aguado (2011); Sacanell (2003); Moya Vaquero (2000); Cercadillo (2008); Del Pozo Herráiz y Sánchez Pérez (2010).

${ }^{5}$ Véase una aproximación en Barbero y Díez Aramburu (2009).

${ }^{6}$ Véase una experiencia de gran interés en Espinosa (2007).

7 El documento IWA 4 proporciona lineamientos para la aplicación de la norma ISO 9001:2000 en los Gobiernos locales, describe ejemplos puntuales que facilitan la interpretación y, además, cuenta con un mapa de procesos que proporciona una guía para organizar la gestión de los Gobiernos locales. Incluye también una herramienta integral de autodiagnóstico, que contiene parámetros de medición de los elementos mínimos que un Gobierno local no puede dejar de tener, y que enriquece la aplicación de las directrices. El IWA 4 tiene como objetivo establecer las directrices para auxiliar al Gobierno local en la implementación de un sistema de gestión de la calidad que cumpla los requisitos de la norma ISO 9001:2000, de tal manera que se logren condiciones confiables de calidad en las actividades que realiza el Gobierno local para satisfacer los requisitos de la población presente en su territorio.
Hoy podemos afirmar, sin miedo a equivocarnos, que la mejora de la calidad de los servicios públicos y, en particular, de los servicios sociales municipales, equivale a la defensa del sistema público de servicios sociales. También podríamos preguntarnos por qué es tan importante la calidad en los servicios sociales comunitarios, de base o de atención primaria. Parafraseando a Ángel Parreño (2007), podríamos indicar lo siguiente:

- Por la estructura de los equipos de atención primaria: complejos, con roles profesionales en constante redefinición, con problemas de estabilidad en la plantilla, con vaivenes políticos y voluble definición de programas y prestaciones.

- Por las características de la toma de decisiones: alta autonomía en la atención y la prescripción profesional, puerta de entrada a un sistema que frecuentemente cierra la siguiente puerta (servicios especializados, con límites definidos e inflexibles), decisiones interinstitucionales.

- Por las dificultades de la vida municipal (resistencias internas a simplificar y agilizar procedimientos), y la tendencia permanente al fraccionamiento de competencias y la creación de nuevos 'chiringuitos'.

- Por la variabilidad de modelos de funcionamiento y de cobertura de necesidades.

Nosotros añadiríamos un motivo más: porque son el rostro que reconocen las y los usuarios, y es preciso que se midan con la necesaria cautela las relaciones que se establecen, de forma que se proceda al análisis de satisfacción de las y los usuarios y se les devuelva la información, con el fin de que sean partícipes del proceso prestacional (Medina Ruiz, 2011).

\section{Metodología}

\subsection{Objetivos}

Esta investigación tiene como objetivo principal evaluar la calidad percibida por los y las usuarias de dos centros de servicios sociales del Ayuntamiento de Murcia, mediante el instrumento SERVQUAL. Para alcanzar este objetivo general, se han propuesto los siguientes objetivos específicos:

- Identificar las principales dimensiones de calidad, según el instrumento SERVQUAL.

- Conocer la opinión que tienen las y los usuarios sobre las dimensiones de calidad.

- Analizar y elaborar conclusiones.

\subsection{Población objetivo}

La recogida de información se ha realizado durante los meses de mayo a julio de 2010. La población objeto del estudio ha sido el conjunto de usuarias y 
usuarios del Centro de Servicios Sociales 'Ciudad de Murcia' y del Centro de Acción Comunitaria 'La Paz-La Fama'. La muestra comprende un total de 41 individuos (hombres y mujeres) que utilizan el servicio de atención primaria de dichos centros. Para llevar a cabo la recogida de datos, nos hemos desplazado a los centros, y a las personas que habían visitado el servicio de atención primaria les hemos ofrecido la oportunidad de responder voluntariamente al cuestionario, mediante una entrevista.

\subsection{Instrumento de análisis}

Hemos utilizado un cuestionario basado en el modelo propuesto por Parasuraman, Zeithmal y Berry (1988) para medir variables tales como la tangibilidad, la fiabilidad, la capacidad de respuesta, la profesionalidad, la cortesía, la credibilidad, la seguridad y la accesibilidad. El presente estudio sólo ha medido la percepción del servicio de atención primaria, debido a que la mayoría de las personas encuestadas eran asiduos a estos servicios, y poseían una confirmación (o no) de sus expectativas, por lo que no se podía medir el gap entre las expectativas y las percepciones del servicio prestado. La Escala SERVQUAL tiene 32 ítems medida y es una escala Likert de 7 puntos que van desde 'totalmente de acuerdo' (7) hasta 'nada de acuerdo' (1). En este caso, el conjunto de las preguntas han sido formuladas de forma positiva, por lo que no ha habido que invertir valores. La administración del cuestionario, con formato de entrevista, se realizó durante los días de atención en las unidades de trabajo social mencionadas. Para el tratamiento y análisis de los datos, se utilizó el paquete informático SPSS 15.0 para Windows.

\section{Análisis de resultados}

\subsection{Datos sociodemográficos}

A continuación presentamos los datos sociodemográficos generales, referidos a las personas que han participado en el estudio, centrándonos en las variables relativas a sexo, edad, estado civil, nivel de estudios y situación laboral.

Como hemos dicho anteriormente, el estudio, se realizó en dos centros de servicios sociales del Ayuntamiento de Murcia. En el centro A, participaron 18 sujetos, y en el centro B, 24. El 59,5\% (seis de cada diez) eran mujeres, proporción desigual que pone de manifiesto el marcado predominio de las mujeres entre los usuarios y usuarias de servicios sociales. Mayoritariamente se encontraban casados o solteros (70\% de la muestra), seguidos de los viudos (19\%), y los separados y divorciados ( $4,8 \%)$.

Por segmentos de edad, el grupo más numeroso es el comprendido entre 51 y 60 años (33,3\%), seguido por el de 31 a 40 años (23,8\%). En cuanto al nivel de estudios, el grupo mayoritario es el de estudios básicos o primarios, con un $42,9 \%$ de la muestra. Se observa un importante número de encuestados sin estudios ( $26,2 \%$ ), siendo más acentuada esa tendencia entre las mujeres que entre los hombres. Otro dato destacable es la ausencia de encuestados con titulación universitaria, ya sea media o superior. No debemos olvidar el progresivo envejecimiento de la población usuaria, así como su feminización y bajo nivel educativo.

En cuanto a la situación laboral de los encuestados, observamos cómo los dos grupos mayoritarios (que representan más de la mitad de la muestra) están formados por desempleados (31\%) y 'otros' (31\%), categoría compuesta principalmente por jubilados y pensionistas. Le siguen los empleados por cuenta ajena $(26,2 \%)$, las amas y los amos de casa $(9,4 \%)$ y los autónomos (2,4\%). Sobresale la ausencia de funcionarios. El resultado está relacionado con las altas tasas de paro que predominan actualmente y con el envejecimiento de la población usuaria, que pertenece generalmente al cupo de 'otros'.

\subsection{Dimensiones de calidad percibida}

Una vez analizadas las variables sociodemográficas que conforman la muestra, se procede a comentar los resultados que miden la calidad percibida del servicio de atención primaria de los dos centros de servicios sociales que han sido objeto de estudio. Recordamos que el instrumento elegido para ello ha sido la escala SERVQUAL. Con él medimos las distintas dimensiones de la calidad percibida del servicio, que se agrupan en cinco bloques (Tabla 1).

Tabla 1. Resultado de las dimensiones de calidad percibida

\begin{tabular}{l|l|c}
\hline Dimensión & Descripción & $\begin{array}{c}\text { Puntuación } \\
\text { media }\end{array}$ \\
\hline $\begin{array}{l}\text { Elementos } \\
\text { tangibles }\end{array}$ & $\begin{array}{l}\text { Apariencia de las } \\
\text { instalaciones, equipo, } \\
\text { personal y materiales } \\
\text { para comunicaciones }\end{array}$ & 6,05 \\
\hline Confiabilidad & $\begin{array}{l}\text { Capacidad para brindar } \\
\text { el servicio prometido en } \\
\text { forma precisa y digna de } \\
\text { confianza }\end{array}$ & 6,39 \\
\hline $\begin{array}{l}\text { Capacidad de } \\
\text { respuesta }\end{array}$ & $\begin{array}{l}\text { Buena disposición para } \\
\text { ayudar a los clientes } \\
\text { a proporcionarles un } \\
\text { servicio expedito }\end{array}$ & 5,73 \\
\hline Seguridad & $\begin{array}{l}\text { Conocimiento y cortesía } \\
\text { de los empleados, así } \\
\text { como capacidad para } \\
\text { transmitir seguridad y } \\
\text { confianza }\end{array}$ & 6,70 \\
\hline Empatía & $\begin{array}{l}\text { Cuidado y atención } \\
\text { individualizada que la } \\
\text { empresa proporciona a } \\
\text { su clientes }\end{array}$ & 6,32 \\
\hline
\end{tabular}

Fuente: Elaboración propia. 
Como observamos en la Tabla 2, los 'elementos tangibles' son los que peor puntuación obtienen en las valoraciones de las y los usuarios, con una media de 6,05. Dentro de éstos, se aprecian diferencias. Lo que mejor perciben es lo relacionado con el aspecto y aseo de los profesionales, que casi obtiene una puntuación de $7(6,98)$, seguido de las instalaciones agradables y atractivas $(6,00)$. Sin embargo, cuando se les pregunta por la modernidad del equipamiento y por los materiales relacionados con el centro, los encuestados los valoran con un 5,81 y un 5,43 respectivamente, unas puntuaciones de las más bajas de todo el cuestionario. El usuario o usuaria interactúa no sólo con el profesional, sino también con los aspectos tangibles asociados al servicio, que dan forma a sus impresiones acerca de la calidad del servicio del centro (Morales y Calderón, 2005).

Tabla 2. Resultado de la dimensión 'elementos tangibles'

\begin{tabular}{l|c|c|c}
\hline & Media & Desv. típ. & Media \\
\hline $\begin{array}{l}\text { Las instalaciones del centro } \\
\text { de servicios sociales son } \\
\text { agradables y atractivas }\end{array}$ & 6,00 & 1,40 & \\
\cline { 1 - 2 } $\begin{array}{l}\text { Los profesionales del } \\
\text { centro de servicios sociales } \\
\text { presentan buen aspecto y } \\
\text { van aseados }\end{array}$ & 6,98 & 0,15 & \\
\cline { 1 - 2 } $\begin{array}{l}\text { El centro de servicios } \\
\text { sociales cuenta con un } \\
\text { equipamiento moderno }\end{array}$ & 5,81 & 1,70 & \multirow{2}{*}{6,05} \\
\cline { 1 - 2 } $\begin{array}{l}\text { Los materiales } \\
\text { relacionados con el centro } \\
\text { (folletos explicativos, } \\
\text { web, cartelería...) son } \\
\text { visualmente atractivos }\end{array}$ & 5,43 & 1,64 & \\
\hline
\end{tabular}

Fuente: Elaboración propia.

En cuanto a la dimensión 'confianza' (Tabla 3), la puntuación media es superior a los elementos tangibles, con un 6,39. La variable que obtiene una mayor valoración es la referida a la manera 'clara y comprensible' de informar, que obtiene 6,86 , casi la máxima puntuación. Le siguen 'el personal del centro realiza bien el trabajo desde la primera vez' $(6,52)$, mantener el sistema de información y registro al día $(6,33)$, cumplir lo que se promete hacer en cierto tiempo $(6,19)$ y la seguridad de las instalaciones $(6,05)$. La dimensión 'confianza' significa que el servicio se brinda sin fallas (McElwee y Redman, 1993). Los usuarios y usuarias esperan que el servicio sea confiable $y$, por ello, puntúan muy positivamente que no haya errores (Prasuraman, Zeithaml y Berry, 1998).

La dimensión 'capacidad de respuesta' (Tabla 4) es la que obtiene la puntuación más baja de las cinco dimensiones, con un 5,73 de media. La dimensión mejor valorada es 'el personal me informa con precisión de cuándo concluirá el servicio ofrecido’ $(6,14)$, seguida de 'los profesionales se encuentran disponibles para atenderme' $(6,00)$. Realizar las actividades con prontitud y atender rápidamente a las peticiones es lo menos valorado, con un 5,71 y 5,05 respectiva- mente, siendo esta última la puntuación más baja de todo el cuestionario.

Tabla 3. Resultado de la dimensión 'confianza'

\begin{tabular}{|c|c|c|c|}
\hline & Media & Desv. típ. & Media \\
\hline $\begin{array}{l}\text { Cuando el personal del } \\
\text { centro de servicios sociales } \\
\text { promete hacer algo en } \\
\text { cierto tiempo, lo cumple }\end{array}$ & 6,19 & 1,06 & \multirow{5}{*}{6,39} \\
\hline $\begin{array}{l}\text { Las instalaciones del centro } \\
\text { de servicios sociales son } \\
\text { seguras }\end{array}$ & 6,05 & 1,78 & \\
\hline $\begin{array}{l}\text { El personal del centro de } \\
\text { servicios sociales realiza } \\
\text { bien su trabajo desde la } \\
\text { primera vez }\end{array}$ & 6,52 & 0,92 & \\
\hline $\begin{array}{l}\text { Los profesionales del centro } \\
\text { de servicios sociales me } \\
\text { informan de una manera } \\
\text { clara y comprensible }\end{array}$ & 6,86 & 0,35 & \\
\hline $\begin{array}{l}\text { Los profesionales del } \\
\text { centro de servicios sociales } \\
\text { mantienen el sistema de } \\
\text { información y registro al día }\end{array}$ & 6,33 & 1,22 & \\
\hline
\end{tabular}

Fuente: Elaboración propia.

Tabla 4. Resultado de la dimensión 'capacidad de respuesta'

\begin{tabular}{l|c|c|c}
\hline & Media & Desv. típ. & Media \\
\hline $\begin{array}{l}\text { El personal del centro de } \\
\text { servicios sociales no está } \\
\text { demasiado ocupado para } \\
\text { responder rápidamente a } \\
\text { mis peticiones }\end{array}$ & 5,05 & 1,62 & \\
\hline $\begin{array}{l}\text { El personal del centro } \\
\text { de servicios sociales me } \\
\text { informa con precisión de } \\
\text { cuándo concluirá el servicio } \\
\text { ofrecido }\end{array}$ & 6,14 & 1,12 & \\
\hline $\begin{array}{l}\text { Los profesionales del centro } \\
\text { de servicios sociales se } \\
\text { encuentran disponibles } \\
\text { para atenderme }\end{array}$ & 6,00 & 1,17 & \\
\hline $\begin{array}{l}\text { Los trabajos relacionados } \\
\text { con la acogida y } \\
\text { seguimiento, tales como } \\
\text { entrevistas, informes, } \\
\text { cuestionarios, etc., se } \\
\text { realizan con prontitud }\end{array}$ & 5,71 & 1,44 & \\
\hline
\end{tabular}

Fuente: Elaboración propia.

La dimensión 'seguridad' (Tabla 5) es la mejor valorada de todas, con una puntuación media de 6,70. Las variables que la componen están relacionadas con el trato recibido por parte del profesional (que obtiene la puntuación máxima, 6,95), la cualificación del profesional y su capacidad para inspirar confianza (6,76 cada una) y la recogida de forma adecuada de las sugerencias y quejas por parte de los profesionales $(6,33)$. Los resultados obtenidos coinciden con los publicados por Instituto Nacional de la Seguridad Social (Pérez Menayo, 2007), que se ha decantado por adoptar el modelo SERVQUAL para avanzar en su estrategia de calidad. En ese estudio, aparece que las 
usuarias y usuarios de los servicios sanitarios conceden una mayor importancia a la variable 'seguridad'.

Tabla 5. Resultado de la dimensión 'seguridad'

\begin{tabular}{l|c|c|c}
\hline & Media & Desv. típ. & Media \\
\hline $\begin{array}{l}\text { El comportamiento de los } \\
\text { profesionales del centro } \\
\text { de servicios sociales me } \\
\text { inspira confianza }\end{array}$ & 6,76 & 0,69 & \\
\hline $\begin{array}{l}\text { El personal del centro de } \\
\text { servicios sociales está } \\
\text { totalmente cualificado para } \\
\text { las tareas que realiza }\end{array}$ & 6,76 & 0,53 & \\
\hline $\begin{array}{l}\text { Los profesionales del centro } \\
\text { de servicios sociales se } \\
\text { muestran dispuestos a } \\
\text { ayudarme, y su trato es } \\
\text { considerado y amable }\end{array}$ & 6,95 & 0,22 & \multirow{2}{*}{6,70} \\
\cline { 1 - 2 } $\begin{array}{l}\text { Los profesionales del } \\
\text { centro de servicios sociales } \\
\text { recogen de forma adecuada } \\
\text { mis quejas y sugerencias } \\
\text { como usuario }\end{array}$ & 6,33 & 1,34 & \\
\hline
\end{tabular}

Fuente: Elaboración propia.

La dimensión 'empatía' (Tabla 6) obtiene una puntuación media de 6,32. Dentro de ella, se observan diferencias entre las variables encargadas de medir la calidad percibida. Lo mejor valorado es el trato personalizado $(6,57)$ y la comprensión, por parte de los profesionales, de las necesidades como usuario/a; pero si hablamos de cómo satisfacen los horarios las necesidades como usuario/a, la puntuación desciende $(5,76)$. Hay autores que apuntan que las bajas puntuación en la dimensión de empatía puede deberse a que el instrumento SERVQUAL podría no cubrir correctamente esta dimensión de la calidad en aquellos casos en los que la interacción profesionalusuario/a es muy intensa (Villegas y Rosa, 2003), como por ejemplo, en servicios sanitarios o de atención primaria en un centro de servicios sociales.

Dentro del cuestionario, se incluyó un ítem a modo de resumen, para que los encuestados hicieran una valoración general sobre el servicio prestado (Tabla 7). La puntuación media de dicha variable es de 6,21.
Tabla 6. Resultado de la dimensión 'empatía'

\begin{tabular}{l|c|c|c}
\hline & Media & Desv. típ. & Media \\
\hline $\begin{array}{l}\text { El personal del centro } \\
\text { de servicios sociales } \\
\text { me ha dado un trato } \\
\text { personalizado }\end{array}$ & 6,57 & 0,97 & \\
\hline $\begin{array}{l}\text { El centro de servicios } \\
\text { sociales tiene horarios } \\
\text { que satisfacen mis } \\
\text { necesidades como }\end{array}$ & 5,76 & 1,49 & \multirow{2}{*}{6,32} \\
$\begin{array}{l}\text { usuario } \\
\text { Los profesionales del } \\
\text { centro de servicios } \\
\text { sociales comprenden } \\
\text { cuáles son mis } \\
\text { necesidades }\end{array}$ & 6,62 & 0,96 & \\
\hline
\end{tabular}

Fuente: Elaboración propia.

Tabla 7. Satisfacción general

\begin{tabular}{l|c|c}
\hline & Media & Desv. típ. \\
\hline $\begin{array}{l}\text { Mis sentimientos hacia los servicios } \\
\text { que presta el centro de servicios } \\
\text { sociales pueden ser descritos como } \\
(1=\text { muy insatisfactorios, }\end{array}$ & 6,21 & 0,78 \\
$\begin{array}{l}7=\text { excelentes })\end{array}$ & & \\
\hline
\end{tabular}

Fuente: Elaboración propia.

Una vez analizado el resultado por variables de las dimensiones de calidad, se procede a relacionarlo con los factores sociodemográficos, con el fin de detectar posibles resultados significativos. En la valoración media de las dimensiones según el sexo, se ha determinado que no existen diferencias significativas entre hombres y mujeres. Sin embargo, a la hora de analizar las variables por distintos grupos de edad (Tabla 9), encontramos diferencias significativas en las dimensiones 'elementos tangibles' y 'empatía'. En elementos tangibles, las y los usuarios que más alto valoran son los del grupo de edad de 31 a 40 años $(6,40)$, seguidos de los de 51 a 60 años $(6,14)$, los de 21 a 30 y 41 a 50 (6,08 cada uno) y, por último, las y los usuarios de más de 60 años $(5,21)$. La diferencia entre el que más alto califica y el que menos es de 1,19. En la dimensión 'empatía', son los mayores de 60 años quienes mejor valoran las capacidades de los profesionales $(6,89)$, mientras que los que peor

Tabla 8. Valoración media, según grupos de edad

\begin{tabular}{l|c|c|c|c|c}
\hline Valor promedio & $\mathbf{2 1 - 3 0}$ años & $\mathbf{3 1 - 4 0}$ años & $\mathbf{4 1 - 5 0}$ años & $\mathbf{5 1 - 6 0}$ años & \multicolumn{1}{c}{$\mathbf{6 0}$ años } \\
\hline Elementos tangibles & 6,08 & 6,40 & 6,08 & 6,14 & 6,21 \\
\hline Confianza & 6,20 & 6,32 & 6,73 & 6,60 \\
\hline Capacidad de respuesta & 5,58 & 5,90 & 6,00 & 5,68 \\
\hline Seguridad & 6,92 & 6,38 & 6,88 & 6,71 \\
\hline Empatía & 6,56 & 6,33 & 6,22 & 6,03 \\
\hline Media total & 6,28 & 6,32 & 6,43 & 6,89 & 6,16 \\
\hline
\end{tabular}

Fuente: Elaboración propia. 
Tabla 9. Valor promedio, según estado civil

\begin{tabular}{l|c|c|c|c|c}
\hline Valor promedio & Soltero/a & Casado/a & Separado/a & Divorciado/a & Viudo/a \\
\hline Elementos tangibles & 6,28 & 6,08 & 7,00 & 6,00 & 5,80 \\
\hline Confianza & 6,41 & 6,31 & 6,80 & 6,55 \\
\hline Capacidad de respuesta & 5,80 & 5,50 & 6,50 & 7,00 \\
\hline Seguridad & 6,72 & 6,55 & 6,75 & 7,00 \\
\hline Empatía & 6,33 & 6,20 & 5,00 & 6,88 \\
\hline Media total & 6,35 & 6,14 & 6,51 & 6,67 \\
\hline
\end{tabular}

Fuente: Elaboración propia.

valoran son los de 51 a 60 años $(6,00)$. En este caso, la diferencia entre ambos es menor, de sólo 0,89. Para el resto de dimensiones, no hay diferencias significativas.

\section{Conclusiones}

Los resultados nos indican que, desde un punto de vista global, no existen grandes diferencias entre las distintas dimensiones de calidad percibida que hemos medido. Sin embargo, como primera apreciación, el análisis muestra tres resultados estrechamente vinculados y que, a efectos del estudio, son importantes: los de 'seguridad', 'confianza' y 'empatía'.

Las dimensiones que mejor han sido valoradas han sido las relacionadas con las capacidades del profesional: su disposición al trabajo, su cualificación, su capacidad para inspirar confianza o cumplir los plazos, entre otras. Las peor valoradas, por su parte, han sido las ajenas a la labor del profesional, los elementos tangibles, los referidos al aspecto y las funciones del centro, y a la capacidad de respuesta, que son aquellas variables que miden la rapidez con que se realiza el servicio, o la disponibilidad de los trabajadores, entre otras.

La primera conclusión que se puede derivar es que la percepción que las y los usuarios tienen de la labor profesional es buena o muy buena. Estos resultados no son novedosos si tenemos en cuenta que el analizado es un servicio de tipo asistencial, en el que el factor humano prima por encima de las instalaciones. En un servicio donde el contacto con el usuario o usuaria es tan elevado como lo es la relación establecida entre el usuario o usuaria y el trabajador social, es lógico que las variables referidas a la labor profesional cobren una mayor importancia. Esto sucede, por ejemplo, al medir la calidad percibida en las y los usuarios de un centro de salud (Villegas y Rosa, 2003).

Los y las usuarias califican por debajo de la media cuando se les pregunta por los elementos tangibles, excepto en la variable 'aspecto y aseo' de los profesionales. Los centros de servicios sociales objeto del estudio no son de nueva construcción, ni están dotados de un equipamiento moderno y visualmente atractivo enfocado a las y los usuarios, lo que conlleva que los usuarios no tengan una calidad percibida alta sobre ellos.

Que los servicios de atención primaria están desbordados es una realidad, y las y los usuarios así lo han manifestado: la dimensión con una calidad percibida más baja es la relacionada con realizar las tareas con prontitud, ya sea una cita por teléfono, una visita o una entrevista. Los profesionales, debido al colapso, no siempre se encuentran disponibles para atender de forma rápida las demandas de usuarias y usuarios. Tener un horario de atención tan constreñido también hace que las citas se demoren y que los y las usuarias tengan que esperar, a veces, hasta un mes, para ser atendidos por el trabajador social. La mayoría, además, contesta negativamente si le preguntan si el horario de atención satisfacía sus necesidades como usuario/a.

Nos encontramos ante un reto importante en los servicios sociales del Ayuntamiento de Murcia y el resto de ayuntamientos. Queremos que se abra paso un cambio en la cultura de los centros, para reorientarlos hacia las y los usuarios. La voz de éstos debe incorporarse al diseño y la evaluación de los procesos asistenciales para determinar el nivel de excelencia alcanzado. 
ÁLVAREZ FERNÁNDEZ, M. (1998): El liderazgo de la calidad total, Madrid, Editorial Escuela Española.

AYUNTAMIENTO DE REUS (2009): Pla de Qualitat dels Serveis Socials, Reus, Ayuntamiento de Reus [rhttp:// www.reus.cat/sites/default/files/Fitxers/ arees/benestar/documents/MvaLeNvUmA. $p d f>]$.

BALL, S. J. (1997): “La escuela participativa en el contexto de la política postmoderna y el market del modelo participativo en U.K”, en GARAGORRI, X., Participación, autonomía y dirección en los centros docentes, Madrid, Forum Europeo de Administradores de la Educación y Escuela Española.

BARBERO, I.; y DÍEZ ARAMBURU, V. (2009): “Orientaciones para la implantación progresiva de sistemas de calidad en los servicios sociales de la CAPV", Zerbitzuan, no-45, págs. 39-47 [ [http://www. zerbitzuan.net/documentos/zerbitzuan/3. pdf〉].

BITNER, M. (1990) "Evaluating service encounters: The effects of physical surroundings and employee responses", Journal of Marketing, n- 54 , págs. 69-82.

BOLTON, R.; y DREW, H. (1991a): “A longitudinal analysis of the impact of service changes on customer attitudes”, Journal of Marketing, $\mathrm{n}$ 55 , págs. 1-9 [<http://www.ida.liu.se/ steho/und/ htddo1/9602205187.pdf>].

- (1991b): “A multistage model of customers'assessments of service quality and value", Journal of Consumer Research, n- 17 , págs. 375-384 [fftp://ftp.cba.uri.edu/Classes/banerjee/ websyagnik/webpage/technology $\% 20$ adoption $\% 20$ and $\% 20$ lifestyles/service $\% 20$ \%20quality\%2ond\%2ovalue.pdf $)$.
BREZMES, Mำ J (2010): Propuesta para la configuración de un modelo actualizado de servicios sociales municipales, Madrid, Federación Española de Municipios y Provincias [<http://www.femp. es/files/566-894-archivo/nuevos_servicios_ sociales._libro.pdf〉].

CABRERA, F. A.; et al. (2010): "Valoración de la satisfacción de usuarios de programas sociales: propuesta de un modelo de análisis", Revista de Educación, no 351, págs. 311-336 [<http://www. revistaeducacion.mec.es/re351/re351_13.pdf)].

CARMAN, J. M. (1990): “Consumer perceptions of service quality: An assessment of the SERVQUAL dimensions", Journal of Retailing, $\mathrm{n}^{0}$ 66, págs. 33-55.

CATALINA, C.; PALACIOS, J. L; y FULGUEIRAS, F. J. (2002): “La medición de la calidad en la administración local: el caso de los servicios socioculturales del Ayuntamiento de Alcobendas", Dirección y Organización. Revista de Dirección, Organización y Administración de Empresas, no- 28, págs. 147-158.

CERCADILLO, M. (2008): “Un viaje hacia la calidad de los servicios sociales municipales: experiencia de una mancomunidad", Trabajo Social Hoy, nํ5 54, págs. 71-82.

DEL POZO HERRÁIZ, B.; y SÁNCHEZ PÉREZ, M. C. (2010) "Trabajando por la calidad desde los servicios sociales básicos”, Bits. Boletín Informativo Trabajo Social, no 14 [<http://www.uclm.es/ bits/sumario/79.asp〉].

ESCOBAR RANDO, G.; y GIL VALENZUELA, C. (2004): “El sistema de gestión de la calidad del Centro de Servicios Sociales Comunitarios del Distrito Centro: profesionalización y garantía de derechos", Documentos de Trabajo Social. 
Revista de Trabajo y Acción Social, nº 33 , págs. 55-114.

ESPINOSA, E. (2007): "Gestión de calidad en los servicios sociales. ISO 9001 y compromiso social", UNE. Boletín de AENOR, n- 217, págs. 22-25.

FUNDACIÓN EDE (2008) Proyecto de investigación-acción sobre la gestión de la calidad en el tercer sector de acción social de Bizkaia (20052008) / Bizkaiko gizarte ekintzako hirugarren sektoreko kalitatearen kudeaketaren inguruko ikerketa-ekintza proiektua (2005-2008), Bilbao, Fundación EDE [<http://www.fundacionede. org/calidad/docs/contenidos/_calidadCAST\%20\%2022\%20julio_.pdf〉, 〈http://www. fundacionede.org/calidad/docs/contenidos/_ PUBLICACION-calidad-EUSK $\% 20 \% 2022 \% 20$ julio_.pdf $\rangle$.

GÁLVEZ, P.; y MORALES, V. (2011): “Evaluación de la calidad en programas municipales deportivos: generalizabilidad y optimización de diseños de medida", Cuadernos de Psicología del Deporte, vol. 11, no extra 2, págs. 123-130.

GARCÍA ROCA, J. (1992): Público y privado en la acción social, Madrid, Editorial Popular.

GAONA, J. L. (2001): “Una herramienta para evaluar la calidad de los servicios públicos: la aplicación del modelo EFQM en la Generalit Valenciana", Revista Valenciana d'Estudis Autonòmics, nº 34, págs. 99-119.

GÓMEZ, P.; y SATURNO, P. J. (1997): “La calidad en atención primaria de salud según sus diferentes protagonistas", en I Congreso Regional de Calidad Asistencial. Murcia, 27 y 28 de noviembre de 1997, Murcia [<http://www. murciasalud.es/archivo.php?id=136568〉].

GRÖNROOS, C. (1994): Marketing y gestión de servicios, Madrid, Díaz de Santos.

- (1988): "Service quality: The six criteria of good service quality", Review of Business, $\mathrm{n}^{\circ}-3$.

GUMMERSON, E. (1987): Quality-The Ericsson Approach, Estocolmo, Ericsson.

HOFFMAN, D.; y BATESON, J. (2002): Fundamentos de marketing de servicios, Madrid, McGraw Hill.

IGAMI, M. P. (2005): “El uso del SERVQUAL en la verificación de la calidad de los servicios de unidades de información: el caso de la biblioteca del IPEN", Revista Interamericana de Bibliotecología, vol. 28, noำ 2, págs. 177-191 [<http://hdl.handle. net/10760/9095'].

PÉREZ MEYANO, V. (2007) “El INSS: una apuesta por la calidad". Comunicación presentada en la XXI Reunión de Referentes de Progreso 2007. Madrid, 18 de octubre de 2007 - Barcelona, 25 de octubre de 2007 [<http://www.qualitat.org/ cgi-bin/view/97cpvpm.htmls].

KOELEMEIJER, K.; ROEST, H.; y VERHALLEN, T. (1993): “An integrative framework of perceived service quality and its relations to satisfaction/ insatisfaction, attitude and repurchase intention. A multilevel approach", en European Marketing Academy (EMAC). Proceedings, Barcelona, ESADE, págs. 25-28 [ [http://arno. uvt.nl/show.cgi?fid=10852>].
MARTÍNEZ DEL OLMO, M. T. (1994): "La calidad de los servicios sanitarios y la participación de los usuarios/as", en IX Jornadas de Salud Pública y Administración Sanitaria, Granada, Escuela Andaluza de Salud Pública, pág. 81.

MCELWEE, G.; y REDMAN, T. (1993): “Upward appraisal in practice: An illustrative example using the QUALED scale", Education and Training, vol. $35, \mathrm{n}-2$.

MEDINA RUIZ, E. (2011): Evaluación de la calidad percibida en servicios sociales, Murcia, Diego Marín Editor.

MEDINA TORNERO, M. E. (2000): Evaluación de la calidad asistencial del servicio de ayuda a domicilio, Murcia, Universidad de Murcia.

- (1997a): "La evaluación de la calidad de los servicios sociales", en II Congreso de Psicología Profesional, Murcia, Colegio Oficial de Psicólogos.

- (1997b): "Utilidad de la evaluación en los servicios sociales comunitarios", Apuntes de Psicología, no 49-50, págs. 127-151.

- (1996): "Evaluación de la calidad asistencial en servicios sociales", Intervención Psicosocial, vol. 5 , no 14, págs. 23-42 [rhttp://www.copmadrid. org/webcopm/publicaciones/social/1996/ vol2/arti2.htm〉].

MEDINA TORNERO, M. E.; y MEDINA RUIZ, E. (2011): La calidad en las leyes de servicios sociales autonómicas. Estudio presentado en el $X$ Congreso de Organizaciones de Mayores, Albacete, 12-14 de abril de 2011.

MORALES SÁNCHEZ, V. (2003): Evaluación psicosocial de la calidad en servicios municipales deportivos: aportaciones desde el análisis de la variabilidad, Málaga, Spicum.

MORALES, M.; y CALDERÓN, L. F. (2005): “Desarrollo de un instrumento para medir la calidad de servicio en cursos y programas de educación para ejecutivos", Revista de Empresa, vol. 13, nํㅜ 1, págs. 30-41.

MORRIS, S. (1992): Citizens and Local Democracy: Encouraging and Managing Complaints, Luton, Local Government Management Board.

MOYA VAQUERO, E. (2000): "Herramientas para gestionar la calidad de un centro de servicios sociales", Revista de Servicios Sociales y Política Social, nํ- 49, págs. 85-90.

NGUYEN, N. (1991): “Un modèle explicatif de l'évaluation de la qualité d'un service: une étude empirique", Recherche et Applications en Marketing, vol. 6, nํㅡ 2, págs. 83-98.

PALLARES, L.; y GARCÍA, M. J. (1996): Guía práctica para la evaluación de la calidad en la atención enfermera, Madrid, Olalla Ediciones.

PARASURAMAN, A.; ZEITHAML, V.; y BERRY, L. (1994): "Reassessment of expectations as a comparison standard in measuring service quality: Implications for further research", Journal of Marketing, $\mathrm{n}^{0}$ 58, págs. 111-124 ['http://goo.gl/DsrVP)].

- (1993): Calidad total en la gestión de servicio, Madrid, Díaz de Santos. 
- (1988): "SERVQUAL: A multiple scale for measuring consumer perceptions of service quality", Journal of Retailing, n- 64, págs. 12-40.

- (1985): "A conceptual model of service quality and its implications for future research", Journal of Retailing, nํ49, págs. 44-60 [rhttp://areas. kenan-flagler.unc.edu/Marketing/FacultyStaff/ zeithaml/Selected\%20Publications/A\%20 Conceptual\%2oModel\%20of\%20Service $\% 20$ Quality\%20and\%20Its\%2olmplications\%20 for $\% 20$ Future\%20Research.pdf $>$.

PARREÑO, A. (2007): Retos para la atención primaria de los servicios sociales en el marco de la Ley de Promoción de la Autonomía Personal [rhttp:// www2. Mancohortasud.es/otrosproyectos/ Ponencia_Angel_Parreño.pdfı].

PÉREZ MEYANO, V. (2007) “El INSS: una apuesta por la calidad”. Comunicación presentada en la XXI Reunión de Referentes de Progreso 2007. Madrid, 18 de octubre de 2007 - Barcelona, 25 de octubre de 2007 [<http://www.qualitat.org/ cgi-bin/view/97cpvpm.htmlı?].

PÉREZ MOROTE, R. (2001): “El análisis de las demandas ciudadanas y la consecución de servicios públicos municipales de calidad total: especial referencia al servicio de recogida de residuos sólidos urbanos", Análisis Local, nํ34, págs. 45-56.

REAL ACADEMIA ESPAÑOLA (1992): Diccionario de la Real Academia Española, Madrid, Real Academia Española.

SACANELL, E. (2003): "Calidad y servicios sociales: la experiencia del Ayuntamiento de Getxo", en SETIÉN, Ma L. L; y SACANELL, E. (coords.), La calidad de los servicios sociales: conceptos y experiencias, Valencia, Tirant lo Blanc, págs. 297-316.
SÁNCHEZ AGUADO, A. (2011): "La calidad en la gestión de los servicios sociales municipales: algunas experiencias de INTRESS", TS Nova. Trabajo Social y Servicios Sociales, no 3 , págs. 49-54.

SÁNCHEZ PÉREZ, M. C. (2010): “Calidad de satisfacción de usuarios: una investigación para la mejora de los servicios sociales", en RODRÍGUEZ MONGE, Á.; y RAYA LOZANO, E. E. (coords.) Una Europa social y plural. Actas del VII Congreso Estatal de Escuelas Universitarias de Trabajo Social, Granada, Universidad de Granada, págs. 1.4571.467.

SATURNO, P. J. (1991): "Métodos de evaluación de la calidad asistencial (prólogo a la edición española)", en NUTTING, P. et al., Métodos de evaluación de la calidad en atención primaria: guía para clínicos, Barcelona, SG Editores.

SENLLE, A. (1996): Calidad total en los servicios y en la administración pública, Barcelona, Gestión 200.

SUÑOL, R. (1987): “El estudio de la opinión del usuario y su aplicación en los programas de control de calidad”, Control de Calidad Asistencial, no 2.

VILA, I.; SÁNCHEZ, C.; y MANASSERO, Ma. . A. (2009) "Satisfacción percibida de los usuarios de las instalaciones deportivas municipales de Palma de Mallorca", Revista Iberoamericana de Psicología del Ejercicio y el Deporte, vol. 4, no - 1, págs. 59-74 [<http://www.webs.ulpgc.es/riped/ docs/20090104.pdfs].

VILLEGAS, M. M.; y ROSA, I. M. (2003): "La calidad asistencial: concepto y medida”, Dirección y Organización, no 29 [shttp://www.revistadyo. com/index.php/dyo/article/view/142/142>].

VUORI, H. (1998): El control de calidad en los servicios sanitarios, Madrid, Masson. 


\title{
Actitudes y opiniones sobre el uso de prestaciones económicas por parte del colectivo inmigrante en el País Vasco
}

\author{
Gorka Moreno Márquez \\ Ikuspegi-Observatorio Vasco de Inmigración \\ Euskal Herriko Unibertsitatea-Universidad del País Vasco \\ <gorka.moreno@ehu.es>
}

\author{
Arkaitz Fullaondo Elordui-Zapaterietxe \\ Ikuspegi-Observatorio Vasco de Inmigración \\ Euskal Herriko Unibertsitatea-Universidad del País Vasco
}

\begin{abstract}
Artikulu honetan aztertzen da bertako jendearen jokabidea immigranteek osatutako kolektiboak egindako prestazio ekonomikoen erabileraren gaian. Zehazki, aztergai hartzen da diru-sarrerak bermatzeko errentaren gaia (lehenagoko oinarrizko errenta), hau da, Euskal Autonomia Erkidegoko diru-sarrerak bermatzeko politika publiko nagusia. Betekizun honetarako, xeheki analizatzen da urteroko Ikuspegi-Immigrazioaren Behatokiaren Atzerriko Immigrazioaren Jarrerak eta Pertzepzioen inguruko Barometroak 2010. eta 2011. urteetan buruturiko inkesta. Azterlanak erakusgai jartzen du biztanle immigranteek diru-sarrerak bermatzeko egiten duten erabileraz jokabide ezkorren nagusitzea. Fenomenoa interpretatu daiteke, neurri batean behintzat, egun bizi dugun krisi ekonomikoak baldintzatua, eta, ondorioz, immigrazioa mehatxu gisara nabarmentzen da.
\end{abstract}

\section{HITZ-GAKOAK:}

immigrazioa, gutxieneko errenta, jokabideak, gizarte-politikak, gizarte zaurgarritasuna.
Este artículo examina la actitud de la población autóctona hacia el uso de prestaciones económicas por parte del colectivo inmigrante. En concreto, hace especial hincapié en la renta de garantía de ingresos (antigua renta básica), la principal política pública en materia de garantía de ingresos en la Comunidad Autónoma del País Vasco. Para este cometido, se analiza detalladamente la información que ofrece al respecto el Barómetro anual sobre Percepciones y Actitudes hacia la Inmigración Extranjera en sus oleadas de 2010 y 2011, una encuesta que realiza Ikuspegi-Observatorio Vasco de Inmigración. El estudio pone de manifiesto el predominio de actitudes negativas hacia el uso que la población inmigrante hace de la renta de garantía de ingresos. Este fenómeno puede interpretarse, al menos en parte, como un reflejo de la actual crisis económica, que alimenta la percepción de la inmigración como una amenaza.

\section{Palabras clave:}

inmigración, rentas mínimas, actitudes, políticas sociales, vulnerabilidad social. 


\section{Introducción}

En este artículo vamos a indagar en el modo en que la población autóctona percibe el uso de la renta de garantía de ingresos, el programa de rentas mínimas de inserción existente en la Comunidad Autónoma del País Vasco (CAPV). Para ello, vamos a analizar los datos que aporta el Barómetro sobre Percepciones y Actitudes hacia la Inmigración Extranjera que realiza Ikuspegi-Observatorio Vasco de Inmigración. Se trata de una encuesta que sondea la opinión de la población autóctona hacia la inmigración en la CAPV. La primera oleada de este estudio se realizó en 2004 , y desde 2007 se ha elaborado con carácter anual. Son 1.200 encuestas y el margen de error se sitúa en un $\pm 2,82 \%$. El cuestionario es de carácter personal y se articula con base en un muestreo estratificado por cuotas, según el tamaño del hábitat, la edad y el sexo. Se compone de entre 25 y 30 preguntas -dependiendo del año-. En el caso concreto que atañe a nuestro artículo, desde la edición de 2010 se incluye un apartado compuesto por tres preguntas $(11,12 a$ y 12 b del cuestionario) sobre la percepción de la población autóctona acerca del uso de la renta de garantía de ingresos (RGI) por parte de la población inmigrante. Por ello, a lo largo de este trabajo vamos a analizar, en clave comparativa, los datos recogidos en estas preguntas a lo largo de los barómetros realizados en 2010 y 2011, haciendo especial hincapié en el más reciente.

El apartado sobre el uso de la RGI se ha introducido en las dos últimas ediciones del barómetro, porque es uno de los temas que ha suscitado mayor interés público y político en los últimos años cuando se analiza la actitud de la población autóctona hacia la inmigración en el País Vasco. El interés deriva de diferentes cuestiones. En primer lugar, y aunque el porcentaje de personas inmigrantes siga siendo relativamente bajo en la CAPV con respecto a otras comunidades autónomas -un 6,6\% frente al 12,2\% estatal-, en los últimos años se ha dado un cierto incremento del número de personas extranjeras en nuestro entorno, que ha hecho que poco a poco la inmigración haya ido ganando protagonismo tanto dentro de la opinión pública como de la agenda política.

En segundo lugar, la renta de garantía de ingresos es una prestación económica, asistencial, selectiva y no universal. Estas características la sitúan lejos de otras políticas sociales, como la sanidad o la educación, de carácter técnico o material, y universales, que son entendidas frecuentemente como un derecho humano universal. En la mayoría de los estudios realizados sobre percepciones hacia las políticas sociales, ya sean acotadas al colectivo inmigrante (Cea d'Ancona, 2007; Cea d'Ancona y Vallés, 2008, 2009, 2010; Rinken y Pérez Yruela, 2007; Rinken et al., 2009; Rinken, Escobar y Velasco, 2011; Ikuspegi, 2008, 2009) o a la población en general (Centro de Investigaciones Sociológicas, 2010; Gobierno Vasco, 2010), la tónica es que la aceptación de la sanidad o la educación es superior a la de otras políticas sociales, como, en nuestro caso, la RGI. Esta diferente valoración se da, en gran parte, debido a las características de unas y otra. En el caso del colectivo inmigrante, la percepción hacia esta ayuda por parte de la población autóctona es más negativa que hacia la sanidad o la educación.

En tercer lugar, las características y la magnitud de la renta de garantía de ingresos hacen de ella una prestación importante en la lucha contra la vulnerabilidad y la exclusión social, y que sea conocida por gran parte de la opinión pública. Este hecho, unido a sus condiciones -es un derecho subjetivo al que pueden acceder todas aquellas personas que lleven al menos un año empadronadas en la CAPV ${ }^{1}$, al margen de su nacionalidad o situación administrativa-, hacen que tanto el gasto en esta partida como su visibilidad social sean altos, y que el debate en torno a esta prestación sea notable, más aún en el caso del colectivo inmigrante.

Si a estos tres factores les sumamos la crisis económica y los recortes en materia social que estamos atravesando, y el aumento de personas que solicitan y acceden a esta prestación, tanto autóctonas como extranjeras, el contexto de competencia social es patente y tiene un claro reflejo en la controversia que se está dando acerca de su uso, muy en particular en lo que respecta al colectivo inmigrante. Por todo ello, creemos que resulta de gran utilidad profundizar en los datos que nos ofrece el barómetro y delimitar, en la medida de lo posible, ciertas afirmaciones y discursos que aparecen recurrentemente tanto en la opinión pública como en los medios de comunicación.

Antes de entrar en el análisis de los datos que emanan del cuestionario, definiremos y contextualizaremos la renta de garantía de ingresos de la CAPV, para así comprender mejor el contorno del debate y situar esta prestación dentro de la respuesta que se da, tanto a escala autonómica como estatal, a la vulnerabilidad y la exclusión social.

\section{La renta de garantía de ingresos y su contexto}

La renta de garantía de ingresos es el actual programa de rentas mínimas de inserción en el País Vasco. Dicho programa ha respondido a varias designaciones desde sus comienzos, allá por 1989. Inicialmente, fue conocido como ingreso mínimo familiar (IMF); entre 1990 y 2000 , se denominó ingreso mínimo de inserción (IMI); desde 2000 hasta 2008, renta básica; y tras la aprobación de la Ley para la Inclusión y la Garantía de Ingresos, en enero de 2009 , se llama renta de garantía de ingresos.

${ }^{1}$ Tras la reciente reforma realizada en la Ley de Inserción y Garantía de Ingresos de 2008, el requisito de un año de empadronamiento, a partir de enero de 2012, pasará a ser de tres años, o de uno más cinco de cotización en la Seguridad Social. 
Las rentas mínimas en el País Vasco nacen como una herramienta para hacer frente a la pobreza de finales de la década de 1980 , consecuencia principalmente de la crisis en el sector industrial y que irrumpe con gran fuerza en el debate político y social de aquellas fechas (Aguirre, 1991), tal como se puede comprobar en el informe La pobreza en la Comunidad Autónoma del País Vasco, publicado en 1987 (Gobierno Vasco, 1987). Con el paso de los años y los cambios sociales acaecidos en las últimas dos décadas, los programas de rentas mínimas vascos han ido centrándose en hacer frente a las problemáticas relacionadas con la vulnerabilidad y la exclusión social, de tal modo que hoy día la RGI es la principal herramienta de lucha contra la exclusión social en la CAPV (Moreno, 2008).

La renta de garantía de ingresos es un derecho subjetivo -y, por lo tanto, no atiende a limitación presupuestaria-, dirigido a aquellas personas que cumplen los requisitos que se enuncian a continuación:

- Existencia previa de una unidad de convivencia autónoma al menos un año antes de solicitar las prestación.

- Estar empadronado y residir en la CAPV al menos un año antes de solicitar la prestación (hasta diciembre de 2011) ${ }^{2}$.

- No poseer ingresos superiores a la cuantía establecida para cada caso y unidad de convivencia.

- Tener más de 23 años.

El aumento del número de personas perceptoras de la RGI ha sido sostenido en el tiempo. De las 4.110 personas que recibían el IMI en octubre de 1989 (Emaiker, s/a), se pasó a las 12.982 a finales de 2000 (Consejo Económico y Social Vasco, 2001: 425). Según los últimos datos disponibles ofrecidos por el Gobierno Vasco, en septiembre de 2011 eran 54.942 las personas titulares. El aumento en el número de las prestaciones, así como el incremento a lo largo de los años de la cuantía o una mayor flexibilidad en ciertos requisitos han hecho que el gasto en esta partida haya aumentado sensiblemente en estos últimos años. Así, dicho gasto era de 4,2 millones de euros en 1989, de 114 millones en 2004, y de 314 millones euros en 2010. La cuantía actual para una unidad de convivencia constituida por una sola persona es de unos 650 euros mensuales, que se reciben en 12 pagas anuales.

En lo tocante al perfil de las personas perceptoras, según una encuesta realizada a este colectivo (Gobierno Vasco, 2008), el 68,3\% son mujeres.

Ciñéndonos al tema que nos compete en este artículo y siguiendo con datos de esta encuesta, un $30 \%$ de las personas eran extranjeras, frente al $70 \%$ que eran autóctonas. Datos más recientes ofrecidos por Lanbide-Servicio Vasco de Empleo corroboran estas cifras y sitúan el número de mujeres beneficiarias

${ }^{2}$ Véase la nota anterior en un $65 \%$. También es destacable que un $27,4 \%$ sean personas mayores de 65 años. En lo tocante a la nacionalidad, los datos se mantienen estables: un $30,7 \%$ de extranjeros, frente a un $69,3 \%$ de autóctonos.

Todos estos datos se pueden entender mejor en el marco de los programas de rentas mínimas existentes a escala estatal, que, al ser de carácter autonómico, muestran una gran diversidad (Roberts, 2001; Gaviria y González, 2002). Una característica común es el escaso desarrollo de estos programas: con excepción de los programas vasco, navarro, madrileño o asturiano (Laparra y Ayala, 2009), en el resto de comunidades autónomas no puede hablarse realmente de programas de rentas mínimas. Miguel Laparra (2004b) subraya que, para el $80 \%$ de la población española, no existen programas de rentas mínimas.

Sobre todos los programas, destaca sobremanera el modelo vasco, que es el único que suele equipararse a otros similares del ámbito europeo (Moreno et al., 2003; Laparra, 2004a). Algunos ejemplos concretos pueden ilustrar esta afirmación. La renta de garantía de ingresos ofrece una cobertura seis veces superior a la media del resto de los programas de rentas mínimas estatales (Ministerio de Trabajo y Asuntos Sociales, 2005). De igual forma, según estimaciones de Laparra y Ayala (2009: 32) un tercio del total de los perceptores de rentas mínimas se sitúan en el País Vasco. Aunque no disponemos de datos concretos al respecto, los efectos de la crisis nos hace pensar que, debido a que la RGI es un derecho subjetivo en la CAPV, pero no en la mayoría de las comunidades autónomas, en torno al $50 \%$ del gasto total en rentas mínimas actuales puede circunscribirse al País Vasco. Estos datos nos dan una buena imagen de la dimensión del programa dentro del ámbito estatal y de su incidencia dentro del propio País Vasco.

En este contexto, se está dando una importante reflexión en torno a la renta de garantía de ingresos que, de forma más o menos directa, alcanza también al uso que de esta ayuda hace el colectivo inmigrante. Así, se espera que, para finales de 2011, se haya reformado en parte la Ley de Inclusión y Garantía de Ingresos (2008) -actualmente en tramitación legislativa-, que regula la ayuda que nos ocupa, y que la gestión de ésta pase de los servicios sociales de base a Lanbide-Servicio Vasco de Empleo. También se cree que puede haber modificaciones parciales en otros aspectos, en un contexto de contención presupuestaria, recortes en algunas prestaciones sociales, crisis económica y aumento exponencial del gasto en esta prestación en los últimos años ${ }^{3}$.

En este sentido se sitúa, precisamente, la propuesta lanzada por el Partido Popular del País Vasco días antes del inicio oficial de la campaña electoral de las

${ }^{3}$ N.E.: Este artículo se recibió a mediados de noviembre de 2011 $y$, por tanto, no tiene en cuenta los cambios legislativos producidos desde entonces. 
elecciones municipales (Vasco Press, 12-IV-11) de que el requisito de estar al menos un año empadronado en la CAPV aumente a cinco años. Parece que dicha propuesta podría llevarse al Parlamento e introducirse como enmienda en el nuevo texto legal en el que se está trabajando. Una medida de estas características afectaría, de facto, sobre todo al colectivo inmigrante, ya que todas las personas que hayan llegado recientemente -la mayoría, en el caso de los inmigrantes- se verían privadas de la posibilidad de solicitar la RGI.

En el plano social, también se detecta en los últimos meses el aumento de discursos y actitudes que relacionan al colectivo inmigrante con el fraude en la prestación de la renta de garantía de ingresos, o que apuntan a que este colectivo tiene mayores facilidades que otros a la hora de obtener dicha prestación u otras. En este sentido, puede destacarse la detección de estos discursos sobre todo en Internet a través de correos anónimos que inciden en este aspecto. También pueden encontrarse frecuentemente opiniones de este tipo en los comentarios que se recogen en las ediciones digitales de los principales periódicos de tirada regional, sobre todo en noticias referentes a la inmigración. El propio Ararteko (defensor del pueblo) ha hecho recientemente unas declaraciones que hacen hincapié en el riesgo de unir inmigración y uso fraudulento y abusivo de prestaciones sociales, así como en el aumento de este discurso dentro de la CAPV (Efe, 29-III-11).

Por todo ello, en el próximo apartado de este artículo vamos a intentar medir estas opiniones y así conocer mejor la situación, más allá de percepciones o discursos con mayor o menor incidencia mediática. El mismo Ararteko destacaba la inexistencia de estudios rigurosos al respecto y, en la medida de lo posible, este artículo quiere propiciar un mayor conocimiento dentro de este ámbito.

\section{La opinión de la población autóctona sobre el uso de la renta de garantía de ingresos por parte del colectivo inmigrante}

Como se apuntaba en la introducción, en este apartado vamos a analizar los datos referentes a la actitud de la población autóctona sobre el uso de la renta de garantía de ingresos por parte del colectivo inmigrante, tal como aparecen en el Barómetro anual sobre Percepciones y Actitudes hacia la Inmigración Extranjera. En concreto, examinaremos tres preguntas del cuestionario que hacen referencia directa a esa prestación. De igual forma, se contrastarán los datos de 2011 con los de 2010, buscando los cambios producidos de un año a otro.

En la primera de las cuestiones ( $n-11)$, se pregunta acerca de la postura que tendrían que tomar las instituciones con respecto al acceso de la RGI por parte de la población inmigrante. Un 6,9\% de las personas encuestadas opinan que tan sólo la deberían recibir las personas autóctonas y que las inmigrantes tendrían que quedar al margen. Un 31,2\% cree que los inmigrante la deberían recibir, pero únicamente cuando todos los autóctonos que la necesiten la hayan cobrado. Un $\mathbf{2 7 , 2} \%$ considera que tan sólo deben recibirla los inmigrantes en situación administrativa regular. Y finalmente, un $33,1 \%$ dice que la deberían obtener en las mismas condiciones que un autóctono -tal como sucede en la actualidad ${ }^{4}$-.

En esta pregunta no se aprecian grandes diferencias por sexo y edad, salvo por lo que se refiere a las personas de más de 65 años, que apoyan la preferencia de los autóctonos en mayor proporción que el resto. Según el nivel de estudios, puede subrayarse que aquellas personas con menor formación se muestran más restrictivas respecto al acceso. Así, un 47,3\% de la población sin estudios cree que los inmigrantes no deberían poder recibir la RGI (media: 31,2\%). Por el contrario, en ese grupo se recogen los menores apoyos (un $23 \%$ frente a una media del $33,1 \%$ ) a que la población inmigrante reciba esa ayuda en igualdad de condiciones. Aquellos con estudios universitarios o superiores, en cambio, muestran una pauta totalmente opuesta a los que no poseen estudios: son menos entre quienes niegan el acceso (un 12,2\%) y más (un $54,4 \%$ ) quienes abogan por la igualdad de condiciones de acceso.

Gráfico 1. Opinión de la ciudadanía sobre la postura que las instituciones deberían tomar con respecto a la renta básica, por nivel de estudios. CAPV, 2011 (\%)

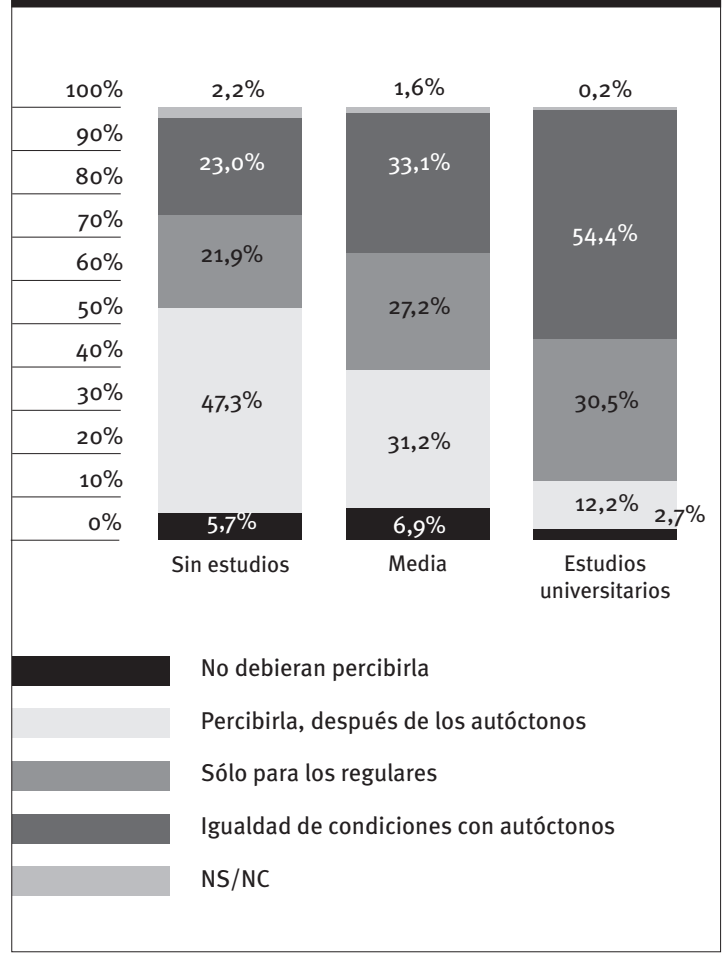

Fuente: Ikuspegi, Barómetro 2011.

${ }^{4}$ El trabajo de campo del barómetro 2011 se realizó entre marzo y abril de ese año. Por lo tanto, no se habían dado las recientes modificaciones normativas. 
Junto a los estudios, aquí toman relevancia las variables asociadas a la situación y la actividad económica. Así, entre las personas con mayores ingresos, es decir, quienes cobran entre 1.800 y 3.000 euros, y quienes cobran más de esta última cifra, la opción de que los inmigrantes accedan a la renta de garantía de ingresos es la mayoritaria: un $40,8 \%$ en el primer grupo y un $56,4 \%$ en el segundo. Estos porcentajes descienden al 34,8\% y al 31,4\%, respectivamente, entre aquellas personas con ingresos de hasta 600 euros, y de entre 600 y 1.800 euros.

En el caso de la actividad económica, mientras que los jubilados o las amas de casa muestran una actitud más reacia hacia el acceso a la prestación del colectivo inmigrante, las personas activas manifiestan una opinión más positiva. En este sentido, no podemos dejar a un lado que tanto las personas jubiladas como las amas de casa son frecuentemente colectivos precarios, con bajos ingresos, y además, en este caso concreto, perfiles habituales entre los perceptores de la renta de garantía de ingresos, tal como hemos podido observar cuando comentábamos brevemente los colectivos más representados entre los beneficiarios de esta prestación.

Por último, y para acabar con las variables asociadas a la situación socioeconómica, aquellas personas con un estatus social alto se muestran más receptivas hacia los inmigrantes, en oposición a aquellas que se sitúan en un estatus más bajo. Así, mientras que un $50,4 \%$ de las primeras creen que los inmigrantes tienen que acceder a la RGI en igualdad de condiciones, ese porcentaje desciende a un $22,8 \%$ entre aquellas que se sitúan en un estatus social bajo. Aunque el cambio en los enunciados de algunas de las respuestas de esta pregunta limitan en parte las posibles comparaciones, parece que los datos de 2011 son menos restrictivos que los de 2010. De este modo, el porcentaje de personas que creen que los inmigrantes no debían tener derecho a la prestación desciende de un $9,8 \%$ a un $6,9 \%$.

La segunda de las preguntas hace referencia al grado de acuerdo o desacuerdo en torno a la afirmación de que los inmigrantes se aprovechan excesivamente de la renta de garantía de ingresos y llegan, incluso, a acapararla. Un 33\% de las personas encuestadas están muy de acuerdo con esta afirmación, un 32,9\% están de acuerdo, un 10,5\% no están ni en acuerdo ni en desacuerdo, un 12,4\% están en desacuerdo, un $4,8 \%$ están muy en desacuerdo, y un $6,4 \%$ no saben o no contestan. Si aglutinamos las categorías que muestran acuerdo con la afirmación, podemos observar que casi dos tercios de las personas encuestadas $(65,9 \%)$ están de acuerdo con la idea de que los inmigrantes abusan de la RGI. En el lado opuesto, un $17,2 \%$ estaría en desacuerdo con dicha tesis.

En esta pregunta parecen percibirse las mismas pautas detectadas en la anterior. Así, entre quienes creen que los inmigrantes se aprovechan de la RGI se sitúan aquellas personas con más de 65 años, sin estudios o con estudios primarios, insatisfechas con su situación económica y con un estatus social bajo. En el lado opuesto, es decir, entre quienes más creen que los inmigrantes no abusan de la renta de garantía de ingresos, se encuentran las personas con estudios universitarios, agnósticas o ateas, con ingresos superiores a 3.000 euros y un estatus social medio-alto 0 alto.

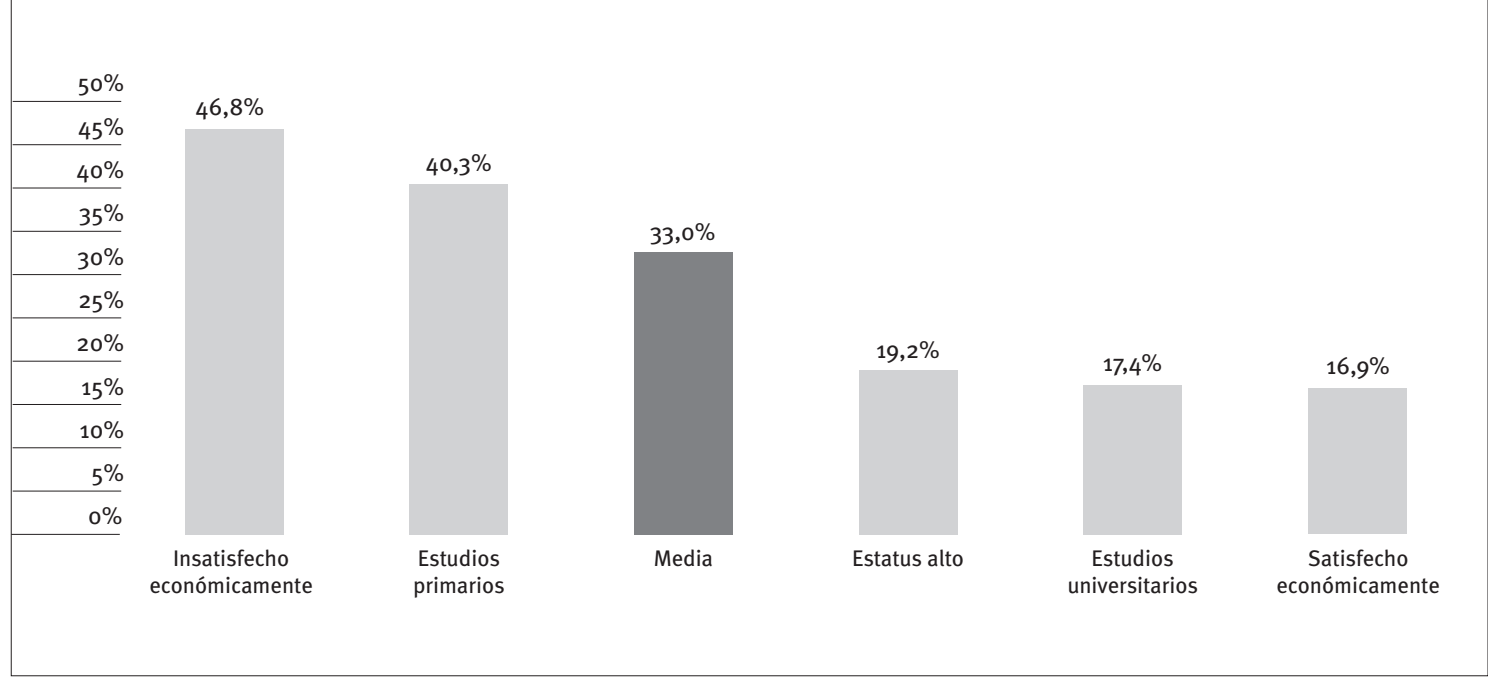

Fuente: Ikuspegi, Barómetro 2011. 
En términos comparativos, las cifras se mantienen muy similares a las del año anterior en todas las categorías, y tan sólo se detecta algún cambio, en especial en el nivel de intensidad. Así, aumenta el número de quienes están muy de acuerdo con la afirmación, y desciende el de quienes están de acuerdo. En el resto de opciones, no se detectan casi variaciones.

Tabla. 1. Opinión de la ciudadanía con la afirmación de que las personas inmigrantes se aprovechan excesivamente de la renta de garantía de ingresos, llegando a acapararla. CAPV, 2010 y 2011 (\%)

\begin{tabular}{l|c|c}
\hline & $\mathbf{2 0 1 0}$ & $\mathbf{2 0 1 1}$ \\
\hline Muy de acuerdo & 23,6 & 33,0 \\
\hline Acuerdo & 41,5 & 32,9 \\
\hline Acuerdo & 65,1 & 65,9 \\
\hline Ni acuerdo ni desacuerdo & 12,9 & 10,5 \\
\hline Desacuerdo & 12,8 & 12,4 \\
\hline Muy en desacuerdo & 4,1 & 4,8 \\
\hline Desacuerdo & 16,9 & 17,2 \\
\hline
\end{tabular}

Fuente: Ikuspegi, Barómetros 2010 y 2011.

Siguiendo con la vía abierta en la pregunta anterior, en la tercera y última pregunta del barómetro sobre el uso de la renta de garantía de ingresos por parte del colectivo inmigrante se ha sondeado el grado de acuerdo con la idea de que esta prestación hace que los inmigrantes no quieran trabajar o no busquen trabajo. Un 26,6\% está muy de acuerdo con esta afirmación; un 29,4\% está de acuerdo; un 17,3\%, ni de acuerdo ni en desacuerdo; un 15,8\% está en desacuerdo; y un 5,2\% está muy en desacuerdo. Como en la pregunta anterior, es mayoritaria la opinión de quienes consideran que el colectivo inmigrante hace un uso indebido de la RGI, aunque con un porcentaje algo menor, ya que un $56 \%$ cree que hace que no busquen un empleo o quieran trabajar, frente a un $21 \%$ que es contrario a esa idea.

En gran medida, se repiten las tendencias que han podido detectarse en las dos preguntas previas. Así, variables como los estudios, la religión, la ideología, la satisfacción económica, la actividad económica o el estatus marcan importantes diferencias en las respuestas. Aquellas personas con estudios universitarios, agnósticas o ateas, de izquierdas, con ingresos de más de 3.000 euros, satisfechas económicamente, estudiantes o de estatus alto son más reacias a creer que la RGI desincentiva la búsqueda de un empleo en el colectivo inmigrante, mientras que aquellas personas con estudios primarios, de derechas, insatisfechas económicamente o en paro muestran un mayor grado de acuerdo con esa afirmación.

Con respecto al año anterior, se detectan dos pautas que aparecen por separado en las dos preguntas previas. Por un lado, las respuestas más positivas hacia la inmigración son mayores, en la línea de los datos globales del Barómetro 2011, que son mejores que los del año anterior en términos generales. De esta forma, aquellas personas que están muy en desacuerdo con la afirmación de que la RGI desincentiva el empleo de los inmigrantes sumaban un 3,3\% en 2010 , y son un $5,2 \%$ en 2011 . De igual forma, aquellos que están en desacuerdo con esta afirmación pasan de un $13,8 \%$ a un $15,8 \%$. Agrupando estas dos categorías, aquellas personas en desacuerdo eran un $17,1 \%$ el año pasado y son un $21 \%$ este año. Por otro lado, aunque desciende el porcentaje de quienes están de acuerdo con la afirmación -en 2010 eran un $59,7 \%$ y en el 2011 son un $56 \%$-, el cambio más destacable es en la intensidad, ya que las opiniones negativas más extremas hacia el colectivo inmigrante toman fuerza ( $26,6 \%$ en 2011 frente a $19,6 \%$ en 2010), en detrimento de las más moderadas (29,4\% en 2011 y $40,1 \%$ en 2010).

Tabla 2. Opinión de la ciudadanía sobre la afirmación de que la renta básica hace que inmigrantes no quieran trabajar, o no busquen trabajo. CAPV, 2011 (\%)

\begin{tabular}{|c|c|c|c|c|c|c|c|}
\hline & \multirow{2}{*}{ Media } & \multicolumn{2}{|c|}{ Estudios } & \multicolumn{2}{|c|}{ Ideología } & \multicolumn{2}{|c|}{ Satisfacción económica } \\
\hline & & Primarios & Universitarios & Derecha & Izquierda & Insatifecho & Satisfecho \\
\hline Muy de acuerdo & 26,6 & 32,7 & 16,0 & 29,9 & 23,6 & 35,9 & 12,8 \\
\hline Acuerdo & 29,4 & 32,4 & 20,7 & 43,6 & 18,8 & 23,0 & 31,0 \\
\hline Acuerdo & 56,0 & 65,1 & 36,7 & 73,5 & 42,4 & 58,9 & 43,8 \\
\hline $\mathrm{Ni}$ acuerdo ni desacuerdo & 17,3 & 16,3 & 16,9 & 13,5 & 21,7 & 16,1 & 18,7 \\
\hline Desacuerdo & 15,8 & 10,9 & 23,8 & 8,0 & 23,2 & 19,9 & 23,8 \\
\hline Muy en desacuerdo & 5,2 & 2,1 & 15,1 & 0,0 & 11,9 & 3,6 & 5,4 \\
\hline Desacuerdo & 21,0 & 13,0 & 38,9 & 8,0 & 35,1 & 23,5 & 29,2 \\
\hline
\end{tabular}

Fuente: Ikuspegi, Barómetro 2011. 


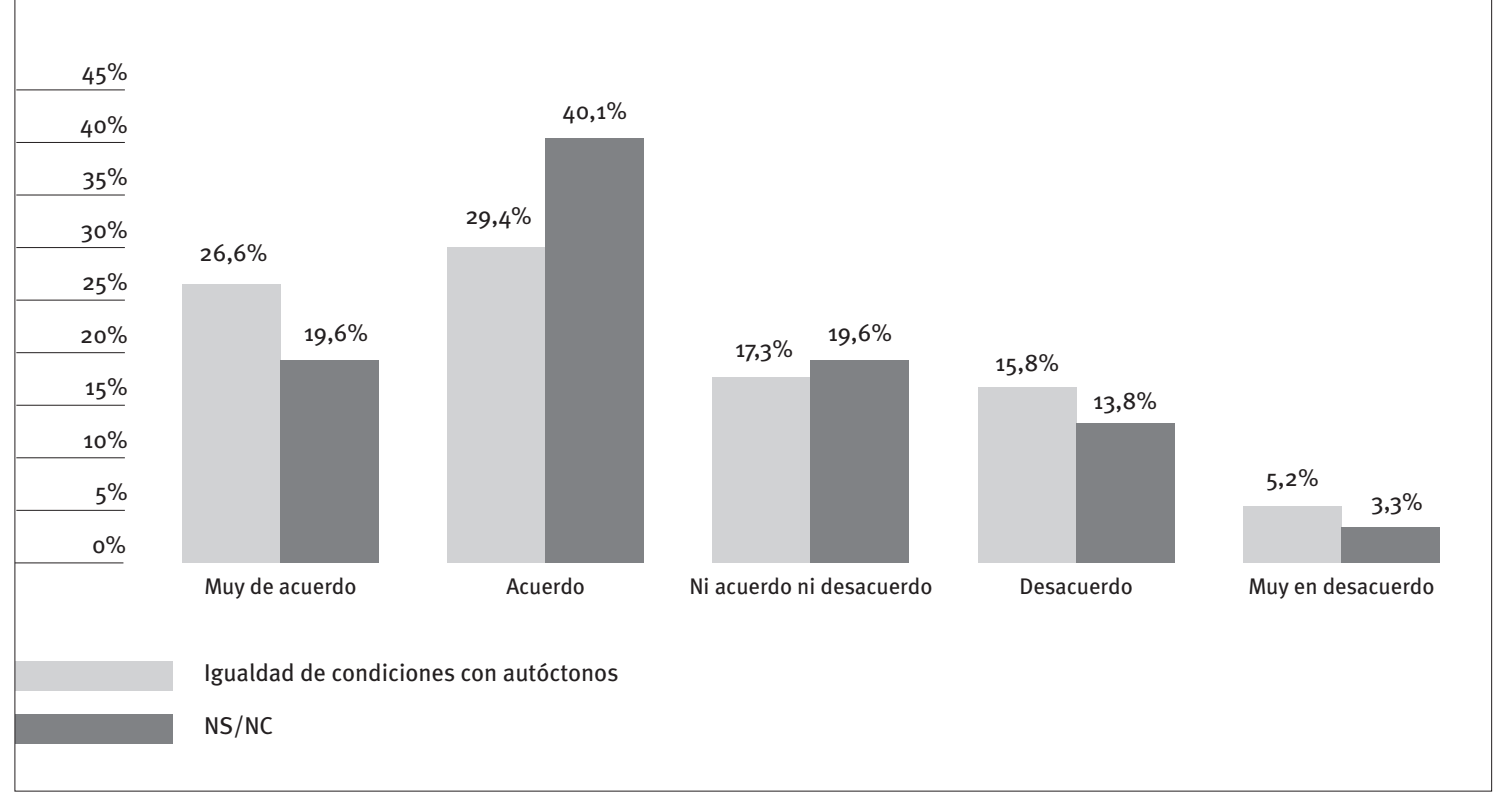

Fuente: Ikuspegi, Barómetro 2010 y 2011.

\section{Conclusiones}

Para acabar este artículo, queremos compilar algunos de los resultados más relevantes sobre los datos presentados en el punto anterior y plantear también ciertas reflexiones que sirvan para el debate. En primer lugar, hay que destacar que las actitudes hacia el uso de la renta de garantía de ingresos por parte del colectivo inmigrante son mayoritariamente negativas, y en todas las preguntas realizadas, prevalecen las opiniones que subrayan el mal uso o los efectos negativos de la prestación sobre este colectivo. Únicamente un tercio de las personas encuestadas $(33,1 \%)$ se posicionan a favor de los requisitos actuales, en los que prevalece la igualdad de condiciones en el acceso tanto para autóctonos como para extranjeros. Aunque tan sólo un $6,9 \%$ cree que no deberían cobrarlo, un 65,3\% opta por una gestión más restrictiva hacia el colectivo inmigrante. En las otras respuestas también prevalecen las respuestas negativas. Así, un $65,9 \%$ opina que los inmigrantes abusan de la RGI, y un 56\%, que desincentiva la búsqueda de empleo. Las posiciones contrarias a esta afirmación se sitúan, respectivamente, en un $17,2 \%$ y en un $21 \%$.

En lo tocante a las diferencias entre los datos de 2010 y 2011, cabe subrayar que se percibe una actitud más favorable al colectivo inmigrante en 2011, una pauta que ha podido detectarse en otras cuestiones abordadas en el Barómetro 2011. De igual modo, también parece detectarse que, aunque las opiniones más negativas no aumentan, la intensidad de éstas sí que lo hace, de tal manera que las opiniones negativas más moderadas pierden fuerza en detrimento de las más extremas. Habrá que comprobar si en próximas ediciones del Barómetro, y más aún en un contexto de crisis económica y competencia por los recursos sociales existentes, esta tendencia se afianza o aumenta, o si se trata únicamente de una pauta coyuntural o temporal.

Por colectivos o variables, puede detectarse una serie de diferencias significativas que merece la pena destacar. En este sentido, y siguiendo la pauta general del Barómetro, aquellas personas con menores estudios, en situación de inactividad económica, con bajos ingresos, insatisfechos económicamente o con un estatus social más bajo muestran opiniones más negativas hacia la inmigración en general, y hacia el uso que hacen de la RGI en concreto. En el lado opuesto, se sitúan aquellas personas con estudios universitarios, activas o estudiantes, con ingresos altos, satisfechos económicamente, con un estatus social alto, agnósticas o ateas, y de izquierdas.

En todo caso, son las variables socioeconómicas las que más diferencias muestran y las que parecen explicar estas diferencias en mayor medida. Así, los estudios, la satisfacción económica o el estatus social marcan diferencias mucho más notorias que otras variables. La variable ingresos mostraba en 2010 una influencia mayor que en 2011, aunque sigue arrojando importantes diferencias.

Aquellas personas con menores ingresos, mayor insatisfacción económica y menor estatus social muestran una opinión más desfavorable al uso de la RGI por parte del colectivo inmigrante; $y$, a la inversa, aquellas personas con mayores ingresos muestran una opinión más positiva, o por lo menos más 
moderada y atemperada. Este patrón se repite en la mayoría de las encuestas realizadas sobre opiniones y actitudes en torno a la inmigración -ya citadas en este artículo- y en las diferentes ediciones del Barómetro de Ikuspegi-Observatorio Vasco de Inmigración también ha aparecido recurrentemente.

De esta forma, aquellos colectivos con menos seguridad vital, social y económica son los que se muestran más reacios a la utilización de la renta de garantía de ingresos por parte del colectivo inmigrante. De hecho, las preguntas plantean afirmaciones clásicas en torno a este tipo de prestaciones económicas, que históricamente han tenido cierta relevancia en la opinión pública, sobre todo cuando se relacionan con colectivos autóctonos precarios o en situación de exclusión social, como el gitano. En la actualidad, resulta destacable cómo estas mismas afirmaciones son empleadas por las clases bajas autóctonas para denunciar el uso de estas prestaciones por parte de los inmigrantes. No es nada nada extraño, ya que son los grupos autóctonos peor situados los que compiten directamente con gran parte de los inmigrantes para acceder a los nichos laborales más precarios, o a las prestaciones de carácter asistencial que se dirigen a hacer frente a la vulnerabilidad y la exclusión social.

En el lado opuesto de la estructura social, se sitúan aquellas personas con ingresos altos, satisfechas económicamente o con un estatus social alto. Es decir, las clases medias, que muestran un discurso mucho más amable hacia la inmigración en general.
En este sentido, no podemos obviar que, para este sector, la población inmigrante no suele suponer una competencia, ya que no se sitúan en el mismo escalafón laboral o de acceso a prestaciones sociales. Es más, en muchas ocasiones la inmigración se convierte, para las clases medias, en una suerte de ventaja añadida, ya que, gracias a ella, pueden cubrir necesidades relacionadas con los cuidados domésticos y personales que facilitan un mejor acceso al mercado laboral, o una mayor disponibilidad horaria para el ocio.

Como puede observarse, el contexto dual y sin vasos comunicantes que surge en la relación entre los colectivos autóctonos y el inmigrante propicia una dinámica en la que es muy lógico que unos vean la inmigración como una amenaza, mientras que otros la ven como una oportunidad. Es un escenario en el que se permite la construcción de discursos contrarios y negativos hacia la inmigración, por un lado y, discursos favorables y positivos por el otro. Más aún, la crisis que estamos viviendo alimenta estos estados de opinión y es el contexto más propicio para que puedan reproducirse lo que en palabras de De la Corte y Blanco son el "discurso impecable e implacable” hacia la inmigración (2006). Resulta de gran interés hacer un seguimiento de estas actitudes en los próximos años, condicionados por los efectos de la crisis, para ver si la opinión sobre el uso de las prestaciones económicas por parte del colectivo inmigrante aumenta o se mantiene en cifras similares a las actuales. 
AGUIRRE, J. A. (1991): “Evaluación del primer año de implantación del ingreso mínimo familiar en el País Vasco", en VV.AA., IV. Jornadas de Economía de los Servicios Sociales, VitoriaGasteiz, Gobierno Vasco.

CEA D’ANCONA, M. A. (2007): Inmigración, racismo y xenofobia en la España del nuevo contexto europeo, Madrid, Observatorio Español del Racismo y la Xenofobia.

CEA D’ANCONA, M. A.; y VALLES, M. S. (2010): Evolución del racismo y la xenofobia en España. Informe 2010, Madrid, Observatorio Español del Racismo y la Xenofobia [khttp://www.oberaxe. es/files/datos/4e20230088dc8/INFORME\%20 RACISMO\%202010.pdf >].

- (2009): Evolución del racismo y la xenofobia en España. Informe 2009, Madrid, Observatorio Español del Racismo y la Xenofobia [<http://www. oberaxe.es/files/datos/4b26574eb2f66/ Informe2009.pdf $\rangle$.

- (2008): Evolución del racismo y la xenofobia en España. Informe 2008, Madrid, Observatorio Español del Racismo y la Xenofobia [<http://www. oberaxe.es/files/datos/49dgb81191e7f/ CEA2008.pdf $>$.

CENTRO DE INVESTIGACIONES SOCIOLÓGICAS (2010): Opinión pública y política fiscal, serie Estudios, no 2.841, Madrid, Centro de Investigaciones Sociológicas [khttp://www.cis.es/cis/opencm/ ES/1_encuestas/estudios/ver.jsp?estudio $=105$ $62 \&$ cuestionario $=12616 \&$ muestra $=18139$ > $]$.

CONSEJO ECONÓMICO Y SOCIAL VASCO (2001): Memoria socioeconómica 200o: Comunidad Autónoma del País Vasco, Bilbao, Consejo Económico y Social Vasco, pág. 425.
DE LA CORTE, L.; y BLANCO, A. (2006): “Conflictos intergrupales y prejuicios étnicos en las sociedades receptoras de inmigrantes", en VV.AA., Inmigración. Un desafío para España, Madrid, Fundación Pablo Iglesias.

EFE (2011) “El Ararteko ve 'alarmante’ unir inmigración y prestaciones sociales", El Correo, 29-III-11 [rhttp://www.elcorreo.com/alava/20110329/ mas-actualidad/sociedad/ararteko-alarmanteunir-inmigracion-201103291237.html/].

EMAIKER (s/d): Informe del estudio-panel de beneficiarios del ingreso mínimo de inserción, VitoriaGasteiz, Eusko Jaurlaritza-Gobierno Vasco.

GAVIRIA, L.; y GONZÁLEZ, F. (2002): Propuestas integradas de políticas activas de bienestar y empleo: sumario, Dublín, Fundación Europea para la Mejora de las Condiciones de Vida y de Trabajo [khttp://www.eurofound.europa.eu/ pubdocs/2002/60/es/1/efo26oes.pdf>].

GOBIERNO VASCO (2010): Políticas públicas, serie Sociómetro Vasco, no 43, Vitoria-Gasteiz, Eusko Jaurlaritza-Gobierno Vasco.

- (2008): Estudio de las personas perceptoras de Renta Básica, Vitoria-Gasteiz, Eusko JaurlaritzaGobierno Vasco.

- (1987): La pobreza en la Comunidad Autónoma del País Vasco, Vitoria-Gasteiz, Eusko JaurlaritzaGobierno Vasco.

IKUSPEGI (2011): Barómetro 2010. Percepciones y actitudes hacia la inmigración extranjera, Bilbao, Ikuspegi [khttp://www.ikuspegi-inmigracion. net/documentos/barometros/2010/ barometro2010cas.pdf)].

- (2010): Barómetro 2009. Percepciones y actitudes hacia la inmigración extranjera, Bilbao, Ikuspegi [khttp://www.ikuspegi-inmigracion.net/ 
documentos/investigacion/es/bar_2009_cas. pdf>].

- (2008): Barómetro 2007. Percepciones y actitudes hacia la inmigración extranjera. Bilbao, Ikuspegi [«http://www.ikuspegi-inmigracion.net/ documentos/investigacion/es/bar_2008_ completo.pdf〉].

LAPARRA, M. (2004a): "La travesía del desierto de las rentas mínimas en España”, Documentación Social, no 135, págs. 57-76 [<http://www.caritas.es/ imagesrepository/CapitulosPublicaciones/485/ Doc.\%20Social\%20135\%20Capitulo\%203. pdf>].

- (2004b): “Las rentas mínimas en España”. Trabajo presentado en el 'Encuentro Renta Básica y Procesos de Inserción, 1-2 diciembre, VitoriaGasteiz'.

LAPARRA, M.; y AYALA, L. (2009): El sistema de garantía de ingresos mínimos en España y la respuesta urgente que requiere la crisis social, Madrid, Fundación FOESSA [<http://www.caritashuelva. org/spip212/IMG/pdf_SGIMEspana2009.pdf〉].

MINISTERIO DE TRABAJO Y ASUNTOS SOCIALES (2005): III Plan Nacional de Acción para la Inclusión Social del Reino de España. 2005-2006, Madrid, Ministerio de Trabajo y Asuntos Sociales [rhttp://www.mtas.es/SGAS/ServiciosSocDep/ inclusionsocial/plannacional/IIIPNAin.pdf〉].

MORENO, G. (2008): Crisis y reconstrucción del Estado del bienestar. Las posibilidades de la Renta Básica de Ciudadanía, Vitoria-Gasteiz, Gobierno Vasco.

MORENO, G.; y AIERDI, X. (2008): “Inmigración y servicios sociales: ¿última red o primer trampolín?”, Zerbitzuan, no ${ }^{44}$, diciembre, págs. 7-18 [rhttp://www.zerbitzuan.net/documentos/ zerbitzuan/Inmigracion $\% 20 y \% 20$ servicios\%20 sociales.pdf $\rangle]$.
MORENO, L.; et al. (2003): "Existe una malla de seguridad en la Europa del sur", serie Documentos de Trabajo, n-0 03-17, Consejo Superior de Investigaciones Científicas [rhttp://hdl.handle. net/10261/1579>].

RINKEN, S.; ESCOBAR, Mํ. S.; y VELASCO, S. (2011): Opiniones y actitudes de la población andaluza ante la inmigración (III): más allá del discurso funcionalista, Sevilla, Junta de Andalucía [<http://www.juntadeandalucia.es/empleo/ www/adjuntos/publicaciones/1_2144_LibroOPIA-III.pdf>].

RINKEN, S; et al. (2009): Opiniones y actitudes de los andaluces ante la inmigración (II): entre la estabilidad y el cambio, Sevilla, Junta de Andalucía [shttp://www.juntadeandalucia. es/empleo/opam/sites/default/files/DOC/ texto_completo_OPIA_II.pdf \].

RINKEN, S.; y PÉREZ YRUELA, M. (2007): Opiniones y actitudes de la población andaluza ante la inmigración, Sevilla, Junta de Andalucía [<http://digital.csic.es/ bitstream/10261/15129/1/OPAM_7.pdf>].

ROBERTS, E. (2001): “Coordination of activation programmes for minimum income recipients. European experiences: A synthesis". Comunicación presentada en la $5^{\text {th }}$ Conference 'Visions and Divisions. Helsinki, August 28 - September 1, 2001', organizada por la European Sociological Association [khttp:// www.shakti.uniurb.it/Eurex/esa/PDF/ESARoberts.pdf $\rangle$.

VASCO PRESS (2011) “Basagoiti propone pedir cinco años de empadronamiento para percibir ayudas sociales", El Correo, 12-IV-11 [shttp://www. elcorreo.com/alava/20110412/local/basagoitipropone-pedir-cinco-201104121316.html ]. 


\section{El papel del asociacionismo en la integración sociopolítica de las personas migrantes de origen subsahariano. El caso del País Vasco.}

\section{Maria Giulia Di Carlo}

Universidad de Deusto, Bilbao

<giulia.dicarlo@gmail.com>
EAEn lekututako Sahara azpiko afrikar jatorriko immigranteen elkarteak hartu dira aztergai artikulu honetan, betiere, partaidetzaren eta integrazio soziopolitikoaren alorretan elkarte horien betekizunean egindakoa aztertzen delarik. Sakonki buruturiko 22 elkarrizketa baliatuz, elkarte horietako ordezkarien bidez jakin nahi izan da berauen barneantolaketaren ezaugarriez, funtzionamenduaz, sare-lana eta elkarte horietan burututako ekintza politikoaz; eta, faktore horien guztien berri izanik, ezagutu nahi izan da elkarte horien eragina kolektiboaren integrazio soziopolitikoaren baliabide gisara.

\section{GAKO-HITZAK:}

asoziazionismoa, integrazio soziopolitikoa, partaidetza, Afrikako migrazioak, Euskal Autonomia Erkidegoa.
Este artículo estudia las asociaciones de personas migrantes de origen subsahariano en el País Vasco, analizando el papel que estas entidades desempeñan en la participación y la integración sociopolítica del citado colectivo. A través de 22 entrevistas en profundidad con representantes de asociaciones, se indaga en las características organizativas, el funcionamiento, el trabajo en red y la acción política de estas asociaciones, como factores que pueden influir en el papel que desempeñan en la integración sociopolítica del colectivo que agrupan.

\section{Palabras Clave:}

asociacionismo, integración sociopolítica, participación, migraciones africanas, País Vasco.

${ }^{1}$ Este artículo se inscribe en el marco de una tesis doctoral titulada "El papel del asociacionismo en la integración social de las personas migrantes de origen subsahariano: transnacionalismo, participación y co-desarrollo. El caso del País Vasco y de Sicilia”, y que está financiada por una beca de Formación de Personal Investigador del Dpto. de Educación del Gobierno Vasco. El trabajo presenta parte de los resultados provisionales de dicha investigación, aún en curso. 


\section{Introducción}

A lo largo de la última década, en la Comunidad Autónoma Vasca se ha producido un aumento progresivo de la llegada de población de origen extranjero, sobre todo entre 2005 y 2009. En la actualidad, la población de origen extranjero en el País Vasco representa el 6,4\% de la población total (Ikuspegi, 2010). El rápido crecimiento de la población extranjera desde 1998 hasta hoy y la variación en la tipología de las migraciones en estos últimos diez años, con el aumento de la población migrante de origen extranjero respecto a la de origen nacional, han generado cambios estructurales que obligan a pensar en la gestión adecuada de las que ya se presentan como sociedades multiculturales, y, por lo tanto, en el desarrollo de procesos conformes a la integración social y la convivencia. La participación de las personas migrantes en el ámbito público, especialmente en aquellos espacios de toma de decisión que se encargan de los procesos de convivencia, resulta fundamental para lograr su integración efectiva. La participación ciudadana es una condición indispensable para que las sociedades en que vivimos se constituyan en verdaderos espacios democráticos.

En este sentido, las asociaciones conformadas por personas de origen subsahariano pueden actuar como agentes sociales que permitan a estas personas hacerse oír, proponer y participar en el proceso de elaboración de políticas públicas, bien sobre aspectos relacionados con la migración, bien sobre otros que afectan a su vida cotidiana y a la sociedad en la que viven. El colectivo de origen subsahariano no tiene ningún derecho político formal reconocido en el País Vasco (ni en España); por lo tanto, debe reconocerse la particular relevancia de sus asociaciones, que pueden funcionar como verdaderos canales de participación de estas personas en el sistema político democrático y en la vida pública del país. Asociaciones fuertes y bien estructuradas podrían representar los instrumentos para reforzar el capital social del grupo y de las personas que lo constituyen, favoreciendo, en última instancia, la participación política y su acceso al voto.

Sin embargo, existen algunas limitaciones para hacer realidad ese objetivo. El derecho al voto de las personas de origen extranjero que residen en España se concede exclusivamente por tratado o por ley, atendiendo a criterios de reciprocidad con terceros países, lo que excluye a este grupo de personas y genera comunidades con derechos políticos diferentes. Esta circunstancia refuerza el surgimiento de cauces de participación política alternativos y provoca una gradación en el efecto real del voto que puede ejercerse: desde el que se deposita en las elecciones de órganos consultivos de representatividad ad hoc, hasta el que se da de manera activa o pasiva en las elecciones administrativas. Este trato discriminatorio en nada contribuye al objetivo de la plena integración de las personas de origen subsahariano.
Es en este contexto en el que se reconoce la particular relevancia de las asociaciones, que pueden funcionar como canales de participación en el sistema político democrático y en la vida pública del país de destino (Fennema y Tillie, 2001). De hecho, estas asociaciones a menudo se constituyen 'desde abajo', es decir, para responder a necesidades y exigencias de los grupos que se reconocen en alguna identidad común, como la étnico-nacional o la religiosa. Lejos de actuar en un sistema vacío, estas asociaciones se encuadran en contextos en los que se dan determinadas reglas y en los que operan unas instituciones que pueden contribuir, en mayor o menor medida, a dar forma a sus demandas y reivindicaciones. Las asociaciones se enfrentan siempre a nuevas realidades, nuevas reglas, instituciones y organizaciones ya presentes en el territorio de destino, por lo que desempeñan la importante función de socialización de las personas en la esfera de la participación cívicopolítica, premisa fundamental para la integración. En consecuencia, el asociacionismo de estas personas estará más consolidado allí donde las políticas sean más favorables a la apertura de los diferentes grupos, es decir, allí donde se den políticas que aseguren no sólo el reconocimiento simbólico de estos grupos, sino también el material (Bloemraad, 2005: 866).

\section{Las asociaciones pueden funcionar como canales de participación en el sistema político democrático}

Según esta idea, las asociaciones fuertes y bien estructuradas representarán instrumentos importantes para reforzar el capital social del grupo y de los individuos que las constituyen, favoreciendo en última instancia la participación política y el acceso al voto. Por lo tanto, la agencia colectiva de las personas migrantes adquiere mayor importancia cuando el marco legal del contexto de recepción restringe sus derechos de ciudadanía, en este caso, los derechos políticos. Cuanto más difíciles y restrictivos sean los requisitos de acceso a la ciudadanía, más confinado estará el colectivo migrante a las formas de participación política no convencional de naturaleza colectiva -protestas, huelgas, presión mediática- (Martiniello, 2005: 16).

Aunque el asociacionismo extranjero constituye una práctica habitual en todos los países europeos, tanto en aquellos países receptores de nueva inmigración como en aquellos donde este fenómeno revista mayor antigüedad, su consistencia y relevancia puede variar en función de los contextos nacionales y locales. En el caso de España, y particularmente en el País Vasco, el asociacionismo de la población migrante de origen subsahariano empezó a configurarse alrededor de 2000 , sobre todo en las capitales de los tres territorios históricos: Bilbao, VitoriaGasteiz y Donostia-San Sebastián. 


\section{Participación como vía de integración: los derechos de las personas extranjeras en la sociedad de acogida}

La integración puede definirse como "el proceso a través del cual la persona se convierte en una parte aceptada de la sociedad" (Martinello y Penninx, 2006: 127). En términos generales, una persona es parte de la sociedad -está integrada- cuando puede ejercer plenamente sus derechos de ciudadanía. Los diferentes planos en los que se produce la integración (social, económico, cultural, político) equivalen a las tres dimensiones que tradicionalmente se han distinguido en el concepto de ciudadanía: la política, la socioeconómica y la cultural. En sentido etimológico y sociológico, integración significa formar parte de la sociedad en que se vive, y muchas veces esto no es válido para los migrantes. El concepto de integración social comprende muchos sectores de la vida de un migrante: el trabajo, la vivienda y la vida social.

En el presente trabajo se considera la dimensión cívico-política de la ciudadanía. Por lo tanto, se utiliza la noción de integración política multicultural empleada, por ejemplo, en un estudio realizado en Madrid sobre asociaciones de migrantes (González Ferrer y Morales, 2006). Las autoras de dicho estudio afirman que:

El modelo deseable de integración es aquel que combina un acceso a la ciudadanía exclusivamente basado en la concesión de derechos tras cumplirse una serie de requisitos de tipo universalista, y la reserva de un papel comprometido a los ciudadanos en el proceso democrático (pág. 4).

Es decir, la integración política del colectivo migrante exige el reconocimiento formal de sus derechos políticos como ciudadanos, a través del sufragio activo y pasivo, así como del derecho a asociarse como el resto de la población; y por otro lado, tiene que garantizar su participación activa en el espacio público, con el fin de trasladar sus ideas, proyectos y necesidades a los procesos de toma de decisión. En este sentido, las asociaciones de migrantes, como organizaciones de la sociedad civil, pueden servir para canalizar demandas, intereses y sugerencias del colectivo a las instituciones públicas y a la sociedad en general. De hecho, la agencia colectiva de las personas migrantes adquiere mayor importancia cuando el marco legal del contexto de recepción restringe sus derechos de ciudadanía, en este caso, los derechos políticos. En función de cuáles sean las normas de acceso a la ciudadanía y de pérdida de ésta, las personas tendrán mayores o menores oportunidades de participar en la vida pública formal. Si el acceso a la ciudadanía se ve restringido, el colectivo migrante se verá empujado a utilizar formas de participación política no convencionales.

Según González y Morales (op. cit.), el concepto de integración política multicultural aplicado a la ciudadanía en el plano individual puede trasladarse al plano organizativo del colectivo migrante. Por lo tanto, podemos ajustar este concepto al caso específico de las asociaciones de migrantes subsaharianos. Con respecto a los derechos de acceso a la ciudadanía en el plano individual, se plantea, haciendo referencia al reconocimiento formal de las asociaciones, el reconocimiento de un estatus favorable de acceso al proceso de toma de decisiones a través de la inclusión en algún registro formal de la administración pública y de su reconocimiento legal, así como su inclusión formal en mecanismos de decisión y consultivos, tales como consejos, foros, mesas de diálogo, etc.

Sin embargo, como se ha mencionado anteriormente, la participación efectiva de la población migrante en el espacio público es condición imprescindible para conseguir una integración efectiva. De ahí que sea también necesario analizar cómo y en qué medida las asociaciones de migrantes están influyendo y participando activamente en los procesos de toma de decisiones sobre las cuestiones que afectan específicamente al colectivo, pero también, sobre los que interesan al desarrollo de su vida cotidiana y a la convivencia en la sociedad receptora. Esta participación efectiva de las asociaciones puede estudiarse a través de la información sobre el tipo de actividades políticas que realizan, de sus contactos con organizaciones políticas y de la forma en que participan en los mecanismos de toma de decisiones a los que han tenido acceso. Ahora bien, debe tenerse en cuenta que la movilización y participación política de las asociaciones dependerá de varios factores, entre los que pueden destacarse las características sociodemográficas de las personas miembros (contexto socioculturales de origen, nivel socioeconómico, roles de género), las individuales y su capital social interno y externo, junto a la estructura de oportunidades políticas que ofrecen las sociedades de origen y destino.

Este artículo sobre la realidad asociativa migrante subsahariana centrará su atención en los factores que están influyendo en el capital social externo de las asociaciones estudiadas. En general, el capital social puede definirse como el conjunto de relaciones que se establecen y desarrollan entre los diversos actores de la sociedad civil, con el fin de conseguir unos objetivos concretos y colectivos (vínculos de mutua confianza, de intercambio de información y de otros recursos). La noción de capital social aquí utilizada se basa en el enfoque empleado por Fenemma y Tillie (2001), quienes distinguen entre:

- Capital social étnico, que se refiere a los vínculos que se establecen en el ámbito interno de las asociaciones y entre asociaciones de migrantes.

- Capital social no étnico, que se refiere a las conexiones externas de las asociaciones con otras organizaciones y grupos heterogéneos.

Algunos estudios realizados en diferentes áreas de Europa confirman la relación existente entre partici- 
pación política, por un lado, y capital social del colectivo migrante y sus asociaciones, por otro (Fennema y Tillie, 2001; Berger, Galonska y Koopmans, 2004; Tillie y Slijper, 2006). Las personas migrantes, como las autóctonas, tienden a crear organizaciones en los lugares donde se asientan y desarrollan su vida cotidiana. Estas organizaciones pueden servir, por lo tanto, como espacios de encuentro y apoyo mutuo, y también como un medio para trasladar sus demandas, necesidades e intereses a las instituciones públicas y a la sociedad en general.

En este trabajo se toma en consideración al colectivo de África Subsahariana. Esta comunidad, asentada en España, no posee ningún derecho político formal, ni a escala estatal ni autonómica. Por lo dicho, los espacios de participación política informal, como las asociaciones que estas personas crean, pueden ser lugares donde entrenar prácticas democráticas aplicables tanto a la sociedad de origen como a la de destino.

Las instituciones públicas siguen tratando la migración como un fenómeno coyuntural y la asocian a menudo al ámbito económico-laboral. Esto ha influido en la menor atención prestada a la dimensión cívico-política de la integración de la población migrante. Sin embargo, en la actualidad las personas migrantes representan una realidad consolidada en nuestras sociedades. El asentamiento a largo plazo conlleva la necesidad de desarrollar el proyecto migratorio en todos los ámbitos de la vida -social, económico, cultural y político-, y plantea el reto compartido de generar un marco de convivencia adecuado para el desarrollo efectivo de sus proyectos vitales. La participación en el espacio público, es decir, en aquellos espacios de toma de decisión de la sociedad en que viven, es un aspecto crucial para la integración efectiva de las personas migrantes. El reconocimiento de las personas extranjeras como ciudadanas de pleno derecho en nuestras sociedades es un paso fundamental para la integración sociopolítica de aquéllas.

En este sentido, las asociaciones de personas migrantes se consideran, en origen y destino, como canales abiertos, a través de los cuales estas personas puedan tramitar demandas y propuestas a las instituciones públicas en los dos lugares 'a los que pertenecen', incluyendo aquellas acciones de incidencia política que puedan fomentar procesos de cambios democráticos en los países de origen, y procesos de adquisición de derechos en los países de residencia.

\section{Las migraciones africanas de origen subsahariano en el País Vasco y sus asociaciones}

Los movimientos migratorios son parte constitutiva de la historia más reciente del País Vasco. Tanto la emigración como la inmigración de personas han ido conformando la sociedad vasca actual. Sin embargo, en cuanto a la llegada de personas de origen extranjero a la CAV, es a partir de 1998 cuando ese flujo se hace más intenso. Aunque las migraciones no son un fenómeno nuevo, sí lo es el tipo de migración que se configura desde ese año, y que ha hecho que el País Vasco pase de ser una región receptora de personas migrantes internas a una región receptora de migraciones extranjeras, lo que ha provocado cambios sociales notables (diversidad racial, cultural, lingüística y religiosa).

Dentro de los colectivos presentes en las tres provincias vascas, el de las personas de origen subsahariano no destaca entre los más numerosos, aunque en los últimos años ha habido un incremento importante de las personas de origen subsahariano en todo el territorio vasco. La mayoría de los migrantes subsaharianos llegaron a la CAV entre 2000 y 2004 , sobre todo por motivos económicos, en búsqueda de un trabajo o por reagrupaciones familiares ${ }^{2}$ (Moreno, 2008). Bizkaia, en 2010, acogía el 64,16\% de las personas migrantes de origen subsahariano asentadas en la CAV, mientras que Gipuzkoa albergaba al $22,47 \%$, y Álava, al 13,37\%.

Hoy día, en el País Vasco viven 8.437 personas de origen subsahariano, es decir, que la población subsahariana representa el 6,06\% del total de la población extranjera en la CAV. El mayor crecimiento de la población africana de origen subsahariano se registró entre 2004 , cuando se contaba con la presencia de 3.592 personas de este colectivo, y 2010, año en que ascendía a 8.437 personas (Gráfico 1). Por países, Senegal aporta 2.192 personas, es decir, el $25,98 \%$ de las procedentes del africana subsahariana. Le siguen Nigeria, con 1.221 personas, y Guinea Ecuatorial, con 876 personas. Otras presencias importantes son las del colectivo mauritano, el maliense y el del ghanés. 


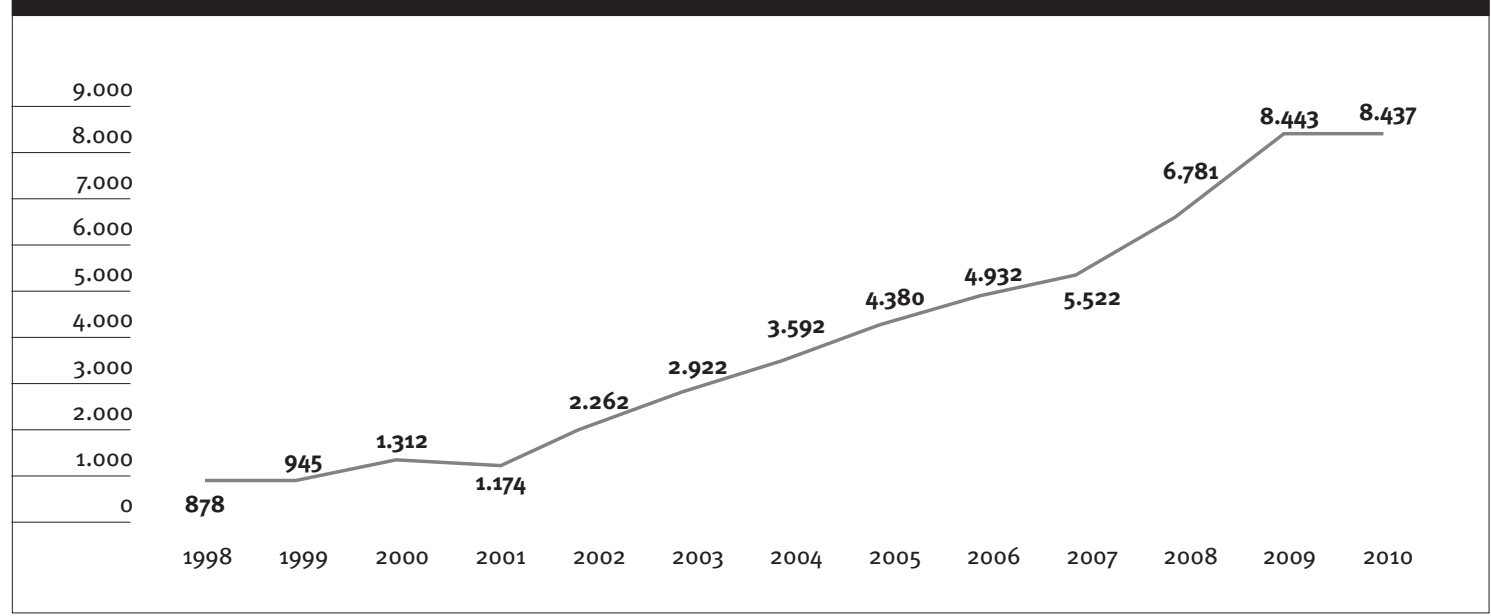

Fuente: Elaboración propia.

Tabla 1. Principales países de origen de la inmigración subsahariana en Euskadi (2010)

\begin{tabular}{l|c|c}
\hline Países de origen & N & $\begin{array}{c}\text { \% sobre la } \\
\text { población } \\
\text { extranjera total }\end{array}$ \\
\hline Senegal & 2.192 & 1,57 \\
\hline Nigeria & 1.221 & 0,88 \\
\hline Guinea Ecuatorial & 876 & 0,63 \\
\hline Mauritania & 581 & 0,42 \\
\hline Mali & 572 & 0,41 \\
\hline Ghana & 568 & 0,41 \\
\hline Camerún & 493 & 0,35 \\
\hline República Democrática del & 323 & 0,23 \\
\hline Congo & 1.002 & 0,72 \\
\hline Angola & 8.437 & 0,23 \\
\hline Guinea-Bissau & 322 & 0,21 \\
\hline Resto de países & 287 & \\
\hline
\end{tabular}

Fuente: Elaboración propia a partir de datos de Ikuspegi.

En el conjunto de la CAV, se encontraron un total de 47 asociaciones compuestas por personas de origen subsahariano. De éstas, 43 están registradas formalmente en los registros municipales y autonómicos, y hay cuatro grupos informales, es decir, que todavía no se han constituido formalmente, pero que funcionan de facto como asociaciones, a todos los efectos. De las 43 formales, 30 están ubicadas en Bizkaia, 10 en Álava y tres en Gipuzkoa. Los grupos informales se ubican en Bilbao (3) y Vitoria-Gasteiz (1).

Como hemos visto, las personas que proceden de África Subsahariana no destacan por una presencia numerosa en el País Vasco. Por el contrario, las asociaciones que éstas impulsan resultan ser las más abundantes de Euskadi entre las formadas por personas migrantes (Unzueta y Di Carlo, 2010; Di Carlo, Ruiz Aranguren y Ruiz Balzola, 2011). En dos estudios recientes editados por Bakeaz sobre las asociaciones de personas migrantes en las tres provincias vascas, los resultados arrojan un predominio de las asociaciones de origen africano subsahariano en Bizkaia y Álava: en el primer caso, el 35,29\% (30 de 85) de las asociaciones censadas están compuestas por personas de origen subsahariano; en el segundo, alcanzan el 37,5\% (10 de 24). Finalmente, en Gipuzkoa estas asociaciones representan el 9,68\% (3 de 31) de todas las censadas.

Estos datos contrastan con la distribución de la población extranjera por nacionalidad en la CAV, puesto que dominan las personas latinoamericanas, con un 48,14\%. Dicho de otra manera, la densidad asociativa de la población africana es sustancialmente mayor $(5,6 \%)^{3}$ que la de la población de otros orígenes.

Las asociaciones censadas hasta hoy se concentran principalmente en Bilbao (10), Vitoria-Gasteiz (10) y Durango (4), de acuerdo con los datos estadísticos sobre la población extranjera en esas tres ciudades vascas. Otros municipios que cuentan con asociaciones de personas de origen subsahariano son Markina (1), Ondarroa (1), Zarautz (1), Donostia-San Sebastián (1) y Hondarribia (1).

Respecto a la nacionalidad de origen de las personas miembros de estas asociaciones, en la Tabla 2 se observa que los países que registran un mayor número de asociaciones son Senegal (13), Camerún (5), Nigeria (4) y Ghana (3). Cabe subrayar la presencia de 11 asociaciones compuestas por personas de países subsaharianos de la misma aérea geográfica.

3 Elaboración propia. 
Dentro del resto de asociaciones, se encontró una gran variedad de países de origen (nacionalidades), entre ellos, Guinea, Guinea Bissau, Guinea Ecuatorial, Angola y Mali.

Tabla 2. Origen nacional de las asociaciones subsaharianas en el País Vasco (2010-2011)

\begin{tabular}{l|c|c}
\hline País de origen & N & $\%$ \\
\hline Senegal & 13 & 27,66 \\
\hline $\begin{array}{l}\text { Diferentes países } \\
\text { subsaharianos }\end{array}$ & 11 & 23,40 \\
\hline Camerún & 5 & 10,64 \\
\hline Nigeria & 4 & 8,51 \\
\hline Ghana & 3 & 6,38 \\
\hline Resto de países & 11 & 23,40 \\
\hline Total & 47 & 100,00 \\
\hline
\end{tabular}

Fuente: Elaboración propia.

En el caso de las asociaciones de personas de origen senegalés, que destacan por la mayor densidad asociativa en la CAV -conforme a su mayor presencia demográfica-, se encontraron asociaciones constituidas por personas de diferentes áreas geográficas (sur/norte) y religiones (musulmanes/católicos). Dentro del colectivo nigeriano, hay asociaciones formadas por personas de diferentes regiones geográficas de Nigeria. Por último, entre las asociaciones de personas de Guinea Conakry se encontraron asociaciones que agrupan a personas según su etnia (poulares, malinkes). A raíz de los resultados cuantitativos obtenidos, cabe decir, pues, que son asociaciones muy variadas y que, dentro de una misma nacionalidad, las personas pueden agruparse por etnia o religión. Otra de las características generales de las 43 asociaciones formales analizadas es su reciente creación, comprendida mayoritariamente entre cuatro y cinco años de antigüedad.

Las asociaciones de migrantes normalmente suelen dedicarse a más de un área de trabajo, lo que también sucede entre las compuestas por el colectivo migrante originario del África Subsahariana. Las áreas de intervención más desarrolladas en estas últimas son la sociocultural -en la que se incluyen aquellas actividades destinadas a la promoción de la cultura de origen- y la de intervención a favor del migrante. Otras áreas de trabajo destacables son las de cooperación y co-desarrollo, deporte y prácticas religiosas. En el área sociocultural intervienen más de la mitad de las asociaciones (51,06\%). Cabe mencionar que, dentro de las asociaciones registradas formalmente, ninguna se dedica específicamente a promover la participación sociopolítica en la sociedad de destino, mientras que dentro de los grupos informales, dos destacan por la labor que vienen desempeñando a favor de los derechos de las personas que los componen en la sociedad de acogida, a través de actividades de reivindicación y de promoción del voto en origen.

\section{El asociacionismo de origen subsahariano en el País Vasco: características estructurales, trabajo en red y acción política}

En lo expuesto anteriormente, se ha querido contextualizar el fenómeno del asociacionismo migrante de origen subsahariano en la CAV, para acercarnos, a continuación, a los resultados de las entrevistas en profundidad realizadas con las asociaciones (22 en total) y así marcar algunas reflexiones que pueden ayudarnos a comprender el papel que están desempeñando como sujeto sociopolítico.

Por lo que se refiere a las características organizativas, un volumen importante de asociaciones contactadas orienta principalmente sus actividades a facilitar la integración sociolaboral de las personas a quienes se dirigen, $y$, en menor medida, a facilitar la integración política. Una amplia mayoría presenta, por esta misma razón, una estructura asociativa de servicios, mientras que algunas combinan una estructura de tipo reivindicativo con otra de servicios. El hecho de que estas asociaciones dediquen gran parte de su trabajo a la prestación de servicios, como respuesta a la demanda y las necesidades del colectivo migrante, conlleva que muchas personas acudan a ellas en primer lugar como demandantes de servicios, y éste parece ser uno de los factores que más está influyendo en la capacidad de movilización interna de las asociaciones. De hecho, todas las personas entrevistadas han afirmado que uno de los retos más difíciles a los que se enfrentan cada día es el de garantizar la participación activa de sus miembros. Además, la situación vital de las personas migrantes y los conflictos de liderazgo y de gestión asociativa aparecen como problemas fundamentales para mantener una base social sólida, aunque la disponibilidad de recursos influye también.

En general, todas las asociaciones han declarado tener dificultades para garantizar los recursos físicos y humanos que requiere el mantenimiento de toda estructura asociativa, aunque varíen en intensidad de unas a otras. De hecho, todas las asociaciones dependen del voluntariado para su funcionamiento y una gran mayoría carecen de un lugar de reunión propio y estable. Esto está relacionado, evidentemente, con las vías de financiación a las que acceden y con las posibilidades reales que encuentran para garantizar los recursos económicos necesarios para su funcionamiento.

A pesar de que algunas han conseguido acceder a subvenciones públicas, todas experimentan, o han experimentado, dificultades comunes de acceso, como el alto nivel de exigencia burocráticoadministrativa en relación con el nivel de formación y experiencia técnica de los miembros, o la resolución tardía de las subvenciones, en el caso de algunas administraciones públicas. La postura mayoritaria pide que las instituciones públicas se comprometan más activamente en el fortalecimiento del asociacio- 
nismo migrante, y se percibe un recelo generalizado hacia los recortes de presupuesto público que se han registrado en el actual contexto de crisis económica. En concreto, se comentan los temores que estos recortes puedan influir negativamente en las políticas de apoyo y promoción del asociacionismo entre el colectivo migrante.

\section{Los vínculos que se} establecen con las asociaciones de migrantes se dan mayoritariamente para crear redes de trabajo o para organizar actividades culturales puntuales

El análisis de las relaciones que las asociaciones establecen con otras (redes), bien sean de migrantes o de no migrantes, muestra que, por lo general, las asociaciones contactadas están predispuestas al contacto y la colaboración con otras organizaciones, tanto si son de migrantes como de autóctonos. Dicha apertura se observa, en mayor medida, hacia aquellas asociaciones que comparten elementos comunes, como el origen nacional de una misma zona geográfica o algunos rasgos culturales. Los vínculos que se establecen con las asociaciones de migrantes se dan mayoritariamente para crear redes de trabajo o para organizar actividades culturales puntuales. La densidad de las redes con otras organizaciones de 'no migrantes' es baja y, en la mayoría de los casos, se tiende a privilegiar los contactos con organizaciones de apoyo que puedan resultar útiles para solventar algunas problemáticas del día a día de las personas que acuden a las asociaciones.

Por lo tanto, las actividades de tipo cultural y las de prestación de servicios son las que más contribuyen al acercamiento, el contacto y la colaboración de unas asociaciones con otras. Sin embargo, estos lazos de colaboración centrados en el aspecto sociocultural no son los únicos que se dan entre las diferentes asociaciones, y destaca la importancia que tiene, para la mayoría de las asociaciones, la relación constante y continua en el tiempo con organizaciones ubicadas, en los países de origen. Estos vínculos se crean por diferentes razones, entre ellas, la necesidad de llevar a cabo proyectos solidarios o de influir en las políticas exteriores de los países de origen y destino.

Las entrevistas han permitido también averiguar si existen redes organizativas activas en el ámbito de la migración. Son muchas las redes y plataformas identificadas en cada territorio histórico, y muchas también las actividades a que se dedican. Ninguna plataforma/red, sin embargo, ha sido valorada como un nodo de referencia entre las asociaciones de migrantes subsaharianos entrevistadas, si bien debe tenerse en cuenta que la Coordinadora de ONG de Euskadi de Apoyo a Inmigrantes-Harresiak Apurtuz es la que aglutina más asociaciones en toda la CAV y, según se ha comentado en alguna de las entrevistas, está contribuyendo, de alguna forma, a establecer vínculos asociativos más allá de los aspectos socioculturales, actuando como intermediaria con las instituciones públicas para trasladar propuestas, reivindicaciones e intereses del colectivo migrante y sus organizaciones. No obstante, las asociaciones dejan entender que estas redes no parecen aglutinarlas alrededor de unas directrices políticas comunes con el fin de incidir en la participación sociopolítica. El surgimiento de la Federación de Asociaciones de Migrantes Senegaleses del País Vasco en 2010, así como la adhesión de una asociación de guineanos a la Red Haaly Poular ${ }^{4}$, ponen de manifiesto el interés de una parte de estas asociaciones por crear redes que defiendan los intereses de grupos nacionales/ étnicos bien definidos, evitando que sean asumidos o representados por otras organizaciones de apoyo al colectivo migrante, de forma que las sustituyan en los procesos consultivos de las administraciones públicas en materia migratoria, no sólo a escala nacional, sino transnacional. Por otro lado, esto podría significar también unos intereses que pueden generar fracturas dentro del propio colectivo, que probablemente no tiene los mismos objetivos. Esto puede denotar que existen -y se les ha de prestar mayor atención- algunos factores que están dificultando el trabajo en red entre las organizaciones, y por lo tanto, la configuración de un movimiento social con capacidad de acción y propuesta en el ámbito público, y capaz también de influir en los procesos políticos sobre cuestiones que afectan al colectivo y a la sociedad en general. Entre estos factores -algunos de los cuales se han identificado a través del contacto con las asociaciones- tienen que ver con la frágil consolidación interna de muchas asociaciones, que suelen trabajar con personal voluntario y se ven afectadas a menudo por las problemáticas a las que se enfrentan sus miembros, y con la mayor orientación de las ayudas públicas hacia el ámbito cultural.

En cuanto al acceso y la participación en los asuntos públicos de las asociaciones objeto de estudio, así como de las vías que están utilizando para ser escuchadas en sus reivindicaciones y propuestas en materia migratoria, se pueden destacar algunos resultados. En primer lugar, las 43 asociaciones formales han logrado cruzar el umbral de acceso al ámbito público, mediante su formalización e inscripción en los registros de asociaciones municipales y del Gobierno Vasco. Sin embargo, su presencia y participación real se ven muy limitadas, debido a la escasez de canales de participación entre las instituciones de los municipios en los que se ubican. Es decir, por el momento, las oportunidades que

${ }^{4}$ La Red Haaly Poular funciona a escala internacional y aglutina a todas las personas de etnia peul (hablantes de poular) originarias de diferentes países subsaharianos (Guinea, Mali, Senegal principalmente). 
tienen las asociaciones de migrantes de ser consultadas sobre el diseño de políticas públicas en materia migratoria a través de los canales formalizados son muy escasas.

Respecto a los contactos con organizaciones de carácter político, como los partidos y los sindicatos, destacan algunos resultados. La mayoría de las personas entrevistadas afirman que, de momento, no están interesadas en establecer contactos con los partidos políticos, y muchas veces confunden el significado de 'político' con la política en el sentido más amplio del término. Como excepción, dos asociaciones informales se han creado con el claro fin de hacer presión política: una, para proteger los derechos de las personas que integran el grupo, y otra, para influir en las políticas migratorias de los países de origen y destino. Esta reticencia se extiende, en gran parte de las asociaciones, a la relación con los sindicatos, argumentada por la marcada tendencia política de éstos y una insatisfacción frente a las funciones que deberían venir desempeñando. Por lo tanto, parece que estos dos tipos de organizaciones de carácter político tampoco están siendo utilizadas por las asociaciones de migrantes subsaharianos como vías de participación en los asuntos públicos.

En cuanto a la organización de actividades de naturaleza política o a la participación en ellas, se observa que las asociaciones tienden hacia formas reivindicativas y propositivas que no implican una confrontación directa y abierta con las instituciones públicas (manifestaciones, charlas, ruedas de prensa, recogida de firmas). Por lo general, son las entidades de segundo nivel (plataformas y coordinadoras de diferentes ámbitos de actuación) las que movilizan a las asociaciones para su participación en actos de protesta y denuncia, que se centran, principalmente, en cuestiones migratorias (integración y derechos de ciudadanía) y sociales. A menudo, el colectivo de África negra se ve desprotegido y sufre rechazos de varios tipos, por lo que no está motivado a 'dar la cara' de forma directa.

Todo parece indicar que las asociaciones insertas en alguna red o que mantienen algún tipo de relación con éstas son también las que más participan en actividades de naturaleza política. No obstante, el caso de uno de los grupos encontrados pone de manifiesto que no siempre el motor de la acción política de las asociaciones se localiza en las redes y plataformas. Se trata del grupo que trabaja por la defensa de los derechos de las personas que realizan el top manta ${ }^{5}$, y es de destacar que el hecho de no estar constituido formalmente como asociación ni inserto en ninguna de las redes localizadas, no ha sido un obstáculo para su organización y participación en actos públicos de protesta, aunque debe tenerse en cuenta el apoyo continuo que ha recibido por parte de SOS Racismo Bizkaia.

\section{Consideraciones finales}

Concluyendo, podemos afirmar que el grado de participación e integración de las asociaciones de África Subsahariana en el ámbito público, en el proceso político de toma de decisiones sobre aspectos que interesan a las personas migrantes, o sobre otros asuntos que afectan a su vida cotidiana y a la sociedad en la que viven, resulta muy bajo de momento. Además, a día de hoy, las asociaciones subsaharianas no han conseguido conformar un movimiento asociativo migrante que les represente y defienda los intereses del colectivo, al objeto de favorecer su participación pública. Tampoco las instituciones y las organizaciones de segundo nivel han conseguido tener un papel activo en este proceso.

Las asociaciones aquí estudiadas se caracterizan por su juventud, y la escasez de recursos humanos y materiales, que afecta al desarrollo de sus actividades y, muchas veces, a la posibilidad de centrarse en actividades de incidencia política. Los problemas de liderazgo y la escasa base social son factores que también influyen en una "proyección externa exitosa" (Gómez Gil, 2010). El grado de reconocimiento legal de las personas que conforman las asociaciones y su exclusión de la vida política en el país de residencia son algunas de las dificultades mencionadas en las entrevistas para explicar el escaso interés de las personas de origen subsahariano en constituirse como interlocutoras activas en la sociedad vasca. Pero también la mayor orientación de las ayudas públicas al ámbito cultural ha sido mencionada como problema clave a la hora de promover proyectos que se desmarquen del ámbito sociocultural. Las entrevistas dejan entrever claramente que las asociaciones se ven empujadas a dirigir sus actividades al ámbito cultural, debido al tipo de subvenciones promovidas por las instituciones.

Sin embargo, algunas reflexiones realizadas con las personas apuntan hacia un autocuestionamiento, entre parte de estas asociaciones, respecto a la línea de acción principal que debe llevar el colectivo a través de sus asociaciones, en el sentido de que deberían ampliar su horizonte más allá de los ámbitos social y cultural, pensar más allá del propio grupo de origen y crear redes entre todas las personas migrantes. De hecho, las asociaciones comparten dificultades comunes de funcionamiento y participación pública, y coinciden en varias de sus demandas dirigidas a las administraciones públicas.

Las problemáticas mencionadas podrían ser algunos de los factores claves que expliquen la ausencia de un movimiento asociativo fuerte entre la sociedad civil organizada que se trata de estudiar en este trabajo y, por supuesto, algunos de los retos a los cuales se tendrán que enfrentar las dos partes implicadas en el proceso de integración, es decir, las personas migrantes, representadas por las asociaciones, y la sociedad en su conjunto.

\footnotetext{
${ }^{5}$ Venta ambulante a que se dedican las personas migrantes.
} 
BERGER, M.; GALONSKA, C.; y KOOPMANS, R. (2004), "Political integration by a Detour? Ethnic communities and social capital of migrants in Berlin", Journal of Ethnic and Migration Studies, vol. 30, nํㅜ 3, págs. 491-507.

BLOEMRAAD, I. (2005): “The limits of De Tocqueville: How government facilitates organizational capacity in newcomer communities", Journal of Ethnic and Migration Studies, vol. 31, nํㅜ 5 , págs. $865-887$.

DI CARLO, M. G.; RUIZ ARANGUREN, M.; y RUIZ BALZOLA, A. (2011): Estudio-diagnóstico sobre las asociaciones de migrantes de origen extranjero en Álava y Guipúzcoa, Bilbao, Bakeaz.

FENNEMA, M.; TILLIE, J. (2001): "Civic community, political participation and political trust of ethnic groups", Connections, vol. 23, no 2 , págs. 44-59.

GÓMEZ GIL, C. (2010) “El asociacionismo de inmigrantes en el marco de los desafíos de las ONG en las sociedades contemporáneas", en LACOMBA, J.; y FALOMIR, F. (eds.), De las migraciones como problema a las migraciones como oportunidad, Madrid, Catarata, pág. 300.

GONZÁLEZ FERRER, A.; y MORALES, L. (2006): “Las asociaciones de inmigrantes en Madrid. Una nota de investigación sobre su grado de integración política", Revista Española del Tercer Sector, no- 4 [<http:// www.fundacionluisvives.org/rets/4/ articulos/14279/>].
IKUSPEGI (2010), “Población extranjera en la CAPV 2010”, Panorámica de la Inmigración, no- 34 [<http:// www.ikuspegi-inmigracion.net/documentos/ documentos_internos/panoramica34cas.pdf)].

MARTINIELLO, M. (2005): Political Participation, Mobilization and Representation of Immigrants and their Offspring in Europe, serie Willy Brandt Series of Working Papers in International Migration and Ethnic Relations, Malmö, School of International Migration and Ethnic Relations [shdl.handle.net/2043/1495'].

MARTINELLO, M.; y PENNINX, R. (2006): “Procesos de integración y políticas locales: estado de la cuestión y algunas enseñanzas", Revista de Investigaciones Sociológicas, $\mathrm{n}$ 울. págs. 123-156.

MORENO, G.; et al. (2008) Población africana en la CAV 2007, Bilbao, Ikuspegi [<http://www.ikuspegiinmigracion.net/documentos/investigacion/ es/pob_afric_capv_2007.pdf>].

TILLIE, J.; y SLIJPER, B. (2006): “Immigrant political integration and ethnic civic communities in Amsterdam", en BENHABIB, S.; y SHAPIRO, I. (eds.), Identities, Affiliations and Allegiances, Cambridge, Cambridge University Press.

UNZUETA, A.; DI CARLO, M. G. (2010): Estudio-diagnóstico sobre las asociaciones de inmigrantes de origen extranjero en Bizkaia, Bilbao, Bakeaz [khttp://ficheros.bakeaz.org/Informe_final_ asoc_inmigrante.pdf $\rangle$ ]. 



\section{El mapeo de las necesidades como medio de mediación social}

\section{Ada Manfreda}

Università del Salento (Italia)

<info@adamanfreda.com>

Egiatan entzutea beharrekoa da bitartekoaren eginkizuna betetzen denean, eta kontsumitzaile izateaz gain, ekoizle gisara ere ulertu behar da erabiltzailea. Horretarako, derrigorrekoa da bideak izan eta sistema egokiez jabetzea erabiltzailearen esana entzun eta jasotzearren. Hori lortzeko baliabidea da beharrak mapan lekutzea. Beharrak mapan lekutzea ikerketarako metodologia izateaz gain, pedagogia eta hezkuntza-mailako eskuhartzea ere bada, hau da, subjektuaren beharrak agerrarazten saiatzen da prozesu horren bidez, eta forma ematen dio errealitatearen dimentsiora eramanez, gauzagarri bilakatuz eta, horren ondorioz, ahalbidetu daitekeenaren dimentsiora eramanez. Beharren arabera mapan lekutzeak aniztasunaren aitortza ahalbideratzen du, eta elkarrekin jardunean jartzen ditu; izan ere, funtsean, prozesu bat baita bestearen nortasunaren kontakizunerako sarbide izateko. Hori guztia azaldu nahi du artikulu honek, eta horren azalpenerako honako lau ardatzak hartzen dira kontuan: estruktura, epistemologia, metodologia eta fenomenologia.

\section{HITZ-GAKOAK:}

bitartekotasun, beharrak, kontakizun, zentsu, alteritate.
Para mediar adecuadamente, hace falta escuchar de verdad a los usuarios, no sólo como consumidores, sino también como productores; es necesario contar con medios y sistemas adecuados para escuchar y recoger la voz de los usuarios. El mapeo de necesidades nos ayuda a hacer esto. El mapeo de necesidades es tanto una metodología de investigación, como una intervención pedagógicaeducativa, un proceso que intenta poner de manifiesto la necesidad del sujeto, dándole forma, llevándola a la dimensión de lo real, a lo realizable, y por lo tanto, a la dimensión de lo posible. El mapeo de necesidades favorece también el reconocimiento de las diversidades, las pone en diálogo, porque, en esencia, se caracteriza por ser un proceso de introducción del otro en la narración de la identidad. Este artículo quiere explicar esto, siguiendo cuatro ejes expositivos: estructural, epistemológico, metodológico y fenomenológico.

\section{Palabras clave:}

mediación, necesidades, narración, sentido, alteridad. 


\section{Introducción}

Este artículo reflexiona sobre el papel del tercer sector como 'mediador social' entre los ciudadanos y las instituciones para conseguir una mayor cohesión social. La mediación representa un medio muy importante para 'hacerse cargo de...', porque activa procesos de mejor comprensión de uno mismo y de los contextos sociales, de crecimiento de las habilidades relacionales y, por lo tanto, del nivel de emancipación de los individuos. Dicho esto, traigo a este debate mi propuesta metodológica.

Para mediar adecuadamente, hace falta escuchar de verdad a los usuarios, no sólo como consumidores, sino también como productores; es necesario contar con medios y sistemas adecuados para escuchar y recoger la voz de los usuarios. Hay una distancia entre la demanda que viene de abajo (los usuarios), que no encuentra la manera de ser acogida y dirigida a los centros de decisión política y a los lugares de la planificación social, y los planes de acción que hace el tercer sector sobre la base de las directrices y objetivos establecidos en los niveles superiores. Mi propuesta se llama 'mapeo de necesidades': se trata de una metodología de investigación-acción compatible con una idea de tercer sector inspirada en una lógica del servicio que no está interesada principalmente en los sistemas de prestación de servicios, sino que se orienta a los usuarios, a las formas en que el usuario utiliza el servicio y al modo en que obtiene un valor de utilidad para su propia existencia, a través del uso del servicio.

Para llevar a cabo un servicio, siempre deberíamos preguntarnos qué es o no es apropiado en relación con el uso propuesto de los usuarios/beneficiarios para los cuales está diseñado. El mapeo de necesidades nos ayuda a hacer esto. El mapeo de necesidades es tanto una metodología de investigación, porque recoge las necesidades del usuario, las interpreta hermenéuticamente y las convierte en proyecto, como una intervención pedagógica-educativa, porque, gracias a la explicación de las necesidades, promueve un proceso de desarrollo de las capacidades estratégicas necesarias a los usuarios para traducir sus necesidades en el proyecto. El aumento de los niveles de la lectura y la planificación de los usuarios, alcanzado con el mapeo de necesidades, es una garantía de mayor eficacia de las acciones y servicios prestados por el tercer sector.

Voy a ilustrar estos temas siguiendo cuatro ejes expositivos: estructural, epistemológico, metodológico y fenomenológico.

\section{Eje estructural}

La necesidad es el asunto central de todas las acciones educativas y sociales. Investigar y comprender la necesidad es la primera etapa de toda intervención. Esta etapa no hay que verla como algo separado y autónomo de la intervención social, sino como intervención social; es ya una intervención social, un proceso de aprendizaje, cuyo objetivo es promover el cambio y el desarrollo en los sujetos que siguen este proceso.

El concepto de necesidad ha sido históricamente estructurado y desarrollado en las diferentes teorías y los distintos campos disciplinarios -economía, sociología, psicología-. Por esta razón, en la actualidad hay varias definiciones de necesidad. En general, hay una tendencia a considerarla en sentido negativo, es decir, como falta, carencia o ausencia; frente a esta concepción, está la que considera la necesidad como algo que se puede introducir con las intervenciones sociales y educativas, una respuesta que traza el camino que el sujeto debe completar. A mi juicio, esta definición es todavía insuficiente e inadecuada para proporcionar medios eficaces de acción dentro de la complejidad.

La complejidad de los sistemas sociales en que vivimos hoy día nos lleva a hacer referencia al enfoque de ecosistema, que intenta dar cuenta de la complejidad de los fenómenos naturales y la interrelación de los procesos humanos y de los actores/actrices, la naturaleza multifactorial de eventos y experiencias, las muchas miradas que pueden leer el mismo problema. Este marco teórico no admite, por supuesto, una visión reduccionista y mecanicista de la necesidad, ni propuestas para el diagnóstico ortopédico.

Mi propuesta es que es mucho más productivo, interesante y relevante desde el punto de vista pedagógico, desde una perspectiva de desarrollo, considerar la necesidad en un sentido positivo, es decir, como un recurso, subjetivamente significativo y relevante pedagógicamente: es un recurso que necesita ser investigado, interpretado, puesto en forma con el fin de llegar a un proyecto que es existencial, en primer lugar, y, por lo tanto, profesional y social. En este escenario, intervenciones educativas y de formación representan una palanca para que el sujeto pueda dar cuerpo al proyecto de desarrollo.

Es interesante empezar con la formulación teórica que Lévinas (1977) nos ofrece. Este autor propuso darle la vuelta a la visión tradicional negativa de la necesidad y sostuvo que la advertencia de la necesidad depende del diseño de la vida que podemos imaginar: la necesidad es la aspiración de vivir una situación de bienestar, el apetito de perfección, el deseo de plenitud. En este sentido, la necesidad es un recurso para el sujeto. Una vida feliz no es una vida sin necesidades, en la que el sujeto ha cumplido todas las necesidades; es importante tener la capacidad de fijarse de vez en cuando una meta para la propia existencia, es decir, tener la capacidad de re-imaginar una nueva necesidad por y para sí mismo.

La necesidad está relacionada con el proyecto. El proyecto es la manifestación de la intención constructiva del yo, que es perseguida por el sujeto a través de su larga experiencia vivida. Por esta razón, el proyecto se basa en la idea de 'presencia', combinada con la 
intención, con la que la persona se abre al mundo y trata de vivirlo. Desde esta tensión, nunca satisfecha, que es necesaria, surge la necesidad, que es el lugar de la elaboración activa del mundo, del objeto, del otro; es recurso que debe ser interrogado e interpretado para definir un proyecto capaz de articular en el tiempo, hacia un horizonte, la búsqueda de sentido que nos caracteriza como seres humanos, es decir, como seres narrativos, que trabajan para volver a interpretar, reducir, absorber la distancia/diferencia entre el yo y la alteridad, a través de una inversión en creatividad, imaginación y transformación de la realidad y de uno/a mismo/a.

Agnes Heller (1978), por su parte, dentro de una perspectiva marxista heterodoxa, señaló que la aspiración fundamental del ser humano, como ser socializado, es participar en la vida de una comunidad, en la que buscar la satisfacción de sus necesidades para el desarrollo. Por lo tanto, las necesidades son el resultado del equilibrio entre los impulsos identitarios individuales y las dimensiones relacionales, lo que guía y permite los caminos de la vida. En este sentido, creo que podemos hablar de la 'necesidad de comunidad'. La 'necesidad de comunidad' es la necesidad de cada persona de un espacio concreto en que las prácticas narrativas y discursivas son posibles para explorar la relación entre identidad y alteridad, la capacidad de socializar 'cara a cara', el encuentro de la mirada de otros, en un diálogo real entre los sujetos reales y concretos, y no entre los modelos ideales de los sujetos, la sociedad y la comunidad. La comunidad es el espacio de estas posibilidades. La necesidad de comunidad pone de manifiesto que la interpretación que cada persona hace de sí misma y del mundo tiene carácter social y cultural.

¿Cómo se puede satisfacer la 'necesidad de comunidad'? A esta pregunta, la lógica económica del capitalismo ha tratado, y trata, de ofrecer respuestas a través del mero consumo de cualquier bien, desde los bienes materiales hasta los bienes intangibles, que son el reservorio de símbolos y emociones, que están cada vez más comercializados y explotados por el sistema económico, como cualquier otro objeto. Sin embargo, el mero consumo propone sustitutos, es decir, simulacros aparentemente adecuados, pero, en realidad, completamente ineficaces, porque están vacíos; son un espejismo que promete, pero no mantiene, que simplemente alimenta el ciclo de la compulsión por consumir. La satisfacción de las necesidades no se puede reducir al acto de consumo (acción pasiva), sino que es, sobre todo, un acto de producción (acción activa). Es la productividad cultural y social, a la que cada individuo, inscrito dentro de los procesos de participación de la comunidad, contribuye. Cada individuo de la comunidad produce sus narraciones, y al hacerlo se enfrenta a las historias de los demás miembros de la comunidad, creando un intercambio de símbolos, valores, significados y prácticas (Manfreda, 2010a).

En términos más generales, podemos decir que las necesidades de los sujetos son un producto de nuestra necesidad de 'ser' en el mundo en continua búsqueda de significado.

\section{Eje epistemológico}

Las ciencias humanas, hoy más que nunca, se enfrentan con la categoría del cuidado. Las teorías de estas ciencias eligen las prácticas que cada vez utilizan más los métodos de 'hacerse cargo de' para tratar de activar los procesos de cambio y desarrollo (Cambi, 2010). El acto de cuidar no sólo es una intervención en favor de una persona débil, enferma, que necesita ayuda, sino también un medio para la emancipación de los sujetos, para que puedan desarrollar su potencial. Educar significa hacerse cargo del sujeto, del grupo, de una entidad social, mediante la comprensión y la planificación, a través del acto de donación y de dedicación, junto con la empatía y la razón. Cuidar a alguien es asumir la carga de su crecimiento, que se lleva a cabo en la autonomía del sujeto o sujetos que se encuentran en la educación, pero debe ser guiado (Cambi, 2010).

Hasta ahora hemos dicho que el cuidado tiene que ver con la emancipación, pero también significa participación, adhesión, empatía; cuidado es la búsqueda de sentido dentro del proceso abierto y continuo que es la identidad, dentro de la re-construcción del yo, siempre problemática. Mi idea de la necesidad parte de este marco teórico, y se dirige a la pedagogía social y a la pedagogía de la comunidad para obtener las bases científicas de una metodología de investigación coherente. La referencia a la pedagogía de comunidad me lleva a sostener que la necesidad está muy contextualizada desde el punto de vista cultural, social y comunitario. Creo también que es útil combinar la necesidad, su investigación y comprensión, con las representaciones sociales compartidas en el contexto estudiado. La teoría de las representaciones sociales intenta articular la relación entre los factores individuales y los factores sociales en la construcción de representaciones, que median las respuestas conductuales de los sujetos, frente a los problemas relacionados con su vida cotidiana. Esta teoría destaca la "esencia social y colectiva de la comprensión que las personas tienen de sí mismas y del mundo, centrándose en ideas compartidas, en la manera en que se desarrollan, se describen, se modifican" (Zani y Cicognani, 2000). Las representaciones sociales son una forma de conocimiento práctico, el desarrollo de un objeto social por parte de una comunidad que permite a sus miembros comportarse y comunicarse de una manera comprensible.

Esquemáticamente, podemos decir que las representaciones sociales son:

\section{- Una forma de conocer.}

- Un sistema de valores, significados y prácticas que organizan la realidad, permitiendo a quienes los comparten orientarse en su contexto de referencia material y cultural, y actuar. 
- Una lista de categorías con las que empezar a dar sentido a lo que es nuevo.

Las representaciones sociales orientan el comportamiento y las prácticas de los individuos en sus interacciones sociales, debido a que:

- Construyen y dan forma a la realidad.

- Median en la comunicación y la interacción social.

- Definen los límites de un grupo.

- Hacen que lo desconocido se vuelva conocido.

La formulación de las necesidades se lleva a cabo en el marco de las representaciones. Éstas son tanto el fondo - lo que afecta al sujeto, en la formulación de sus necesidades- como un conjunto de claves para la interpretación que el investigador debe tomar necesariamente en consideración, en el proceso de exploración de las necesidades de un determinado grupo social.

\section{Eje metodológico}

¿Cómo investigar la necesidad? El análisis de las necesidades, en general, se configura como una investigación dirigida a recopilar datos e información útil para el diseño de intervenciones educativas y formativas. Es en el ámbito de la formación donde más se ha reflexionado sobre el análisis de las necesidades, las metodologías que deben utilizarse, los propósitos y los objetivos que deben alcanzarse. En materia de educación, sin embargo, el análisis de las necesidades no ha sido suficientemente problematizado para reflexionar sobre las características específicas que debe tener de forma que pueda ser utilizado con éxito en intervenciones socioeducativas. ¿Cuáles son los métodos más adecuados? ¿Cuáles son los fines a los que dar respuesta? ¿Cuál es su significado? En situación operativa, las reflexiones maduradas en el campo de la formación han sido directamente traducidas y adaptadas al ámbito socioeducativo. Así pues, considero que las necesidades y su detección en el contexto socioeducativo merecen una consideración especial.

Existen algunas diferencias fundamentales entre los ámbitos formativo y socioeducativo:

- De contexto:

- En el caso de la formación, la intervención se diseña para el contexto socioeconómico, organizativo y de trabajo, sobre la base del análisis de las necesidades.

- En el caso de las acciones socioeducativas, el contexto es social, cultural, relacional, ambiental; dentro de ese contexto, se coloca la vida de sus miembros y, en particular, de quienes, por quienes y con quienes queremos crear una intervención educativa.
- De objetivo:

- En el caso de la formación, el objetivo se traza principalmente para definir el perfil de las competencias que posee el sujeto y cuáles deben ser desarrolladas a través de un curso de formación.

- En el caso de las acciones socioeducativas, el objetivo es principalmente de asesoramiento: se busca prestar apoyo para que el sujeto pueda hacer un proceso de reflexión sobre sí mismo, valorizar su especificidad, leer sus contextos de vida de la mejor manera, y así, promover o mejorar sus condiciones de emancipación.

Por otra parte, en la formación, podemos resumir las principales áreas y los objetos del análisis de las necesidades, en dos grandes categorías:

- Análisis de las necesidades de la organización: se refiere a todos los actores/actrices de la organización, y su objetivo es superar los problemas, promover el cambio organizacional, identificar planes de formación y puesta al día de los recursos humanos.

- Análisis de las necesidades de los individuos: está diseñado para la orientación profesional, o para proporcionar a las instituciones formativas los datos necesarios para definir y diseñar programas de formación para la profesión y el trabajo (en este caso, la atención se centra principalmente en las competencias técnicas y profesionales de la persona, y por lo tanto, el análisis de necesidades está muy cerca del balance de competencias).

¿Qué pasa en el contexto socioeducativo? Sucede que las dos dimensiones que se han indicado anteriormente asumen características diferentes, y por lo tanto, requieren de un marco teórico y metodológico muy específico:

- Ya no hablamos de organizaciones, sino de grupos y comunidades.

- La investigación de las necesidades individuales no se centra en las competencias técnicas y profesionales (que son importantes, pero en una escala diferente), sino en las competencias emocionales y relacionales, contextuales, y en todas las dimensiones que se combinan para definir una condición de emancipación individual, y por lo tanto, de capacidad de establecer por sí mismo/a un proyecto de vida.

Veamos las consecuencias metodológicas que se derivan de esas dimensiones. En primer lugar, la metodología escogida, debe tener características predominantemente cualitativas, etnográficas y, sobre todo, indiciarias. No anhela resultados exhaustivos, definitivos ni de definición. Esto claramente implica un alto grado de incertidumbre, que debe tenerse en cuenta, pero al mismo tiempo, el necesa- 
rio grado de apertura y flexibilidad, lo que garantiza más posibilidades de intervención:

- En un profundo respeto por la diversidad.

- Lo más libre posible de los estereotipos y prejuicios.

- De acuerdo con una actitud que valoriza realmente al otro.

- De manera coherente con el marco de significado, representado por el contexto de vida en el que los actores/actrices están inmersos.

Debido a todas estas consideraciones, mi propuesta metodológica se llama mapeo de necesidades. El mapeo de necesidades no es un proceso dirigido a encontrar algo que ya existe, sino un proceso para tratar de poner de manifiesto la necesidad del sujeto, dándole forma, llevándola a la dimensión de lo real, a lo realizable, y por lo tanto, a la dimensión de lo posible. Conducir la necesidad a la dimensión de lo real significa hacer progresar la necesidad en un proyecto. Es decir, introducir el espacio de reflexión para hacer explícito lo que, hasta ese momento, se incorpora y está implícito en las acciones del sujeto. El mapeo se coloca entre la necesidad y el proyecto, y trata de facilitar y simplificar la transición de una a otro. Ésta es una actividad que investiga las necesidades, no como si fueran objetos, que se recogen directamente en las personas y son directamente inteligibles para ellas. Es, más bien, un proceso interpretativo, de comprensión y de co-construcción de las necesidades, las cuales se componen en una narrativa posible y socialmente integrada.

El mapeo de necesidades, por lo tanto, tiene una impronta fenomenológica, es abierto, interactivo, y toma la postura metodológica de la observación y de la escucha. Tiene además caracteres ideográficos, porque quiere comprender las estrategias a través de las cuales los individuos construyen significados, para aumentar el nivel de conciencia y sentar las bases para la promoción de la participación, la capacidad de cambio de diseño, y por lo tanto, la emancipación individual y comunitaria (Colazzo 2008). El desafío del mapeo de necesidades es:

integrar los datos estructurales y las variables subjetivas, como las representaciones sociales, los modelos simbólicos y culturales, las expectativas hacia el futuro, las experiencias personales, porque sólo si todos ellos están relacionados, puede encontrar los significados que caracterizan un determinado contexto (Navanco y Novara, 2006).

En este contexto, el investigador se configura como un agente de cambio.

El término 'mapeo', utilizado en vez de 'análisis', da mejor cuenta que este último término de una obra que es, ante todo, un recorrido de descubrimiento de huellas, de elementos de pequeño tamaño, que termina componiendo una imagen representativa, donde adquiere gran importancia la co-construcción hermenéutica, de lecturas subjetivas y objetivas, situadas, particulares, atentas al 'aquí y ahora' de todos los actores/actrices involucrados/as en el proceso. Utilizar el término 'mapeo', nos permite mantener bien claro el carácter representativo, y de interpretación, de la investigación de/sobre las necesidades. Es el resultado de un espacio de trabajo compartido, que siempre puede ser revisado, modificado y rediseñado, porque es intrínsecamente abierto. Mi propuesta de mapeo de necesidades asume el carácter de una actividad de asesoramiento cuyo objetivo es fomentar, en el sujeto, un trabajo de remodelación activa del mundo, para poder hacer evolucionar la necesidad en un proyecto. El hecho de que hablamos de trabajo indica que es un proceso que requiere esfuerzo, compromiso, responsabilidad; un proceso que se desarrolla en el tiempo e involucra a la memoria. También indica que es una tarea que cada sujeto tiene que dirigir hacia sí mismo, por sí mismo, por y para su emancipación. El mapeo de necesidades debe ser considerado como una actividad de investigación educativa, para facilitar, en el contexto de los actores/actrices, el reconocimiento de sus necesidades y su articulación en el proyecto.

El proyecto debe estar vinculado necesariamente a una intrínseca apertura, que se caracteriza por:

- Una indeterminación a priori de los resultados.

- Un sentido procesual.

- Dinamismo.

- Complejidad.

El acuerdo con el sentido de apertura no justifica el abandono del proyecto, no niega y ni frustra el proyecto, no le quita valor, como tampoco significado. Todo lo contrario. El proyecto es verdaderamente un proyecto si es capaz de conjugar, al mismo tiempo, la intencionalidad y la apertura. El mapeo de necesidades promueve la definición de un proyecto para el desarrollo personal, en el contexto del cual se forma parte, visto como una interpretación creativa de la existencia, pero basada en objetivos al alcance, para estar siempre en diálogo con los demás y la realidad, sin caer en los extremos de:

- La mera reproducción de conformismo social.

- Un proyecto, poco realista, no contextual, y por lo tanto, fantasmal, $y$, a veces, incluso delirante.

El mapeo de necesidades es un proceso de suspensión de la vida cotidiana, a fin de establecer un lugar de encuentro entre la imaginación, la creatividad, la productividad y el proyecto. Es decir, un espacio adecuado para formular una representación de las necesidades. Además, el mapeo de necesidades considera el sujeto, en su ser inscrito en contextos específicos de la vida, dentro de los procesos específicos de comunicación y de relación entre determinados grupos y comunidades de práctica. Es por eso 
por lo que tratamos de incluir, en el acto en el que se realiza el mapeo, el sistema de relaciones sociales del sujeto, los otros actores/actrices del contexto, que, por diversas razones, son parte de su constelación relacional, y el marco de sentido en el que las prácticas discursivas y el procesamiento de los significados son realizados por el sujeto. Por estas razones, el mapeo de necesidades es metodológicamente una investigación-intervención.

Los métodos de intervención del mapeo de necesidades consisten en una función narrativa, en la que la interacción entre el sujeto y el investigador es fundamental. Las narraciones son el resultado

\begin{abstract}
"de la construcción de un escenario, complejo y coherente, por el sujeto que narra, integrado por los acontecimientos, que están inseparablemente relacionados con factores emocionales, las creencias personales, las preferencias, el conocimiento científico, las decisiones, las acciones, y así sucesivamente. Esta construcción está implícita en la interpretación, implícita o explícita, consciente o inconsciente, de lo que sucedió. El mismo conjunto de eventos, se puede ordenar temporalmente, y estructurar lógicamente, de diferentes maneras por diferentes narradores, que participan de manera directa, o indirecta, en los eventos" (Giani, 2009).
\end{abstract}

La narración es la forma específica (el proceso cognitivo específico, escribió Bruner [2001]), a través de la cual los seres humanos buscan y dan forma y sentido a las cosas, a sus experiencias cotidianas, a su propia existencia, al contexto en el que viven. Existe una estrecha relación entre narrarse a sí mismo y formarse. A medida que el sujeto narra, produce una reconstrucción significativa de su propia vivencia, recruzando y reorganizando, dando sentido a los acontecimientos y situaciones de la historia personal.

Sin embargo, el objetivo de la función narrativa del mapeo de necesidades es acompañar al sujeto, para pasar de 'narrar', hacia un 're-narrar'. Esto significa hacer que aparezca la alteridad dentro de la narración, romper la unidad de la narración en primera persona, y por lo tanto, producir un desplazamiento. La ruptura es funcional, sirve para producir un proceso de re-significación de sí mismo y la realidad circunstante.

El mapeo de necesidades, utiliza las técnicas de interacción dialógica, ya que representan un dispositivo dinámico, que mantiene unidos a los procesos de diferenciación y de procesos de integración. El diálogo con la alteridad -en mi opinión- puede llevarse a cabo a través de dos movimientos posibles:

- Saliendo de sí mismo, para tratar de estar de parte del otro, desde su punto de vista. Se trata de juzgar a otra persona, asumir otra identidad, de manera temporal, para enfrentarse a otra mirada, para tratar de comprender a los otros, pero, sobre todo, para comprender nuestra mirada.
- Buscando dentro de nosotros mismos, esa parte de 'no yo' que habita en nosotros, el otro que podemos reconocer en nosotros.

Esto crea un efecto de espejo que permite ampliar los límites del sentido y avanzar hacia escenarios más posibles, teniendo en cuenta el proyecto. En estas condiciones, puede ocurrir un cambio productivo. Bajo estas condiciones, el mapeo de necesidades se puede definir como investigación-intervención.

\section{Eje fenomenológico}

La cohesión social es un concepto compuesto. Tiene que ver con la calidad de vida, con las condiciones de empleo, con la salud y el bienestar, con la lucha contra la pobreza y la exclusión social. Por esta razón, es un objetivo que se logra no sólo mediante el aumento de las redes de relaciones interpersonales de desarrollo económico y de mercado. Es necesario, intervenir en el desarrollo y fortalecimiento de los lazos sociales, porque tienen un papel fundamental para el crecimiento de los grupos y comunidades, para el bienestar social, para la calidad de vida en general (Ingrosso, 2006). Es, por tanto, un concepto y un valor que no puede reducirse a mera coexistencia pacífica: un proceso de intercambio, convergencia de intereses y proyectos, mantenimiento y desarrollo de capital social y redes comunitarias.

Los factores que actúan en la dirección favorable a la consecución de la cohesión social son:

- La territorialización de los servicios públicos de infraestructura y recursos.

- El reparto de responsabilidades entre las autoridades del orden público y las administraciones locales, dentro de un concepto amplio de seguridad, que también incluye la habitabilidad social, la calidad de vida, de trabajo y el ocio.

- El aumento de los espacios físicos y de acción social para el sector del voluntariado y el tercer sector.

- El aumento de las situaciones que requieren más responsabilidad individual y la integración de los servicios públicos (Ingrosso, 2006).

Cuando no hay cohesión social, o está en crisis, es esencial la mediación social por parte los actores del tercer sector. De hecho, la mediación:

incluye las prácticas de intervención dirigidas a la reconstrucción de los lazos sociales con el fin de re-socializar a los individuos, y para luchar contra los fenómenos de la desorganización, que atentan contra la vida colectiva.

Es una forma de intervención, que tiene especial importancia para todas las situaciones límite de los individuos, o grupos, que mantienen, con dificultad, vínculos positivos con sus contextos 
de pertenencia, o el contexto social más amplio (Bramanti, 2005).

Tiene que ser un medio de conexión entre los diferentes sujetos, que están buscando fórmulas de convivencia, y debe ser capaz de interpretar estas diferencias como un enriquecimiento recíproco. Esto es absolutamente necesario en una sociedad, que es algo orgánico, pero, al mismo tiempo, también una convivencia de comunidades, micro y macroculturas, diferentes personas, cada una caracterizada por una cultura local, a menudo irreconciliables; una convivencia que es posible, precisamente, porque hay un marco, que lo hace posible.

En este modelo de servicios sociales 'orientados al cliente' al que me refiero, cada sujeto tiene un potencial para el desarrollo que se realiza si se crean las condiciones, que pueden ser la ayuda y el apoyo por parte una persona más competente, de manera que la distancia entre el nivel de desarrollo actual y el nivel de desarrollo potencial pueda llenarse. La mediación es, ante todo, una acción de escuchar y está orientada al reconocimiento de las necesidades de las personas, a fin de facilitar su conexión, su comparación, sus intercambios, su composición productiva; no obstante todo también creíble, dentro de los escenarios contextuales de referencia. El acto de mediación es una composición que viene a través de la escucha, y al reconocimiento de la diversidad y la reciprocidad en la diversidad. La mediación social apunta a la prevención y a la gestión positiva de conflictos socioeconómicos, culturales, étnicos, a través de la restauración de las conexiones y las relaciones sociales, y del desarrollo de competencias de los individuos y grupos.

El mapeo de necesidades puede ser un instrumento importante para la mediación social, a través del cual se pueden promover nuevas reglas de comunicación e interacción entre los ciudadanos/ciudadanas y las instituciones. El mapeo de necesidades tiene la ambición de combinar la diversidad y la cohesión social. Ambas son compatibles, en mi opinión, aunque esto puede parecer una contradicción. La premisa fundamental de la cohesión social no es 'ser iguales', sino 'reconocerse unos a otros, en la diversidad' (porque siempre es diferente uno de otro) y 'estar en diálogo'. El mapeo de necesidades favorece el reconocimiento de las diversidades, las pone en diálogo, porque, en esencia, se caracteriza por ser un proceso de introducción del otro en la narración de la identidad. Sólo de esta manera puede completarse el camino del autoconocimiento. La identidad se define únicamente en su encuentro con la alteridad y depende fundamentalmente de la relación establecida con ella. La diferencia es constitutiva del ser, del yo, de su siempre cambiante dinámica, y por lo tanto, no se puede borrar, marginar, eliminar o cancelar sin afectar negativamente a la misma identidad.

Para descubrir y definir el yo, hay que pasar a través de la diversidad, hay que interactuar con el otro, diferente del yo: el yo, de esta manera, se define en su encuentro con el otro. La identidad no es un dato definitivo e inmutable, no es un sistema cerrado, una fortaleza, que debe ser defendida contra amenazas externas. No es algo ontológico, un a priori monolítico, sino una entidad dinámica, semipermeable, y por lo tanto, contingente, histórica y procesal, en continuo diálogo con el contexto en el que está inmerso el sujeto.

En esta dinámica, es de gran importancia el término 'reconocimiento'; reconocimiento mutuo, sin duda, pero sobre todo, reconocimiento del otro, como condición para ser capaz de reconocerse a sí mismo, como un requisito necesario en el proceso de definición de la identidad. Sin embargo, la existencia del otro en nosotros requiere otra acción fundamental: la acogida. Es decir, la presencia de la alteridad en el yo, el otro en nosotros, sin que ello signifique el deterioro del sujeto que lo acoge. Acogida y reconocimiento son dos palabras clave en el proceso de definición de la identidad. El otro representa "la forma misma que toma el sí, donde el interior se cruza con el mundo exterior, el suyo con el extraño" (Esposito, 2002: 207). Esto no quiere decir que el exterior no exista, que el otro no exista; quiere decir que 'dentro' y 'fuera' se derivan del proceso continuo de su comparación, intercambio y relación que los determina como tal, en una dinámica de co-existencia, que llega a un 'externo internalizado' y una 'interna exteriorizada', en el que la identidad es el resultado de su producto.

Los procesos de desarrollo y emancipación individual y social, son, por lo tanto, siempre, procesos de comparación, procesamiento, constante re-significación de la alteridad, de cualquier forma. Por lo tanto, se deduce que el mapeo de necesidades es particularmente importante para todos los proyectos socioeducativos que se refieren a la interculturalidad y la integración, en los que el destinatario es el marginal, el extraño. 


\section{Referencias bibliográficas}

BRAMANTI, D. (2005): Sociologia della mediazione. Teorie e pratiche della mediazione di comunità, Milán, Franco Angeli.

BRUNER, J. (2001): “L'interpretazione narrativa della realtà", en BRUNER, J., La cultura dell'educazione. Nuovi orizzonti per la scuola, Milán, Feltrinelli.

CAMBI, F. (2010): La cura di sé come processo formativo. Tra adultità e scuola, Roma, Laterza.

COLAZZO, S. (2008): Progettazione e valutazione dell'intervento formativo, Milán, McGraw Hill.

ESPOSITO, R. (2002): Immunitas. Protezione e negazione della vita, Turín, Einaudi.

GIANI, U. (2009): “Le traiettorie del malessere: modello multi metodologico per l'analisi delle narrative di malattia”, en GIANI, U. (ed.), Narrative based medicine e complessità, Nápoles, Scriptaweb, págs. 47-78.

HELLER, A. (1978): La teoria dei bisogni in Marx, Milán, Feltrinelli.

INGROSSO, M. (ed.) [2006]: La promozione del benessere sociale: progetti e politiche nelle comunità locali, Milán, Franco Angeli.
LAVANCO, G.; y NOVARA, C. (2006): Elementi di psicologia di comunità. Dalla teoria all'intervento, Milán, McGraw Hill.

LÉVINAS, E. (1977): Totalità e infinito. Saggio sull'esteriorità, Milán, JacaBook.

MANFREDA, A. (2011): "Narrazione e mappatura dei bisogni di salute", en MINELLI, M.; PERUCCA, A.; y SIMONE, M. G. (eds.), Una nuova cultura per la pratica medica, Lecce, Edizioni di Solidarietà, págs. 45-62.

- (2010a): “'Laboratorio memoria': ricerca educativa e bisogno di comunità", en COLAZZO, S. (ed.), Sapere pedagogico. Scritti in onore di Nicola Paparella, Roma, Armando, págs. 674-683.

- (2010b): “Una metafora influente: l'io immunitario. Dalla pedagogia della salute alla pedagogia di comunita", en In medias res. Studia resoviensia in lingua et litteris, Rzeszów, Wydawnictwo Promar-International, págs. 125-143.

ZANI, B.; y CICOGNANI, E. (2000): Psicologia della salute, Bolonia, Il Mulino. 


\section{La Gran Recesión y el mundo después de la crisis}

\section{Ramón Barinaga Osinalde}

\section{GAUTENA}

<gautena@sarenet.es>

2007. urtean hasitako atzeraldi ekonomiko nabarmenaz gogoeta batzuek jaso ditu artikulu honen egileak, betiere egitasmoa betetzeko ekonomia eta soziologiaren egile batzuen testuak oinarri hartzen dituelarik. Testuaren xedea da egoeraren kausak ezagutarazi eta etorkizuneko bide-orri egoki baten ezaugarriak azaltzea, modu osasungarriago batean beharrezko ekonomia eta gizartearen oinarriak finkatzen lagungarri gertatzeko.

HITZ-GAKOAK:

krisia, atzeraldia, Ongizate-Estatua, iraunkortasuna, etorkizuna.
De la mano de diversos autores que trabajan principalmente en el ámbito de la economía y la sociología, el autor de este artículo expone algunas consideraciones sobre la Gran Recesión iniciada en 2007. El objetivo del texto es intentar comprender las causas que la han generado, y anticipar las características que habría de tener una hoja de ruta que permitiera proyectar a futuro, de manera más saludable, los fundamentos económicos y sociales.

\section{Palabras Clave:}

crisis, recesión, Estado del bienestar, sostenibilidad, futuro. 


\section{Introducción}

La crisis iniciada en 2007 está afectando al equilibrio entre competitividad y cohesión social alcanzado históricamente en las sociedades más avanzadas en las tres décadas posteriores a la Segunda Guerra Mundial. Tal equilibrio se viene deteriorando, de hecho, desde el último tercio del siglo pasado por diversas razones entre las que, junto a las nuevas realidades demográficas y sociológicas, destacan la globalización de la economía y el auge de una concepción fundamentalista de mercado, que aboga por una mínima intervención pública en la economía, una reducida presión fiscal, y la desregulación financiera.

En Europa, escenario por antonomasia del Estado del bienestar, iniciamos el siglo XXI con una unificación monetaria que, si bien reflejaba en parte la voluntad de un funcionamiento más integrado entre los países del Viejo Continente, no llevó consigo la progresiva homogeneización de las políticas fiscales y el establecimiento de una gobernanza económica, que, en momentos de turbulencias, hubiera dado verdadera solvencia a la nueva divisa.

Así, en los últimos meses de 2011, cuatro años después del inicio de la crisis, el problema de la deuda soberana, déficits públicos elevados en determinadas economías, poderosos movimientos especulativos financieros, las dudas en torno a la apuesta por una verdadera integración europea y hasta de la continuidad de la propia moneda común (el euro), una nueva recaída en el crecimiento económico, la pérdida de confianza de la ciudadanía en sus propias instituciones, el desempleo en cotas históricas, la falta de coordinación y entendimiento respecto al tratamiento a aplicar por parte de las principales economías del mundo, definen un panorama preocupante.

Para hacer frente a esta situación, en Europa se viene dando prioridad a las políticas de consolidación fiscal, proponiéndose por toda solución políticas de ajuste, mientras en EE.UU. hay un mayor debate y hasta un apoyo a medidas de estímulo de la actividad económica. Por su parte, los países emergentes comienzan a sentir la crisis y piden a los países particularmente inmersos en ella, medidas urgentes y eficaces para reconducir la situación. La crisis afecta no sólo al funcionamiento del sistema económico, sino a la propia comprensión global de las sociedades actuales, y al tipo de futuro que pudiera aguardarles, con evidentes consecuencias en el futuro de los países y en la vida de las personas.

En un primer apartado del artículo, se señalarán algunas de las características que definen la actual crisis. En el segundo, se apuntarán aquellas formulaciones que pudieran plantear un futuro mejor. Y en el último apartado, se abordará un intento de conclusión.

\section{En torno a la crisis}

Tras la incorporación de China a la economía capitalista y la caída del Muro de Berlín, podemos decir que vivimos en un mundo globalizado cuyo sistema económico es enteramente capitalista; un sistema capitalista que ha entrado en su crisis más profunda desde los años treinta del pasado siglo.

\subsection{La ilusión de la Nueva Economía}

El economista Joseph Stiglitz (2010), profesor en la Universidad de Columbia y Premio Nobel de Economía 2001, venía alertando de los riesgos de la andadura del sistema económico crecientemente dominado desde el último tercio del siglo pasado por un sector financiero que consiguió cada vez mayores cotas de desregulación, y que ha sido uno de los factores fundamentales en la génesis de esta crisis.

La teoría económica moderna, con su fe en el libre mercado y en la globalización, había prometido prosperidad para todos. Se suponía que la tan cacareada Nueva economía -las sorprendentes innovaciones que marcaron la segunda mitad del siglo XX, incluyendo la desregulación y la ingeniería financiera- iba a hacer posible una mejor gestión de los riesgos, y que traería consigo el final de los ciclos económicos. Sin embargo, la 'Gran Recesión' - a todas luces la peor crisis económica desde la Gran Depresión de hace 75 años- ha hecho añicos estas ilusiones y nos está obligando a replantearnos unas ideas muy asentadas. Durante un cuarto de siglo han prevalecido determinadas doctrinas sobre el mercado libre: los mercados libres y sin trabas son eficientes; si cometen errores, los corrigen rápidamente. El mejor Gobierno es un Gobierno pequeño, y la regulación lo único que hace es obstaculizar la innovación. Los bancos centrales deberían ser independientes y concentrarse únicamente en mantener baja la inflación.

\subsection{La creciente brecha social: la tarea pospuesta}

Como señala Stiglitz para el caso de EE.UU., con análisis extensible al resto del mundo occidental, esta crisis ha puesto al descubierto fisuras en nuestra sociedad, "entre Wall Street y Main Street, entre los Estados Unidos ricos y el resto de los ciudadanos". En Estados Unidos, en los últimos treinta años, a los de arriba les ha ido muy bien, "mientras los ingresos de la mayoría de los estadounidenses se han estancado o han bajado. Las consecuencias se han ocultado; a los de abajo -e incluso a los de en medio- se les dijo que siguieran consumiendo como si sus ingresos aumentaran; se les instó a vivir por encima de sus posibilidades, mediante préstamos. $Y$ la burbuja lo hizo posible".

Y continúa señalando Stiglitz: en las últimas décadas se están produciendo una serie de cambios que, interactuando unos con otros, han alterado la naturaleza del mercado y nuestra sociedad; hemos abandonado 
una perspectiva más equilibrada entre individuo y comunidad (incluido el Gobierno), una perspectiva más equilibrada entre las actividades económicas y las no económicas, un papel más equilibrado del mercado y del Estado, y hemos pasado de unas relaciones interindividuales basadas en la confianza a unas relaciones basadas en la aplicación de la ley.

Y mientras las principales economías debaten sobre cómo atender las urgencias provocadas por la crisis, poniendo en práctica medidas no coincidentes y en ocasiones hasta erráticas, la atención a cuestiones de fondo permanentemente abiertas queda pospuesta. En opinión de Stiglitz, la urgente atención a la crisis ha distraído a Estados Unidos y a una gran parte del mundo de problemas más de fondo que hubiera sido necesario afrontar. La lista es conocida: asistencia sanitaria, energía y medio ambiente, y especialmente, cambio climático, educación, envejecimiento de la población y declive industrial, un sector financiero disfuncional, desequilibrios globales, déficit comercial y financiero de Estados Unidos.

Mientras el país luchaba por superar la crisis inmediata, esos problemas quedaron aparcados. Algunos se han agravado. Pero los recursos que estaban disponibles para afrontarlos se han reducido sustancialmente por la forma errónea en que el Gobierno ha gestionado la crisis, especialmente por el dinero que ha derrochado para ayudar al sistema financiero... la restructuración de la economía no se hará espontáneamente. El Gobierno deberá desempeñar un papel fundamental.

\subsection{La persistencia del ciclo económico; la 'banca en la sombra'}

En opinión de Paul Krugman (2009), profesor en la Universidad de Princeton y Premio Nobel de Economía en 2008 , contrariamente a lo que algunos parecían anunciar "los ciclos económicos no han desaparecido y, de hecho, estaríamos en una etapa de vuelta a la economía de la depresión”. Una economía en la que "los fallos... por el lado de la demanda - gasto privado insuficiente para utilizar la capacidad productiva disponible- se han convertido en la limitación, clara y actual, de la prosperidad para una gran parte del mundo".

Y añade, aunque la depresión en sentido propio no ha vuelto, la economía de la depresión -los tipos de problemas que caracterizaron buena parte de la economía mundial en los años treinta, pero que no se han visto desde entonces- se ha instalado de una forma pasmosa. Hace cinco años era difícil que alguien pensara que los países modernos se verían obligados a soportar recesiones apabullantes por temor a los especuladores monetarios; que un gran país avanzado podría verse con persistencia incapaz de generar el gasto suficiente para mantener el empleo de sus trabajadores y de sus fábricas; que incluso la Reserva Federal se preocuparía por su capacidad para contener un pánico del mercado financiero. La economía mundial se ha convertido en un lugar mucho más peligroso de lo que imaginábamos.

La razón principal, para este autor, es haber abandonado el 'pacto keynesiano', aquella intervención macroeconómica que -básicamente reduciendo tipos de interés y aumentando los déficits presupuestarios para luchar contra las recesiones- ha mantenido la economía libre de mercado, más o menos estable y con más o menos pleno empleo, a lo largo del tiempo.

Krugman atribuye gran responsabilidad en la génesis de esta crisis al modo de hacer "banca en la sombra”, a ese conjunto de instituciones y acuerdos que funcionan como "bancos que no son bancos", que han escapado a los sistemas de regulación y que han estado, como en otras crisis históricas, en la génesis de la actual crisis financiera. En las últimas décadas, se sustituyó, de hecho, la adecuada regulación financiera por el culto a la denominada innovación financiera..., con las graves consecuencias que ello ha traído.

\section{4. ¿Falsas evidencias? El manifiesto de los economistas aterrados; el decrecimiento}

La crisis ha generado también un movimiento de respuesta intelectual, desde la propia economía, a los postulados que nos han llevado hasta donde estamos y a los que, en definitiva, seguirían influenciando las políticas que se aplican hoy como solución para el futuro. Ese movimiento ha dado a luz un 'manifiesto de economistas aterrados' (Askenazy et al., 2011). El citado documento hace un repaso de las 'falsas evidencias' sobre las que se construyen los discursos dominantes en economía.

- La falsa evidencia de la eficiencia de los mercados financieros -no producen precios justos y son desestabilizadores-y de su papel en el crecimiento económico -que se cuestiona ya que el capital financiero habría roto el equilibrio histórico entre los distintos intereses en las empresas planteando unas exigencias de rendimiento del capital que provocan una presión a la baja en los salarios y en el poder adquisitivo, que no favorece la demanda-.

- La pretendida bondad de los mercados para valorar la solvencia de los Estados, cuestionando el papel de las agencias de calificación y el carácter no neutral de la evaluación financiera.

- La vinculación del alza excesiva de la deuda pública como consecuencia de un exceso de gasto: el déficit público medio en la zona euro era del 0,6\% del PIB en 2007, pero los planes de salvamento de las instituciones financieras lo elevaron al $7 \%$ en 2010 ; la deuda pública pasó del $66 \%$ al $84 \%$ del PIB, pero ello provendría especialmente no de una tendencia al alza de los gastos públicos - puesto que, al contrario, 
en proporción al PIB, éstos han permanecido estables, o han disminuido en la Unión Europea desde principios de los años noventa-, sino de la caída de los ingresos públicos, como consecuencia de la debilidad del crecimiento económico en ese período y de la contrarrevolución fiscal que la mayor parte de los Gobiernos han emprendido desde hace veinticinco años.

- La falsa evidencia de que la deuda pública traslada el precio de nuestros excesos a nuestros nietos, cuando más bien serían las rebajas fiscales de las últimas décadas las que generan una necesidad de endeudamiento que, en definitiva, es pago de intereses a clases acomodadas, poseedoras de esos títulos, desde presupuestos públicos.

Por su parte, autores como Carlos Taibo (2011) defienden la conveniencia de poner en práctica los principios y valores que se contemplan en la propuesta de decrecimiento. No sería sólo defender reducciones de niveles de producción y consumo en el Norte rico, propiciando actividades económicas que guardan relación con la atención de las necesidades sociales insatisfechas y con el respeto del medio natural, generando así oportunidades entre otros en ámbitos como el transporte colectivo, las energías renovables, o la agricultura ecológica, sino la defensa de principios y valores tales como la primacía de la vida social frente a la lógica frenética de la producción, el consumo y la competitividad, y en definitiva, frente al modo de vida esclavo al que sometería el sistema a la ciudadanía.

\subsection{La gestión de la crisis; la pérdida de confianza}

Stiglitz nos alerta sobre el hecho de que también se estarían haciendo mal las cosas en la gestión de la crisis y añade: "la duración de la crisis dependerá de las políticas que se apliquen. De hecho, los errores ya cometidos tendrán como consecuencia que la crisis económica sea más prolongada y profunda de lo que habría sido en otras circunstancias". Así, el economista estadounidense muestra su preocupación por el hecho de que en algunas áreas importantísimas, en medio de la crisis, las cosas ya han empeorado. No sólo hemos alterado nuestras instituciones -favoreciendo una concentración aún mayor en las finanzas-, sino también las reglas del capitalismo. Hemos anunciado que, para las entidades beneficiadas, debe haber poca o ninguna disciplina de mercado. Hemos creado un sucedáneo de capitalismo con reglas poco claras, pero con un resultado predecible: futuras crisis; asunción de riesgos indebidos a expensas públicas, a pesar de que se prometa un nuevo régimen regulatorio; y mayor ineficiencia.

Una característica clara de la actual situación es la pérdida de confianza. De los ciudadanos hacia las autoridades, de los agentes económicos entre sí: de todos con todos, podríamos concluir. Aquellas instancias a las que atribuimos autoridad han demos- trado ineptitud o interés malsano, o una combinación de ambas. Stiglitz subraya, en la comprensión de esta crisis la pérdida del sentido de comunidad y de la confianza. El modelo de feroz individualismo combinado con el fundamentalismo de mercado ha alterado no sólo la forma en que las personas se ven a sí mismas y sus preferencias, sino también su relación con los demás. En un mundo ferozmente individualista hay poca necesidad de comunidad y no hay necesidad de confianza. El Gobierno es un estorbo; es el problema, no la solución. Pero si las externalidades y los fallos del mercado están omnipresentes, la acción colectiva es indispensable, y el voluntarismo no será suficiente (sencillamente porque no hay ‘imposición’ ni manera de asegurarse de que la gente se comporte como debe). Pero lo peor es que el individualismo feroz combinado con el materialismo rampante ha minado la confianza. Incluso en una economía de mercado, la confianza es el lubricante que hace funcionar la sociedad.

\subsection{La crisis económica que pasamos por alto}

Para Jeremy Rifkin (2011), economista e investigador social, asesor de la Unión Europea y profesor en la Warton School de la Universidad de Pensilvania, desde la década de los 80 se estarían acumulando pruebas que evidenciarían el fin de lo que él denomina la Segunda Revolución Industrial, basada en el petróleo, los combustibles fósiles y las tecnologías construidas y alimentadas con esas fuentes de energía. En julio de 2008 el precio del petróleo alcanzaba un máximo histórico de 147 dólares por barril, siendo así que apenas siete años antes se estaba vendiendo a menos de 24 dólares el barril. Doscientos años de quemar carbón y consumir petróleo y gas han generado, a su vez, un cambio climático inducido por el ser humano que amenaza con efectos devastadores para la vida en el planeta.

Rifkin vincula estrechamente la burbuja del crédito y la deuda pública con el fin del petróleo barato y el previsto agotamiento de los recursos fósiles restantes. En la década de los ochenta se completó, según Rifkin, la Segunda Revolución Industrial, y a partir de ella, se vivió de los ahorros anteriores, agotándolos, en una espiral loca de consumo, propiciada por la cultura de la tarjeta bancaria. Así, en EE.UU. la tasa media de ahorro de las familias a comienzos de la década de los 90 estaba en torno al $8 \%$, en el año 2000 era del $1 \%$, y en 2007 muchos americanos gastaban ya más de lo que generaban. Fue entonces cuando se idearon por el sector financiero las hipotecas de alto riesgo (subpreferenciales), instrumento crediticio sin garantía real, que cuando la burbuja inmobiliaria estalló en 2007, generó la crisis financiera y económica posterior. Para este autor, en clave de futuro, la convergencia entre nuevos sistemas de comunicación y de energía que estaría comenzando a darse en nuestros tiempos - Internet y las energías renovables-sería la clave para crear una nueva y potente infraestructura para una Tercera Revolución Industrial que habría de cambiar el mundo. 
2.7. Debilidad de los instrumentos de intervención; cambios en valores

Desde la sociología, Alain Touraine (2011), premio Príncipe de Asturias en Comunicación y Humanidades 2010, entiende que "la globalización del sistema económico debilita, sobre todo, los instrumentos de intervención que se habían formado en un marco nacional, especialmente la capacidad de regulación y de control de las relaciones entre los actores económicos por un Estado capaz de intervención tanto social como económica".

En su opinión, la responsabilidad de la mala práctica en el sistema financiero es grande en la explicación de esta crisis. Hasta mediados de los setenta, los cuadros superiores y los directivos se remuneraban en función de la posición que ocupaban en la jerarquía de las cualificaciones. Brutalmente, la situación cambió. La apertura de los mercados y la concentración de las empresas condujeron a una evaluación de la actividad de los directivos y de los cuadros dirigentes a escala internacional. La Europa continental se alineó con ese modelo dominante... y rápidamente se hizo obvio que no es la actividad productiva la que enriquece, sino la especulación financiera. Así por ejemplo, en las últimas décadas, en Estados Unidos, las diferencias sociales se han incrementado significativamente pasando la renta de los grandes dirigentes de 40 a 400 veces el salario obrero medio. Por otra parte, "la atmósfera de consumo desenfrenado, alentada por las más altas instancias monetarias arrastraron a muchos estadounidenses por el torbellino de los créditos. Muchos particulares se endeudaron más allá de sus posibilidades de devolución, mientras el propio Estado norteamericano se endeudaba fuertemente con algunos países, especialmente con China".

En opinión de Alain Touraine, la crisis "señala el catastrófico final de la era neoliberal, que había sustituido, a partir de mediados de la década de los 70, a la economía encauzada por el Estado, nacida después de la guerra, en una época en que únicamente los Estados disponían de los medios necesarios para la recuperación de los viejos países industriales y el despegue de la economía de los países descolonizados". Para este sociólogo francés, "si podemos hablar de la sustitución de los actores sociales por unos actores morales, es en la confianza de que surja una sociedad donde el poder dominante de los financieros esté limitado por aquellos que se oponen a la lógica inhumana de la economía globalizada y por las intervenciones de los Estados, preocupados por frenar la irracionalidad de las maniobras especulativas y el incremento de las desigualdades sociales y del paro".

Para Touraine, la crisis no sólo alcanza la gestión y la gobernanza del mundo económico, sino que interviene en la transformación de esta sociedad y de sus valores, marcada por un interés más limitado por el trabajo, el deseo declarado -sobre todo entre los jóvenes- de vivir experiencias personales más que de participar en tareas colectivas, a menudo desper- sonalizadas, y la difusión de nuevos modos de comunicación en la era digital. Por eso es urgente elaborar nuevas categorías de análisis: cuanto más sea la crisis un teatro sin actores, más dependerá la salida de la crisis y la formación de una nueva sociedad de iniciativas que habrán de tomar los Gobiernos, o que impondrán las propias víctimas.

\subsection{El individualismo a ultranza; la tiranía del presente}

El individualismo exacerbado y la preocupación cuasi exclusiva por la inmediatez marcan nuestra época. Zigmunt Bauman (2011), sociólogo, profesor emérito en la Universidad de Leeds, señala que "hemos nacido en una sociedad absolutamente individualizada en la que la autonomía individual, la independencia y el egocentrismo eran axiomas que no requerían (ni aceptaban) demostración y permitían escasa, o nula, discusión”. Y añade que, en la crisis actual, "no sólo han sufrido un duro embate el sistema bancario y los índices del mercado de valores, sino que nuestra confianza en las estrategias vitales, los modos de conducta, y hasta los estándares de éxito y el ideal de felicidad que valía la pena perseguir se han trastocado, como si, de pronto, hubieran perdido una parte considerable de autoridad y atracción. Nuestros ídolos, las versiones modernas líquidas de las bestias sagradas bíblicas, se han ido a pique, junto con la confianza en la economía".

Como dice el sociólogo Daniel Innerarity (2009), profesor en la Universidades de Zaragoza y La Sorbona, vivimos así con una "ligera desesperación", en "sociedades de esperanza limitada". "El comienzo del siglo XXI se destaca sobre un fondo de radical desconfianza". Para este autor, otra característica negativa de las sociedades actuales sería la excesiva focalización en el presente de las sociedades avanzadas - "la tiranía del presente"-, aun a costa del futuro, que se convierte en basurero del presente, como "espacio de carga", lugar donde se desplazan los problemas no resueltos para aliviar así el presente.

\subsection{Pensar el Estado; una era del temor}

Para el historiador Tony Judt (2010), no está tan claro que la globalización que estamos viviendo vaya a suponer la finalización del papel de los Estadosnación: "Ya deberíamos saber que la política sigue siendo nacional, incluso si la economía no lo es". Y añade: "Si vamos a presenciar un retorno del Estado, una necesidad de mayor seguridad y recursos que sólo puede proporcionar un Gobierno, deberíamos prestar más atención a las cosas que pueden hacer los Estados... [, ya que] sólo un Gobierno puede dar respuestas de la magnitud necesaria a los dilemas que presenta la competencia globalizada".

Después de haber reducido el alcance de la propiedad y la intervención públicas durante los últimos 
treinta años, nos encontramos aceptando de facto una acción estatal de tal magnitud como no se había visto desde la Gran Depresión. La reacción contra los mercados financieros no regulados y las ganancias grotescamente desproporcionadas de unos pocos en comparación con las pérdidas de tantos, han obligado al Estado a intervenir en todas partes. $Y$ hay demasiados ámbitos en la vida en que hacer lo que más nos conviene a cada uno de nosotros no sea la mejor manera de satisfacer nuestros intereses colectivos. Hoy, cuando es tan evidente que el mercado y el libre juego de los intereses privados no redundan en beneficio colectivo, tenemos que saber cuándo intervenir.

El argumento a favor de revivir el Estado no se apoya únicamente en sus aportaciones a la sociedad moderna como proyecto colectivo; existe una consideración más urgente: "Hemos entrado en una era de temor. La inseguridad vuelve a ser un ingrediente activo de la vida política en las democracias occidentales. La inseguridad causada por el terrorismo, desde luego, pero también, de forma más insidiosa, el temor a la velocidad incontrolable del cambio, el temor al paro, el temor a perder terreno frente a otros en una distribución de recursos cada vez más desigual, el temor a perder el control de las circunstancias y rutinas de nuestra vida diaria. Y quizás, sobre todo, el temor de que no es sólo que nosotros no podemos dirigir nuestras vidas, sino que quienes ostentan el poder también han perdido el control, que ahora está en manos de fuerzas que se escapan a su alcance. [...] Es la creciente desigualdad en y entre las sociedades lo que genera tantas patologías sociales. Las sociedades con desigualdades grotescas también son inestables. Generan divisiones internas y, más pronto o más tarde, luchas intestinas, cuyo desenlace no suele ser democrático".

Judt invita así no sólo a mirar críticamente el mundo en que vivimos, sino a actuar en congruencia con ese conocimiento, ya que de lo que se trata es de transformarlo.

\subsection{Ideas en torno a la justicia}

Si analizamos la situación actual desde la perspectiva de la filosofía política, el catedrático de Ciencias Políticas en la Universidad de Harvard, Michael J. Sandel (2011), hace un repaso de las principales ideas que se han manejado en torno a la justicia como criterio para orientar la actividad pública, exponiendo las principales aportaciones de la filosofía política a lo largo de la historia, para ayudar a enfocar así esta cuestión en la actualidad.

Desde Aristóteles y la vida buena como propósito de la polis y las instituciones de la vida social como medio para ese fin, junto a su elevado concepto de ciudadanía, "la política no es la economía por otros medios"; continuando con Kant, a favor de una teoría de la justicia apoyada en un contrato social basado en una idea de la razón, que cuente con el asenti- miento de la ciudadanía, piedra de toque de la legitimidad de toda ley pública; pasando por Bentham y los utilitaristas con su propuesta de maximización de la felicidad; los libertarios con John Stuart Mill y la defensa a ultranza de la libertad individual con el único límite de no perjudicar a otros; hasta llegar a Rawls con su defensa de la igualdad y su propuesta del principio de la diferencia que permitiría las desigualdades que puedan favorecer el bien de los menos favorecidos.

En ese entramado de aportaciones históricas, Sandel identifica principalmente tres -las que pretenden maximizar el bienestar, las que abogan por respetar la libertad de elegir, y las que proponen cultivar la virtud y razonar acerca del bien común-, y se inclina por una versión de esta tercera visión, como veremos en el siguiente apartado.

\section{Propuestas para una nueva hoja de ruta}

Destacamos en este apartado algunas de las aportaciones que se proponen para afrontar el futuro de manera más saludable.

\subsection{Reequilibrar el papel del Estado y del mercado, del individuo y de la comunidad}

En opinión de Stiglitz, los mercados son la base de cualquier economía próspera, pero no funcionan bien por sí solos. Es necesario que el Gobierno desempeñe un papel, y no sólo rescatando la economía cuando los mercados fallan y regulándolos para evitar el tipo de fracasos que acabamos de experimentar. Las economías necesitan un equilibrio entre el papel de los mercados y el papel del Gobierno, con importantes contribuciones por parte de las instituciones privadas y no gubernamentales. En los últimos veinticinco años, Estados Unidos ha perdido ese equilibrio y ha impuesto su perspectiva desequilibrada en países de todo el mundo.

Stiglitz llama a aprovechar la oportunidad de la crisis para recuperar el equilibrio entre el mercado y el Estado, el individualismo y la comunidad, el hombre y la naturaleza, los fines y los medios. Para este autor, la crisis financiera demostró que los mercados financieros no funcionan bien de manera automática, y que los mercados no se autorregulan. Pero la lección es más general y va más allá de los mercados financieros. El Gobierno tiene un importante papel que jugar. La 'revolución' de Reagan y Thatcher denigró ese papel. El intento equivocado de reducir el papel del Estado ha dado como resultado una intervención del Gobierno como nadie había previsto ni siquiera durante el New Deal. Ahora tendremos que reconstruir una sociedad donde el papel del Gobierno y el papel del mercado estén más equilibrados. Un mayor equilibrio puede llevarnos a una economía más eficiente y más estable. 


\subsection{Abordar seis retos económicos de envergadura}

Según Stiglitz, el mundo enfrenta en la actualidad seis retos económicos de envergadura.

- La brecha entre la demanda y la oferta global. La capacidad productiva mundial está infrautilizada, en un mundo en el que existen muchas necesidades sin cubrir. La infrautilización más grave es la de recursos humanos: más allá de 240 millones de desempleados en todo el mundo a causa de la recesión, hay miles de millones de personas que no tienen formación para poder utilizar plenamente su potencial humano, y muchas que están formadas no tiene un empleo acorde con sus capacidades.

- El cambio climático. Por primera vez en la historia, el ser humano es capaz de inducir un cambio climático de potenciales efectos devastadores para la vida en el planeta.

- Los llamados ‘desequilibrios globales’, que plantean un problema para la estabilidad mundial. Una parte del mundo está viviendo por encima de sus posibilidades; la otra parte produce mucho más de lo que consume.

- El enigma industrial, que utiliza sus aumentos de productividad para reducir empleos en la industria, tradicionalmente cualificados, sustituyéndolos demasiadas veces por empleos no cualificados en el sector servicios.

- La desigualdad. En la mayoría de los países la desigualdad aumenta y la globalización es uno de los factores que ha contribuido a ello. En las economías avanzadas, aumenta el número de pobres, las clases medias sufren crecientemente, y la brecha entre ricos y pobres se hace cada vez mayor. Mientras tanto, mil millones de personas pasan hambre en el mundo. Como señala Stiglitz, más allá del problema humanitario, "el crecimiento desigual contribuye a agravar el problema de la falta de demanda agregada, ya que el dinero va de aquellos que lo gastarían a los que tienen más del que necesitan".

- La estabilidad. El aumento de la inestabilidad financiera se ha convertido en un problema cada vez más importante. A pesar de los pretendidos avances del sistema, las crisis han sido más frecuentes y más graves.

\subsection{Un nuevo modelo económico; la oportunidad de la crisis; la reforma financiera}

Para Joseph Stiglitz, será necesario construir un nuevo modelo económico; la sostenibilidad exigirá poner menos énfasis en los bienes materiales para aquellos que están consumiendo demasiado y una reorientación hacia las actividades innovadoras. A escala planetaria, una parte excesiva de la innovación mundial se ha orientado a ahorrar trabajo y una parte insuficiente a ahorrar recursos naturales y a proteger el medio ambiente, lo cual apenas es sorprendente dado que los precios no reflejan la escasez de estos recursos naturales. Aboga por "crear un nuevo sistema financiero que sirva para aquello que los seres humanos necesitan de un sistema financiero; la oportunidad de crear un nuevo sistema económico que genere empleos significativos, trabajo decente para todos los que lo quieran, un sistema en el que la brecha entre los que tienen y no tienen se estreche en vez de agrandarse; y, lo más importante de todo, la oportunidad de crear una nueva sociedad en la cual cada persona pueda realizar sus aspiraciones y desarrollar todo su potencial, en la cual los ciudadanos compartan ideas y valores, en la cual hayamos conseguido una comunidad que trate nuestro planeta con el respeto que sin duda a largo plazo exigirá. Estas son las oportunidades. El peligro real ahora es que no las aprovechemos".

Para Paul Krugman, “lo que el mundo necesita ahora es una operación de rescate. El sistema global de crédito se encuentra en una situación de parálisis y [...] la depresión global está cogiendo impulso". Para hacer frente a los peligros que nos amenazan, "los políticos tienen que hacer dos cosas: conseguir que el crédito vuelva a fluir y fomentar el gasto". Y añade que "aun cuando el rescate del sistema financiero empiece a devolver a la vida a los mercados crediticios, seguiremos enfrentándonos a una depresión global que está cogiendo impulso”. ¿Qué debemos hacer al respecto? "La respuesta es, casi con total seguridad, recuperar los viejos estímulos fiscales keynesianos". El nuevo plan debería ser más amplio que las medidas adoptadas hasta la fecha -situarse en torno al $4 \%$ del PIB frente al $1 \%$ de lo ya llevado a cabo- y "centrarse en mantener y ampliar el gasto del Gobierno".

Asimismo propone Krugman una profunda reforma financiera: "Vamos a tener que aprendernos de nuevo las lecciones que la Gran Depresión enseñó a nuestros abuelos". El nuevo régimen regulador ha de tener un nuevo principio básico: todo aquello que deba ser rescatado durante una crisis financiera porque desempeña un papel esencial en el mecanismo financiero debe estar sujeto a regulación cuando no hay una crisis, para evitar así que incurra en unos riesgos excesivos". Y concluye, "todavía no está claro cómo ha de ser la nueva respuesta que demos, pero es evidente que la globalización financiera ha acabado siendo más peligrosa de lo que nos figuramos".

\subsection{Otro tipo de medidas ante la crisis; otra forma de crecer}

Los autores del manifiesto de economistas al que antes se ha hecho referencia ofrecen su argumentación en contra de lo que, en su opinión, serían falsas evidencias, a las que se ha hecho alusión en el apartado anterior, y proponen medidas en orden a la reforma financiera y el control de la especulación; medidas de política fiscal redistributiva; de regulación de las agencias de calificación de riesgo, abogando por un papel más activo del Banco Central 
Europeo en la adquisición de títulos públicos en la Unión, el análisis de la deuda pública para determinar su origen y la identidad de los principales poseedores de títulos de deuda; la defensa e incremento de políticas de intervención pública en protección social, educación, investigación, reconversión ecológica, sostenibilidad; poner límites a la libre circulación de capitales y mercancías entre la Unión Europea y el resto del mundo; basar las políticas europeas en una 'armonización en el progreso' que incorpore indicadores de progreso social (GOPS, grandes orientaciones de política social); asegurar la concertación entre las políticas macroeconómicas y una reducción concertada de los desequilibrios comerciales en Europa, y poner en marcha una fiscalidad europea que favorezca la homogeneización en los Estados de la Unión; y la puesta en marcha de un vasto plan europeo para la reconversión ecológica europea.

Para Niño Becerra (2009), "tendremos que cambiar el modo como deben hacerse las cosas [...] hay que modificar la manera de funcionar porque la antigua se agotó por una razón fundamental: es una manera de hacer las cosas absolutamente ineficiente". Y, añade este autor, nos hemos perdido un proceso de desarrollo equilibrado, de crecimiento sostenible, lo hemos perdido sin llegar a tenerlo. El proceso se ha basado en algo muy simple: "el deseo de ir a más sin pensar en las consecuencias, sin tener que responsabilizarnos de ellas". Hoy, cuando aceptamos que "las reservas de commodities no son inagotables, y cuando ya no se puede continuar suponiendo que la capacidad de endeudamiento es infinita", habrá que hacer las cosas de otra manera. Hoy la tendencia apunta hacia la buena administración, hacia el no-desperdicio, hacia lo necesario, hacia la eficiencia, hacia la productividad. Pero eso equivale al fin de ese bienestar sustentado en el desperdicio, por insostenible".

Los defensores de la idea del decrecimiento, por su parte, plantean el reparto del trabajo, el establecimiento de una renta básica de ciudadanía, la reducción del tamaño de muchas de las infraestructuras productivas, administrativas y de transporte, la recuperación de muchos elementos de la vida local, avanzar hacia un ocio creativo frente a las formas de ocio vinculadas con el dinero y el consumo, y, en el terreno individual, la recuperación de la sobriedad y la sencillez, e incluso la reivindicación de la lentitud, como aspecto articulador de una vida social recuperada.

\subsection{Los pilares de la Tercera Revolución Industrial}

Para Rifkin, los pilares de lo que él denomina 'Tercera Revolución Industrial' deberían ser los siguientes: “la transición hacia la energía renovable; la transformación del parque de edificios de cada continente en microcentrales eléctricas que recojan y reaprovechen in situ las energías renovables; el despliegue de la tecnología del hidrógeno, y a lo largo y ancho de la red de infraestructuras, para acumular energías como las renovables, que son de flujo intermitente; el uso de la tecnología de Internet para transformar la red eléctrica de cada continente en una 'interred' de energía compartida que funcione exactamente igual que Internet; y la transición de la actual flota de transportes hacia vehículos de motor eléctrico con alimentación de red y/o con pilas de combustible, capaces de comprar y vender electricidad dentro de una red eléctrica interactiva continental de carácter inteligente".

Estos pilares generarían una economía colaborativa, a partir de la naturaleza distribuida de las energías renovables, que precisaría de mecanismos colaborativos (no jerárquicos) de control y mando.

Para este autor, serán necesarias cuatro décadas de intensa colaboración público-privada para preparar las infraestructuras de la Tercera Revolución Industrial, que, hacia mediados del siglo, podrían detener el deterioro medioambiental. El despliegue de estas nuevas infraestructuras y la sociedad que devendrá permitirá generar millones de empleos y un futuro sostenible para la humanidad. Se avanzará así en la construcción de nuevo capitalismo distribuido, articulado sobre un régimen energético 'lateral' democratizado, que hará posible una economía colaborativa.

La Tercera Revolución Industrial hará que apreciemos nuestra suerte común como especie, avanzando hacia un ideal de calidad de vida que apunta a un nuevo ideal de futuro, basado en el interés colectivo, en la conectividad y en la interdependencia. Así la libertad se mediría en la riqueza y diversidad de las experiencias de la persona y en la fortaleza de sus vínculos sociales. Para este autor, cuanto más solitaria es la existencia, menos vivida es la vida.

\subsection{Propuestas de otros Nobel de Economía}

En el XLSemanal del 6 de noviembre de 2011 (Sánchez, 2011), leíamos las propuestas de diversos premios Nobel de Economía para superar el actual estado de cosas. Desde cobrar el IVA a las transacciones financieras, como propone James Mirlees, que obtuvo el Nobel por hallar una fórmula para que los impuestos fueran más justos. Este matemático no entiende por qué comerciantes y consumidores deben pagar el IVA en las compraventas y, sin embargo, los grandes fondos pueden hacer inversiones millonarias sin tributar: "Es hora de cobrarles una tasa: no basta con vigilar a los bancos. Lo importante es que todas estas estúpidas derivadas han dado beneficios millonarios a unos individuos que no han aportado riqueza a la sociedad. $\mathrm{j}$ El sistema premia a los que se arriesgan porque no pagan las consecuencias!".

Para John F. Nash, "crear una moneda mundial nos daría estabilidad". Propone un sistema cambiario basado en una moneda ideal, que sirva para estabilizar las monedas nacionales, basando el tipo de cam- 
bio en una cesta de valores sólidos y no en un solo valor, si bien, añade, “desconfía de los políticos que deberían administrar esta moneda ideal. La honradez es importante. Y si la moralidad de los banqueros tampoco es muy alta, sus conocimientos financieros no bastan para proteger las entidades que dirigen".

El alemán Reinhard Selten plantea establecer reglas sencillas al sector financiero, cuyo cumplimiento no se pueda eludir, impidiendo que "bajo ningún concepto se permita que los bancos deslocalicen los negocios altamente especulativos, utilizando sociedades ubicadas en países sometidos a reglas menos estrictas". Propone también por ejemplo, "que las acciones estén señalizadas con etiquetas que indiquen su índice de riesgo", como en el caso de los alimentos.

Roger B. Mierson, catedrático de la Universidad de Chicago, sugiere "regular para que el sistema financiero sea aún más seguro" y "establecer un plan público de inversión en carreteras, colegios, hospitales... que pongan a trabajar a los millones de personas desempleadas", entendiendo como justo que las próximas generaciones hayan de contribuir a pagar parte de la deuda contraída, ya que "a cambio disfrutarán de mejores infraestructuras”. Edmund S. Phelps propone que "los Estados creen un nuevo tipo de bancos que financien a los innovadores", y proporcionen capital a los emprendedores, "esto aseguraría la inversión en nuevos productos y tecnologías”.

Otros premios Nobel, que fueron preguntados por esta publicación, aportaron otras ideas, cada cual desde su propia perspectiva, y en ocasiones claramente discrepantes. Señalar, por último, la aportación de Daniel L. McFadden quien asegura que "esta crisis fue el resultado de una regulación inadecuada y una expansión del crédito exagerada". Y añade, "pero el fallo esencial es moral. En la carrera por lograr beneficios hemos olvidado que un banquero tiene que proteger los intereses de su clientes". Es partidario de aplicar un impuesto a los mercados financieros: "El coste de estas transacciones se ha reducido mucho gracias a la informática. Y esto ha generado una explosión enorme en el volumen de negocio. La mayoría de estos tratos apenas reporta nada a la sociedad; por el contrario, se desvían recursos al sector financiero. Unas tasas modestas, como las que había hace 20 años, ayudarían al sector público a reducir su déficit”.

\subsection{Catástrofe, o regeneración democrática basada en derechos}

Alain Touraine sólo percibe dos posibles salidas a la crisis: "una, la catástrofe, al menos en Europa; y la otra, la creación de una nueva vida social, basada no ya en una redistribución de la renta nacional, sino en la consolidación de la defensa de los derechos universales del hombre como única arma posible contra el aparente triunfo de la economía globalizada”.
Más en concreto apunta cinco conclusiones. El primer objetivo debe ser la reconstrucción de una sociedad en la que los líderes de la economía se vean obligados por el Estado a tener en cuenta las reacciones y los intereses de la población. En segundo lugar, Touraine plantea la necesidad de asumir la imposibilidad de regresar al pasado. Las sociedades industriales han sido heridas de muerte. No es posible devolverles la vida. En tercer lugar, o nos abandonamos a las crisis hasta la catástrofe final, o bien construimos un nuevo tipo de vida económica y social, abogando por avanzar en un proyecto de construcción de nuevas relaciones sociales y de nuevas instituciones.

Su cuarta conclusión, a la que da mayor peso, es aquella en la que aboga por el derecho a la libertad y al reconocimiento por los otros de esta libertad, al mismo tiempo que a las identidades sociales y culturales que se ven amenazadas por el mundo inhumano del beneficio. Propone este sociólogo francés, "volver a dar vida a un humanismo respetuoso con las exigencias de todos los seres humanos".

Por último, propone la reconstrucción de las relaciones entre los actores económicos, y la formulación de sus valores comunes y de nuevas intervenciones públicas. Y añade, "hay que proclamar sobre todo que la democracia, que transforma a los trabajadores en ciudadanos responsables, es la condición primera para la recuperación económica y social, al menos en los países que ya han elegido la libertad política contra el totalitarismo".

\section{8. 'Configurabilidad' del futuro y papel de las instituciones}

Daniel Innerarity, a partir del actual desencantamiento respecto de la política, y para poder enfrentar la insoslayable tarea a la que se enfrentan la sociedades de configurar el futuro, propone adoptar una perspectiva de un escepticismo más bien optimista, que introduzca el futuro en la lógica política, enfrentando ese reto con una esperanza razonable, en la confianza de la 'configurabilidad' del futuro por parte del ser humano. "La idea de que no se puede hacer nada frente a la globalización es una disculpa de la pereza política”. Hemos abandonado la idea de progreso, como algo mecánico, cierto, inexorable, y "tras la disolución de la idea de progreso tenemos la oportunidad de pensar mejor el futuro y cultivar una esperanza mejor fundada. La crisis de una determinada concepción del progreso no tendría que suponer la crisis del progreso como tal. [...] Configurar una suerte de responsabilidad respecto del futuro es una tarea para la cual resulta fundamental la política. El problema estriba en que el futuro es políticamente débil, ya que no cuenta con abogados poderosos en el presente, y son las instituciones las que deben hacerlo valer".

Para Innerarity, la tarea principal de la política democrática es la de establecer la mediación entre 
la herencia del pasado, las prioridades del presente y los desafíos del futuro. Y añade, "hay que volver a situar el futuro en un lugar privilegiado de la agenda de las sociedades democráticas. El futuro debe ganar peso político", definiendo el espacio de la política como "el arte de transformar las limitaciones en oportunidades".

\subsection{Del modelo centrado en el individuo a otro fundado en la ética y la relación; la Nueva Vía de Morin}

Para Zigmunt Bauman, a partir de la crisis "hay quien predice una rápida proliferación de los problemas de salud mental", o la "militarización del yo", en la que fármacos de nueva generación ofrezcan al individuo un "bienestar maravilloso" en las fronteras de su propio yo. Pero existe, en su opinión, una tercera posibilidad: "existe la opción de profundizar en las raíces del presente problema, y [...] hacer lo contrario de aquello a lo que nos hemos acostumbrado. Invertir el modelo de organización del pensamiento, antes centrado en el 'individuo', sustituyéndolo por otro que gire en torno a la práctica ética y estética que favorezca la relación y el contexto".

Edgar Morin (2011), director emérito de investigaciones en el Centro Nacional de Investigaciones Científicas (CNRS) de Francia, subraya la íntima interdependencia entre las reformas políticas, económicas, educativas y vitales, que se necesitan entre sí para hacer avanzar a la humanidad. Desgrana las reformas del pensamiento y de la educación, las reformas de nuestra concepción de la humanidad -medicina y salud, ciudad y hábitat, alimentación, consumo, trabajo-y las reformas de vida -familia, moral, vejez y envejecimiento-, que, basadas en una nueva economía, verde, social y solidaria, podrían alumbrar una nueva andadura para la humanidad.

Destaca el papel que pueden jugar las múltiples iniciativas dispersas -ignoradas por los partidos, las administraciones y los medios- que se dan en la base de las sociedades civiles, cuya eventual convergencia podría ayudar a conformar una Nueva Vía para mejorar "el gran problema de la humanidad, el de las relaciones entre individuos, grupos y pueblos, muchas veces monstruosas y miserables", y plantea en el actual estadio de la civilización humana, diversos "principios de esperanza" que le llevan a pensar en la posibilidad de establecer una Nueva Vía de la humanidad que le permitiera alcanzar la armonía a la que aspira.

Morin confía en las virtudes generadoras/creadoras inherentes a la humanidad: "La conciencia de que todos los grandes movimientos transformadores empiezan siempre, incluso en las sociedades esclerosadas, de forma marginal, desviada, modesta, nos muestra que las innovaciones creadoras son posibles siempre y en todas partes”. Así, para este autor, se ha establecido una voluntad de responder a la globalización tecnoeconómica con un altermundismo, término que hay que entender literalmente como una aspiración a otro mundo, que podría conducir a la elaboración de una verdadera "política de humanidad”. Para Morin, "la esperanza ha resucitado en el corazón mismo de la desesperación”.

\subsection{Una nueva política del bien común}

En opinión de Michael Sandel, deberíamos orientar la actuación pública a partir de una nueva política del bien común, que debería, en primer lugar, cultivar la virtud cívica, propiciando en los ciudadanos una preocupación por el conjunto, una dedicación al bien común, convocándoles a alguna forma de sacrificio compartido y de servicio a la comunidad. De cara al fomento de la virtud cívica, señala el papel que tradicionalmente ha jugado la escuela pública como lugar para la educación cívica, por lo que aboga por su refuerzo y dignificación.

En segundo lugar, debería establecer límites morales a los mercados. Los mercados son instrumentos útiles para organizar la actividad productiva, pero "a no ser que queramos que el mercado rescriba las normas que gobiernan las instituciones sociales, necesitaremos un debate público sobre los límites morales del mercado".

En tercer lugar, debería darse peso político a cuestiones tales como la desigualdad, la solidaridad y las virtudes cívicas. "Una brecha excesiva entre ricos y pobres socava la solidaridad que la ciudadanía democrática requiere”. Por lo siguiente, “a medida que aumenta la desigualdad, ricos y pobres viven vidas cada vez más separadas. Así, “el vaciado de la esfera pública dificulta que se cultiven la solidaridad y el sentimiento comunitario de los que depende la ciudadanía democrática”. Por ello propone Sandel que la generación presente apueste por invertir "en infraestructuras para la renovación cívica”: escuelas públicas a las que tanto ricos como pobres quieran enviar a sus hijos, sistemas de transporte público, hospitales, parques, polideportivos, bibliotecas y museos que lleven a la gente "a los espacios comunes de una ciudadanía democrática compartida”.

En cuarto y último lugar, propone una política del compromiso moral. El profesor de Harvard ve factible guiar nuestra política por la vía del respeto mutuo, si trabajamos por "una vida cívica más robusta y comprometida que ésta a la que nos hemos acostumbrado". En su opinión, una más decidida implicación pública en nuestras discrepancias morales proporcionaría un fundamento más sólido, no más débil, al respeto mutuo. "Una política basada en el compromiso moral no sólo es un ideal que entusiasma más que una política de la elusión. Es también un fundamento más prometedor de una sociedad justa". 


\section{A modo de conclusión}

Concluir en torno a la actual crisis no es tarea fácil, ante la profundidad y complejidad de su naturaleza y consecuencias. Al pretender extraer alguna conclusión en su vertiente económica, por otra parte, recuerdo el consejo del profesor de economía que nos decía, "a lo largo de su vida profesional se encontrarán con mucha gente que les diga, yo no sé nada de economía [...], pero aquí lo que hay que hacer es [tal o cual cosa], [...] háganle sólo caso a sus primeras palabras [...] yo no sé nada de economía”. No libre del desconocimiento al que aludía el profesor, y aun a riesgo de no atender debidamente su consejo, creo que cabe concluir algunas ideas de la mano de los autores a los que hemos recurrido a lo largo de este artículo.

En la génesis de la actual crisis se identifican problemas que tienen que ver con la pérdida de control público de la economía en el nuevo escenario de la globalización, la desregulación financiera, los límites del modelo energético basado en los derivados del carbono, la desigualdad extrema en un mundo cada vez más interconectado, y los propios valores que el sistema contribuye a establecer como orientadores. Lamentablemente, no hay acuerdo suficiente en qué es lo que hay que hacer para salir de esta situación. Se discrepa, fundamentalmente, entre medidas que den absoluta prioridad a la consolidación fiscal, aquellas otras que aún aceptando su importancia la modulan entendiendo la necesidad de complementarla con políticas públicas de estímulo, y las que abiertamente defienden como prioridad intervenciones públicas extraordinarias de estímulo de la economía.

Los ciudadanos, mientras tanto, han perdido confianza a raudales en las instituciones de las que se han dotado. Por ello, las sociedades necesitan una regeneración democrática, y el establecimiento de objetivos comunes para cuya consecución se activen las capacidades disponibles, hoy infrautilizadas, orientándolas a la satisfacción de las ingentes necesidades pendientes de la humanidad, en la que dos mil millones de habitantes viven con menos de dos dólares al día y en los cinco mil millones restantes hay mucho por hacer hasta lograr unos estándares de dignidad adecuados.

Se sabe bien que el funcionamiento del sistema económico no es una ley física de obligado cumplimiento. Es posible hacer las cosas de manera distinta a como se vienen planteando en las últimas décadas. La economía no es, ciertamente, una ciencia exacta, y será necesario establecer un consenso técnico, y finalmente político, sobre lo que hay que hacer para salir de esta situación y para construir un mundo más justo a futuro.

Para Ramón Tamames (2011), el porvenir no está predeterminado, "el futuro dependerá de lo que sean las políticas económicas aplicadas”, aunque lamenta que "en Economía no se dispone de las pacíficas armas precisas para abordar de inmediato y de manera eficaz los nuevos y enjundiosos problemas de un mundo cada vez más complicado”. En opinión de Krugman "hay quien dice que nuestros problemas económicos son estructurales y no tienen solución a corto, pero yo creo que”, como en los tiempos de Keynes, "los únicos obstáculos estructurales para la prosperidad del mundo son las doctrinas obsoletas que pueblan la cabeza de los hombres".

Para Stiglitz, por su parte, "puede que la batalla entre el capitalismo y el comunismo haya terminado, pero las economías de mercado tienen muchas modalidades y la competición entre ellas sigue siendo feroz". Así, señalaba en un artículo publicado en El País el 9 de octubre de 2011: "la receta para el mal que aqueja a la economía global se deduce inmediatamente a partir del diagnóstico: hacen falta sólidos programas de gasto público que apunten a facilitar la restructuración, promover el ahorro energético y reducir la desigualdad; y junto con esto, una reforma del sistema financiero internacional que cree alternativas a la acumulación de reservas [...]. Tarde o temprano, los líderes mundiales (y los votantes que los eligen) se darán cuenta de que es así, ya que, conforme las perspectivas de crecimiento sigan empeorando, no les quedará otra alternativa. Pero, ¿cuánto sufrimiento deberemos soportar hasta que eso ocurra?".

El equilibrio entre una sociedad económicamente competitiva y socialmente cohesionada debe seguir siendo objetivo estratégico de toda sociedad democrática. En esa labor, la ciudadanía ha de jugar un papel activo, probablemente a través de fórmulas novedosas de participación y supervisión -que pudieran surgir de los movimientos ciudadanos 'indignados', y de la indignación, hoy por hoy no articulada, de muchos otros ciudadanos-, que complementen o mejoren el sistema tradicional de representación democrática, velando por los intereses de las mayorías sociales.

Al inicio de la segunda década del siglo XXI, es imprescindible y urgente un análisis global de los problemas que aquejan a la humanidad, que dé respuestas a problemas como el hambre y la desigualdad extrema y creciente, que no pueden esperar más porque está en juego la propia dignidad humana. Cuando la humanidad alcanza los 7.000 millones de habitantes, una hipotética solución para una parte -minoritaria- de la población mundial no es una verdadera solución. Por el contrario, plantear adecuadamente las premisas a escala global será condición sine qua non del éxito de los nuevos planteamientos a aplicar.

Europa tiene la oportunidad de aprovechar esta situación para avanzar en una más efectiva integración económica y política, con sus dos caras, eficiencia económica y cohesión social, en pie de igualdad. Sólo así recuperará, en opinión de los economistas firmantes del manifiesto al que hemos hecho referencia, la legitimidad popular y democrática de la 
que hoy carecería. Los Estados del sur de Europa, que no han alcanzado un nivel de bienestar equiparable al de los más avanzados países europeos, tienen en el logro de ese objetivo un reto legítimo, que deberá venir acompañado de una decidida modernización de sus estructuras productivas y de sus entramados administrativos públicos, y una adecuación de sus políticas fiscales, de manera de hacer sostenible un tipo de sistema público de prestaciones propio de los países de referencia.

En España, en opinión de Ramón Tamames, se reaccionó tarde y mal a la crisis, y no "se elaboró una verdadera estrategia para salir del marasmo económico y consagrar un nuevo modelo de desarrollo, más ágil y de más elevadas productividad y competitividad, en contra de lo que sucedió en tres ocasiones anteriores de la política económica española: Plan de Estabilización de 1959, Pactos de La Moncloa de 1977, y Programa 1996/98 para incorporarnos al euro".

En el País Vasco, una mejor situación relativa en referencia al conjunto del Estado, no puede ocultar la tarea pendiente en orden a la mejora de la competitividad de su economía y a la consolidación de un modelo social avanzado, demandado por la ciudadanía.

Resolver la situación actual no es tarea fácil y tampoco lo es diseñar una hoja de ruta para evitar que cosas como estas no ocurran en el futuro, $y$, en definitiva, para diseñar un futuro digno para todos. Sin embargo, en algún lugar en las coordenadas que nos plantean estos autores -en el equilibrio entre el papel del mercado y el del Estado, el del individuo y el de la comunidad; en la necesidad de una profunda reforma financiera; en las energías renovables; en la recuperación del control democrático de la economía y las nuevas formas de participación social, gobernanza y arquitectura institucional; en la activación de las capacidades productivas y su orientación a la satisfacción de las necesidades humanas insatisfechas; en el no desperdicio, en la buena administración, en la eficiencia; en la innovación; en una justa política fiscal; en el trabajo digno; en la incorporación del futuro en la lógica política-, una nueva formulación del bien común, basada en la decencia y la sensatez, es necesaria y posible, un nuevo contrato social para todos los habitantes del planeta, para, aún inmersos en esta profunda crisis, establecer la hoja de ruta para su superación y el logro de una nueva forma de organizar los fundamentos económicos y sociales.

Según el físico Stephen Hawking (2010), la ciencia estaría próxima a confirmar experimentalmente la teoría unificada que permita al ser humano comprender las leyes que nos rigen a nosotros y al universo, teoría única "que predice y describe un vasto universo lleno de la sorprendente variedad que observamos". A esa teoría, Hawking se refiere como el Gran Diseño. Pues bien, la economía, sin determinismos propios de otros modelos, también necesitaría un a modo de "Gran Diseño", un nuevo diseño que incorporando en su propia esencia criterios éticos, dé respuestas sostenibles a los intereses del conjunto de la humanidad.

Para los autores reseñados, más allá de medidas de orden concreto, algunas de las cuales han sido señaladas, las claves para resolver la actual situación y establecer nuevos fundamentos económicos y sociales más saludables, tienen que ver fundamentalmente con recuperar la democracia y su función de control de la economía; subrayar valores como los derechos humanos, la protección del medio ambiente, la justicia en todo el planeta; formar a la gente en la preocupación por el conjunto -cultivar la virtud cívica-; poner límites morales a los mercados; no dar por aceptable la desigualdad existente y defender la solidaridad. 


\section{Referencias bibliográficas}

ASKENAZY, P.; et al. (2011): Manifiesto de economistas aterrados, Barcelona, Ediciones Barataria; Madrid, Pasos Perdidos.

BAUMAN, Z. (2011): Cuarenta y cuatro cartas desde el mundo líquido, Barcelona, Paidós.

HAWKING, S.; y MLODINOW, L. (2010): El Gran Diseño, Barcelona, Crítica.

INNERARITY, D. (2009): El futuro y sus enemigos. Una defensa de la esperanza política, Barcelona, Paidós.

JUDT, T. (2010): Algo va mal, Madrid, Taurus.

KRUGMAN, P. (2009): El retorno de la economía de la depresión y la crisis actual, Barcelona, Crítica.

MORIN, E. (2011): La vía: para el futuro de la Humanidad, Barcelona, Paidós.

NIÑO BECERRA, S. (2009): El crash del 2010: toda la verdad sobre la crisis, Barcelona, Los Libros del Lince.

RIFKIN, J. (2011): La tercera revolución industrial. Cómo el poder lateral está transformando la energía, la economía y el mundo, Barcelona, Paidós.
SÁNCHEZ, C. M. (2011): "Señores premios Nobel de Economía, ¿cómo salimos de la crisis?", XLSemanal [rhttp://xlsemanal.finanzas. com/web/articulo.php?id=74298\&id _ edicion $=6967>$ ].

SANDEL, M. J. (2011): Justicia: ¿hacemos lo que debemos?, Madrid, Debate.

STIGLITZ, J. E. “La cura para la economía”, El País [<http:// www.elpais.com/articulo/primer/plano/cura/ economia/elpepueconeg/20111009elpn[egl se_14/Tes>].

- (2010): Caída libre. El libre mercado y el hundimiento de la economía mundial, Madrid, Taurus.

TAIBO, C. (2011): El decrecimiento explicado con sencillez, Madrid, Los Libros de la Catarata.

TAMAMES, R. (2011): ¿Cuándo y cómo acabará la crisis? (Tractatus logicus economicus), Madrid, Turpial.

TOURAINE, A. (2011): Después de la crisis. Por un futuro sin marginación, Barcelona, Paidós. 



\title{
Euskadin etxez etxeko laguntzaren esleipenari eta intentsitateari buruz orientabidea eskaintzeko tresnaren garapena
}

\author{
SIIS Dokumentazio eta Ikerketa Zentroa \\ Eguía-Careaga Fundazioa \\ <estudios@siis.net>
}

\begin{abstract}
Artikulu honetan, SIIS Dokumentazio eta Ikerketa Zentroak, Eudel-en eskariari erantzunez, EAEn etxez etxeko laguntza-zerbitzu publikoaren esleipena arautuko duen tresna bat garatu eta balioztatzeko buruturiko ikerketa baten berri ematen da. Tresna horren helburua zerbitzuaren esleipena irizpide objektiboetan oinarritzea litzateke; horrela, tresna EAEko udalerri guztietan ezarriko balitz, baliabide publiko mugatuen erabilera arrazionalagoa egingo litzateke, eta zerbitzurako sarbidea eta haren intentsitatea berdinduko lirateke, EAEko lurralde osoan. Hala eta guztiz ere, irakurleak jakin behar du, artikulu honetan aurkezten dena proiektu pilotu bat dela eta, ondorioz, ez dakigula, azkenik, tresna EAE osoan ezartzea erabakiko ote den. Erabaki hori, etxez etxeko laguntza-zerbitzuaren eskumena duten administrazioei dagokie eta, era berean, EAEko Gizarte Zerbitzuen Sistemako Prestazioen eta Zerbitzuen Karteraren garapenaren inguruan adosturikoaren menpe dago. Artikuluan, proiektuaren beharra eta egokitasuna arrazoitu ondoren, berau aurrera eramateko metodologia zein izan den azaltzen da, eta aukeraturiko tresnaren baliagarritasunari buruz ikerketaren fase praktikoan parte hartu duten hamar udalerrietan lorturiko emaitzak laburbiltzen dira.
\end{abstract}

\section{HITZ-GAKOAK:}

etxez etxeko laguntza-zerbitzua, beharren balorazioa, balorazio-tresna teknikoak, sarbidea, intensitatea.
En este artículo se da cuenta de una investigación llevada a cabo por el SIIS Centro de Documentación y Estudios, a petición de Eudel, con el objetivo de diseñar y validar un instrumento técnico para regular el acceso al servicio público de ayuda a domicilio en la CAPV. La finalidad de este instrumento es que la adjudicación del servicio se base en criterios objetivos, de manera que se consiga hacer un uso más racional de los recursos públicos y se eliminen las desigualdades existentes en el territorio en cuanto al acceso y a la intensidad del servicio. Con todo, ha de tenerse en cuenta que se trata de un proyecto piloto y, por el momento se desconoce si finalmente se optará por implantar el instrumento en todos los municipios de la CAPV. Esa decisión, que corresponde a las administraciones competentes en materia de ayuda a domicilio, está también condicionada por las decisiones que se adopten en el marco del desarrollo de la Cartera de Prestaciones y Servicios del Sistema Vasco de Servicios Sociales. Tras justificar la necesidad y pertinencia del proyecto, el artículo expone la metodología utilizada para llevarlo a cabo y recoge los principales resultados sobre la validez del instrumento que se han obtenido en los diez ayuntamientos vascos que han participado en el proyecto piloto.

\section{Palabras Clave:}

servicio de ayuda a domicilio, valoración de necesidades, instrumentos técnicos, acceso, intensidad. 


\section{Sarrera}

Etxez etxeko laguntza-zerbitzua da, gaur egun, menpekotasun-egoeran diren pertsonak -edo menpekotasuna pairatzeko arriskuan direnakeuren ingurunean mantentzeko erakunde publikoek eskaintzen duten zerbitzu garrantzitsuena. Honen bitartez, eguneroko zereginetarako laguntza behar duten pertsonei euren etxean eskaintzen zaie laguntza hori; horrela, egoitza-zerbitzuetara jo beharra ekiditen dute, edo momentu hori atzeratzea lortzen dute, behintzat. Garrantzi handiko zerbitzua dela esan daiteke, beraz, izaera prebentiboa duelako, lehenik eta behin, baina baita erabiltzaile multzo handia asetzen duen zerbitzua delako ere: Eustaten Gizarte-Zerbitzuetako Erakunde eta Zentroen Estatistikaren arabera, 2008an 26.500 erabiltzaile inguru izan zituen zerbitzuak, eta ia 78 milioi euroko gastua suposatu zuen euskal administrazioentzat.

Laguntza-beharra duten pertsonek Oinarrizko Gizarte Zerbitzuetan egiten dute etxez etxeko zerbitzuaren eskaera, eta, EAEko gizarte-zerbitzuak arautzen dituen abenduaren 5eko 12/2008 Legearen arabera, tokian tokiko administrazioei dagokie eskaera horiek ebaztea. Oraindik orain, udal bakoitzak ezartzen ditu ebazpen horiek egiteko irizpideak eta, ondorioz, desberdintasun nabarmenak ematen dira zerbitzurako sarbidean, eskaera egiten duen pertsonaren bizilekuaren arabera. Esate baterako, aipatutako estatistikaren arabera, 2008an, Araban, zerbitzuaren estaldura (12,3 erabiltzaile 1.000 biztanleko) Gipuzkoakoaren bikoitza izan zen, eta Bizkaiko zerbitzuek eskaini zuten batez besteko intentsitatea, berriz -batez beste astean bi ordu erabiltzaile bakoitzeko-, ez zen iritsi beste bi lurraldeetakoek ematen zutenaren erdia izatera ere.

2007 urtea ezkero, abenduaren 14ko 39/2006 Legeak, Autonomia Pertsonala eta Menpekotasun Egoeran Diren Pertsonen Arretari buruzkoak, etxez etxeko laguntza eta gainontzeko gizartezerbitzuetarako sarbidea arautu du menpekotasun egoeran diren pertsonentzat, balizko erabiltzaileen beharrak neurtzeko Menpekotasuna Baloratzeko Baremoaren (Baremo de Valoración de la Dependencia) erabilera ezarri du-eta. Hala ere, pertsona autonomoen edo menpekotasun arina dutenen kasuan, zerbitzurako sarbidea udal bakoitzaren -eta, azken batean, Oinarrizko Gizarte Zerbitzuetako profesional bakoitzaren- esku dago. Zerbitzuaren intentsitatea ere profesional bakoitzak erabakitzen du -gehieneko kopuru batzuk errespetatuz, noski-, eta haren egokitasuna norberaren trebetasuna eta esperientziaren araberakoa da, beraz, neurri batean. Ikerketa garaian buruturiko bilaketa dokumentalaren emaitzen arabera, EAEko Oinarrizko Gizarte Zerbitzuetan ez da erabiltzen inolako tresna teknikorik eskaintzen den intentsitatea pertsonaren beharrak betetzeko egokia dela bermatzeko.

Egoera hori bideratze aldera, abenduaren 5eko 12/2008 Legeak, Gizarte Zerbitzuei buruzkoak, EAEko biztanleoi gizarte-zerbitzuak jasotzeko eskubidea
1. grafikoa. Etxez etxeko laguntza zerbitzuaren estaldura eta intentsitatea, lurraldeka. EAE, 2008

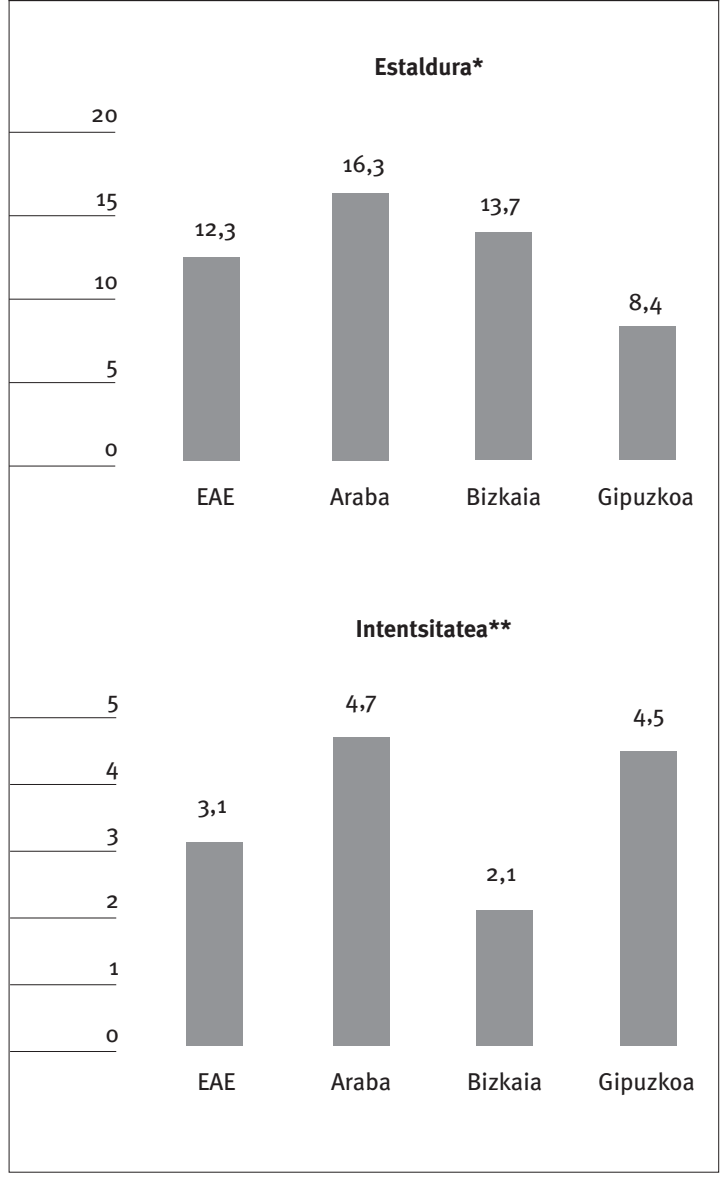

* Erabiltzaile kopurua 1.000 biztanleko.

** Asteko arreta-ordu kopurua erabiltzaile bakoitzeko.

Iturria: Eustaten Gizarte-Zerbitzuetako Erakunde eta Zentroen Estatistikatik moldeatua.

onartzearekin batera, eskubide horien hartzaile izango direnen beharrak neurtzeko tresna tekniko egokiak sortuko direla zehaztu du. Testuinguru honetan, EAEko udalek aukera ikusi dute, ahal den neurrian, irizpide objektibo bateratuetan oinarrituriko tresna bat erabiltzeko, etxez etxeko laguntzazerbitzua esleitu eta haren intentsitatea ezartzeari begira. Horrelako ekimen baten beharra nabarmena da, ondoko arrazoiengatik:

- Justiziari eta berdintasunari begira, lehenik eta behin, alegia, herritar guztiek zerbitzua jasotzeko aukera berberak izan ditzaten. Berdintasuna, kasu honetan, beharren araberako erantzuna ematea izango litzateke, hau da, antzeko beharrei antzeko erantzuna ematea EAEko udalerri guztietan.

- Baita zerbitzua eraginkorrago izan dadin ere; hau da, ahalik eta beharrean diren pertsona gehien artatzeko eta, aldi berean, zerbitzurik gabe ere ondo molda daitezkeenei ematea ekiditeko. Eraginkortasunaren gaia beti ere garrantzitsua den arren, are ardurazkoago da gaurkoa bezalako krisi 
2. grafikoa. Menpekotasuna duten pertsonentzako zerbitzuetan egiten den gastua, helburuaren arabera. EAE, $2009(\%)$
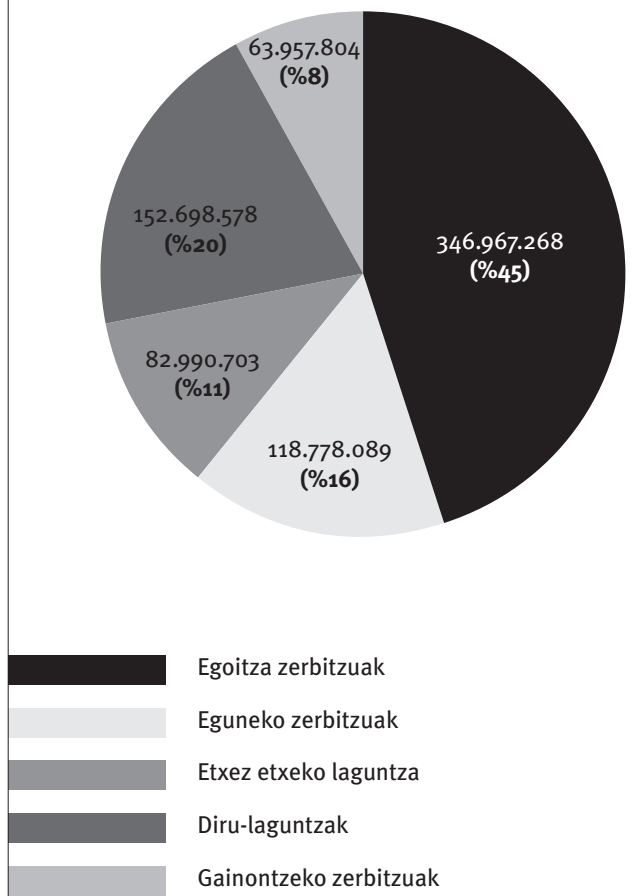

Iturria: Eusko Jaurlaritzaren gizarte zerbitzuetako gastu publikoari buruzko ikerketatik moldatua.

garaietan; batez ere, jakinik, gaur egun, Euskadin, menpekotasun-egoeran diren pertsonentzako zerbitzuetan gastatzen diren hamar eurotik bat etxez etxeko laguntza-zerbitzua ordaintzeko erabiltzen dela.

Horrela, aipatutako helburuak lortu eta, etxez etxeko laguntza jasotzeari dagokionez, EAEko udalen artean ematen diren desberdintasunekin amaitzeko asmoz, 2009ko irailean, Euskal Udalen Elkarteak (Eudel) erabaki zuen Oinarrizko Gizarte Zerbitzuetako langileei orientabidea eskaintzeko tresna garatzea. Tresna horren helburua, aurrerantzean zerbitzuaren balizko erabiltzaileen beharrak objektiboki neurtu eta, balorazio horretan oinarrituz, zerbitzuaren esleipena eta intentsitateari buruzko orientabidea eskaintzea izango da.

Proiektu hau aurrera eramateko, SIIS Dokumentazio eta Ikerketa Zentroarekin (aurrerantzean SIIS) harremanetan jarri zen Eudel. Hortik aurrera, SIISek, EAEko zerbitzuei egokituriko tresna aukeratu edo garatzeko, eta berau balioztatzeko metodologia proposatu zuen. Txosten honen hurrengo ataletan, metodologia hori azalduko da, garaturiko tresnak deskribatuko dira, eta balioztapen ikerketan jaso diren emaitzak ezagutzera emango dira.

\section{Metodologia}

Eudelekin adostutako proiektua hiru fasetan garatu da. Lehen fasean, 2009ko iraila eta 2010-eko urtarrila bitartean, ikerketa bat burutu da etxez etxeko laguntza-zerbitzua esleitzeko orduan erabili beharreko irizpideak ezartzeko, eta irizpide horiek kontuan izango dituen tresna aurkitu edo garatzeko. Bigarren fasean, 2010eko otsaila eta 2011ko otsaila bitartean, aukeraturiko tresna balioztatze-prozesuan izan da. Prozesu horretan, EAEko hamar udalen lankidetza izan dute Eudel eta SIISek. Proiektuaren hirugarren fasean ${ }^{1}$, balioztaturiko tresna Eudelen eta EAEko oinarrizko gizarte-langileen esku ipiniko da eta urte betez erabileraren jarraipena egingo dela aurreikusi da.

\subsection{Tresnaren diseinu-fasea}

Proiektuaren lehen fasean, gurean erabiltzeko tresna egokia aurkitu edo garatzeari begira, etxez etxeko zerbitzuaren inguruko bibliografia bildu eta aztertu da, eta Europako hainbat aditurekin harremanetan jarri da SIIS. Informazio-bilketa horren helburu zehatzak honakoak izan dira:

- Ezagutzea, gurean baino gizarte-politika aurreratuagoak dituzten herrialdeetan, etxez etxeko laguntza-zerbitzua jasotzeko irizpideak zeintzuk diren, nork ezartzen dituen eta nola.

- Herrialde horietan, balizko erabiltzaileen beharrak neurtzeko inolako tresnarik erabiltzen ote duten jakitea.

- Helburu bera edo antzekoa izan dezaketen tresna balioztatuak biltzea.

- Etxez etxeko zerbitzuaren behar objektiboarekin lotura duten faktoreen inguruko ezagutza zientifikoa biltzea, aurkituriko tresnak kritikoki baloratu eta egokiena aukeratzeko edo, hala behar izatekotan, tresna EAErako espresuki garatzeko.

Bilaketa dokumentala egiteko, SIISeko datu-base bibliografikoa ${ }^{2}$ erabili da. Gaiari buruzko dokumentuak aurkitzeko atención domiciliaria, asistencia domiciliaria, valoración de necesidades, eta instrumentos técnicos bilaketa-hitzak erabili dira eta, aurkituriko erreferentzien artean, etxez etxeko zerbitzua esleitzeko irizpideei eta zerbitzuen intentsitatea ezartzeko tresnei buruzko informazioa eskaintzen zuten dokumentuak aukeratu dira. Etxez etxeko zerbitzuari bereziki zegozkion dokumentuak oso urriak zirela ikusirik, bilaketa zabaldu egin da, gainontzeko zaintza-zerbitzuak esleitu eta haien intentsitatea neurtzeko tresnak aipatzen zituzten dokumentuak aintzat hartzeko.

${ }^{1}$ Hirugarren fase honen hasiera data zehazteke dago oraindik, Eudelek balioztatze-ikerketaren emaitzak aztertu bitartean.

2 SIIS Dokumentazio Zentroak 174.500 dokumentu inguruko ondarea du. Bertan aurki daitezke gizarte-politiken eta gizarte-zerbitzuen alorreko nazioarteko argitalpen nagusiak. 
Bestalde, gaiari buruzko literatura zientifikoaren berrikusketa horren bidez bildutako informazioa osatzeko, Austria, Alemania, Danimarka, Erresuma Batua, Frantzia eta Suediako zenbait adituri kontsulta egin zaie ${ }^{3}$. Aditu hauetako bakoitzari egituratutako galdetegi bat bidali zaio, honako informazioa biltzeko asmoz:

- Zeintzuk diren, aditu den herrialdean, etxez etxeko laguntza zerbitzu publikoaren ezaugarri nagusiak, antolakuntza eta finantziazioari dagokionez.

- Zerbitzua emateko irizpideak zeintzuk diren, alegia, eskaria egiten duten pertsonek zerbitzua jaso ahal izateko ze baldintza bete behar dituzten.

- Zerbitzuaren intentsitateari dagokionez, gehieneko kopururik ezartzen al den.
- Tresna teknikorik (eskala edo baremorik) erabiltzen al den erabiltzaileen beharrak neurtzeko.

Bildutako informazioa aztertu ondoren, egiaztatzezerrenda bat garatu da, proiektuaren helburuei egokituriko tresna batek izan behar lituzkeen ezaugarriak zehazten dituena. Zerrenda hau bilaketa dokumentalaren bidez antzemandako tresnen artean egokiena izan zitekeena aukeratzeko erabili da.

Bilaketa dokumentalaren bidez aurkituriko tresnak baloratzeko, ondoko irizpide-zerrenda hau garatu zen. SIIS-eko teknikarien lana izan zen aurkituriko tresna bakoitzak zerrendako irizpideak betetzen zituen ala ez zehaztea.

\section{1. koadroa. Egiaztatze zerrenda}

- Zerbitzuaren eskaera egiten duen pertsonaren autonomia-maila du irizpide nagusitzat.

- Pertsona nagusien nahiz ezintasunak dituzten pertsona gazteagoen beharrak neurtzeko balio du, euren ezintasuna dena delakoa izan (fisikoa ala psikikoa). Ez du zertan haur eta familientzako gizarte-heziketa beharrak neurtzeko aproposa izan (zerbitzu hori, zenbait udalek etxez etxeko laguntza-zerbitzuaren barne eskaintzen duten arren, aparteko zerbitzutzat jotzen da).

- Oinarrizko Gizarte Zerbitzuetan, elkarrizketa bidez aplikatzeko moduko tresna da, konplexutasuna eta luzerari dagokionez.

- Gizarte-laneko gradua duten profesionalek bete ahal izateko moduko tresna da, hau da, ez dago beharrik medikuntza edo beste alor batzuetako profesionalek parte hartzeko.

- Intentsitatea neurtzeko orduan, erabiltzailearen benetako beharrak hartzen ditu kontutan (zaintzaile formal eta informalek eskaintzen dioten laguntza alde batera utzita).

- Beharren zuzeneko neurketan oinarritzen da, ez antzeko ezaugarriak dituzten erabiltzaileei eskaintzen zaien batez besteko intentsitateari buruzko estatistiketan.

- Norberaren zaintzarekin zerikusia duten eguneroko jardueretan laguntzeko eta etxeko lanetarako beharreko denboraren artean bereizten du.

- Pertsonak euren etxean ongi zainduta mantentzeko beharrezko jarduerak kontuan hartzen ditu, eta horiek bakarrik. Baliabide publikoen gestio efizientea egiteari begira, behar-beharrezkoak ez diren jarduerak mugatzea nahitaezkotzat jotzen da.

- Gizarte-zerbitzuetan dagoeneko biltzen den informazioa aprobetxatzen du.

- Gizarte-zerbitzuetan dagoeneko erabiltzen diren tresnekin bateragarria da.

Iturria: Egilearen lana.

${ }^{3}$ Euren ekarpenak eskertu nahi dizkiegu honako pertsonei: Eigil Boll Hansen (Gobernu-Ikerketarako Institutu Daniarra [AKF], Danimarka), Vic Citarella (Gizarte-Zerbitzuetako Zuzendarien Elkartea [ADASS], Erresuma Batua), Alain Colvez (INSERM Montpellier, Frantzia), Mårten Lagergren (Äldrecentrum, Pertsona Nagusiei buruzko Ikerketa Zentroa, Suedia), Kai Lechenring (Gizarte-politiken Ikerketarako Zentro Europarra, Austria), Gerdt Sundström (Gerontologia Institutua, Jönköping Unibertsitatea, Suedia), Hildegard Theobald (Vechta-ko Unibertsitatea, Alemania).
4 Beharrezkotzat jotzen dira higiene pertsonala, elikadura, ebakuazioa, mugikortasuna, oinarrizko osasun neurriak mantentzea (medikazioak hartu, sendagilearengana joan, etab.), etxeko garbiketak eta erosketak. 


\subsection{Balioztatze teoriko eta praktikoa}

Proiektuaren fase honen helburua izan da bermatzea, aukeraturiko tresna EAEko oinarrizko gizartelangileentzat baliagarria dela. Baliagarritasun hori frogatze aldera, lantalde bat sortu da, gure erkidegoko hamar udaletako hamabost gizarte-langile eta gizarte-ongizateko teknikarik, eta Araba eta Gipuzkoako Foru Aldundietako goi-teknikari banak ${ }^{5}$ osatua. Lantalde honen egitekoa bikoitza izan da:

Lehen fase batean, aukeraturiko tresnaren edukibaliotasuna aztertu du taldeak, hau da, zehaztu nahi izan da tresnak zenbateraino jasotzen duen benetan neurtu nahi den ezaugarria, alegia, etxez etxeko laguntzaren beharra. Fase hau 2010eko otsaila eta ekaina bitartean garatu da eta denbora horretan sei aldiz bildu da taldea proposaturiko tresnak aztertzeko. Azterketa honen ondorioz, taldeak tresnari zenbait aldaketa egitea proposatu du.

Balioztatzearen bigarren fasean, fase praktikoan, parte-hartzaileei aurreko fasean moldaturiko tresnak euren zerbitzuan frogatzeko eskatu zaie. Fase honen helburua izan da ikustea tresnak zenbateraino aurresan dezakeen profesionalen irizpidea etxez etxeko laguntza esleitu eta haren intentsitatea ezartzeko orduan. Horretarako, gizarte-langileei eskatu zaie zerbitzuaren eskaera egiten duen pertsona bakoitzari tresna aplikatzeko eta, aldi berean, beren irizpide profesionalean oinarrituz, pertsona horri zerbitzua emango lioketen ala ez zehazteko. Emaitza biak -tresnak emandakoa eta profesionalek zehaztutakoa- konparatuz, tresnaren aurresatebaliotasuna ezarri ahal izan da.

Tresnaren aurresate-baliotasuna aztertzeko ahalik eta laginik adierazgarriena lortzeari begira, EAEko udalen aniztasuna -eta zehazkiago, haien tamaina eta izaera landatarra edo urbanoa- ahalik eta ondoen islatuko zuten udalerriak aukeratu dira balioztatze fasean parte hartzeko, beti ere, kontutan hartuta parte hartu zezaketen udalen kopuruak mugatua izan behar zuela. Bestalde, tresnak erabiltzaile talde desberdinekin erabiltzeko lukeen balioa zehaztu ahal izateko, 282 kasuko lagina bildu beharko litzatekeela kalkulatu da, EAEn urtean jasotzen diren etxez etxeko laguntza eskaeren kopuruan oinarrituta. Jaso beharreko kasuak 1. Taulan zehazten den moduan banatu dira parte hartu duten hamar udalen artean. Banaketa hori, udalerri bakoitzaren biztanle kopuruaren arabera egin da.

${ }^{5}$ Beraien partaidetza eskertu nahi diegu honako pertsonei: Irune Aranburu (Eibarko Udala); Ana Contreras (Laudioko Udala); Marivi Udaeta (Santurtziko Udala); Loli Nadal, Mertxe Galindez, Consuelo Girón eta Ziortza Briñas (Vitoria-Gasteizko Udala); Marivi Etxeberria (Donostiako Udala); Karmele Guinea eta Sara Perez (Bilboko Udala); Leire Espinosa (Zuiako koadrila); Joana Larrauri (Mungialdeko Mankomunitatea); Itziar Morla, Igone Blanco eta Kitty Rebolledo (Getxoko Udala); Ana Lozano (Tolosako Udala); Estrella Gomara eta Ander Zapiain (Gipuzkoako Foru Aldundia); Francisco Castillo eta Elena Martin (Arabako Foru Aldundia); Lourdes Zurbanobeaskoetxea (Bizkaiko Foru Aldundia).
1. taula. Tresnaren balioztatze praktikorako aurreikusitako lagina

\begin{tabular}{l|c}
\hline Udal edo udal-elkargoa & Kasu kopurua \\
\hline Bilbo & 90 \\
\hline Mungialdeko mankomunitatea & 10 \\
\hline Zuiako koadrila & 10 \\
\hline Donostia-San Sebastián & 50 \\
\hline Eibar & 10 \\
\hline Vitoria-Gasteiz & 60 \\
\hline Getxo & 20 \\
\hline Laudio & 10 \\
\hline Santurtzi & 12 \\
\hline Tolosa & 10 \\
\hline Guztira & $\mathbf{2 8 2}$ \\
\hline
\end{tabular}

Iturria: Egilearen lana.

Balioztatze-fase honetan lorturiko emaitzak lantaldearen esku jarri dira eztabaidarako eta eztabaida honetan eginiko proposamenak baliatuz, azken moldaketak egin zaizkio tresnari. Momentu horretan, Eudelen esku jarri dira tresna eta balioztatze-ikerketaren txostena, hark dagokion ibilbidea eman diezaien. Eudelek tresna EAEko udalerri guztietara zabaltzea erabakiko balu, ezarpenfasearen urtebeteko jarraipena egingo du SIIS-ek tresna aplikatzeko orduan sortzen diren arazo edo zailtasunak bideratzeko.

\section{Emaitzak}

Ondorengo ataletan, tresnaren diseinu-fasean buruturiko ikerketaren emaitza nagusiak laburbilduko dira lehenik eta behin. Ondoren, aukeraturiko tresnen deskribapen laburra egingo da eta, azkenik, balioztatze-ikerketaren funtsezko emaitzak eskainiko dira.

\subsection{Etxez etxeko laguntza zerbitzua esleitzeko irizpideak Europako zenbait herrialdetan}

Buruturiko bilaketa dokumentalaren eta aipaturiko adituengandik jasotako informazioaren arabera, azterturiko herrialdeetan etxez etxeko laguntzazerbitzua esleitzeari dagokionez, egoera honakoa da:

Alemanian, Austrian, eta Frantzian, menpekotasuna aitortua duten pertsonek laguntza jasotzeko eskubidea dute. Eskubide hori onartze aldera, eskalak edo balorazio-tresnak garatu dituzte gobernuek. Gainontzeko pertsonek, irizpide horietan sartzen ez diren beharrak badituzte -gizarteratze-arazoak, esaterako-, laguntza jasotzeko aukera izan dezakete, tokian tokiko administrazioen irizpide eta baliabideen arabera. Zentzu honetan, herrialde horiena, gurean ematen denaren antzeko egoera litzateke.

Gainontzeko herrialdeetan -ipar Europan eta Erresuma Batuan-, etxez etxeko laguntza -menpekotasuna duten pertsonena, nahiz autonomoena- tokian tokiko administrazioen eskumena da, eta eurek ezartzen dituzte zerbitzua emateko irizpideak. 
Ingalaterran, zerbitzuen eskaintzan tokitik tokira ematen ziren aldeak ikusita, gobernuak Fair Access to Care (FACS) izenarekin ezagutzen diren irizpideak kaleratu zituen 2002an zaintza-zerbitzuetarako sarbidea arautzeko. Irizpide hauek, ordea, orokorregiak dira, eta ez dute balorazioa egiteko orduan kontuan izan beharreko alorrak -osasuna, eguneroko bizitza, harremanak, etab.- zehaztu baino egiten. Gainera, udal bakoitzaren esku gelditzen da erabakitzea, balorazioa egin ondoren, egoera larrian edo estuan dauden pertsonen beharrak bakarrik artatuko diren edo behar arinagoak dituztenei ere zerbitzua eskainiko zaien. Horrenbestez, ezin esan daiteke gobernuak neurri honekin lortu nahi zuen helburua lortu duenik.

Danimarkan ere gobernua saiatu da zaintza zerbitzuak eskatzen dituzten pertsonen beharrak baloratzeko irizpideak bateratzen. 2004an 'hizkuntza bateratua' izenarekin ezagutzen den tresna kaleratu zuen. Tresna horrek hiru atal ditu. Lehenengo atalean, pertsonaren beraren iritzia jasotzen da, dituen zailtasunei eta, bere ustez, behar duen laguntzari buruz. Bigarren atalean, berriz, eguneroko bizitzako jardueretan dituen zailtasunak neurtzeko eskala jasotzen da, beharren balorazio objektiboa egiteko. Azkenik, eskatzailearekin bizi diren pertsonek eskaini dezaketen laguntza zehazten du. Tresna hau zerbitzuen esleipenean nolabaiteko irizpideberdintasuna bermatzeko baliagarria izan daitekeen arren, berau erabiltzea udalentzat hautazkoa denez, orain arte ez ditu espero zitezkeen emaitzak lortu.

Laburbilduz, esan daiteke azterturiko zenbait herrialdetan etxez etxeko laguntza zerbitzua -eta gainontzeko zaintza-zerbitzu publikoak- emateko orduan aukera-berdintasuna bermatzeko ahaleginak egin direla. Hala ere, zuzenean estatuek ordaintzen dituzten menpekotasuna duten pertsonen arretarako sistemetan soilik lortu da, hein batean, helburu hori. Tokian tokiko administrazioen menpeko zerbitzuetan ez da lortu balizko erabiltzaileen beharrak baloratzeko prozesua bateratzerik.

\subsection{Tresna teknikoak}

Egindako bilaketaren bidez, EAEn etxez etxeko laguntza zerbitzua esleitu eta/edo eskaini beharreko intentsitatea ezartzeko balio dezaketen zenbait tresna aurkitu dira:

- Michigan Choice algoritmoa (MI-Choice).

- Ongoing Needs Identification Tool (ONI).

- Classification par Type en Milieu de Soins et Services Prolongés (CTMSP 87).

- Resident Assessment Instrument (RAI), bertsio suitzarra.

- Valutazione Integrata dei Tempi Asistenziali (VITA).

- Système de Mesure de l'Autonomie Fonctionnelle (ISO-SMAF).

- Resource Utilization Groups (RUG), etxerako bertsioa.

Tresna bakoitzari buruzko informazioa irakurri eta, ahal izan den kasuetan, tresna bera aztertu dute SIISeko teknikariek. Informazio hori baliatuz, aurkituriko tresna bakoitza EAEko etxez etxeko laguntzazerbitzuei zenbateraino egokitzen zaien aztertu da, metodologia atalean aipaturiko egiaztatze-zerrenda baliatuz (ikus 2. eta 3. Koadroak).

2. koadroa. Zerbitzuaren esleipena ebazteko tresna

\begin{tabular}{|c|c|c|c|c|c|c|}
\hline & MI-Choice & ONI & CTMSP 87 & VITA & ISO-SMAF & RUG-23 \\
\hline \multicolumn{7}{|l|}{ Ezinbesteko ezaugarriak } \\
\hline Pertsonaren autonomia du irizpide nagusi & + & - & + & - & + & + \\
\hline $\begin{array}{l}\text { Adineko pertsonekin eta ezintasunak dituzten } \\
\text { pertsonekin erabiltzeko garatu da }\end{array}$ & + & + & + & + & + & + \\
\hline $\begin{array}{l}\text { Oinarrizko gizarte-zerbitzuan, elkarrizketa bidez } \\
\text { aplikatzeko modukoa da (luzera, konplexutasuna eta } \\
\text { abarri dagokionez) }\end{array}$ & + & + & - & + & + & - \\
\hline $\begin{array}{l}\text { Gizarte-laneko gradua duten profesionalek bete ahal } \\
\text { izateko moduko tresna da }\end{array}$ & + & + & - & + & + & + \\
\hline \multicolumn{7}{|l|}{ Desiragarritzat jotzen diren ezaugarriak } \\
\hline Sinplea eta laburra da & + & + & - & + & + & - \\
\hline $\begin{array}{l}\text { Oinarrizko gizarte-zerbitzuetan dagoeneko jasotzen } \\
\text { den informazioa aprobetxatzen du }\end{array}$ & + & - & - & - & - & + \\
\hline $\begin{array}{l}\text { Gure zerbitzuetan erabiltzen diren beste tresna } \\
\text { batzuekin bateragarria da }\end{array}$ & + & - & - & - & - & + \\
\hline
\end{tabular}

Iturria: Egilearen lana. 


\begin{tabular}{|c|c|c|c|c|c|}
\hline & CTMSP 87 & $\begin{array}{c}\text { RAI-HC } \\
\text { (suitzarra) }\end{array}$ & VITA & ISO-SMAF & RUG-23 \\
\hline \multicolumn{6}{|l|}{ Ezinbesteko ezaugarriak } \\
\hline Pertsonaren autonomia du irizpide nagusi & + & + & - & + & + \\
\hline $\begin{array}{l}\text { Erabiltzailearen benetako beharrak hartzen ditu kontutan (laguntza } \\
\text { informala eta pribatua kontutan hartzeke) }\end{array}$ & + & + & + & + & - \\
\hline Beharren zuzeneko neurketan oinarritzen da & + & + & + & - & - \\
\hline $\begin{array}{l}\text { Pertsonak behar duen zuzeneko arreta-ordu kopurua neurtzen du } \\
\text { (joan-etorrietarako denbora kontutan izan gabe) }\end{array}$ & + & + & + & - & - \\
\hline $\begin{array}{l}\text { Gutxienez, arreta pertsonalerako eta etxeko zereginetarako behar } \\
\text { den denboraren artean bereizten du }\end{array}$ & + & + & + & - & - \\
\hline $\begin{array}{l}\text { Beharrezkotzat jotzen diren jarduera guztiak kontutan hartzen ditu, } \\
\text { eta horiek soilik }\end{array}$ & - & - & - & $\begin{array}{c}\text { Ez } \\
\text { dagokio }\end{array}$ & $\begin{array}{c}\mathrm{Ez} \\
\text { dagokio }\end{array}$ \\
\hline \multicolumn{6}{|l|}{ Desiragarritzat jotzen diren ezaugarriak } \\
\hline Sinplea eta laburra da & - & - & + & + & - \\
\hline $\begin{array}{l}\text { Oinarrizko gizarte-zerbitzuetan dagoeneko jasotzen den } \\
\text { informazioa aprobetxatzen du }\end{array}$ & - & - & - & - & + \\
\hline $\begin{array}{l}\text { Gure zerbitzuetan erabiltzen diren beste tresna batzuekin } \\
\text { bateragarria da }\end{array}$ & - & - & - & - & + \\
\hline
\end{tabular}

Iturria: Egilearen lana.

Azterturiko tresnen konparaketa-koadroetan ageri denez, bai MI-Choice algoritmoak, bai ISO-SMAF tresnak, gurean erabiltzeko tresnarentzat ezinbestekotzat jotzen diren ezaugarri guztiak betetzen dituzte. Biak ere nazioarteko ospea duten ikerlari taldeek garatutakoak dira, eta euren jatorrizko herrialdeetan ikerketa zorrotzen bidez balioztatu dituzte. Gainera, euren erabilera ez da eremu zientifikora mugatu, aitzitik, praktikan balorazio tresna gisa erabilera praktikoa izan duten tresnak dira: SMAF tresna, Canadan epe-luzeko zaintza behar duten pertsonen beharrak neurtzeko erabiltzen den dimentsio anitzeko tresnaren parte da duela urte batzuetatik; MI-Choice tresna, berriz, Michigango estatuan etxeko zerbitzuak eskatzen dituzten pertsonen beharrak zehaztu eta horiek zerbitzu egokienetara bideratzeko erabili izan da urteetan.

Tresna bien arteko desberdintasun nagusia, beraz, desiragarritzat jotzen diren ezaugarri kopuruan datza. Etxez etxeko laguntza-zerbitzua eskatzen duten pertsonen beharrak zehazteko SMAF tresna aukeratzeak gure sisteman tresna berri bat sartzea suposatuko luke (menpekotasun egoera baloratzeko erabiltzen den BVD-a, eta Bizkaia eta Gipuzkoan Foru Aldundien baliabideetarako sarbidea arautzeko aukeratu den RAI tresnaz gain). Horrek zerbitzuetara sartzeko prozedura erabiltzaileentzat gaur egun dena baino ere oraindik konplikatuago egingo luke.

MI-Choice tresnak berriz, ondoren ikusiko den moduan, RAI metodoan oinarritzen denez, eta Gipuzkoa eta Bizkaiko Aldundiek beren zerbitzuetarako sarbidea arautzeko erabiltzen duten Screener Plus tresnan sartua dagoenez, tokian tokiko eta Foru Aldundietako administrazioetan egiten den balorazio prozesuari jarraitasuna eta koherentzia emango lioke eta dagoeneko balorazio zerbitzuetan jasotzen den informazioaren zati handi bat aprobetxatzeko aukera ematen du.

Aurreko guztia kontutan hartuz, EAEn etxez etxeko laguntza-zerbitzurako sarbidea arautzeko tresna egokiena MI-Choice algoritmoa dela ondorioztatu da eta berau erabiltzea proposatu zaio Eudeli.

Bestalde, zerbitzuaren intentsitatea neurtzeko tresnei dagokionez, taulak agerian uzten du aurkituriko tresnetatik batek ere ez dituela EAEko etxez etxeko laguntza-zerbitzuetan erabiltzeko tresnarentzat ezinbestekotzat jotzen diren baldintzak betetzen eta, ondorioz, tresna gure zerbitzuetarako bereziki garatzeko beharra dagoela adierazi zaio Eudeli. Aurrerantzean Tempo izendatuko dugun tresna hori garatzeko, RAI-aren bertsio suitzarra eta CTMSP kanadarra hartu dira oinarri.

\subsubsection{MI-Choice algoritmoa}

MI-Choice algoritmoa Michigango Unibertsitateko Gerontologia Institutuko ikerlari talde batek sortu zuen 2002an, Michigango Estatuko Administrazioaren eskariari erantzunez, eta interRAl baloraziotresnen familiako kide da. Algoritmo hori formula moduko bat da, familia bereko RAI-Home Care galdetegiko item kopuru txiki batean oinarrituz, baloratutako pertsonarentzat zerbitzurik egokiena zein den adierazten duena ${ }^{6}$. Orientabide hori bost zerbitzu-klase handitan eskaintzen du:

${ }^{6}$ MI-Choice algoritm oak RAI- Home Care galdetegiaren hirurehundik gora itemetatik, 30 baliatzen ditu balizko erabiltzaileentzat zerbitzurik egokiena zein den adierazteko. 
- Egoitza-zerbitzua (etxean jarraitzea komenigarria ez den kasuak bideratzen dira egoitza-zerbitzura).

- Etxeko laguntza pertsonal intentsiboa edo etxeko erizaintza-zerbitzua (egunero, hainbat oinarrizko jardueratarako laguntza behar duten pertsonentzako egokitzat jotzen dena).

- Etxeko laguntza pertsonal intermitentea (laguntzarik egunero behar ez dutenentzat, edo behar izanez gero, jarduera baterako soilik behar dutenentzat aproposa).

- Etxeko lanetarako laguntza (etxeko zereginetarako laguntza soilik behar duten pertsonentzako pentsatua).

- Informazio eta deribazioa (inolako zerbitzurik behar ez dutenentzat).

Zerbitzu-klase horiek nahiko ongi egokitzen zaizkio gure gizarte-zerbitzuen antolaketari. Bestalde, esan bezala, tresna honek gure zerbitzuetan erabiltzeko dituen abantailen artean aipatzekoak dira, datu enpirikoetan oinarrituz sortutakoa dela, Michiganen hainbat urtetan erabili dela zerbitzu komunitarioetarako sarbidea arautzeko edo gizarte-zerbitzuetan elkarrizketa bidez betetzeko moduko luzera duela, besteak beste.

\subsubsection{Tempo, zerbitzuaren intentsitatea neurtzeko tresna}

EAEn etxez etxeko laguntza-zerbitzuak erabiltzaile bakoitzari eskaini beharreko laguntza-orduen kopurua zehazteko garatu den tresna erabat intuitiboa da. Funtsean, eguneroko bizitzan egin beharreko jarduerak zehazten dituen zerrenda bat da, oro har, zeregin bakoitza burutzeko behar den denbora, eta epe jakin batean zeregin hori zenbat aldiz errepikatuko den zehazten duena7. Gizarte-langileak zerrenda horretan adierazi behar du zerbitzuaren eskaera egiten duen pertsonak zein jardueretan behar duen laguntza. Honenbestez, tresnak -hartarako prestaturiko aplikazio informatikoaren bitartezjarduera bakoitzari dagokion denbora gehitzen du.

Behin erabiltzaileak astean behar dituen laguntzaorduak zehaztuz gero, etxekoek eskaini diezaioketen laguntza zehaztu behar da, zeregin bakoitzean. Prozesu horretan, etxekoen partaidetza haientzat epe luzera eramangarri izan daitekeela ziurtatu behar du gizarte-langileak. Erabiltzaileak behar duen ordukopurua eta zaintzaile informalek eskaini diezaioketen kopuruaren arteko aldea da, printzipioz, etxez etxeko laguntza-zerbitzu publikoak eskaini beharrekotzat jotzen den intentsitatea.

\footnotetext{
7 Guztira 36 jarduera zehaztu dira katalogoan, 3 taldetan bilduta: arreta-pertsonaleko jarduerak (higienea, elikadura, mugikortasuna, eliminazioa eta nork bere osasunaren ardura) etxezaintza (garbiketak, erosketak, sukaldean egitea, gestioak, etab.) eta gizarte-heziketako jarduerak (higiene- eta osasun-ohituretan trebatzea, protesien erabileran trebatzea, jatekoa prestatzen erakustea, beste etxeko lan batzuek egiten erakustea edo etxeko tresnen erabileran trebatzea).
}

Emaitzetan, tresnak zehazten du erabiltzaileak astean beharko duen laguntza-orduen kopurua, aldi berean, jarduera pertsonaletarako, etxeko zereginetarako eta gizarte-heziketako jardueretarako beharko duenaren artean bereizten du. Baita ere, espero da, behin betiko tresna informatikoa garatzen denean, zerbitzua kudeatzen duten enpresei erabiltzaileen etxeetan egin beharreko jarduerak zehazteko zerrenda eman ahal izatea.

\subsection{Balioztatze-ikerketaren emaitzak}

Guztira, 2010eko ekaina eta 2011ko otsaila bitartean, 117 balorazio jaso dira parte hartu duten 10 udalerrietan, aurreikusitako kopurua baino askoz gutxiago, beraz. Udaletako gizarte-langileen partaidetza sustatu eta errazteko ahaleginak egin diren arren, -hala nola, tresnaren erabilerari buruzko prestakuntza sesio bereziak hala behar izan duten udalentzat, balorazioak tresna informatikoaren bidez ala eskuz betetzeko aukera, zalantzak sortu hala, haiek telefonoz argitzeko aukera, etab.- arrazoi desberdinak medio, ez da posible izan kopuru hori gehitzea, eta horrek asko murrizten du balioztatze-ikerketaren adierazgarritasuna. Hala eta guztiz ere, jasotako kasu-kopurua nahikoa izan da tresna erabiltzeko orduan sortu zitezkeen funtsezko arazoak antzemateko, eta, horiek konpontze aldera tresnari egin beharreko moldaketak proposatzeko.

\section{2. taula. Bildutako laginaren oinarrizko ezaugarri} sozio-demografikoak

\begin{tabular}{|c|c|c|c|}
\hline \multicolumn{2}{|c|}{ Ezaugarri sozio-demografikoak } & \multirow{2}{*}{$\begin{array}{c}\text { Abs. } \\
36\end{array}$} & \multirow{2}{*}{$\begin{array}{c}\% \\
30,8\end{array}$} \\
\hline \multirow{3}{*}{ Lurraldea } & Araba & & \\
\hline & Bizkaia & 51 & 43,6 \\
\hline & Gipuzkoa & 30 & 25,6 \\
\hline \multirow{5}{*}{ Adina } & 65 urte baino gutxiago & 8 & 6,8 \\
\hline & $65-75$ urte & 14 & 12,0 \\
\hline & $75-85$ urte & 51 & 43,6 \\
\hline & 85 urte edo gehiago & 42 & 35,9 \\
\hline & E.E. & 2 & 1,7 \\
\hline \multirow{4}{*}{$\begin{array}{l}\text { Menpekotasun } \\
\text { balorazioa }\end{array}$} & Autonomoa & 21 & 17,9 \\
\hline & Menpekotasuna duena & 58 & 49,6 \\
\hline & Balorazioa abian & 10 & 8,5 \\
\hline & Baloratzeke & 28 & 23,9 \\
\hline \multirow{4}{*}{ Bizikideak } & Bakarrik & 63 & 53,8 \\
\hline & Bikotearekin & 25 & 21,4 \\
\hline & Beste senide batzuekin & 22 & 18,8 \\
\hline & Beste egoera batzuetan & 7 & 6,0 \\
\hline \multicolumn{2}{|l|}{ Guztira } & 117 & 100,0 \\
\hline
\end{tabular}

E.E.: erantzunik ez.

Iturria: Egilearen lana. 
Zerbitzurako sarbidea arautuko lukeen MI-Choice tresnaren kasuan, tresnak zerbitzua jasotzeko aukera emango lioke ikerketan parte hartu duten pertsonen $\% 71,8$ ri: pertsona autonomoen $\% 61$,9ri eta menpekotasuna dutenen \%93,1-i, hain zuzen. Erabiltzaile hauei eskaini beharreko zerbitzuaren intentsitatea, berriz, astean 10 ordukoa litzateke, bataz beste, tresnaren irizpideen arabera: astean ia lau ordu pertsona autonomoei eta 13,5 ordu menpekotasuna dutenei.

3. taula. Aztertutako kasuetan, balioztaturiko tresnak ematen duen emaitza, zerbitzurako sarbidea eta haren intentsitateari dagokionez

\begin{tabular}{l|c|c}
\hline & $\begin{array}{c}\text { Etxez etxeko } \\
\text { laguntza jaso } \\
\text { dezakete (\%) }\end{array}$ & $\begin{array}{c}\text { Intentsitatea } \\
\text { bataz beste } \\
\text { (orduak } \\
\text { hilabeteko) }\end{array}$ \\
\hline Autonomoak & 61,9 & 15,5 \\
\hline Menpekotasuna dutenak & 93,1 & 54,3 \\
\hline Balorazioa abian dutenak & 80,0 & 43,9 \\
\hline Baloratzeke daudenak & 32,1 & 16,9 \\
\hline Lagin osoa & $\mathbf{7 1 , 8}$ & 39,8 \\
\hline
\end{tabular}

Iturria: Egilearen lana.

3. Taulan ageri denez, menpekotasuna onartua duten pertsonen \%6,9ak ez luke etxez-etxeko laguntza jasotzeko aukerarik izango MI-Choice tresnaren arabera eta emaitza hau desegokitzat hartu behar da, noski, Estatuko legeak pertsona hauei zerbitzua jasotzeko eskubidea onartzen dien neurrian.

Nolanahi ere, kontutan hartzekoa da datu absolutue$\tan 4$ kasu baino ez direla okerreko emaitza ematen dutenak eta horien proportzioa txikitzen joan dela analisirako kasu kopurua hazi ahala. 2011eko urrian, adibidez, guztira 62 kasu bilduta zeudenean, errore tasa \%8,8koa zen ${ }^{8}$. Horrek adierazten duena da, emaitza desegoki horien atzean balorazioa egiteko orduan buruturiko akatsak egon daitezkeela, edo ezaugarri bereziak dituzten pertsonei buruturiko balorazioak izan daitezkeela. Horrela balitz, okerreko emaitzen pisu erlatiboa txikitzen joango litzateke balorazio gehiago egin ahala.

Esan bezala, MI-Choice tresnak, etxez etxeko laguntza-zerbitzurako sarbidea irekitzeaz gain, pertsona bakoitzarentzat egokiena litzatekeen zerbitzu motari buruz orientabidea ere ematen du. Horri dagokionez, baloratutako kasuen erdia baino gehiago, \%52,1-a hain zuzen, arreta pertsonaleko etxeko zerbitzura bideratuko lituzke, \%9,4-a egoitza zerbitzuetan artatuak izateko egokiagotzat joko lituzke, eta \%10,2-ari etxeko lanetarako laguntzazerbitzua egokituko litzaioke.
3. grafikoa. Azterturiko kasuetan MI-Choice tresnak ematen duen orientabidea, zerbitzu motari dagokionez (\%)

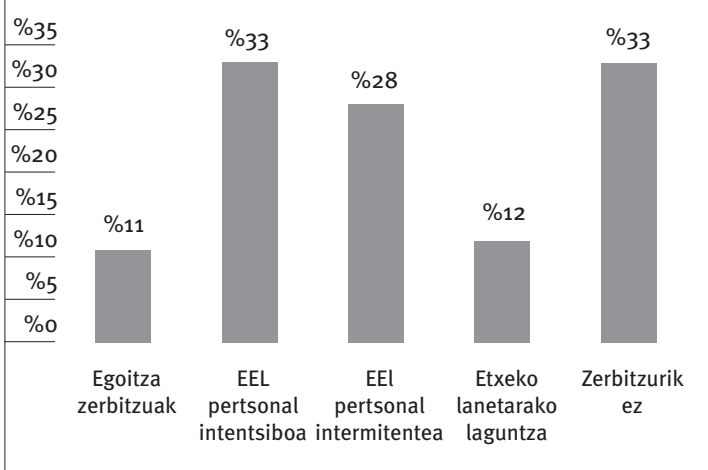

EEL: Etxez etxeko laguntza. Iturria: Egilearen lana.

\subsubsection{Emaitzen egokitasuna gizarte-langileen iritziz}

Gizarte-langileek egokitzat jotzen dituzte tresnaren emaitzak azterturiko kasuen $\% 79,8$ an, zerbitzurako sarbideari dagokionez, eta \%69an intentsitateari dagokionez. Kasu bietan, gainera, menpekotasuna duten pertsonekin lortzen diren emaitzak egokiagotzat jotzen dira pertsona autonomoekin lortzen direnak baino. Zerbitzurako sarbidea arautzeko tresnaren kasuan, menpekotasuna duten pertsonei egindako balorazioen \%94,3 hartzen dute gizartelangileek egokitzat, baina autonomoei egindakoen $\% 68,4$ besterik ez. Intentsitatea neurtzeko tresna aztertzean berriz, zifra horiek $\% 74,5$ eta $\% 66,7$ dira, hurrenez hurren.

4. taula. Azterturiko kasuen artean, gizarte-zerbitzuetako profesionalek egokitzat ematen dituzten balorazioak, menpekotasun-mailaren arabera (\%)

\begin{tabular}{l|c|c}
\hline \multirow{2}{*}{} & \multicolumn{2}{|c}{$\begin{array}{c}\text { Tresnaren emaitzari } \\
\text { egokia deritzozu? }\end{array}$} \\
\cline { 2 - 3 } & $\begin{array}{c}\text { Sarbidea } \\
\text { arautzeko } \\
\text { tresna } \\
(\mathbf{N}=\mathbf{1 0 4})\end{array}$ & $\begin{array}{c}\text { Intentsitatea } \\
\text { neurtzeko } \\
\text { tresna } \\
(\mathbf{N}=94)\end{array}$ \\
\hline Autonomoak & 68,4 & 66,7 \\
\hline Menpekotasuna dutenak & 94,3 & 74,5 \\
\hline Balorazioa abian dutenak & 88,9 & 62,5 \\
\hline Baloratzeke daudenak & 52,2 & 55,6 \\
\hline Lagin osoa & 79,8 & 69,0 \\
\hline
\end{tabular}

Iturria: Egilearen lana.

Bizitokiaren arabera ere desberdintasunak ageri dira gizarte-langileek egokitzat jotzen duten baloraziokopuruan. Zerbitzua jasotzeari begira, bikotearekin edo beste senideren batzuekin bizi diren pertsonei egindako hamar baloraziotatik bederatzi hartzen dira balekotzat, baina bakarrik bizi direnen $\% 68,5$ baino ez. Intentsitateari dagokionez, berriz, bikotearekin bakarrik bizi diren pertsonekin lortutako emaitzak
${ }_{8}^{8}$ 2011ko urriaren 8an, balioztatze praktikoaren jarraipena egiteko lantaldearekin buruturiko bilera batean, behin-behineko txosten bat aurkeztu zen, momentu hartan profesionalek bilduak zituzten 62 kasuekin lortutako emaitzak jasotzen zituena. 
4. grafikoa. Azterturiko kasuen artean, gizarte-zerbitzuetako profesionalek egokitzat ematen dituzten balorazioak, bizimoldearen arabera (\%)

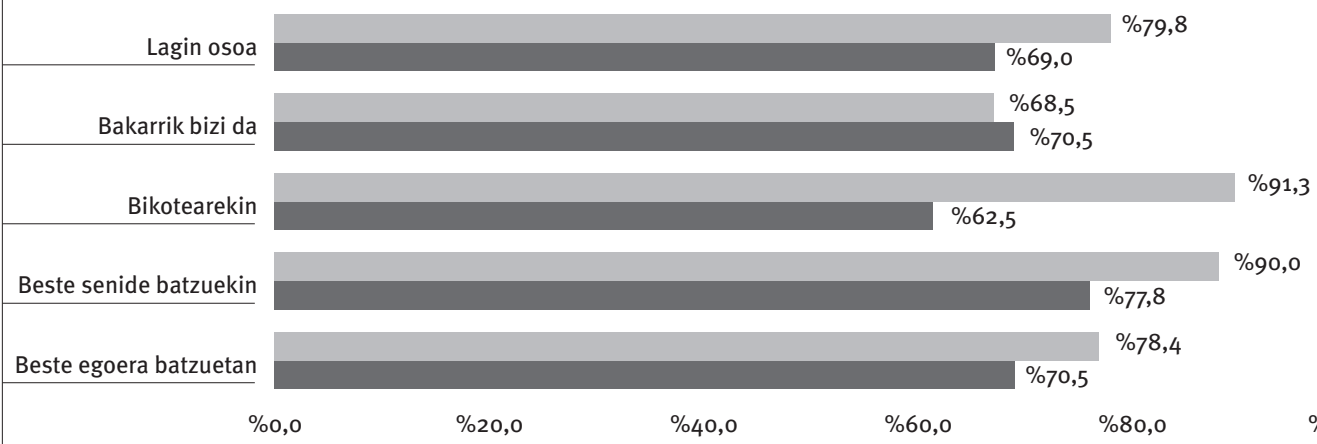

Sarbide arautzeko tresna

Intentsitatea neurtzeko tresna

Iturria: Egilearen lana.

dira kaskarrenak: bakarrik edo beste senitarteko batzuekin (oro har, seme-alabekin) bizi diren pertsonei egindako balorazioen \%7oetik gora dira egokiak gizarte-langileen ustez, baina senarra edo emaztea-

\subsubsection{MI-Choice tresnaren sentikortasuna eta zehaztasuna}

Ikerketa honen helburuetako bat, MI-Choice tresnaren aurresate-baliotasuna aztertzea izan da, tresnaren emaitzak ikerketaren fase praktikoan parte hartu duten profesionalen irizpideekin konparatuz. Horretarako, oro har, tresnaren emaitzen egokitasuna baloratzeko eskatzeaz gain, euren iritziz, baloraturiko pertsona bakoitzari etxez etxeko laguntzazerbitzua jasotzeko aukera eskaini beharko litzaiokeen adierazteko esan zitzaien gizartelangileei.

Profesionalek emandako 'urrezko estandar' hau tresnaren sentikortasuna eta zehaztasuna neurtzeko erabiliko da. Tresnaren sentikortasuna da, profesionalen irizpideen arabera zerbitzua behar duten pertsonak antzemateko duen ahalmena. Tresnaren zehaztasuna, berriz, zerbitzua behar ez duten pertsonei sarbidea eragozteko duen ahalmena izango da.

Definizio honetatik ondorioztatzen da, proba edo tresna bat oso sentikorra izan daitekeela eta aldi berean zehaztasun gutxikoa -hau da, behar egoeran dauden pertsona guztiei sarbidea emango lieke, baina baita zerbitzua behar ez duten pertsona askori ere (gaindiagnosia eginez)- edo alderantziz, oso zehatza baina sentikortasun gutxikoa izan daiteke, beharra duten pertsona asko zerbitzurik gabe utziz. Tresna on batek irizpide biak maximizatu beharko lituzke aldi berean.

4. koadroa. Kasuak sailkatzeko eskema

\begin{tabular}{|c|c|c|}
\hline $\begin{array}{l}\text { Zerbitzua jaso } \\
\text { dezake MI- } \\
\text { Choice tresnaren }\end{array}$ & \multicolumn{2}{|c|}{$\begin{array}{l}\text { Zerbitzua jasotzeko aukera izan behar luke } \\
\text { profesionalen arabera }\end{array}$} \\
\hline & $\mathrm{Ez}$ & Bai \\
\hline Ez & $\begin{array}{l}\text { Aurresate zuzena } \\
\text { (egiazko negatiboa) }\end{array}$ & $\begin{array}{l}\text { Aurresate okerra } \\
\text { (negatibo faltsua) }\end{array}$ \\
\hline Bai & $\begin{array}{l}\text { Aurresate okerra } \\
\text { (positibo faltsua) }\end{array}$ & $\begin{array}{l}\text { Aurresate zuzena } \\
\text { (egiazko positiboa) }\end{array}$ \\
\hline
\end{tabular}

Iturria: Egilearen lana.

Bildu diren 84 kasuekin $^{9}$ ez da posible sentikortasuna eta zehaztasuna fidagarritasunez aztertzea, izan ere, ez da jaso profesionalen ustez zerbitzutik kanpo gelditu behar lirateken kasu nahikorik eta, ondorioz, ezinezkoa da tresnaren zehaztasuna aztertzea. Nolanahi ere, oro har, \%71,4-ko adostasuna dago tresnaren emaitzen eta profesionalen irizpidearen artean.

Tresnaren emaitzak eta balioztatze praktikoan parte hartu duten udaletan erabiltzen diren irizpideak konparatuz lortzen den adostasun maila profesionalen iritzia aztertzean lortutakoaren antzekoa da, $\% 73,1$-koa hain zuzen. Gainera:

- Tresnaren sentikortasuna (egiazko positiboen tasa) \%74,5-ekoa da.

${ }^{9}$ Hogei kasutan ezin izan da jakin gizarte-langileak etxez etxeko laguntza zerbitzua baloratutako pertsonarentzat egoki kontsideratzen duen ala ez. 
- Tresnaren zehaztasuna (egiazko negatiboen tasa) askoz txikiagoa da, \%50ekoa. Hala eta guztiz ere, kontutan izan behar da, guztira, profesionalen iritziz zerbitzua jasotzeko beharrik ez luketen pertsonei dagozkien sei kasu besterik ez direla jaso eta, ondorioz, emaitza hau estimazio moduan ematen dela.

5. taula. Etxez etxeko laguntza zerbitzurako sarbidea MIChoice tresna eta gaur egun oinarrizko gizarte-zerbitzuetan erabiltzen diren irizpideen arabera

\begin{tabular}{l|c|c|c}
\hline $\begin{array}{l}\text { MI-Choice tresnaren } \\
\text { arabera, etxez etxeko } \\
\begin{array}{l}\text { laguntza zerbitzua } \\
\text { jasoko luke }\end{array}\end{array}$ & \multicolumn{3}{|l}{$\begin{array}{l}\text { Udalaren irizpideen arabera, etxez } \\
\text { etxeko laguntza zerbitzua jasoko luke }\end{array}$} \\
\hline & Ez & Bai & Guztira \\
\hline Ez & 3 & 25 & 28 \\
\hline Bai & 3 & 73 & 76 \\
\hline Guztira & 6 & 98 & 104 \\
\hline
\end{tabular}

Iturria: Egilearen lana.

Aukeraturiko tresnaren baliotasuna ezartzeaz gain, Ikerketaren fase praktiko honen beste helburuetako bat, tresna EAEko gizarte-langileen beharretara egokitzeko proposamenak burutzea zen, eta, horrenbestez, merezi du tresnaren emaitza desegokia den kasuen ezagugarriak aztertzea. Esan bezala, bi okerreko emaitza mota bereiz daitezke:

- Negatibo faltsuak: Profesionalen irizpideen arabera etxez etxeko laguntza behar duten pertsonak eta balioztatutako tresna erabiliz zerbitzutik kanpo geratuko liratekeenak. 23 kasu dira, honako ezaugarriak dituztenak:

- Gehienek euren menpekotasun egoera baloratzeke dute $(\% 65,2)$.

- Orokorrean bakarrik bizi dira (\%74).

- Gehienek etxeko zereginetarako zailtasunak dituzte, baina batek ere ez du bainurako zailtasunik (\%78).

- Gehienek ez dute erabaki sinpleak hartzeko zailtasunik (\%96).

- Positibo faltsuak, hau da, profesionalen iritziz zerbitzurik behar ez duten pertsonak baina tresnaren emaitzen arabera zerbitzua jaso ahal izango luketenak. Kasu bakar bat jaso da, normalean gizarte-langileek etxez etxeko laguntza-zerbitzua jasotzeko apropostzat hartzen dituzten pertsonen antzeko ezaugarriak dituena, berau (88 urteko emakumea, autonomoa baina etxeko lanetarako eta bere burua garbitzeko arazoak dituena, eta bakarrik bizi dena). Kasu honetan, beraz, profesionalaren irizpidea eta tresnaren arteko desadostasuna pertsonaren balorazioa egiteko orduan egindako akatsen bati zor dakioke, algoritmoaren emaitza desegoki bati baino gehiago.
3.3.3. Tempo, zerbitzuaren intentsitatea neurtzeko tresnaren emaitzen egokitasuna

Esan bezala, oro har, balioztatze praktikoan parte hartu duten profesionalek Tempo, etxez etxeko laguntza-zerbitzuaren intentsitatea neurtzeko garaturiko tresnak ematen dituen emaitzak egokitzat hartzen dituzte azterturiko kasuen \%69-an. Bestalde, tresnak ematen duen intentsitatea txikiegitzat jotzen dute 15 kasutan (\%18) eta gehiegizkotzat 11 kasutan (\%13).

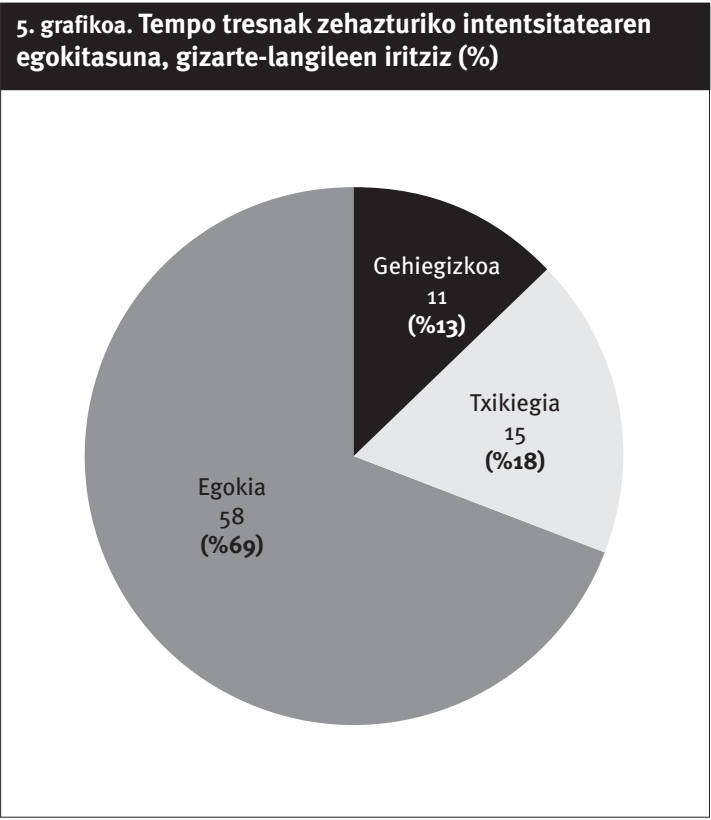

Menpekotasun mailaren arabera, tresnak adierazitako zerbitzuaren intentsitatea egokiagotzat jotzen dute profesionalek baloraturiko pertsonak menpekotasuna duenean $(\% 74,5)$, autonomoa denean baino $(\% 66,7)$. Bestalde egokitasun maila baxuenak baloratzeke dauden pertsonekin $(\% 62,5)$ eta balorazioa abian dutenekin ematen dira $(\% 55,6)$.

Azkenik, Tempo tresnaren katalogoan sartutako jardueren eta gizarte-langileek lortutako intentsitatearen egokitasunaz egiten duten balorazioaren artean harreman esanguratsuren bat ote zegoen ikusteko, Chi-karratu estatistikoa erabili da. Metodo honekin, lau jarduera antzeman dira, zeinetan, pertsonak laguntza beharra zuela adieraziz gero, lorturiko intentsitatea gizarte-langileen ustez gehiegizkoa baitzen. Jarduera horiek honakoak dira: bazkaldu edo afaltzeko laguntza, etxean ibiltzeko laguntza, bazkaria prestatzeko laguntza eta afaria prestatzeko laguntza. 
Bazkaldu/afaltzeko laguntza behar du

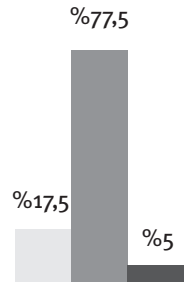

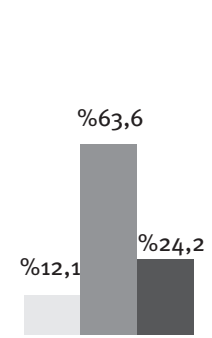

Bai

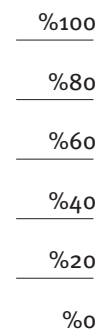

Bazkaria prestatzeko laguntza behar du

$$
\% 100
$$

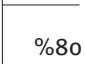

\begin{tabular}{|l}
$\% 80$ \\
\hline$\% 60$ \\
\hline
\end{tabular}

$\% 40$

$\% 20$

$\%$

Bazkaldu edo afaltzeko, etxe barruan ibiltzeko edo bazkaria edo afaria prestatzeko laguntza behar duten pertsonen kasuan, Tempo tresna erabiliz lortzen den zerbitzuaren intentsitatea gehiegizkotzat jotzen da baloratutako kasuen laurdena baino gehiagorentzat, kasu guztiak kontutan izanez gero, proportzio hori \%13-koa zen bitartean. Desberdintasun hauek estatistikoki esanguratsuak diren neurrian, tresna balioztatzeko eratutako lantaldeak jarduera horientzat hasiera batean emandako denbora eta maiztasuna aldatzea erabaki du.

\section{Ondorioak}

Jaso ahal izan den kasu-kopuru murritzak ezartzen dituen mugak kontuan hartuta, esan daiteke, oro har, ikertu den tresna baliogarria dela EAEko etxez etxeko laguntza-zerbitzua esleitu eta haren intentsitatea neurtzeari begira.

Tresnak emaitza onak lortzen ditu menpekotasuna duten pertsonen beharrak neurtzeko orduan (hamarretik bederatzi kasu baino gehiagotan emai-

Etxean ibiltzeko laguntza behar du

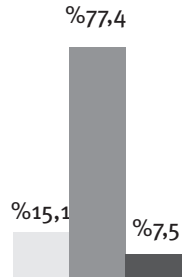

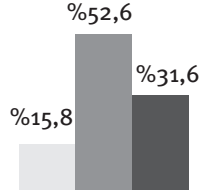

Bai

Afaria prestatzeko laguntza behar du

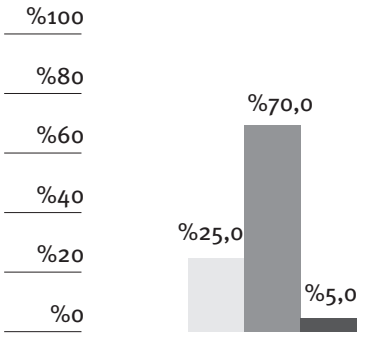

Ez

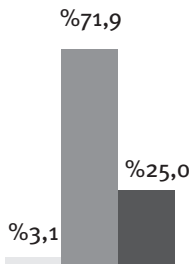

Bai tza egokia ematen du sarbideari dagokionez, eta hamarretik zazpitan, intentsitatea neurtzean), baina ez horrenbeste pertsona autonomoen kasuan. Hain zuzen, balioztatze-prozesuan parte hartu duten gizarte-langileen iritziz, tresnaren errurik nabarmenena da bakarrik bizi diren pertsona autonomoei, etxeko lanetarako laguntza soilik behar dutenean, ez diela zerbitzua jasotzeko aukerarik ematen. Honenbestez, tresna balioztatzeko bildutako aditutaldeak erabaki du tresnari moldaketak egitea, ezaugarri horiek dituzten pertsonei sarbidea emateko.

Era berean, ikerketaren bidez ezarri ahal izan da Tempo tresnaren katalogoan sartutako jarduera batzuek harremana dutela gizarte-langileen ustez gehiegizkoa litzatekeen emaitza batekin, alegia, jarduera jakin horietan laguntza behar dutela adieraziz gero, sarriagotan gertatzen dela tresnak ematen duen intentsitatea gehiegizkoa izatea. Honenbestez, lantaldeak jarduera horiei emandako denbora eta maiztasun balioak berrikusi eta aldatzea erabaki du, emaitza orokorrak euren irizpideetara hobeto egokitu daitezen. 
Moldaketa hauek egin ondoren, tresna eta balioztatze-txostena Eudelen esku ipini dira eta orain, udalen baitan dago tresnaren erabilerari buruz erabakitzea. Nolanahi ere, ikerketa honetan bildu ahal izan den kasu kopuru murritza kontutan hartuta, bertan parte hartu duen aditu-taldeak beharrezkotzat jo du, tresnaren erabilera udal guztietara hedatu aurretik, haren baliagarritasuna zalantzarik gabe ezartzeko ikerketa zabalago bat egitea. Froga horretan, kasu kopuru nahikoa bildu beharko litzateke, etxez etxeko laguntza-zerbitzuaren erabiltzaile izan daitezkeen populazio-talde desberdinei aplikatuz gero (ezintasunak dituzten pertsonak, buru gaixotasunak dituztenak, etab.), tresnak ze emaitza ematen dituen aztertzeko.

Azkenik, garaturiko tresnaren erabilera EAEko udal guztietara hedatzea erabakiko balitz, SIISeko teknikariek tresnaren erabileraren jarraipena egingo dute, urte betez, sortzen diren arazoak eta zailtasunak bideratzeko. 
(2003): Supplément Suisse au Manuel RAl-domicile, version 2.o. Manuel d'application de la méthode RAI-Domicile pour les Services à Domicile en Suisse, Paris, Editions de l'École Nationale de la Santé Publique.

ALEMANY, P. (2002): Instrumentos de valoración del programa de atención a domicilio, Valentzia, Societat Valenciana de Medicina Familiar i Comunitària [<http://www.svmfyc.org/grupos/ Publicaciones/ValorAD.pdf〉].

ASDO (2008): Étude perception par les usagers des outils d'évaluation des besoins de compensation de la perte d'autonomie, Caisse Nationale de Solidarité pour L'Autonomie [«http://www. cnsa.fr/IMG/pdf/2b.Rapport_ASDO_avec_les_ annexes.pdf>].

ASSOCIATION SUISSE DES SERVICES D’AIDE ET DE SOINS À DOMICILE (1998): Évaluation des besoins. Rapport final, Berna, Association Suisse des Services d'Aide et de Soins à Domicile.

BJÖRKGREN, M. A.; FRIES B. E.; eta SHUGARMAN, L. R. (2000): "A RUG-IIl case-mix system for home care”, Canadian Journal on Aging, 19. bol., 2. gehi., 106-125 or.

BRODSKY, J.; HABIB, J.; eta MIZRAHI, I. (2000): Long-Term Care Laws in Five Developed Countries. A Review, Ginebra, Osasunaren Mundu Erakundea [ http://whqlibdoc.who.int/hq/2000/WHO_ NMH_CCL_00.2.pdf)].

BUNTINX, F.; et al. (2004): "Options for a new procedure for determining care needs in Belgium: An initial exploration", Archives of Public Health, 62 zb., 173-184 or.

COLVEZ, A.; et al. (1997): “Analyser les pratiques pour construire un plan d'aide: une 'démarche qualité’ pour les services à domicile aux personnes âgées dépendantes", Revue Française des Affaires Sociales, zb. berezia, 283-298 or.

CONSEJERÍA DE TRABAJO Y POLIITICA SOCIAL (2001): Guía informativa del procedimiento del servicio de ayuda a domicilio para profesionales de los centros de servicios sociales, Murcia, Consejería de Trabajo y Política Social.

COUTTON, V. (2000): Les instruments médico-économiques fondés sur les groupes iso-ressources. Rapport réalisé pour la Direction de la Recherche, des Études, de l'Evaluation et des Statistiques, Paris, Ministère de l'Emploi et de la Solidarité.

CSONKA, A.; eta BOLL, J. L. (2001): Home Care in Denmark, in: MERMET E.; eta LEHNDORFF, S. (ed.), New Forms of Employment and Working Time in the Service Economy, Brusela, European Trade Union Institute [shttp://ec.europa.eu/research/ social-sciences/pdf/finalreport/soe2ct983078final-report.pdf>].

DEPARTMENT OF HEALTH (2002): The Single Assessment Process. Assessment Tools and Scales. Guidance, Londres, Department of Health [<http://207.61.67.46/GEIDEFile/instruments. PDF?Archive $=191225791940$ \& File $=$ instrumen ts_PDF>].

DIWAN, S.; et al. (1997): "Composition of the home care service package: Predictors of type, volume, and mix of services provided to poor and older people", The Gerontologist, 37. bol., 2. zb., 169-181 or.

DUBUC, N., HÉBERT, R.; eta DESROSIERS, J. (2004): “Les soins de longue durée aux personnes âgées: choix d'un système clinico-administratif dans le contexte d'un réseau de soins intégrés", Canadian Journal on Ageing, 23 bol., 1. zb., $35-45$ or. 
DUBUC, N.; RÉJEAN, H.; eta TOUSIGNANT, M. (2004): “Du développement à l'implantation des profils ISO-SMAF: une mise à jour", in: HÉBERT, R.; TOURIGNY, A.; GAGNON, M. (ed.), Intégrer les services pour le maintien de l'autonomie des personnes, Edisem, 177-206 [<http://www. medetic.com/docs/03/Prisma\%202004.pdf〉].

ENNUYER, B. (2006): Repenser le maintien à domicile: enjeux, acteurs, organisation, Paris, Dunod.

EVANS CUELLAR, A. E.; eta WIENER, J. M. (2000): “Can social insurance for long-term care work? The experience of Germany", Health Affairs, 19. bol., 3. zb., 8-25 or. [<http://content. healthaffairs.org/content/19/3/8.full.pdf〉].

FALEZ, F.; et al. (2007): “Étude comparée de trois échelles d'évaluation de la dépendance des personnes âgées en Belgique", La Revue de Gériatrie, 32. bol., 1. zb., 12-24 or.

FRIES, B. E.; et al. (2004): “Is telephone screening feasible? Accuracy and cost-effectiveness of identifying people medically eligible for home- and community based services", The Gerontologist, 44. bol., 5. zb., 680-688 or.

FRIES, B. E.; et al. (2002): "A screening system for Michigan's home- and community-based longterm care programs", The Gerontologist, 42. bol., 4. zb., $462-474$ or.

GARDENT, H. (2001): “Évaluer: avec quoi?”, Gérontologie et Société, 99. zb., 97-109 or.

GLENDINNING, C.; et al. (2004): Funding Long-Term Care for Older People. Lessons from other Countries, York, Joseph Rowntree Foundation [<http:// www.jrf.org.uk/sites/files/jrf/1859352065. pdf>].

HAMMAR, T.; et al. (2008): "Home-care clients' need for help, and use and costs of services", European Journal on Ageing, 5. bol., 147-160 or.

HARDY, J. P.; eta L'HUILLIER, J. M. (2008): L'aide sociale aujourd'hui, Issy-Les-Moulineaux, ESF Editeur.

HEALTH CANADA (1999): Provincial and Territorial Home Care Programs: A Synthesis for Canada, Health Canada [<http://publications.gc.ca/collections/ Collection/H88-3-30-2001/pdfs/other/hc_e. pdf>].

HÉBERT, R.; TOURIGNY, A.; eta GAGNON, M. (2004): Intégrer les services pour le maintien de l'autonomie des personnes, Quebec, Edisem [/http://www. medetic.com/docs/03/Prisma\%202004.pdf)].

HÉBERT, R.; et al. (2003): "Le système de mesure de l'autonomie fonctionnelle (SMAF)", La Revue de Gériatrie, 28. bol., 4. zb. [<http://expertisesante.com/modules/AxialRealisation/img repository/files/documents/SMAF_Revue $\% 20$ de\%20geriatrie\%202003.pdf〉].

HÉBERT, R.; et al. (2001): "Resources and costs associated with disabilities of elderly people living at home and in institutions", Canadian Journal on Aging, 20. bol., 1. zb., 1-19 or.

HIRDES, J. P.; et al. (1999): “Integrated health information systems based on the RAI/MDS series of instruments", Healthcare Management Forum, 12. bol., 4. zbk., 30-40 or.

HIRDES, J. P.; POSS, J. W.; eta CURTING-TELEGDI, N. (2008): "The method for assigning priority levels (MAPle): A new decision-support system for allocating home care resources", BMC Medicine, 6. bol., 9. zb. [khttp://www. springerlink.com/content/y27k5393lo74580o/ fulltext.pdf $\rangle$.

HUDSON, B.; HENWOOD, M. (2008): Analysis of Evidence Submitted to the CSCI Review of Eligibility Criteria. A Report Commissioned by CSCI for the Review of Eligibility Criteria, Londres, Commission for Social Care Inspection [rhttp://archive.cqc.org.uk/_db/ documents $/ 20080730 \% 20$ Tracked $\% 20$ FACS\%20Eligibility\%2oreview_typeset $1 \% 20$ v3\%20Dom.pdf s].

HUTTEN, J. B. F.; eta KERKSTRA, A. (ed.) [1996]: Home Care in Europe: A Country-Specific Guide to its Organization and Financing, Vermont, Ashgate.

KIPP, J.; et al. (2002): "Predicting in-home time of community care professionals", International Journal of Health Care Quality Assurance, 15. bol., 1. zb., 11-16 or.

LAGERGREN, M.; eta JOANSSON, P. A. (1998): "Are there differences in standard of care for the elderly? A comparative study of assistance decisions in Stockholm", Scandinavian Journal of Social Welfare, 7. bol., 340-349 or.

LARSSON, K. (2006): "Care needs and home-help services for older people in Sweden: Does improved functioning account for the reduction in public care?", Ageing and Society, 26. bol., 413-429 or.

LAUKKANEN, P.; et al. (2001): "Coping with activities of daily living in different care settings", Age and Ageing, 30. bol., 489-494 or.

LEICHSENRING, K. (2008): A Major Policy Impact of the European Centre's Consultancy: A New Long-term Care Scheme for Bolzano Alto Adige (Italy), saila: Policy Brief, European Centre [<http://www.euro.centre.org/ data/1201260830_78098.pdf)].

LEWINTER, M.; et al. (2004): "Developments in home help for elderly people in Denmark: The changing concept of home and institution", International Journal of Social Welfare, 13. zb., 89-96 or.

MAP (2005): Modèle d'accompagnement personnalisé. Guide pratique, Montigeon, Unapei [rhttp:// www.awiph.be/pdf/AWIPH/projets_nationaux/ logement/Outils/GuideMap2006.pdf`].

MDS (2006): Richtlinien der Spitzenverbände der Pflegekassen zur Begutachtung von Pflegebedürftigkeit nach dem XI. Buch des sozialgesetzbuches.

MEINOW, B.; KAREHOLT, I.; eta LAGERGREN, M. (2005): "According to need? Predicting the amount of municipal home help allocated to elderly recipients in an urban area of Sweden", Health and Social Care in the Community, 13. bol., 4 zb., 366-377 or.

MINISTÈRE DE LA SANTÉ ET DES SERVICES SOCIAUX (2003): Pour faire les bons choix. Chez soi: le premier choix. La politique de soutien à domicile, Quebec, Ministère de la Santé et des Services Sociaux [rhttp://publications.msss.gouv.qc.ca/ acrobat/f/documentation/2002/02-704-01. pdf $>$. 
- (2002): Outil d'Évaluation Multi Clientèle, Quebec, Ministère de la Santé et des Services Sociaux.

- (2000): Comité aviseur sur l'adoption d'un outil d'évaluation intégré des besoins des personnes en perte d'autonomie et de détermination des services requis notamment en institution ou à domicile, Quebec, Ministère de la Santé et des Services Sociaux [<http:// publications.msss.gouv.qc.ca/acrobat/f/ documentation/2000/00-703.pdf)].

MINISTÈRE DE LA SÉCURITÉ SOCIALE (2009): L'Assurance dépendance. Guide pratique, Luxenburg, Ministère de la Sécurité Sociale [<http://www. sante.public.lu/publications/remboursementsindemnites/assurance-dependance/assurancedependance-guide-pratique/assurancedependance-guide-pratique-fr.pdf`].

MINISTERIO DE TRABAJO Y ASUNTOS SOCIALES (1999): Vejez y protección social a la dependencia en Europa, Madrid, Ministerio de Trabajo y Asuntos Sociales.

MOYA, P.; et al. (2009): Costes asociados al cuidado informal en mayores dependientes del ámbito rural. Envejecer en Cuenca, Centro de Estudios Sociosanitarios. Universidad de Castilla-La Mancha.

OLAISON A.; eta CEDERSUND, E. (2006): “Assessment of home care: Negotiating solutions for individual needs", Journal of Aging Studies, 20. zb., 367380 or.

PAMPALON, R.; COLVEZ, A.; eta BUCQUET, D. (1991): "Établissement d'une table de passage de la dépendance des personnes âgées au besoin d'aide à domicile", Revue d'Epidémiologie et Santé Publique, 39 zb., 263-273 or.

PLYMOUTH COUNCIL (2005): Fair Access to Care Services. Practice Guidance (Revised), Plymouth, Plymouth Council [rhttp://www.plymouth.gov. uk/fair_access_to_care_services_-_practice_ guidance.pdf`].

POMMER, E.; WOITTIEZ, I.; eta Stevens, J. (2007): Comparing Care. The Care of the Elderly in Ten EUCountries, Haga, The Netherlands Institute for Social Research [khttp://www.scp.nl/english/ dsresource? objectid=21605\&type=org ].

POSS, J. W.; et al. (2008): "Validation of Resource Utilization Groups Version III for Home Care (RUG-III/ HC). Evidence from a Canadian Home Care Jurisdiction", Medical Care, 46. bol., 4. zb., 380-387 or.

ROBBINS D. (2008): Criteria for Care: Assessing Eligibility for Long-Term Care Services in Europe, Commission for Social Care Inspection; Social Care Institute for Excellence.

ROUSILLE, B. (2004): L'évaluation du handicap dans la perspective de la nouvelle prestation de compensation, saila: Rapport, 150. zb., Paris, Inspection Generale des Affaires Sociales [<http://lesrapports.ladocumentationfrancaise. $\mathrm{fr} / \mathrm{BRP} / 054000098 / 0000 . p d f$ )].

SUNDSTRÖM, G.; MALMBERG, B.; eta JOHANSSON, L. (2006): "Balancing family and state care:
Neither, either or both? The case of Sweden", Ageing and Society, 26 zb., 767-782 or.

SWEDISH ASSOCIATION OF LOCAL AUTHORITIES AND REGIONS (2007): Care of the Elderly in Sweden Today, Stockholm, Swedish Association of Local Authorities and Regions.

TARRICONE, R.; eta TSOUROS A. D. (ed.) [2008]: Home Care in Europe. The Solid Facts, Kopenhage, Osasunaren Mundu Erakundea.

THEOBALD, H. (2004): Care Services for the Elderly in Germany: Infraestructure, Access and Utilisation from the Perspective of Different User Groups, Berlin, Wissenschaftszentrum Berlin fur Sozialforschung [<http://bibliothek.wzb.eu/ pdf/2004/io4-302.pdf >].

TILQUIN, C. (1999): “Effets pervers associés aux modalités d'allocation des ressources aux organisations prenant en charge les personnes dépendantes. Apports d'un financement fondé sur la mesure des ressources requises individuellement EROS", Ruptures, 6. bol., 1. zb., 47-66 or. [〈http://www.medsp.umontreal.ca/ruptures/ pdf/articles/rup061_047.pdf)].

TILQUIN C.; eta COUPAL, M. (1997): CTMSP ‘87. La détermination des services requis et la mesure des ressources requis par le bénéficiaire, Quebec, EROS.

TIMONEN, V.; eta DOYLE, M. (2007): Home Care for Ageing Populations: A Comparative Analysis of Domiciliary Care in Denmark, the United States and Germany, Northhampton, Edward Elgar Publishing.

TOUSIGNANT, M.; et al. (2007): “Home-care programmes for older adults with disabilities in Canada: How can we assess the adequacy of services provided compared with the needs of users?", Health and Social Care in the Community, 15. bol., 1. zb., 1-7 or.

TOUSIGNANT, M.; et al. (2003): “Application of a case-mix classification based on the functional autonomy of the residents for funding long-term care facilities", Age and Ageing, 32. zb., 60-66 or.

TOUSIGNANT, M.; et al. (2003): Détermination du profil d'autonomie fonctionnelle et du taux de réponse aux besoins de la clientèle long terme du programme soutien à domicile des CLSC de Montérégie, Sherbrooke, Institut Universitaire de Gériatrie [rhttp://www.prismaquebec.ca/ documents/document/resumemonteregie. pdf〉].

VAN CAMPEN, C.; eta VAN GAMEREN, E. (2005): "Eligibility for long-term care in the Netherlands: development of a decision support system", Health and Social Care in the Community, 13. bol. [khttp://dx.doi.org/10.1186/1472-6963-11207)].

VAN RAAK, A.; et al. (ed.) [2003]: Integrated Care in Europe: Description and Comparison of Integrated Care in Six EU Countries, Maarssen, Elsevier. 


\section{Experiencias de voluntariado en la CAPV}

\section{Dirección de Política Familiar y Comunitaria, Dpto. de Empleo y Asuntos Sociales, Eusko Jaurlaritza-Gobierno Vasco}

<familia@ej-gv.es>

Gertu dago Boluntariotzaren Europako Urtearen bukaera, eta testu honek Euskal Autonomia Erkidegoan esparru ezberdinetan garatzen diren laguntzarako ekintzen zenbait adibide erakutsi nahi ditu: DYAren errepideko laguntza, Gurutze Gorriaren akonpainamendu zerbitzua eta Euskadiko laguntzarako txakurren taldea. Gaur egungo testuinguru zailean, boluntariotzaren laguntza handia izan daiteke biztanleriaren bizi-kalitatea hobetzeko, eta boluntarioek egiten duten lanak esker ona merezi du hartan jartzen duten konpromiso eta ardurarengatik.

\section{HITZ-GAKOAK:}

boluntariotza, motibazioa, irabazi asmorik gabeko elkarteak, esperientziak, laguntza.
A punto de que termine la celebración del Año Europeo del Voluntariado, este texto muestra algunos ejemplos de actividades de ayuda que se desarrollan en distintos ámbitos en la CAPV y que cuentan principalmente con personal no remunerado: la Asociación de Ayuda en Carretera DYA, el Programa de Acompañamiento de la Cruz Roja y el Grupo del Perro de Salvamento de Euskadi. En un contexto social difícil, el voluntariado constituye una importante fuente de ayuda para mejorar la calidad de vida de la población, y la labor que realizan las personas voluntarias merece un reconocimiento, por su dedicación y compromiso.

\section{PALABRAS CLAVE:}

voluntariado, motivación, entidades sin ánimo de lucro, experiencias, apoyo.

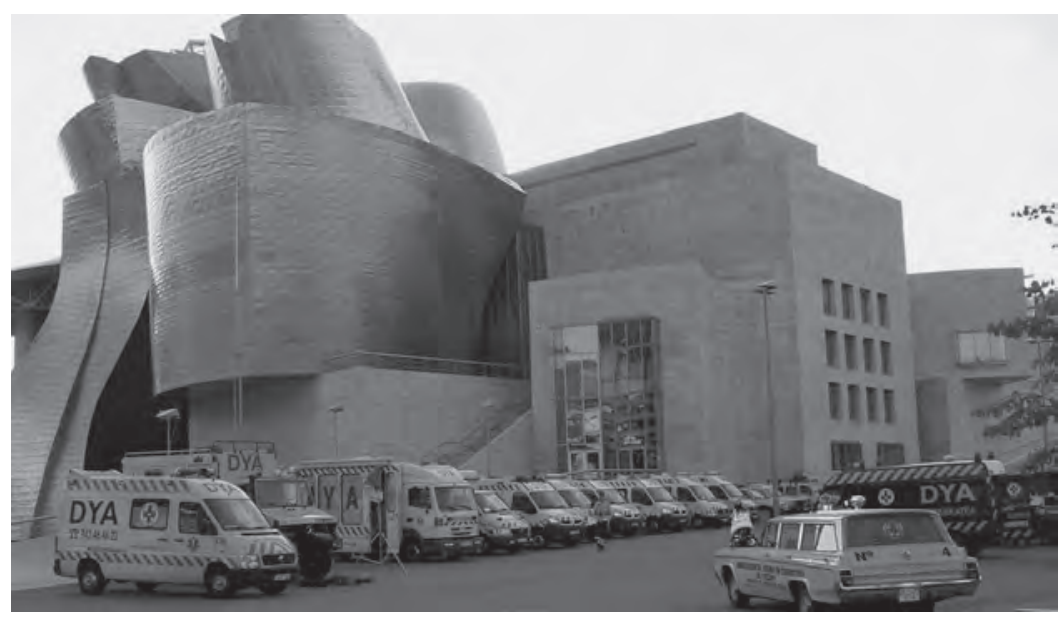

Ambulancias de la DYA en el exterior del Museo Guggenheim.

Fuente: Asociación de Ayuda en Carretera DYA. 


\section{Introducción}

La Ley 17/1998 del Voluntariado de la CAPV define el voluntariado como el conjunto de actividades de interés general desarrolladas por personas físicas, siempre que se realicen en las siguientes condiciones: de manera desinteresada y con carácter solidario; voluntaria y libremente, sin traer causa de una relación laboral, funcionarial o mercantil, o de una obligación personal o deber jurídico; a través de organizaciones sin ánimo de lucro, y con arreglo a programas o proyectos concretos; sin retribución económica y sin sustituir, en ningún caso, servicios profesionales remunerados. Con respecto a las actividades de interés general, son aquellas que comportan un compromiso en favor de la sociedad o de la persona y que se desenvuelven tanto en el ámbito social, comunitario, cívico, cultural, de cooperación al desarrollo, de protección al medio ambiente o cualquier otro de naturaleza análoga. Dentro del voluntariado, por lo tanto, puede hablarse de una gran diversidad de actividades y de ámbitos de actuación.

Este 2011 ha sido el año Europeo del Voluntariado, en el que han participado todos los Estados miembros, y que ha convocado en toda Europa multitud de exposiciones, programas y actividades de todo tipo. Para estos doce meses, el Parlamento Europeo se marcó, como objetivos principales (Comisión Europea, 20102011), trabajar para lograr un entorno que favorezca el voluntariado, ofrecer medios de actuación a las organizaciones de voluntarios con el fin de ayudarles a poner en marcha nuevos tipos de acciones voluntarias, y propiciar el establecimiento de redes y cooperación con la sociedad civil.

El voluntariado es una actividad fundamental en todas las entidades sin ánimo de lucro, y una expresión de participación social que las enriquece y les ofrece un valor añadido. Sin embargo, algunas organizaciones han visto reducirse el número de personas voluntarias en los últimos años. Parece que, entre los principales obstáculos para atraer a nuevas personas voluntarias, están la coyuntura de crisis económica, las crecientes dificultades para conciliar la vida laboral, familiar y personal, y también los cambios que se están produciendo en el sistema de valores. En cuanto a las dificultades para mantener al voluntariado en las organizaciones, hay que destacar algunos factores relacionados con el desarrollo organizativo (crecimiento desordenado o rápido, procesos de profesionalización), igual que la forma de gestionar el voluntariado en las organizaciones (carencias en el seguimiento y el apoyo al personal voluntario, escasa formación y falta de programas de captación, entre otras).

El último informe anual del Gobierno Vasco sobre la situación del voluntariado en la CAPV (2009) afirma que las organizaciones de voluntariado en el territorio tienen, en su gran mayoría, más de cinco años de antigüedad $(93,2 \%)$, lo que indica que se trata de organizaciones con experiencia. La mayoría $(81,8 \%)$ son asociaciones, el $58 \%$ de ellas son organizacio- nes especializadas y un $71 \%$ desarrollan su trabajo voluntario a favor de otras personas. Con respecto al voluntariado que participa en estas organizaciones, según el informe, la mayoría de éstas cuentan con un voluntariado sin límite de edad (77,6\%). En el 89,4\% de las entidades el voluntariado representa más del $50 \%$ del total de personas que intervienen en ellas, y en la mayoría de casos el personal voluntario supera al remunerado. La mayor parte de las organizaciones tienen entre 10 y 50 personas voluntarias, con una presencia algo superior del voluntariado femenino con respecto al masculino. El grupo de edad que predomina entre el voluntariado va de los 18 a los 45 años, y su labor tiene, en general, carácter estable (una media de más de 6 horas semanales). Sólo el $6,8 \%$ realiza tareas directivas en la organización.

Como ya hemos señalado, los tipos de voluntariado que pueden realizarse son de muy diversa índole. En la CAPV, en concreto, y según el informe antes mencionado, la actividad del personal voluntario se centra preferentemente en la atención a la población en general; a niños/as, adolescentes y jóvenes; y a las mujeres, en este orden. Este artículo es el primero de una serie que se encargará de recoger las diferentes experiencias de voluntariado que se dan en la comunidad autónoma de Euskadi, tanto dentro como fuera de los servicios sociales, con la intención de mostrar el valor del trabajo que realizan estas personas para el bienestar de la sociedad, y la heterogeneidad de los servicios a los que dedican su tiempo y su esfuerzo.

\section{Asociación de Ayuda en Carretera (DYA)}

La Asociación de Ayuda en Carretera (DYA) nació en 1966, con el objetivo de tratar de forma humana a las víctimas de accidentes de tráfico, dado que en ese momento no había ambulancias para atender a las personas accidentadas. Todos los voluntarios que participan en ella tienen el título de socorrista, y quienes no lo tienen van con personas experimentadas mientras se preparan para obtenerlo. Para conducir ambulancias, es preciso tener al menos de 21 años y adquirir una formación previa, además de otros requisitos.

La asistencia que proporciona la asociación consiste en la ayuda de primeros auxilios: explorar, estabilizar, frenar hemorragias o entablillar, entre otras tareas. Si la urgencia lo requiere, se realiza el soporte vital básico con maniobras de reanimación, siempre que la víctima esté inconsciente, tenga comprometida la respiración y la circulación cardiovascular, y no sea posible esperar a que llegue otra ambulancia al lugar de los hechos. Aun así, en la asociación tienen claro que una persona voluntaria no puede hacer más de lo que le permiten sus conocimientos, así que cuando la atención requerida es más específica, se cuenta con ayuda suplementaria, como una ambulancia de soporte vital avanzada con un médico propio. Actualmente, además de la ayuda en carretera, la asociación también trabaja en la sensibilización y la 
educación vial, puesto que considera que la educación y la prevención son las principales herramientas para evitar los riesgos del tráfico sin recurrir a las sanciones.

\section{Programa de Acompañamiento de Cruz Roja}

La Cruz Roja española nació a mediados del siglo XIX con el fin de prestar auxilio a los heridos en conflictos armados. Desde entonces, se ha ido adaptando a las necesidades que se iban detectando en la sociedad, desde la atención a las madres de familias desfavorecidas en la década de 1920 , a reunir a familias durante la Guerra Civil, o a promover la prevención de la diabetes, hasta llegar a la década de los noventa, cuando se produjo una gran modernización de la entidad, que se adaptó a nuevos retos: consolidar la intervención social con los colectivos vulnerables (personas mayores, inmigrantes y refugiados, personas afectadas por VIH, drogodependientes, infancia y juventud, discapacidad, mujeres o población reclusa), aumentar los programas internacionales, incorporar el medio ambiente como un ámbito más de actuación y utilizar las nuevas vías de colaboración surgidas gracias a las nuevas tecnologías. El objetivo del programa de acompañamiento, que se puso en marcha en 1996, es paliar la soledad de personas mayores que viven en residencias o en sus domicilios particulares. La labor del personal voluntario no consiste en cubrir necesidades básicas, como la higiene personal o la del entorno de la persona mayor, sino su falta de compañía. El voluntariado dedica entre una hora y media y dos horas semanales a realizar con ellos sus actividades preferidas (pasear, charlar, leer el periódico, hacer gestiones o jugar a cartas). Además, merece la pena notar que el programa se interrelaciona con otros proyectos, como el de telealarma, ya que las visitas a las personas mayores en sus domicilios sirven para valorar los casos que son susceptibles de necesitar el servicio.

Los voluntarios reciben formación específica por parte de cruz Roja para atender a las necesidades de las personas mayores de la manera más adecuada, pero la organización no les exige requisitos específicos para participar en el programa, siempre que tengan más de 18 años y disfruten estando con personas mayores. Cualquier persona puede aportar su experiencia, sus conocimientos y su tiempo. Además de un elevado número de proyectos, la organización también tiene la capacidad y la experiencia de desarrollar nuevos programas ideados por la propia institución, o que nacen de las ideas que aporta el personal voluntario.

El voluntariado de acompañamiento puede vivir situaciones muy diversas, asistiendo a personas que no pueden hablar debido a que tienen parálisis cerebral, a personas que necesitan ayuda para poder moverse 0 a otras que no tienen a nadie con quien compartir una conversación. Esas dos horas que pasan con el voluntariado son muy valiosas para las

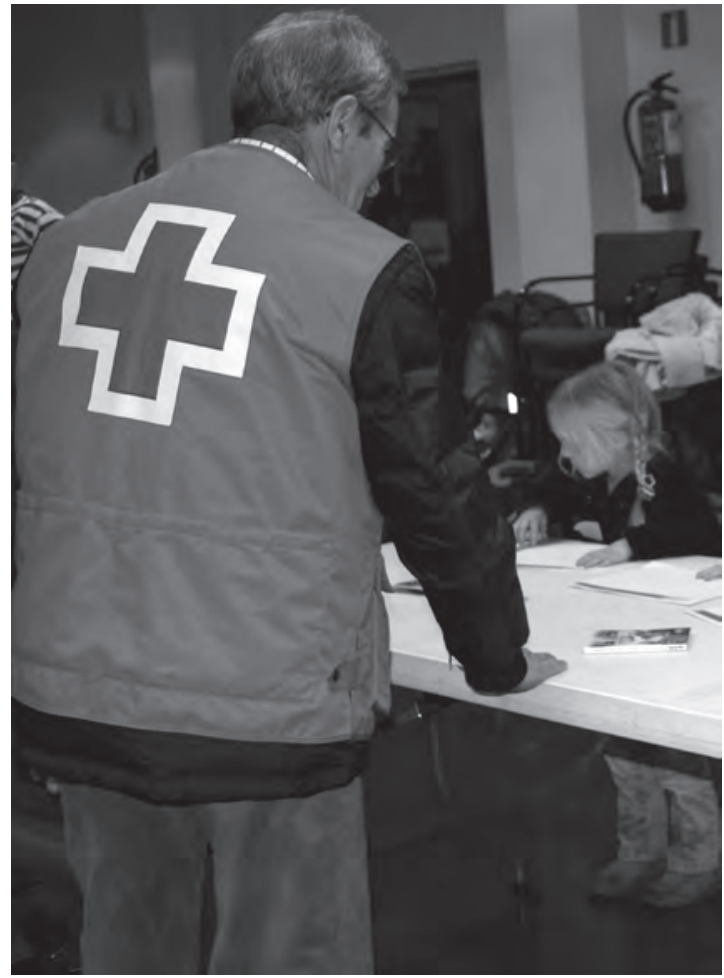

Voluntario de la Cruz Roja en una actividad con niños y niñas. Fuente: Cruz Roja.

personas acompañadas. Porque, aunque es evidente que la sociedad ha mejorado en lo que respecta a la preocupación por la salud y las comodidades de las personas mayores, la soledad sigue estando muy presente en el colectivo atendido.

\section{Grupo del Perro de Salvamento de Euskadi}

El Grupo del Perro de Salvamento de Euskadi se creó en 1983 , con el objetivo principal de preparar equipos formados por un guía y un perro, destinados a localizar personas perdidas en el monte, sepultadas entre escombros o enterradas bajo la nieve. Con sede en Elorrio (Bizkaia), la asociación está formada por personas voluntarias, que prestan un servicio de 24 horas al día los 365 días del año. Esta disponibilidad se consigue gracias a que el voluntariado negocia con las empresas la posibilidad de ausentarse del puesto de trabajo en caso de activación para una búsqueda, y recuperar esas horas más delante, pero sobre todo gracias al apoyo de sus familiares y amistades, que son quienes más sufren las ausencias de las personas voluntarias, debidas a los entrenamientos, las intervenciones y demás aspectos relacionados con la actividad del grupo.

Empiezan a trabajar con los perros a los tres meses de su nacimiento, en el momento del destete. El entrenamiento responde a diversas pautas y métodos fijados dentro del grupo, para que, hacia los dos años, el perro esté equilibrado y preparado para 
empezar a trabajar en rescates. Aun así, el trabajo de los equipos no termina nunca. Se realizan tres entrenamientos en grupo a la semana, que suponen unas diez horas, además del entrenamiento personal de cada equipo (persona y perro) y la actividad cotidiana con el animal, que incluye los paseos o la práctica de la obediencia. Además del tiempo invertido en el entrenamiento, la asociación tiene un compromiso firmado con el Gobierno Vasco para homologar a todos los equipos por lo menos una vez al año.

Con respecto a los rescates, la mayor parte de las movilizaciones se realizan a través de SOS Deiak, que informa al responsable de intervención del grupo sobre la situación en la que deben intervenir. $\mathrm{El}$ grupo valora las circunstancias, y activa a los equipos y personas de apoyo que considera necesarios. Siempre hay una persona de SOS Deiak como responsable de la búsqueda, que es la encargada de adjudicar la zona de trabajo a los equipos. La labor de los voluntarios es batir con los perros la zona que les han indicado y descartarla si la persona desaparecida no está en ella.

Este tipo de voluntariado requiere mucho esfuerzo, puesto que desde que se empieza a trabajar con un perro hasta que llega a ser operativo en rescate pasan dos años, como mínimo, e incluso puede no llegar a estarlo nunca. Por eso, llega mucha gente nueva al grupo, pero son pocos los que se quedan. Quienes lo hacen afirman que su principal motivación es ser amantes de los perros, pero también valoran los profundos lazos de amistad que se crean entre personas que comparten infinidad de momentos, tanto buenos como malos, y la sensación de enriquecimiento personal que proporciona un servicio a la sociedad.

\section{A modo de cierre}

Éstos son sólo tres ejemplos de las numerosas acciones de voluntariado desarrolladas en la CAPV, que muestran que la actividad voluntaria ofrece enormes satisfacciones, pero también requiere esfuerzo y compromiso. A fin de no perder voluntariado y conseguir a más personas que quieran colaborar con ellas, las organizaciones deben identificar nuevas fórmulas de captación y seguimiento, que estén bien organizadas y sigan un proceso estructurado. En lo referente a la sensibilización, es importante que las entidades cuenten con una persona encargada de comunicación, que planifique adecuadamente la estrategia, para poder llegar a la sociedad y al voluntariado potencial.

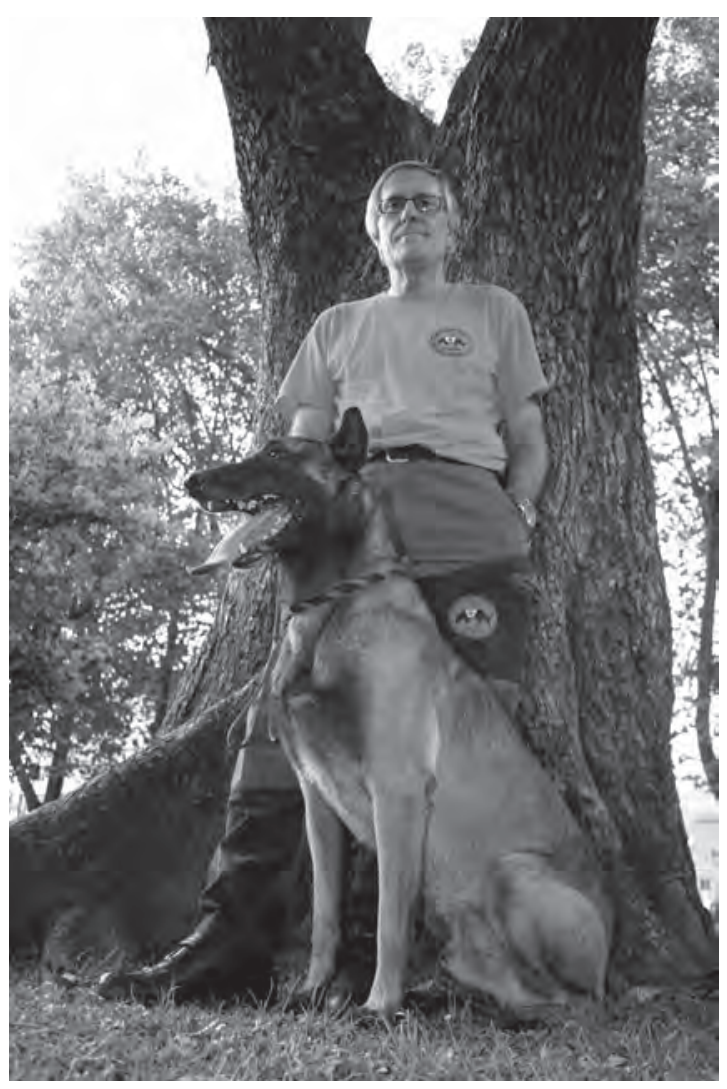

Un equipo del Grupo del Perro de Salvamento de Euskadi, formado por un voluntario y su perro.

Fuente: Grupo del Perro de Salvamento de Euskadi.

\section{Referencias bibliográficas}

COMISIÓN EUROPEA (2010-2011): Año Europeo del Voluntariado 2011 [rhttp://europa.eu/ volunteering/es/ $/$ ].

GOBIERNO VASCO (2010): Informe anual de la situación de las organizaciones de voluntariado en la CAPV 2009, Vitoria-Gasteiz, Eusko JaurlaritzaGobierno Vasco ['http://goo.gl/k8FtO〉]. 


\section{Normas de presentación de originales para Zerbitzuan}

- Zerbitzuan está abierta a la publicación de artículos sobre servicios y políticas sociales por parte de profesionales, investigadores, representantes institucionales y de todas aquellas personas interesadas en las políticas de bienestar social.

- Todos los artículos deberán ser inéditos y girar en torno a los ejes temáticos básicos de la revista (servicios sociales y políticas de bienestar social, participación social, inmigración, pobreza y exclusión social, discapacidad, atención a las personas mayores, infancia y menores en situación de desprotección, drogodependencias e intervención social en general). Una vez recibidos, los artículos serán sometidos a la consideración de los miembros del Consejo de Redacción, que decidirán sobre su publicación de acuerdo a criterios de calidad científica y oportunidad editorial.

- Una vez aceptados los artículos para su publicación, la dirección de la revista se reserva el derecho de modificar el título y epígrafes de los textos, así como de realizar las correcciones de estilo que se estimen convenientes, de acuerdo con las normas de estilo de la revista.

- Los artículos se enviarán en un documento de Word y por correo electrónico.

- Los artículos pueden redactarse tanto en euskera como en castellano, y serán publicados en el idioma en el que se reciba el original.

- Desde el punto de vista formal, se ruega atenerse a las siguientes pautas:

- La extensión del contenido de cada artículo será de entre 6.000 y 15.000 palabras, contando las posibles tablas, cuadros, gráficos y bibliografía. Se ruega adjuntar sólo las tablas y gráficos que se consideren imprescindibles.

- En la primera página, se hará constar el título del artículo, el nombre del autor o autores, su dirección y teléfono de contacto, así como su adscripción institucional. Se añadirá también un breve resumen o sumario del artículo (máximo 150 palabras) y cinco palabras clave que describan el contenido del texto. El resumen y las palabras clave irán en castellano y euskera.

- Las citas o notas irán a pie de página.

- Las referencias bibliográficas de los artículos seguirán las Normas ISO 690/1987.

La dirección y teléfono de contacto

de la revista son los siguientes:

Zerbitzuan

SIIS Centro de Documentación y Estudios

SIIS Dokumentazio eta Ikerketa Zentrua

General Etxague 10 bajo

20003 Donostia-San Sebastián

Tel. 943423656

Fax 943293007

publicaciones@siis.net 


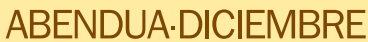 2011}

Prestaciones económicas versus prestaciones en especie: el resurgir de un viejo debate

El papel de las organizaciones empresariales y sindicales en la política social de atención a la dependencia

Códigos deontológicos e ideología en trabajo social

Dinámicas relacionales entre servicios sociales comunitarios y entidades sociales. Un estudio de caso

El papel de los observatorios en el conocimiento de los procesos de exclusión social

Infancia y exclusión social en España: realidades y retos a partir de la crisis

Análisis de la calidad percibida en usuarios/as de servicios sociales comunitarios

Actitudes y opiniones sobre el uso de prestaciones económicas por parte del colectivo inmigrante en el País Vasco

El papel del asociacionismo en la integración sociopolítica de las personas migrantes de origen subsahariano. El caso del País Vasco

El mapeo de las necesidades como medio de mediación social

La Gran Recesión y el mundo después de la crisis

Euskadin etxez etxeko laguntzaren esleipenari eta intentsitateari buruz orientabidea eskaintzeko tresnaren garapena

Experiencias de voluntariado en la CAPV 